\title{
The neural and psychological mechanisms of yoga and mindfulness meditation
}

Citation for published version (APA):

Gard, T. (2015). The neural and psychological mechanisms of yoga and mindfulness meditation. [Doctoral Thesis, Maastricht University]. Maastricht University. https://doi.org/10.26481/dis.20150320tg

Document status and date:

Published: 01/01/2015

DOI:

10.26481/dis.20150320tg

Document Version:

Publisher's PDF, also known as Version of record

\section{Please check the document version of this publication:}

- A submitted manuscript is the version of the article upon submission and before peer-review. There can be important differences between the submitted version and the official published version of record.

People interested in the research are advised to contact the author for the final version of the publication, or visit the DOI to the publisher's website.

- The final author version and the galley proof are versions of the publication after peer review.

- The final published version features the final layout of the paper including the volume, issue and page numbers.

Link to publication

\footnotetext{
General rights rights.

- You may freely distribute the URL identifying the publication in the public portal. please follow below link for the End User Agreement:

www.umlib.nl/taverne-license

Take down policy

If you believe that this document breaches copyright please contact us at:

repository@maastrichtuniversity.nl

providing details and we will investigate your claim.
}

Copyright and moral rights for the publications made accessible in the public portal are retained by the authors and/or other copyright owners and it is a condition of accessing publications that users recognise and abide by the legal requirements associated with these

- Users may download and print one copy of any publication from the public portal for the purpose of private study or research.

- You may not further distribute the material or use it for any profit-making activity or commercial gain

If the publication is distributed under the terms of Article $25 \mathrm{fa}$ of the Dutch Copyright Act, indicated by the "Taverne" license above, 


\section{The neural and psychological}

\section{mechanisms of yoga}

\section{and mindfulness meditation}
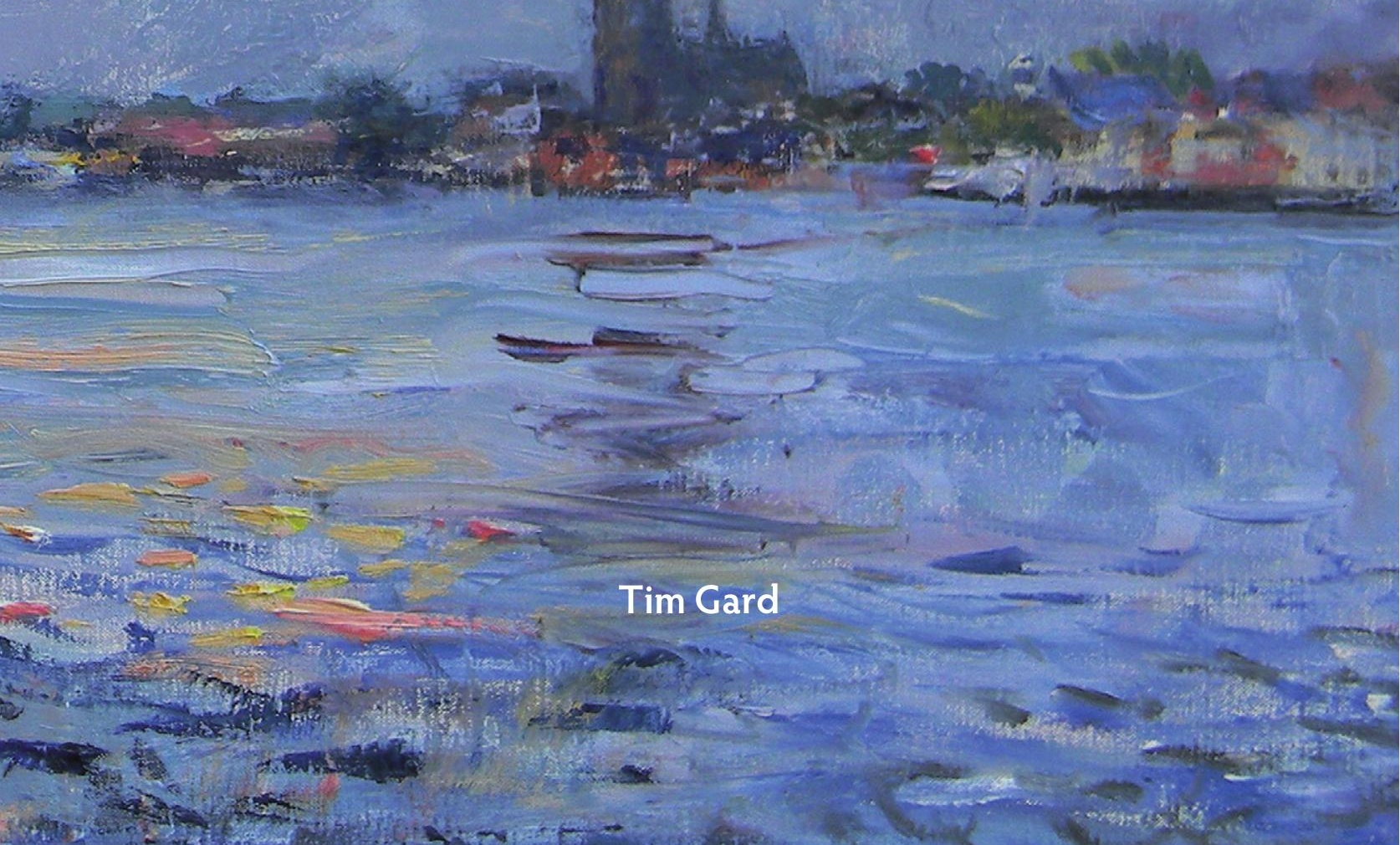

THE NEURAL AND PSYCHOLOGICAL MECHANISMS OF YOGA AND MINDFULNESS MEDITATION 
(c) Tim Gard, Maastricht, the Netherlands, 2015

Cover image: $\quad$ ( $\quad$ René de Jong (renedejongart.nl)

View on Dordrecht - oil on canvas - 65 ×90 cm - 2009

Layout and printing: *studio Michał Sławiński, thesisprint.eu

ISBN 978-90-823440-0-4

All rights reserved. No part of this publication may be reproduced, stored or transmitted in any form or by any means, without written permission of the copyright owner. 


\title{
THE NEURAL AND PSYCHOLOGICAL MECHANISMS OF YOGA AND MINDFULNESS MEDITATION
}

\author{
Dissertation \\ to obtain the degree of Doctor at the Maastricht University, \\ on the authority of Rector Magnificus, Prof. dr. L.L.G. Soete, \\ in accordance with the decision of the Board of Deans, \\ to be defended in public on Friday 20 March 2015 at 14:00 hours \\ by
}

TIM GARD 


\section{Supervisors}

Prof. dr. A.T. Sack

Prof. dr. R. Goebel

\section{Co-supervisor}

Dr. B.K. Hölzel, Technische Universität München, Germany

\section{Assessment Committee}

Prof. dr. M.L. Peters (chair)

Dr. H.J.E.M. Alberts

Prof. dr. M. Desseilles, University de Namur, Belgium

Prof. dr. E. Formisano

Prof. dr. A.E.M. Speckens, Radboud UMC, the Netherlands

The studies that are presented in this dissertation were funded by the Bender Institute of Neuroimaging, the German Academic Exchange Service (DAAD), the Kripalu Center for Yoga and Health, the Yawkey Foundation, and the National Institutes of Health (NIH; grant no. R21AT003673, 1S10RR023401, S10RR019307, and 1S10RR023043). 
To Max and Lex 



\section{CONTENTS}

\section{ChAPTER 1}

General introduction

\section{ChAPTER 2}

Neural mechanisms of pain modulation through mindfulness

\section{ChAPTER 3}

Psychological mechanisms of increased well-being and resilience through yoga in young adults

\section{Chapter 4}

The potential effects of meditation on age-related cognitive decline

\section{ChAPTER 5}

Neural and psychological mechanisms of offset age-related decline in fluid intelligence in yogis and meditators

\section{ChAPTER 6}

Greater caudate connectivity in aging yogis and meditators

as potential mediator of increased behavioral flexibility, mental health, and well-being

\section{ChAPTER 7}

General discussion

SUMMARY 


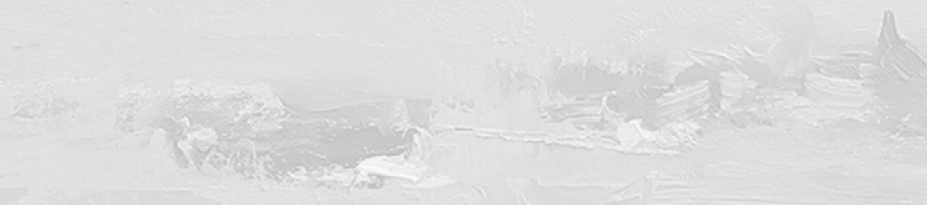


ChAPTER 1

\section{GenerAL INTRODUCTION}



The understanding of and striving for well-being is central to human existence. It has been documented in many cultures and has a long history (Deci \& Ryan, 2008; Joshanloo, 2014; Ryan \& Deci, 2001). In the West, as early as the fourth century BCE, Aristotle described "eudemonia", which translates to "human flourishing" as a central concept in his work on ethics and political philosophy. In more recent years well-being is scientifically studied as an integral aspect of the positive psychology movement (Ryff \& Singer, 2008; Seligman \& Csikszentmihalyi, 2000).

Mindfulness meditation, which has its roots in Buddhism, and yoga are ancient Eastern practices that are traditionally concerned with cultivating well-being (Feuerstein, 2008; McWilliams, 2014; Sengupta, 2012; Wallace \& Shapiro, 2006). Currently these practices are very popular in the West as spiritual and recreational practices and more recently as health interventions. Together with the popularity there is growing scientific interest in the effects of these practices and in the mechanisms that underlie these effects.

This thesis investigates the psychological and neural mechanisms that underlie the positive effects of yoga and mindfulness meditation on human well-being and extends this young field by providing insights at different levels and from different angles. To better understand how yoga and mindfulness meditation are traditionally related to well-being and to each other, a brief historical and philosophical overview will be provided here. Where appropriate, in the introduction Sanskrit words are used and printed in italic.

\section{YoGA}

Yoga, which originated in India, is observed through a variety of physical and mental exercises and disciplines. Although different forms of yoga are practiced through many different schools and branches, the essential goal of these practices is to help practitioners achieve a specific form of consciousness; a deep state of concentration which is referred to as "ecstasy" (samādhi). Ecstasy is best explained as a state of spiritual realization in which "ego-personality" or "lower self" is transcended, so that a "higher" reality can be realized. Depending on a yoga school's philosophy, this state can be understood as the "transcendental self" or as the "divine" (god or goddess). The permanent achievement of this state can be seen as the ultimate goal of yoga and is referred to as "liberation" (mokșa, kaivalya). In other words, the aim of yoga is to obtain a broader and clearer perspective on the boundless nature of experience instead of being stuck in a limited material world. Yoga can be seen as a practice designed to achieve sustainable happiness through the realization of this true boundless nature (Feuerstein, 2008, 2011). 
Yoga has a long history, although the exact beginning of the yoga tradition is not known and still debated. Some scholars argue that there is evidence for the existence of yoga in the Indus-Sarasvati civilization, which flourished approximately between 2800-1900 BCE in northern India. Indeed, yoga was already referred to as ancient in the Bhagavad-Gita, an important Hindu scripture that was composed around 600-500 BCE. Further extensive texts on yoga have been found in the ShvetashvataraUpanishad and the Maitrayaniya-Upanishad, Hindu scriptures that were formulated approximately between the third and fourth century BCE (Feuerstein, 2008).

Feuerstein $(2008,2011)$, distinguishes between pre-classical, classical and postclassical yoga. While the above mentioned Bhagavad-Gita and Upanishads belong to the key writings of the pre-classical yoga (approximately $500 \mathrm{BCE}-100 \mathrm{CE}$ ), the basic scripture of classical yoga is the Yoga Sutra that was formulated by Patanjali around 200 CE. The classical yoga of Patanjali, also referred to as Raja Yoga, became the most influential system of yoga and forms the basis of many schools of yoga that are currently practiced in the West. In his Yoga Sutra, Patanjali outlines the system and practice of yoga in just 195 short aphorisms, or short statements. The path to liberation or self-transcendence is described as eight limbs, namely 1) moral restraint (yama), 2) discipline (niyama), 3) posture (āsana), 4) breath control (prānāyāma), 5) sense withdrawal (pratayāhāra), 6) concentration (dhāranā), 7) meditation (dhyāna), and 8) ecstasy (samādhi). These 8 limbs are intended to support a final limb: a form of deep concentrative meditation also called ecstasy or self-realization (Feuerstein, 2008, 2011).

The variety of yogic schools that emerged in the period after classical yoga are referred to as post-classical yoga. While classical yoga has a dualistic world-view, pre- and post-classical yoga have a non-dualistic view. In this non-dualistic view, the transcendental self, true self or spirit (ätman, puruṣa) is underlying all phenomena including nature (prakrti), to which mind and matter including our ego-personalities belong. The goal of yoga, which means union, is to unify the ego-personality with the self. In the dualistic view, self or spirit (ätman, purusa) and mind-matter (prakrti) are separated entities. Self-realization cannot be reached through union but through disconnection with or stopping of the fluctuations of mind-matter (prakrti). Indeed, Patanjali defines yoga as the "restriction of the fluctuations of consciousness" (cittavrtti-nirodhah). One well known post-classical school of yoga is Hatha Yoga, a body focused form of yoga in which postures and breath control play particularly important roles (Feuerstein, 2008, 2011).

Currently, yoga is very popular in the West, but the practice is mostly focused on postures. Practitioners use yoga to strengthen the body, find relaxation, and improve health. Liberation is seldom an explicit intention (Feuerstein, 2011). Increasingly, yoga is used in clinical settings under the name "yoga therapy", which resulted in the foundation of the International Association of Yoga Therapists in 1989 (http://www.iayt.org/). 


\section{MINDFULNESS MEDITATION / BUDDHISM}

Mindfulness meditation has its roots in Buddhism. Buddhism refers to an ancient religious and philosophical tradition with a long and complex history that started over 2500 years ago in India through the teachings of Siddharta Gautama, generally known as "the Buddha", or the "the awakened one". Over the past two and a half millennia, Buddhism has spread throughout most of Asia and evolved into a great number of diverse Buddhist traditions. Although there seems to be agreement amongst historians about the existence of a historical Buddha, there still is debate about when exactly he lived with estimates ranging from 500-400 BCE. The story about the life of Siddharta Gautama has less historical evidence and should rather be considered a legend (Gethin, 1998).

According to the legend, Siddhartha Gautama was born as prince and grew up in an extremely protected environment. At age 29 , he discovered the existence of suffering/dissatisfaction (duhkha) in the world, and he renounced his royal life to find liberation from this suffering. Six years later, after an intensive path that included yoga training and ascetics, he found a way, what he called "the middle path", to liberation and then became the Buddha. The Buddha spent the remaining 45 years of his life teaching others this path to enlightenment (Gethin, 1998; Landaw, Bodian, \& Bühnemann, 2011).

The core teachings of the Buddha are the four noble truths, which are:

1. Suffering/dissatisfaction $(d u h k h a)$. Although this may sound pessimistic, there are many unavoidable parts of life that are associated with suffering including sickness, aging and death.

2. The cause of suffering (samudaya). Due to the impermanence of things craving and attachment will result in suffering.

3. The cessation of suffering (nirodha). Suffering can be extinguished through removal of ignorance, which is the cause of craving and attachment.

4. The path that leads to the cessation of suffering (mārga). This eightfold path leads the way to cessation of suffering and comprises 1) right view (samyagdrsții), 2) right intention (samyaksamkalpa), 3) right speech (samyagvāc), 4) right action (samyakkarmānta), 5) right livelihood (samyagājīva), 6) right effort (samyagvyāyāma), 7) right mindfulness (samyaksmrti), and 8) right concentration (samyaksamādhi). (Gethin, 1998; Landaw et al., 2011).

As the four noble truths suggest, the concept of mindfulness is core to Buddhist teachings. In the Satipațthānasutta (Smrityupasthānasūtra) and an expanded version of it, the Mahāsatipatthānasutta, instructions how to cultivate mindfulness are provided. Both sutras belong to the most important discourses of the oldest Buddhist tradition, the Theravada tradition (Buswell Jr \& Lopez Jr, 2013; Gunaratana \& Gunaratana, 2011; Landaw et al., 2011). 
In the seventies, mindfulness meditation, also called vipassana or insight meditation, was brought to the West by pioneers including Jack Kornfield and Sharon Salzberg (Buswell Jr \& Lopez Jr, 2013). Mindfulness is concerned with a steady open awareness and a widely used definition of mindfulness is "paying attention in a particular way: on purpose, in the present moment, and non-judgmentally" (Kabat-Zinn, 1990). Mindfulness meditation is mostly practiced in a seated posture, but also walking meditation is common. First the mind is quieted through concentrative, calming meditation (śamatha), often in the form of focusing attention on the breath. Calming meditation forms the basis of insight meditation (vipaśyanā) or mindfulness meditation, which is practiced with the aim to gain insight in the three characteristics of all conditioned phenomena (trilakșana): impermanence (anitya), suffering (duhkha), and non-self (anātman), leading to liberation. Mindfulness is typically cultivated through paying attention to bodily sensations, thoughts, and emotions and opening the field of awareness, allowing and noticing whatever arises and being with it in a non-judging, accepting way until it passes away (Buswell Jr \& Lopez Jr, 2013; Gethin, 1998; Gunaratana \& Gunaratana, 2011; Kornfield, 1985).

In the late seventies and early eighties, Jon Kabat-Zinn developed a secularized program to teach mindfulness: the mindfulness-based stress reduction (MBSR) program (Kabat-Zinn, 1982, 1990). This program gained great popularity for clinical and non-clinical applications. Modifications of the program have been developed to suit specific clinical populations such as relapse prevention of depression with mindfulness-based cognitive therapy (MBCT) (Segal, Williams, \& Teasdale, 2002). These secularized mindfulness group interventions have additional components to seated meditation and walking meditation, including yoga postures, mindful daily life activities, psycho-education, and group-based exploration of individual experiences also called inquiry (Kabat-Zinn, 1990; Segal et al., 2002).

\section{COMMONALITIES BETWEEN YOGA AND MINDFULNESS MEDITATION}

There are many parallels between the teachings of the Buddha and the Yoga Sutra of Patanjali. Both serve as practical paths to liberation and in both, suffering plays a key role. A more concrete example is that in both traditions, three types of suffering are mentioned: suffering due to agony (Patanjali: tāpa-duḥkha, Buddha: duhkhaduhkhatā), suffering due to conditioning (both samskäraduhkhatā), and suffering due to change (both viparināmaduhkhatā) (Buswell Jr \& Lopez Jr, 2013; Tandon, 1995). Not only are there 
conceptual similarities, but also similarities in the offered practice. The eight limbs of Patanjali's Yoga Sutra and the eightfold path as described by the Buddha both have an ethical component which comprises moral restraint (yama) and discipline (niyama) in yoga and right view (samyagdrști), right intention (samyaksamkalpa), right speech (samyagvāc), right action (samyakkarmānta), and right livelihood (samyagājīva) in Buddhism. Both practices also have a concentrative/meditative component which comprises sense withdrawal (pratayāhāra), concentration (dhāranā), meditation (dhyāna), and ecstasy (samāahi) in yoga and right effort (samyagvyāyāma), right mindfulness (samyaksmrti), and right concentration (samyaksamādhi) in Buddhism (Feuerstein, 2008; Gethin, 1998). Posture (āsana) and breath control (prānāyāma) mentioned in the Yoga Sutra of Patanjali are also found in the teachings of the Buddha. Buddhist meditation is often performed in a cross legged posture (vajraparyanka), one in which, according to the legend, Siddharta Gautama sat before he achieved enlightenment and became the Buddha (Buswell Jr \& Lopez Jr, 2013; Gethin, 1998). The properties of the meditative posture of being steady and comfortable are similarly described in the Yoga Sutra and in Buddhism (Feuerstein, 2008; Tandon, 1995). In his description of prānāyāma, Patanjali does not describe any active regulation of the breath but rather describes properties of the normal breath. This makes prānāyāma, similar to the important Buddhist practice of mindfulness of breathing (ānāpānasmrti) (Buswell Jr \& Lopez Jr, 2013; Tandon, 1995).

There are also differences between classical yoga and Buddhism. One important difference between the two systems is that while both systems have a concentrative/meditative component, all forms of yogic meditation are one-pointed concentrative meditations resulting in deep states of concentration/ecstasy (samādhi), while in Buddhism these states that are cultivated through calming meditation (śamatha) only form the basis for insight meditation (vipaśyanā) or mindfulness meditation, the final practice to reach liberation (Buswell Jr \& Lopez Jr, 2013; Feuerstein, 2008; Gethin, 1998; Tandon, 1995). For a more complete discussion of the commonalities and differences between classical yoga and Buddhism, see Tandon (1995).

The fact that there are so many parallels between classical yoga and Buddhism is not surprising, considering that Siddartha Gautama was thought to have intensively practiced yoga before he became a Buddha and that the Yoga Sutra of Patanjali was composed in a time in which Buddhism was influential (Feuerstein, 2008; Tandon, 1995). However, there is an ongoing debate in which tradition Buddhism is rooted. One, probably dominant view is that it evolved as a reaction to brahamanical thought, which includes pre-classical yoga (Gethin, 2012; Gombrich, 2009), while others see its origin independent from Brahmanism (Bronkhorst, 2007; Bronkhorst, 2013). 


\section{MINDFULNESS AND YOGA RESEARCH}

Together with the large-scale introduction of yoga and mindfulness meditation to the West in the seventies and its rapidly growing popularity, there was growing research interest in these practices. This growing research interest in mindfulness meditation and yoga is evidenced by the rapidly growing number of publications since the seventies (Figure 1). The research includes studies investigating the effects of mindfulness meditation and yoga on healthy participants as well as the effectiveness of mindfulness- and yoga-based interventions on a variety of clinical conditions. In addition to the investigation of only the effects of these practices, an increasing number of studies has focused on the mechanisms that underlie these effects. However, it is only since the beginning of this century that the mechanisms of meditation and yoga are investigated with neuroimaging methods and that the field of contemplative neuroscience was born.

While meditation research has grown exponentially since the seventies, it is only since the beginning of this century that yoga research is rapidly increasing (Figure 1). Not only amongst researchers, but also in the wider community there seems to be a growing interest in yoga and mindfulness as is evidenced by the popularity of science-based practice books such as "Meditation für Skeptiker" (Meditation for sceptics) (Ott, 2010) and "Yoga für Skeptiker” (Yoga for sceptics) (Ott, 2013).

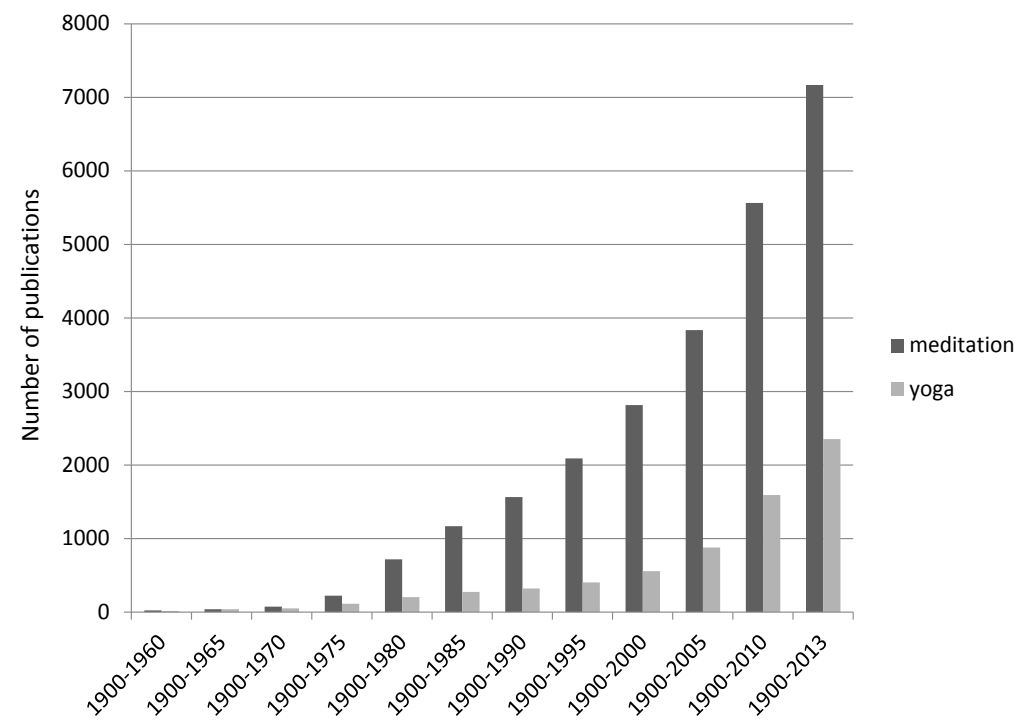

Figure 1. Number of publications on yoga and meditation from 1900 to 2013. 


\section{OUTLINE OF THESIS}

The topic of this thesis "The neural and psychological mechanisms of yoga and mindfulness meditation" is placed within this rapidly growing field of yoga and mindfulness research and particularly in the young field of contemplative neuroscience. Because of the broad effects and applications of mindfulness meditation and yoga, we investigated the neural and psychological mechanisms of yoga and meditation in three distinct but particularly relevant areas for human well-being and society. These domains are 1) chronic pain, 2) well-being and resilience at young age, and 3) aging. In addition to the different domains that shape the view, different levels of analyses were used, ranging from self-report via behavioral measures to neurobiological investigations, and within the neurobiological domain from global network approaches via local network approaches to local brain activation.

\section{PAIN}

In chapter 2 the neural mechanisms of pain modulation through mindfulness were investigated. Chronic pain is an important problem for society as it has high prevalence and poses a huge burden on patients, their significant others and society. Estimates of prevalence rates are ranging from around 20\% to more than $70 \%$ (Breivik, Collett, Ventafridda, Cohen, \& Gallacher, 2006; Gureje, Von Korff, Simon, \& Gater, 1998; Tsang et al., 2008; Wenig, Schmidt, Kohlmann, \& Schweikert, 2009). In the US the prevalence of chronic pain has been estimated to be $43 \%$ (Tsang et al., 2008), meaning that over 116 million Americans are suffering from this condition, which is more than the number of Americans affected by heart disease, cancer and diabetes combined (IOM, 2011; Pizzo \& Clark, 2012). In Germany the estimated annual cost of back pain is $€ 49$ billion, while in the US the annual cost of chronic pain is estimated to be up to $\$ 635$ billion (Gaskin \& Richard, 2012). In addition to the high prevalence and the huge burden to patients and society, chronic pain is difficult to treat (Turk, Wilson, \& Cahana, 2011) and has been conceptualized as public health challenge by the Institute of Medicine of the National Academies (2011).

Growing research evidence suggests that chronic pain and pain related symptoms such as depression can be reduced by mindfulness-based interventions (for a review see Veehof, Oskam, Schreurs, \& Bohlmeijer, 2011). Yoga-based interventions also have been suggested to have the potential to reduce pain and pain related disability (for reviews see Bussing, Ostermann, Ludtke, \& Michalsen, 2012; Wren, Wright, Carson, \& Keefe, 2011). While the neural mechanisms that underlie the effects of mindfulness- and yoga-based interventions are still unknown, recently 
a number of functional magnetic resonance imaging (fMRI) studies, including ours, have been conducted to investigate the neural correlates of the modulation of experimentally induced pain in healthy participants through mindfulness (Gard et al., 2012; Grant, Courtemanche, \& Rainville, 2011; Lutz, McFarlin, Perlman, Salomons, \& Davidson, 2013; Zeidan et al., 2011). The level of analysis in this study is local brain activation as inferred through fMRI.

\section{FOSTERING RESILIENCE AND WELL-BEING IN YOUNG ADULTS}

Chapter 3 is concerned the psychological mechanisms of how yoga can increase well-being and foster resilience in young adults. To build a flourishing society with happy and healthy members, it is important to foster resilience early on.

Well-being is negatively related to a number of variables, including mental health problems and suicidality in young adults (Valois, Zullig, Huebner, \& Drane, 2001), while high levels of stress on the other hand contributes to psychopathology (Grant, McMahon, Dufy, Taylor, \& Compas, 2009). College is a high risk period as young adults are particularly vulnerable to mental health problems and because the transition to college is a challenging period (Conley, Travers, \& Bryant, 2013; Reavley \& Jorm, 2010). Despite the opportunity to support young adults in this critical phase of life, not many interventions have been developed and tested to foster wellbeing and resilience in this group, as opposed to children (Conley et al., 2013; Durlak, Weissberg, Dymnicki, Taylor, \& Schellinger, 2011; Reavley \& Jorm, 2010). In chapter 3 we investigated the effectiveness of a residential yoga-based program that targeted exactly this challenge, to provide young adults with skills to handle the transition to independence and to college and improve their quality of life. For this study we relied on self-report measures to investigate the effects of the intervention on quality of life, perceived stress and the potential mediators mindfulness and self-compassion.

\section{AGING}

Aging is a major concern for society. The world population is rapidly aging, due to increases in life expectancy and the aging baby boom generation (Administration on Aging, 2012; United Nations, 2002). In Germany for instance more than 20\% of the population is already older than 65 (Statistisches_Bundesamt, 2014). It is no surprise that the European Commission regards aging as one of the greatest social and economic challenges of the $21^{\text {st }}$ century (European_Commission, 2014).

It is a well-established that normal healthy aging is accompanied by decline in cognitive function (Salthouse, 2009; Tucker-Drob, 2011; Wilson, Beckett, Bennett, Albert, \& Evans, 1999) and related declines in neural structure and activity (Morrison \& Hof, 1997; Persson et al., 2006; Salat et al., 2004). The decline can progress to mild 
cognitive impairment (MCI) and dementia, which are characterized by limitations of daily functioning and typically result in a reduced quality of life. Therefore cognitive decline is an often feared aspect of aging. It is not only a burden for the affected individual but also for relatives and society (Deary et al., 2009; Plassman, Williams, Burke, Holsinger, \& Benjamin, 2010).

In Chapter 4 we reviewed studies that investigate the effects of meditation on cognitive function in older adults. Chapter $\mathbf{5}$ is based on the preliminary evidence that meditation can off-set age-related decline and follows the recommendations of the fourth chapter that lifestyle factors should be controlled for and that outcome measures that are closer to real-life should be used. We investigated decline in fluid intelligence and brain functional organization in experienced meditation and yoga practitioners as compared to controls. This study involved a behavioral measure and investigated brain function in terms of global network architecture. Chapter $\mathbf{6}$ further relies on the strength of a whole-brain network approach, but here we used it to investigate local differences in brain networks between the three groups. This approach was then replicated in an independent sample.

\section{REFERENCES}

Administration on Aging. (2012). A Profile of Older Americans. June 18. http://www.aoa.gov/ AoARoot/Aging_Statistics/Profile/2012/docs/2012profile.pdf

Breivik, H., Collett, B., Ventafridda, V., Cohen, R., \& Gallacher, D. (2006). Survey of chronic pain in Europe: prevalence, impact on daily life, and treatment. European Journal of Pain, 10(4), 287-333. doi: 10.1016/j.ejpain.2005.06.009

Bronkhorst, J. (2007). Greater Magadha: Studies in the culture of early India. Leiden, The Netherlands: Brill.

Bronkhorst, J. (2013). Buddhist Nativism in its Homeland. In H. Blezer \& M. Teeuwen (Eds.), Challenging Paradigms: Buddhism and Nativism: Framing Identity Discourse in Buddhist Environments. Leiden, The Netherlands: Brill.

Bussing, A., Ostermann, T., Ludtke, R., \& Michalsen, A. (2012). Effects of yoga interventions on pain and pain-associated disability: a meta-analysis. The Journal of Pain, 13(1), 1-9. doi: 10.1016/j.jpain.2011.10.001

Buswell Jr, R. E., \& Lopez Jr, D. S. (2013). The Princeton Dictionary of Buddhism. Princeton, NJ: Princeton University Press.

Conley, C. S., Travers, L. V., \& Bryant, F. B. (2013). Promoting psychosocial adjustment andsStress management in first-Year college students: the benefits of engagement in a psychosocial wellness seminar. Journal of American College Health, 61(2), 75-86. doi: 10.1080/07448481.2012.754757 
Deary, I. J., Corley, J., Gow, A. J., Harris, S. E., Houlihan, L. M., Marioni, R. E., Penke, L., Rafnsson, S. B., \& Starr, J. M. (2009). Age-associated cognitive decline. British Medical Bulletin, 92(1), 135-152. doi: 10.1093/bmb/ldp033

Deci, E. L., \& Ryan, R. M. (2008). Hedonia, eudaimonia, and well-being: an introduction. Journal of Happiness Studies, 9(1), 1-11. doi: 10.1007/s10902-006-9018-1

Durlak, J. A., Weissberg, R. P., Dymnicki, A. B., Taylor, R. D., \& Schellinger, K. B. (2011). The Impact of enhancing students' social and emotional learning: a meta-analysis of school-based universal interventions. Child Development, 82(1), 405-432. doi: 10.1111/j.1467-8624.2010.01564.x

European_Commission. (2014). Retrieved June 2nd, 2014, from http://ec.europa.eu/health/ageing/policy/index_en.htm

Feuerstein, G. (2008). The yoga tradition: its history, literature, philosophy, and practice (3 Ed.). Prescott, AZ: Hohm Press

Feuerstein, G. (2011). The Path of Yoga: An Essential Guide to Its Principles and Practices. Boston, MA: Shambhala.

Gard, T., Hölzel, B. K., Sack, A. T., Hempel, H., Lazar, S. W., Vaitl, D., \& Ott, U. (2012). Pain attenuation through mindfulness is associated with decreased cognitive control and increased sensory processing in the brain. Cerebral Cortex, 22(11), 2692-2702. doi: $10.1093 /$ cercor/bhr352

Gaskin, D. J., \& Richard, P. (2012). The economic costs of pain in the United States. The Journal of Pain, 13(8), 715-724. doi: 10.1016/j.jpain.2012.03.009

Gethin, R. (1998). The foundations of Buddhism. Oxford, United Kingdom: Oxford University Press.

Gethin, R. (2012). Review of Gombrich, Richard F., What the Buddha Thought. H-Buddhism, H-Net Reviews. http://www.h-net.org/reviews/showrev.php?id=31586

Gombrich, R. F. (2009). What the Buddha thought: Equinox.

Grant, J., Courtemanche, J., \& Rainville, P. (2011). A non-elaborative mental stance and decoupling of executive and pain-related cortices predicts low pain sensitivity in Zen meditators. Pain, 152(1), 150-156. doi: 10.1016/j.pain.2010.10.006

Grant, K. E., McMahon, S. D., Dufy, S., Taylor, J. J., \& Compas, B. E. (2009). Stressors and Mental Health Problems in Childhood and Adolescence. In R. M. Piscitelli (Ed.), The Handbook of Stress Science: Biology, Psychology, and Health (pp. 359-372). New York, NY: Springer Publishing Company.

Gunaratana, B., \& Gunaratana, H. (2011). Mindfulness in plain English: 20th Anniversary Edition. Boston, MA: Wisdom Publications Inc.

Gureje, O., Von Korff, M., Simon, G. E., \& Gater, R. (1998). Persistent pain and well-being: a World Health Organization Study in Primary Care. Journal of the American Medical Association, 280(2), 147-151. doi: 10.1001/jama.280.2.147

IOM. (2011). Relieving pain in America: A blueprint for transforming prevention, care, education, and research. Washington, DC: The National Academies Press. 
Joshanloo, M. (2014). Eastern Conceptualizations of Happiness: Fundamental Differences with Western Views. Journal of Happiness Studies, 15(2), 475-493. doi: 10.1007/ s10902-013-9431-1

Kabat-Zinn, J. (1982). An outpatient program in behavioral medicine for chronic pain patients based on the practice of mindfulness meditation: theoretical considerations and preliminary results. General Hospital Psychiatry, 4(1), 33-47. doi: 10.1016/01638343(82)90026-3

Kabat-Zinn, J. (1990). Full catastrophe living: Using the wisdom of your body and your mind to face stress, pain and illness. New York, NY: Delta.

Kornfield, J. (1985). The Eight Fold Path for the Householder. Berkeley, CA: DharmaNet International. Landaw, J., Bodian, S., \& Bühnemann, G. (2011). Buddhism for dummies. Hoboken, NJ: John Wiley \& Sons.

Lutz, A., McFarlin, D. R., Perlman, D. M., Salomons, T. V., \& Davidson, R. J. (2013). Altered anterior insula activation during anticipation and experience of painful stimuli in expert meditators. Neuroimage, 64, 538-546. doi: 10.1016/j.neuroimage.2012.09.030

McWilliams, S. (2014). Foundations of Mindfulness and Contemplation: Traditional and Contemporary Perspectives. International Journal of Mental Health and Addiction, 12(2), 116-128. doi: 10.1007/s11469-014-9486-1

Morrison, J. H., \& Hof, P. R. (1997). Life and death of neurons in the aging brain. Science, 278(5337), 412-419. doi: 10.1126/science.278.5337.412

Ott, U. (2010). Meditation für Skeptiker: ein Neurowissenschaftler erklärt den Weg zum Selbst. München, Germany: Droemer Knaur.

Ott, U. (2013). Yoga für Skeptiker: ein Neurowissenschaftler erklärt die uralte Weisheitslehre. München, Germany: Droemer Knaur.

Persson, J., Nyberg, L., Lind, J., Larsson, A., Nilsson, L. G., Ingvar, M., \& Buckner, R. L. (2006). Structure-function correlates of cognitive decline in aging. Cerebral Cortex, 16(7), 907-915. doi: 10.1093/cercor/bhj036

Pizzo, P. A., \& Clark, N. M. (2012). Alleviating suffering 101--pain relief in the United States. The New England journal of medicine, 366(3), 197-199. doi: 10.1056/NEJMp1109084

Plassman, B. L., Williams, J. W., Burke, J. R., Holsinger, T., \& Benjamin, S. (2010). Systematic review: factors associated with risk for and possible prevention of cognitive decline in later life. Annals of Internal Medicine, 153(3), 182-193. doi: 10.7326/0003-4819-153-3201008030-00258

Reavley, N., \& Jorm, A. F. (2010). Prevention and early intervention to improve mental health in higher education students: a review. Early Intervention in Psychiatry, 4(2), 132-142. doi: 10.1111/j.1751-7893.2010.00167.x

Ryan, R. M., \& Deci, E. L. (2001). On happiness and human potentials: a review of research on hedonic and eudaimonic well-being. Annual Review of Psychology, 52, 141-166. doi: 10.1146/annurev.psych.52.1.141 
Ryff, C. D., \& Singer, B. H. (2008). Know thyself and become what you are: a eudaimonic approach to psychological well-being. Journal of Happiness Studies, 9(1), 13-39. doi: 10.1007/s10902-006-9019-0

Salat, D. H., Buckner, R. L., Snyder, A. Z., Greve, D. N., Desikan, R. S., Busa, E., Morris, J. C., Dale, A. M., \& Fischl, B. (2004). Thinning of the cerebral cortex in aging. Cerebral Cortex, 14(7), 721-730. doi: 10.1093/cercor/bhh032

Salthouse, T. A. (2009). When does age-related cognitive decline begin? Neurobiology of Aging, 30(4), 507-514. doi: 10.1016/j.neurobiolaging.2008.09.023

Segal, Z. V., Williams, J. M. G., \& Teasdale, J. D. (2002). Mindfulness-based cognitive therapy for depression: A new approach to preventing relapse. New York, NY: The Guilford Press.

Seligman, M. E. P., \& Csikszentmihalyi, M. (2000). Positive psychology. An introduction. American Psychologist, 55(1), 5-14. doi: 10.1037//0003-066X.55.1.5

Sengupta, P. (2012). Health impacts of yoga and pranayama: a state-of-the-art review. Int J Prev Med, 3(7), 444-458.

Statistisches_Bundesamt. (2014). Retrieved June 2nd, 2014, from https://www-genesis.destatis.de Tandon, S. (1995). A Re-appraisal of Patanjali's Yoga-sutras in the Light of the Buddha's Teaching. Igatpuri, India: Vipassana Research Institute.

Tsang, A., Von Korff, M., Lee, S., Alonso, J., Karam, E., Angermeyer, M. C., Borges, G. L. G., Bromet, E. J., de Girolamo, G., \& de Graaf, R. (2008). Common chronic pain conditions in developed and developing countries: gender and age differences and comorbidity with depression-anxiety disorders. The Journal of Pain, 9(10), 883-891. doi: 10.1016/j.jpain.2008.05.005

Tucker-Drob, E. M. (2011). Global and domain-specific changes in cognition throughout adulthood. Developmental Psychology, 47(2), 331-343. doi: 10.1037/a0021361

Turk, D. C., Wilson, H. D., \& Cahana, A. (2011). Treatment of chronic non-cancer pain. Lancet, 377(9784), 2226-2235. doi: 10.1016/S0140-6736(11)60402-9

United Nations. (2002). World population ageing, 1950-2050. New York, NY: United Nations

Valois, R. F., Zullig, K. J., Huebner, E. S., \& Drane, J. W. (2001). Relationship between life satisfaction and violent behaviors among adolescents. American Journal of Health Behavior, 25(4), 353-366. doi: 10.5993/AJHB.25.4.1

Veehof, M. M., Oskam, M.-J., Schreurs, K. M. G., \& Bohlmeijer, E. T. (2011). Acceptance-based interventions for the treatment of chronic pain: a systematic review and meta-analysis. Pain, 152(3), 533-542. doi: 10.1016/j.pain.2010.11.002

Wallace, B. A., \& Shapiro, S. L. (2006). Mental balance and well-being: building bridges between Buddhism and Western psychology. American Psychologist, 61(7), 690-701. doi: 10.1037/0003-066X.61.7.690

Wenig, C. M., Schmidt, C. O., Kohlmann, T., \& Schweikert, B. (2009). Costs of back pain in Germany. European Journal of Pain, 13(3), 280-286. doi: 10.1016/j.ejpain.2008.04.005

Wilson, R. S., Beckett, L. A., Bennett, D. A., Albert, M. S., \& Evans, D. A. (1999). Change in cognitive function in older persons from a community population: relation to age 
and Alzheimer disease. Archives of Neurology, 56(10), 1274-1279. doi: 10.1001/archneur.56.10.1274

Wren, A. A., Wright, M. A., Carson, J. W., \& Keefe, F. J. (2011). Yoga for persistent pain: New findings and directions for an ancient practice. Pain, 152(3), 477-480. doi: 10.1016/j. pain.2010.11.017

Zeidan, F., Martucci, K. T., Kraft, R. A., Gordon, N. S., McHaffie, J. G., \& Coghill, R. C. (2011). Brain mechanisms supporting the modulation of pain by mindfulness meditation. Journal of Neuroscience, 31(14), 5540-5548. doi: 10.1523/JNEUROSCI.5791-10.2011 


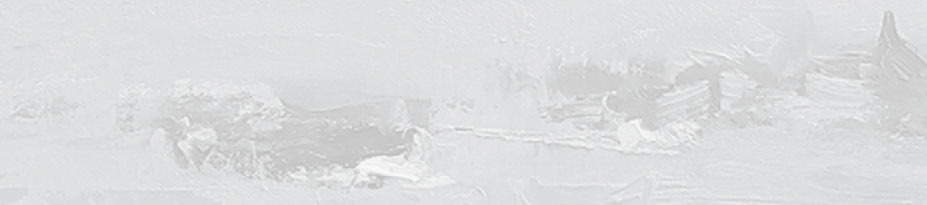


CHAPTER 2

\section{NEURAL MECHANISMS OF PAIN MODULATION THROUGH MINDFULNESS}

Based on: Gard, T., Hölzel, B. K., Sack, A. T., Hempel, H., Lazar, S. W., Vaitl, D., \& Ott,

U. (2012). Pain Attenuation through Mindfulness is Associated with Decreased

Cognitive Control and Increased Sensory Processing in the Brain. Cerebral Cortex, 22(11), 2692-2702. doi: 10.1093/cercor/bhr352 


\section{AbStract}

Pain can be modulated by several cognitive techniques, typically involving increased cognitive control and decreased sensory processing. Recently, it has been demonstrated that pain can also be attenuated by mindfulness. Here we investigate the underlying brain mechanisms by which the state of mindfulness reduces pain. Mindfulness practitioners and controls received unpleasant electric stimuli in the fMRI scanner during a mindfulness and a control condition. Mindfulness practitioners, but not controls, were able to reduce pain unpleasantness by $22 \%$ and anticipatory anxiety by $29 \%$ during a mindful state. In the brain this reduction was associated with decreased activation in the lateral prefrontal cortex and increased activation in the right posterior insula during stimulation and increased rostral anterior cingulate cortex activation during the anticipation of pain. These findings reveal a unique mechanism of pain modulation, comprising increased sensory processing and decreased cognitive control, and are in sharp contrast to established pain modulation mechanisms. 


\section{INTRODUCTION}

Pain is a common symptom of many medical conditions and can significantly interfere with a person's quality of life and general functioning. Pain conditions show high prevalence rates and place a high burden on society with annual costs of up to $\$ 61.2$ billion (due to lost productive time) in the US alone (Stewart, Ricci, Chee, Morganstein, \& Lipton, 2003). Over the past decades a large body of research has focused on pharmacological and non-pharmacological ways to alleviate chronic and acute pain.

Several non-pharmacological strategies can be used to modulate the experience of pain, including: distraction (Bantick et al., 2002; Petrovic, Petersson, Ghatan, Stone-Elander, \& Ingvar, 2000), perceived control/reappraisal (Wiech et al., 2006), changing expectations about the intensity of pain (Koyama, McHaffie, Laurienti, \& Coghill, 2005), placebo (Lu et al., 2010; Wager et al., 2004), hypnosis (Vanhaudenhuyse et al., 2009), hypnotic suggestion (Rainville, Duncan, Price, Carrier, \& Bushnell, 1997), non-hypnotic suggestion (Derbyshire, Whalley, \& Oakley, 2009), induced emotion (Roy, Piche, Chen, Peretz, \& Rainville, 2009), and religious contemplation (Wiech, Farias, et al., 2008). These strategies have variable effects, either reducing or not modulating activity in affective pain related regions such as the dorsal anterior cingulate (dACC), and sensory pain related areas such as the somatosensory cortex, the thalamus, and in some cases the posterior insula (e.g. Lu et al., 2010). Although there is no consensus, many authors also regard the posterior insula as a region related to sensory aspects of pain (Apkarian, Bushnell, Treede, \& Zubieta, 2005; Kross, Berman, Mischel, Smith, \& Wager, 2011). Modulation of pain through distraction, reappraisal, and placebo often also leads to increased activation in the rostral anterior cingulate cortex (rACC), which may reflect the top-down modulation of painrelated areas. This top-down modulation is thought to be initiated by increased activity in the lateral prefrontal cortex (lPFC; Petrovic et al., 2010; Wager, Atlas, Leotti, \& Rilling, 2011; Wiech et al., 2006). Similarly, these modulatory regions are also involved in emotion regulation (Ochsner \& Gross, 2005), suggesting shared mechanisms of emotion and pain modulation (Wiech, Ploner, \& Tracey, 2008).

Mindfulness has recently been described as another strategy that can effectively modulate clinical (Grossman, Tiefenthaler Gilmer, Raysz, \& Kesper, 2007; Kabat-Zinn, Lipworth, \& Burney, 1985) and experimentally induced pain (Grant \& Rainville, 2009; Kingston, Chadwick, Meron, \& Skinner, 2007; Perlman, Salomons, Davidson, \& Lutz, 2010; Zeidan, Gordon, Merchant, \& Goolkasian, 2010; Zeidan et al., 2011). It is important to understand the mechanisms of mindfulness as a pain modulation strategy, as it is both efficacious and increasingly being applied in clinical contexts. The aim of the present study therefore is to investigate the neural mechanisms underlying mindfulness induced pain attenuation. 
Mindfulness is a practice that has its roots in Buddhist meditation and is defined as purposefully paying attention to experiences in the present moment in a non-judgmental way (Grossman, Niemann, Schmidt, \& Walach, 2004; KabatZinn, 1990). There is growing evidence that mindfulness-based interventions are effective in treating a variety of conditions with affective components, such as anxiety and depression (Baer, 2003; Hofmann, Sawyer, Witt, \& Oh, 2010). This is thought to be the result of improved emotion regulation through mindfulness, which involves prefrontal regions (Creswell, Way, Eisenberger, \& Lieberman, 2007; Lutz, Slagter, Dunne, \& Davidson, 2008). Indeed a number of studies found increased activation in prefrontal cortex (PFC) during the state of mindfulness (Brefczynski-Lewis, Lutz, Schaefer, Levinson, \& Davidson, 2007; Hölzel et al., 2007) and during rest after a mindfulness intervention (Tang et al., 2009). Based on the suggestion that mindfulness involves prefrontal mechanisms of known emotion regulation strategies and based on the similarity between emotion regulation and pain modulation strategies, it might be hypothesized that the neural mechanisms of mindfulness induced pain attenuation are not different from the previously mentioned mechanisms including distraction, reappraisal, and placebo.

However, the two key components of mindfulness, namely 1) attention to experiences in the present moment, and 2) non-judgmental attitude, are conceptually different from other attention- and cognition-driven pain-modulation strategies, such as distraction, reappraisal, and change of expectations. In the strategy of distraction, attention is focused away from the pain by performing a cognitively demanding task, whereas attention is directed towards the pain in mindfulness (Bantick et al., 2002; Hart, 1987). Although counter intuitive, some studies have shown that bringing attention towards painful stimuli, specifically to the objective/sensory aspects can result in decreased pain perception, especially in subjects with high health anxiety (Hadjistavropoulos, Hadjistavropoulos, \& Quine, 2000) and high fear of pain (Roelofs, Peters, van der Zijden, \& Vlaeyen, 2004). As mindfulness involves bringing the focus of attention towards the sensory aspects of pain (Hart, 1987), and as it has been shown that attention towards sensory stimuli results in increased recruitment of the respective neural representation (Gregory et al., 2003), we might expect increased recruitment of sensory areas during mindfulness induced pain attenuation.

Reappraisal involves actively reinterpreting the pain, e.g. as less threatening or relevant (Wiech et al., 2006), whereas the pain is not judged or appraised at all in mindfulness. Furthermore, mindfulness does not involve striving to change expectations about the intensity of the pain stimulus - by definition a top-down process (Koyama et al., 2005) - rather, mindfulness emphasizes bottom-up processing of sensory stimuli. Mindfulness is also different from a placebo response, which involves both a modification of the expectations about stimulus intensity and reappraisal of the stimuli (Wiech, Ploner, et al., 2008). 
A recent neuroimaging study provides preliminary support for the notion that mindfulness is different from attention- and cognition-driven pain and emotion regulation strategies by showing that mindfulness practitioners have different neuronal responses to painful stimuli than controls, involving greater activation in the insula (anterior to posterior) and thalamus, and decreased activation in PFC (Grant, Courtemanche, \& Rainville, 2011), but see (Brown \& Jones, 2010). However, these studies did not investigate a state of mindfulness, but rather studied a resting state in mindfulness meditators, making the assumption that repeatedly cultivating a state of mindfulness through meditation practice results in neural processing similar to that state, even during rest. These studies also did not manipulate states of mindfulness, making it impossible to establish causality. Here we compare states of rest with states of mindfulness to investigate the neural correlates of the pain attenuating effects of the state of mindfulness.

We hypothesize that mindfulness involves neural mechanisms to modulate pain that are different from known mechanisms such as distraction, reappraisal, and placebo. More specifically, we hypothesize that modulation through mindfulness involves decreased activity in cognitive modulatory regions, such as the PFC, and increased activation in regions involved in sensory processing of pain, such as posterior insula, somatosensory cortex, and thalamus.

\section{MATERIALS AND MethodS}

\section{PARTICIPANTS}

Thirty-four participants were recruited: seventeen mindfulness practitioners (16 right-handed as assessed with the Edinburgh Inventory of Handedness (Oldfield, 1971); 13 male, $M$ age $=37.59$ years, $S D=7.87$ years) and seventeen controls matched for age, gender, education, and handedness (16 right-handed, 13 male, $M$ age $=36.59$ years, $S D=7.80$ years). Practitioners and controls did not differ in age $(t(32)=0.372, p=0.712)$ and education $\left(\chi^{2}(1)=1.619, p=0.203\right)$. Neither practitioners nor controls were suffering from psychological illness or taking medication. Practitioners were all trained in Vipassana meditation, twelve in the tradition of Goenka (Hart, 1987) and five in other Vipassana traditions, and their experience ranged from 910 to 20,855 hours $(M=5,979 ; S D=5,114)$ and 1.93 to 24.56 years $(M=10.20 ; S D=6.85)$. Controls had no prior experience with meditation. Practitioners were recruited from German meditation centers and controls were recruited through advertisements on notice boards and online classifieds. In an attempt to recruit groups with comparable lifestyles, advertisements stated that we were looking for subjects with a healthy lifestyle. Participants received a compensation of $€ 25$ or travel reimbursement. All 
participants complied with scanner safety requirements and provided written informed consent after receiving written information about the study. The study was approved by the ethics committee of the Psychology Department of Giessen University.

\section{ELECTRICAL STIMULATOR}

Transcutaneous electrical stimuli were generated with a custom-made impulse-generator ( $833 \mathrm{~Hz}$; Stark et al., 2006). Stimuli were applied to the left lower arm, using stainless steel electrodes $(Æ=2 \mathrm{~mm})$. Electrodes were positioned and individually adjusted such that the experienced sensation was a sharp, focused needle prick. Stimulus intensity was adjusted for each participant individually to a moderate intensity level $(M=5.65, S D=1.72$ on a 10 -point scale) using the ascending method of limits, starting with a charge of $103 \mathrm{~V}$ and increasing in increments of $5 \mathrm{~V}$.

\section{IMAGE ACQUISITION}

Brain images were acquired with a 1.5 T Siemens Symphony scanner with standard head coil using a T2*-weighted gradient echo-planar imaging sequence (EPI) with 20 transversal slices (thickness $=5 \mathrm{~mm}$; gap $=1 \mathrm{~mm}$; descending order; $\mathrm{TR}=2 \mathrm{~s} ; \mathrm{TE}=50$ $\mathrm{ms}$; flip angle $=90^{\circ}$; field of view $=192 \times 192 \mathrm{~mm}$; matrix size $=64^{\prime} 64 \mathrm{~mm}$ ). All scans were performed at the Bender Institute of Neuroimaging in Giessen, Germany.

For the purpose of normalizing functional data, structural images were acquired using a T1-weighted magnetization prepared rapid acquisition gradient echo (MPRAGE) sequence with parameter settings as recommended by the Alzheimer's Disease Neuroimaging Initiative (ADNI; 160 sagittal slices, slice thickness $=1.2 \mathrm{~mm}, \mathrm{TR}=3 \mathrm{~s}, \mathrm{TE}=3.61$ $\mathrm{ms}$, flip angle $=90^{\circ}$, field of view $=240 \times 240 \mathrm{~mm}$, matrix $=192 \times 192 \mathrm{~mm}$; Jack et al.2008).

\section{SELF-REPORT RATINGS}

Stimulus intensity, unpleasantness, and anticipatory anxiety were rated with visual rating scales with the anchors "not noticeable" versus "very strong", "not unpleasant" versus "very unpleasant", and "not anxious" versus "very anxious", respectively. The intensity and unpleasantness scales were based on the scales of Price et al.(1983) and their original instructions to explain the difference between intensity and unpleasantness were used. Scales consisted of a red bar, where the length of the bar indicated the rating. The length of the bar could be adjusted in 10 increments by pressing two keys of a button box. A third key needed to be pressed to confirm the rating. Visual rating scales were administered in the scanner after every stimulation phase (see Figure 1). 
Before and after the scanning participants rated their mood on 7-point Likert scales. After scanning they also rated task difficulty and the self-perceived success with which they had performed each condition on 7-point Likert scales. Furthermore, the Freiburg Mindfulness Inventory (FMI; Walach, Buchheld, Buttenmüller, Kleinknecht, \& Schmidt, 2004) and the German version of the Fear of Pain Questionnaire (FPQ; McNeil \& Rainwater, 1998) were administered. During scanning, the respiration rate was recorded using the scanner's breathing belt (Siemens Symphony).

\section{Procedure}

\section{Stimulation protocol/conditions}

The study design was based on a mixed blocked/event-related design (Visscher et al., 2003) and employed a mindfulness condition and a baseline condition during which transcutaneous stimuli were randomly delivered to the left forearm. There also was an attention condition which will not be further discussed here as it failed to manipulate pain and anxiety perception, and there was an aversion condition which was not related to the aim of the current paper and will be reported elsewhere. Each condition was presented 6 times. Presentation of the conditions was organized into 6 blocks, such that each block comprised all conditions. After each block there was a break (45 s) in which participants were not stimulated. The order of conditions was permutated within and across subjects to control for carryover and sequencing effects.

During the mindfulness condition participants (mindfulness practitioners and controls) were asked to bring their attention to the skin surface underneath the electrode on their forearm and to observe the sensations related to the stimuli, making sure to be mindful, accepting, and being aware of the transient nature of the stimuli. During the baseline condition, participants were instructed not to employ any specific strategy. During the breaks following each block, participants did not receive stimulation and were instructed to close their eyes and stay awake. Breaks comprised 5 seconds of instruction and 40 seconds of actual break with the sound of a bell at the end. Conditions were also preceded by a 5 second instruction with a visual presentation of the name of the condition, followed by a 40 second stimulation phase. During this phase, 3 transcutaneous stimuli ( $100 \mathrm{~ms}$ duration) were randomly delivered (with a minimum of 5 seconds between stimuli). As participants were asked to keep their eyes closed during all stimulation phases, the sound of a bell indicated to participants that they should open their eyes at the end of the stimulation phase, and to rate intensity, unpleasantness, and anxiety on visual rating scales (duration $7 \mathrm{~s}$ each). See Figure 1 for trial structure. 


\begin{tabular}{|c|c|}
\hline $5 \mathrm{sec}$. & $40 \mathrm{sec}$. \\
\hline Inst. & Stimulation \\
\hline
\end{tabular}

Figure 1. Stimulation protocol. Mindfulness and baseline conditions consisted of an instruction phase, a stimulation phase with 3 random shocks, and a rating phase in which intensity, unpleasantness, and anticipatory anxiety were rated on a visual rating scale. Each condition was presented six times and orders were permutated within and over subjects. Inst. = instruction, sec. $=$ seconds.

\section{Instructions}

Participants received written instructions in which all conditions were described. Mindfulness instructions were based on standardized Vipassana courses as taught by Goenka (Hart, 1987). To ensure that instructions were correctly understood by participants, they were asked to explain them to the experimenter. If necessary, clarification was provided. Then, participants were asked to mentally practice the different strategies. Prior to starting each test run, participants were asked to repeat the instructions once again, to make sure they remembered them in detail. In addition, after the completion of the protocol, study participants were asked to describe what they had done in each of the conditions. Reviewing the descriptions revealed that all participants had a correct understanding of the conditions.

Participants were not informed about the exact number of shocks during each condition and no cues were presented in order to keep anticipation of shocks constant over the entire duration of each condition. Furthermore, in order to make the repeated rating of stimuli meaningful, participants were naïve to the fact that stimulus intensity was kept constant.

\section{ANALYSES}

All analyses of behavioral data described below were conducted with SPSS 17 (SPSS Inc., Chicago, IL, USA), and all imaging data were analyzed with BrainVoyagerQX 1.10.4. (Brain Innovation, Maastricht, Netherlands).

\section{Behavioral data}

The effects of group, time, and condition on the dependent variables intensity, unpleasantness, anxiety, and respiration rate (breaths per minute) were assessed with $2 \times 6 \times 2$ repeated measures ANOVAs with group (mindfulness practitioners vs. controls) as a between subject factor, and time (number of stimulation block 1-6) and condition (mindfulness vs. baseline) as within subject factors. Where the sphericity assumption was not met, the Greenhouse-Geisser correction of degrees of freedom was applied. To further understand what was driving identified group $\times$ condition 
interactions, paired-samples t-tests (two-tailed), comparing ratings during baseline and mindfulness, were conducted for the mindfulness and control group separately. In addition, independent samples t-test (two-tailed) were conducted to test for differences in baseline ratings between mindfulness practitioners and controls. As participants did not always confirm their rating within the given time ( $7 \mathrm{~s}$ per rating), not all 36 ratings ( 2 conditions ' 6 repetitions ' 3 scales) were available for all participants. Therefore the ANOVAs reported here are based on varying numbers of subjects. Missing values were less than 3\% for most ratings, with only one rating missing $9 \%$ of values. When performing the same analyses with missing values replaced by subjects' means, comparable results to those reported here were obtained.

To rule out possible confounds, we tested for group differences in fear of pain as measured with the FPQ, chosen stimulation charge, mood, perceived task difficulty, perceived success in task performance, and respiratory rates. Between groupdifferences of fear of pain, stimulation charge, mood before, and mood after scanning were assessed with independent samples t-tests (two-tailed). To compare the difficulty and the success of adhering to the baseline and the mindfulness instructions between mindfulness practitioners and controls, two repeated measures ANOVAS with condition as a within-subject factor and group as between-subject factor were performed. To assess effects of group, condition, and time on respiration rate, an ANOVA with group, condition, and time as factors, and respiration rate as dependent variable was conducted. In addition, correlations between change in respiration rate (baseline-mindfulness) and changes in stimulus intensity, unpleasantness, and anxiety (baseline-mindfulness) were calculated.

\section{Imaging}

\section{Preprocessing}

Blood Oxygen Level Dependent (BOLD) imaging data underwent the following preprocessing steps: 1) slice time correction with sinc interpolation, 2) 3D motion correction with trilinear/sinc interpolation, 3) drift removal consisting of linear trend removal, 4) temporal high pass filtering at $0.0016 \mathrm{~Hz}$, and 5) spatial smoothing with a $8 \mathrm{~mm}$ Gaussian full with half maximum (FWHM) kernel.

Structural brain data was resampled at $1 \times 1 \times 1 \mathrm{~mm}$ using a sinc interpolation and corrected for inhomogeneities (Vaughan et al., 2001). Subsequently, data was transformed to the anterior commissure-posterior commissure (ACPC; rigid body transformation) and Talairach (piecewise linear transformations) space using sinc interpolations. For the Talairach transformation 8 landmarks were specified, dividing the brain into 12 subvolumes to which linear transformations were applied. To normalize BOLD data, functional and structural data were co-registered (header and intensity based) and the same transformation steps as performed for the structural data were applied (Goebel, Esposito, \& Formisano, 2006). 


\section{Modeling \& statistical tests}

One mindfulness practitioner and two controls were excluded from analyses because they had head motion of $3 \mathrm{~mm}$ /degrees or more (Goebel et al., 2006). Design matrices consisted of eleven predictors, namely instruction, baseline anticipation (all periods during the stimulation phase of the baseline condition except for the stimuli and the bell), baseline stimulus (i.e., electrical stimulation events during the baseline condition), mindfulness anticipation (all periods during the stimulation phase of the mindfulness condition except for the stimuli and the bell), mindfulness stimulus (i.e., electrical stimulation events during the mindfulness condition), bell, rating phase, and two predictors (anticipation and stimulus) for each of the other two conditions. To avoid overspecification, the break was not modeled. Predictors were derived by convoluting the respective box-car waveforms with a double-gamma hemodynamic response function (onset $=0$, response undershoot ratio $=6$, time to response peak $=5 \mathrm{~s}$, time to undershoot peak $=15 \mathrm{~s}$, response dispersion $=1$, undershoot dispersion $=1$ ).

To investigate the neural correlates of the response to the electric stimuli without instructed regulation, whole brain random effects (RFX) generalized linear model (GLM) analyses were performed for mindfulness practitioners and controls separately. The contrast of interest was stimulus during baseline $>$ rest. Resulting maps were corrected for multiple comparisons using a cluster level threshold procedure that is based on the approach described by Forman et al.(1995) and has been extended and implemented in BrainVoyager QX (Goebel et al., 2006). We used this procedure with 1000 Monte Carlo simulations, a search mask excluding the skull, and a voxel level threshold of $p<0.001$. Reported clusters are significant at $p<0.05$ (extent 6 in mindfulness practitioners and 7 in controls) and were labeled using the Talairach daemon (Lancaster et al., 2000).

In order to investigate where the effect of mindfulness on brain activity during the anticipation of pain and during electric stimulation was different for mindfulness practitioners than for controls (interaction of group and condition), whole brain RFX GLM analyses were performed. Contrasts of interests were mindfulness $>$ baseline for mindfulness practitioners $>$ controls and for controls $>$ mindfulness practitioners, and mindfulness stimulus $>$ baseline stimulus for mindfulness practitioners $>$ controls and for controls $>$ mindfulness practitioners. Resulting maps were corrected for multiple comparisons using the above outlined cluster level threshold procedure with a voxel level threshold of $p<0.05$. Reported clusters are significant at $p<0.05$ (extent 41 for the anticipation contrasts and 44 for the stimulation contrasts) and were labeled using the Talairach daemon (Lancaster et al., 2000). Post-hoc analyses were conducted to further investigate what was driving the group $\times$ condition interactions in clusters in the $\mathrm{rACC} /$ ventromedial PFC (vmPFC), left and right IPFC, posterior insula/S2, left temporal lobe, left superior temporal gyrus, and cerebellum, that where identified by whole brain RFX GLM analyses. These analyses comprised paired-samples t-tests (two-tailed), comparing 
activation during mindfulness and baseline for mindfulness practitioners and controls separately, and independent samples t-tests (two-tailed) comparing activation between mindfulness practitioners and controls during the baseline condition. Furthermore, to explore whether changes in activation in these regions were related to changes in pain reports, correlations between activations (mindfulness-baseline) in these clusters, and changes in unpleasantness and anxiety ratings (baseline-mindfulness) were calculated for mindfulness practitioners and controls separately. While whole brain analyses were corrected for multiple comparisons, post-hoc analyses and behavioral analyses were not. Only significant correlations will be reported in the following section.

\section{RESULTS}

We investigated how mindfulness modulated neural responses to pain anticipation and to pain perception. Pain was induced by transcutaneous electrical stimuli at random time intervals while participants either rested (baseline condition) or engaged in a state of mindfulness. Baseline and mindfulness conditions were each performed in six $40 \mathrm{sec}-$ ond blocks. Subjects rated intensity and unpleasantness of the painful stimuli and anticipatory anxiety right after each block (Figure 1). Due to missing values, analyses involving pain ratings can have a varying number of subjects. For details see methods section.

\section{PAIN RATINGS}

To investigate the effects of group, condition and time on pain intensity ratings, a repeated measures ANOVA was conducted ( $\mathrm{n}=14$ mindfulness practitioners and 15 controls). This analysis did not reveal significant main effects for group $(F(1,27)=2.56$, $p=0.617$, n.s. $)$ or condition $(F(1,27)=0.46, p=0.502$, n.s). A main effect for time was found $\left(F(2.95,79.51)=4.42, p=0.007, \eta_{p}^{2}=0.14\right)$, which can be described by a linearly decreasing function $\left(F(1,27)=4.46, p=0.044, \eta_{p}^{2}=0.14\right)$, indicating habituation to the stimulus. No significant interaction effect for condition $\times$ group $(F(1,27)=1.92$, $p=0.177$, n.s.) was found, indicating that the effect of condition (mindfulness vs. baseline) did not differ for mindfulness practitioners and controls (Figure 2a). The absence of time $\times$ group $F(2.95,79.51)=0.16, p=0.978$, n.s. $)$ or time $\times$ condition $F(3.29,88.92)=1.32 p=0.274$, n.s. $)$ interactions indicates that habituation did not differ between conditions or groups. There also was no significant three way interaction between condition, group, and time $F(3.29,88.92)=0.98, p=0.411$, n.s.).

A repeated measures ANOVA ( $n=14$ mindfulness practitioners and 15 controls) with group, condition, and time as factors, and unpleasantness rating as dependent variable revealed a main effect for condition $\left(F(1,27)=7.74, p=0.010, \eta_{p}^{2}=0.22\right)$, and time $\left.F(5,135)=3.26, p=0.008, \eta_{p}^{2}=0.11\right)$, but not for group $(F(1,27)=1.37$, 

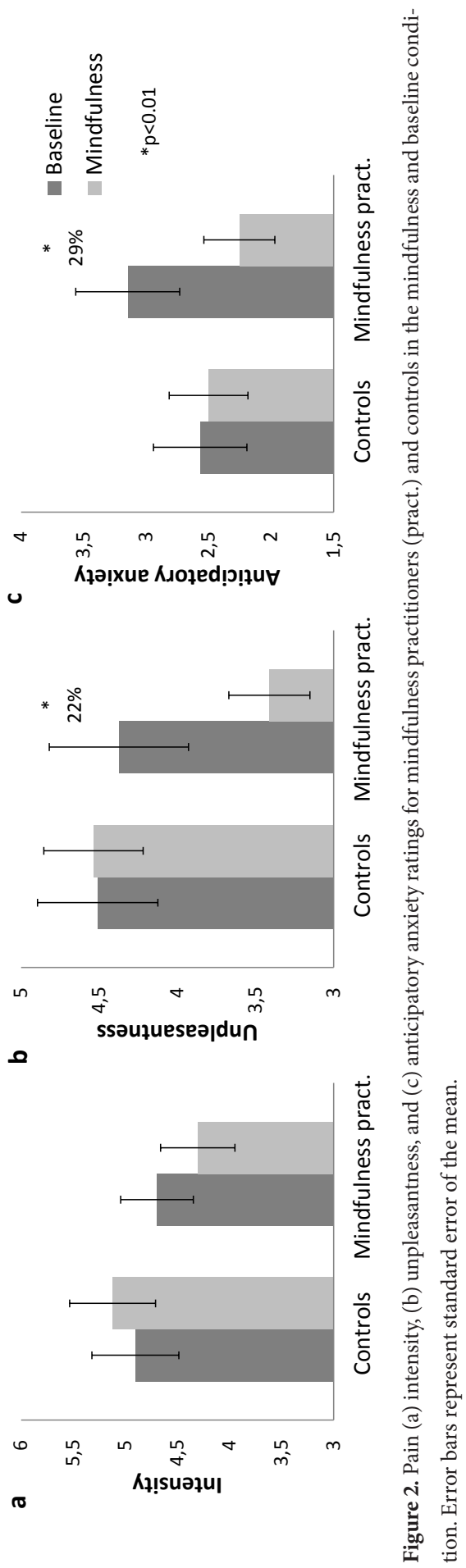
$p=0.252$, n.s.). This effect of time is linearly decreasing $(F(1,27)=6.76, p=0.015$, $\left.\eta_{p}^{2}=0.20\right)$, indicating that pain unpleasantness decreased over the six blocks. A significant interaction between group and condition was found $(F(1,27)=6.11, p=0.020$, $\eta_{p}^{2}=0.19$ ), indicating that the effect of condition (mindfulness vs. baseline) was different for mindfulness practitioners and controls (Figure $2 \mathrm{~b}$ ). Paired samples t-test revealed that this interaction was driven by decreased (22\%) pain unpleasantness during the mindfulness condition as compared to the baseline condition in experienced mindfulness practitioners $(t(16)=2.97, p=0.009)$ but not in controls $(t(16)=-0.13$, $p=0.895$; Figure $2 \mathrm{~b}$ ). Independent samples t-tests revealed that mindfulness practitioners and controls did not significantly differ in unpleasantness ratings during the baseline condition $(t(32)=-0.23, p=0.820)$. The ANOVA further revealed the absence of interactions between time and group $(F(5,135)=0.71, p=0.615$, n.s. $)$ or time and condition $(F(3.56,96.16)=0.78, p=0.531$, n.s. $)$, indicating that the habituation of the unpleasantness of the stimuli did not differ across groups or conditions. No time $\times$ group $\times$ condition interaction was found $(F(3.56,96.16)=0.43, p=0.769$, n.s. $)$.

Another repeated measures ANOVA was conducted to investigate the effects of group, condition, and time on anticipatory anxiety. This analysis revealed significant main effects for condition $\left(F(1,30)=7.05, p=0.013, \eta_{p}^{2}=0.19\right)$ and time $(F(5$, $\left.150)=12.97, p=<0.001, \eta_{p}{ }^{2}=0.30\right)$ but not for group $(F(1,30)=0.28, p=0.601$, n.s. $)$. Furthermore, a significant interaction between group and condition was found $(F(1$, $\left.30)=5.16, p=0.031, \eta_{p}^{2}=0.15\right)$. Paired samples t-tests revealed that this interaction was driven by a significant decrease (29\%) in the mindfulness condition as compared to the baseline condition in experienced mindfulness practitioners $(t(16)=2.98$, $p=0.009)$, but not in controls $(t(16)=0.45, p=0.659$; Figure $2 c)$. Surprisingly, mindfulness practitioners had higher anticipatory anxiety ratings during baseline than controls $(M=3.15, S D=1.71$ and $M=2.5, S D=1.54$ respectively). However this difference was not statistically significant $(t(32)=1.036, p=0.308)$. The ANOVA further revealed the absence of time $\times$ group $(F(5,150)=1.10, p=0.364$, n.s. $)$ and time $\times$ condition $(F(3.52,105.50)=0.36, p=0.811$, n.s. $)$ interactions. However, the three way interaction between time, group, and condition was significant $(F(3.52,105.50)=2.96, p=0.029$, $\left.\eta_{p}^{2}=0.09\right)$, can best be described as linear $\left(F(1,30)=8.80, p=0.006, \eta_{p}^{2}=0.23\right)$, and is characterized by lower anxiety during mindfulness than during baseline at all time points in mindfulness practitioners, and a more variable pattern of lower and higher anxiety ratings during mindfulness as compared to baseline over time in controls.

To determine whether differences in fear of pain as measured with the FPQ, chosen stimulation charge, mood, perceived task difficulty, perceived success in task performance, and respiratory rates differed between groups, thereby potentially impacting results, we tested for group differences on these variables. There were no differences in fear of pain $(t(31)=1.57, p=0.126)$, stimulus charge $(t(32)=0.63, p=0.53)$, mood before $(t(32)=-1.2, p=0.24)$, and mood after $(t(32)=1.53, p=0.14)$ scanning 
between mindfulness practitioners and controls, indicating that these variables were not potential confounders in the current study. Furthermore, a repeated measures ANOVA with group and condition as factors and perceived difficulty of establishing the condition state as dependent variable revealed a main effect for condition $(F(1$, $\left.32)=5.34, p=0.027, \eta_{p}{ }^{2}=0.14\right)$ but not for $\operatorname{group}(F(1,32)=1.50, p=0.230$, n.s. $)$, indicating that it was more difficult to establish the mindful state $(M=2.26 ; S D=1.44$ on a 7-point scale, collapsed over group) than the baseline state $(M=1.71 ; S D=0.76)$. The absence of an interaction between group and condition $(F(1,32)=0.37, p=0.547$, n.s.) indicates that the condition effect was not different for mindfulness practitioners and controls. An identical ANOVA with perceived success in establishing the condition state did not reveal significant effects for group $(F(1,32)=0.19, p=0.664$, n.s. $)$, condition $(F(1,32)=2.66, p=0.113$, n.s. $)$, or group $\times$ condition $(F(1,32)=0.14, p=0.709$, n.s.). This, in combination with the high average success rating $(M=5.48 ; S D=1.35$ on a 7-point scale, collapsed over group and condition), indicates that participants, regardless of which group they belonged to, felt highly successful about establishing, maintaining, and switching between the mindfulness and the baseline states. Another repeated measures ANOVA was used to calculate the effects of group, condition, and time on respiration rate. No differences in respiratory rate were found between groups $(F(1,28)=2.38, p=0.134$, n.s. $)$ and conditions $(F(1,28)=1.27, p=0.269$, n.s. $)$, and there was no interaction between the two $(F(1,28)=0.051, p=0.823$, n.s. $)$. Respiratory rate also did not change over time, as indicated by the absence of a main effect of time $(F(2.83,79.11)=0.53, p=0.653$, n.s. $)$ or interactions between time and group $(F(2.83,79.11)=1.85, p=0.148$, n.s. $)$, time and condition $(F(5,140)=0.79, p=0.557$, n.s.), and time $\times$ group $\times$ condition $(F(5,140)=1.01, p=0.416$, n.s.). There was no correlation between change (baseline-mindfulness) in respiratory rate and change (baseline-mindfulness) in rated stimulus intensity $(r(28)=0.082, p=0.666)$, unpleasantness $(r(28)=0.066, p=0.728)$, or anticipatory anxiety $(r(28)=0.215, p=0.254)$, indicating that perceived pain and anxiety were not affected by respiration rate.

\section{IMAGING}

\section{Pain}

As a manipulation check of the effect of the electric stimuli, we explored neural correlates of the stimuli in the baseline condition. Both mindfulness practitioners and controls showed activation in regions that are typically activated during the experience of pain, such as the ACC, insula, thalamus, S1, S2, and PFC (Figure 3 and Table 1 and 2). 


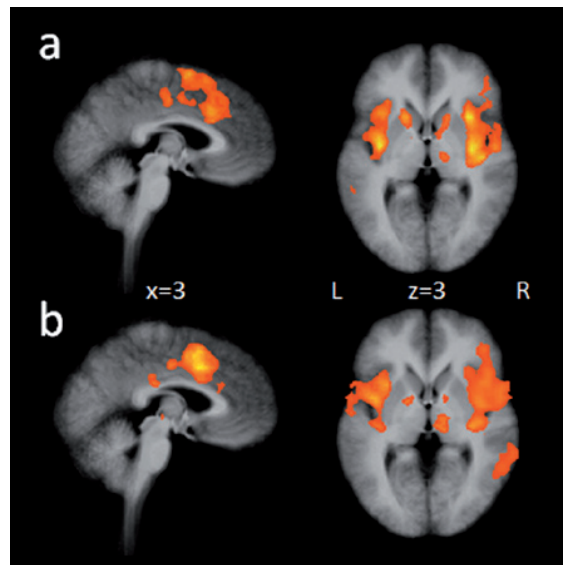

Figure 3. Activation in response to electric stimulation in a) mindfulness practitioners and b) controls during the baseline condition. Maps are the result of a whole brain random effects analysis and are cluster level corrected for multiple comparisons at $p<0.05$ (voxel threshold $p<0.001$, extent 6 for $\mathrm{a}$, and 7 for $\mathrm{b}$ ).

Table 1. Activation in response to electric shocks in mindfulness practitioners during baseline (whole brain corrected $p<0.05$, using cluster thresholding with voxel threshold $p<0.001$ and extent 6). Cluster size in $\mathrm{mm}^{3}$, coordinates, $\mathrm{t}$ - and $p$-values are of peak voxels, BA: Brodman area.

\begin{tabular}{|c|c|c|c|c|c|c|c|c|}
\hline Structure & BA & Side & $\mathbf{X}$ & $\mathbf{Y}$ & $\mathrm{Z}$ & Size & $t$ & $p$ \\
\hline Insula & 13 & $\mathrm{R}$ & 42 & 2 & -8 & 33971 & 10.65 & $<0.001$ \\
\hline S1 & 2 & $\mathrm{R}$ & & & & & & \\
\hline S2 & 40 & $\mathrm{R}$ & & & & & & \\
\hline Lateral Prefrontal Cortex & 46 & $\mathrm{R}$ & & & & & & \\
\hline Precentral Gyrus & 4 & $\mathrm{R}$ & 57 & -7 & 25 & 220 & 6.58 & $<0.001$ \\
\hline Inferior Frontal Gyrus & 9 & $\mathrm{R}$ & 39 & 8 & 31 & 2502 & 8.56 & $<0.001$ \\
\hline Thalamus & & $\mathrm{R}$ & 15 & -16 & 1 & 792 & 6.03 & $<0.001$ \\
\hline Caudate & & $\mathrm{R}$ & 15 & 14 & 4 & 806 & 5.40 & $<0.001$ \\
\hline Medial Frontal Gyrus & 6 & $\begin{array}{l}\mathrm{R} \\
\mathrm{L}\end{array}$ & 3 & 2 & 61 & 8967 & 6.67 & $<0.001$ \\
\hline Cingulate Gyrus & 24,32 & $\mathrm{R} / \mathrm{L}$ & & & & & & \\
\hline Cingulate Gyrus & 24 & $\begin{array}{l}\mathrm{L} \\
\mathrm{R}\end{array}$ & 0 & -16 & 37 & 821 & 5.17 & $<0.001$ \\
\hline $\begin{array}{l}\text { Claustrum } \\
\text { Insula }\end{array}$ & 13 & $\begin{array}{l}\mathrm{L} \\
\mathrm{L}\end{array}$ & -36 & -7 & 1 & 12990 & 9.72 & $<0.001$ \\
\hline Superior Frontal Gyrus & 10 & $\mathrm{~L}$ & -24 & 44 & 25 & 320 & 5.08 & $<0.001$ \\
\hline Precentral Gyrus & 9 & $\mathrm{~L}$ & -42 & 17 & 40 & 939 & 5.65 & $<0.001$ \\
\hline Precentral Gyrus & 6 & $\mathrm{~L}$ & -45 & -1 & 31 & 279 & 5.28 & $<0.001$ \\
\hline Postcentral Gyrus & 2 & $\mathrm{~L}$ & -54 & -22 & 31 & 6935 & 6.93 & $<0.001$ \\
\hline
\end{tabular}

Note. S1 is primary somatosensory cortex, S2 is secondary somatosensory cortex. 
Table 2. Activation in response to electric shocks in controls during baseline (whole brain corrected $p<0.05$, using cluster thresholding with voxel threshold $p<0.001$ and extent 7). Cluster size in $\mathrm{mm}^{3}$, coordinates, $\mathrm{t}$ - and $p$-values are of peak voxels, BA: Brodman area.

\begin{tabular}{|c|c|c|c|c|c|c|c|c|}
\hline Structure & BA & Side & $\mathbf{X}$ & $\mathbf{Y}$ & $\mathbf{Z}$ & Size & $t$ & $p$ \\
\hline Claustrum & & $\mathrm{R}$ & 33 & -19 & 7 & 52178 & 12.46 & $<0.001$ \\
\hline Insula & 13 & $\mathrm{R}$ & & & & & & \\
\hline S1 & $1,2,3$ & $\mathrm{R}$ & & & & & & \\
\hline S2 & 40 & $\mathrm{R}$ & & & & & & \\
\hline Lateral Prefrontal Cortex & 10,46 & $\mathrm{R}$ & & & & & & \\
\hline Middle Temporal Gyrus & 21 & $\mathrm{R}$ & 51 & -28 & -8 & 208 & 4.91 & $<0.001$ \\
\hline Middle Frontal Gyrus & 6 & $\mathrm{R}$ & 39 & -1 & 46 & 779 & 7.18 & $<0.001$ \\
\hline Inferior Parietal Lobule & 40 & $\mathrm{R}$ & 39 & -46 & 37 & 1056 & 6.75 & $<0.001$ \\
\hline Postcentral Gyrus & 3 & $\mathrm{R}$ & 36 & -31 & 58 & 192 & 5.86 & $<0.001$ \\
\hline Precuneus & 7 & $\mathrm{R}$ & 18 & -46 & 55 & 595 & 6.79 & $<0.001$ \\
\hline Thalamus & & $\mathrm{R}$ & 9 & -19 & 1 & 1863 & 6.42 & $<0.001$ \\
\hline Globus Pallidus & & $\mathrm{R}$ & 12 & 2 & 1 & 199 & 4.97 & $<0.001$ \\
\hline Paracentral Lobule & 6 & $\mathrm{R}$ & 9 & -28 & 55 & 268 & 7.36 & $<0.001$ \\
\hline \multirow[t]{3}{*}{ Cingulate Gyrus } & 24 & $\mathrm{R}$ & 6 & 8 & 37 & 10751 & 8.40 & $<0.001$ \\
\hline & 24 & $\mathrm{~L}$ & & & & & & \\
\hline & 32 & $\mathrm{R} / \mathrm{L}$ & & & & & & \\
\hline Middle Frontal Gyrus & 6 & $\mathrm{R} / \mathrm{L}$ & & & & & & \\
\hline Cingulate Gyrus & 23 & $\mathrm{~L}$ & 0 & -28 & 28 & 474 & 7.76 & $<0.001$ \\
\hline & & $\mathrm{R}$ & & & & & & \\
\hline Globus Pallidus & & $\mathrm{L}$ & -15 & -1 & 1 & 343 & 5.91 & $<0.001$ \\
\hline Insula & 13 & $\mathrm{~L}$ & -39 & -4 & -5 & 19610 & 8.55 & $<0.001$ \\
\hline S1 & 2 & $\mathrm{~L}$ & & & & & & \\
\hline S2 & 40 & $\mathrm{~L}$ & & & & & & \\
\hline Inferior Parietal Lobule & 40 & $\mathrm{~L}$ & -48 & -34 & 34 & 538 & 5.78 & $<0.001$ \\
\hline Inferior Parietal Lobule & 40 & $\mathrm{~L}$ & -45 & -46 & 40 & 320 & 5.45 & $<0.001$ \\
\hline
\end{tabular}

Note. $\mathrm{S} 1$ is primary somatosensory cortex, $\mathrm{S} 2$ is secondary somatosensory cortex. 


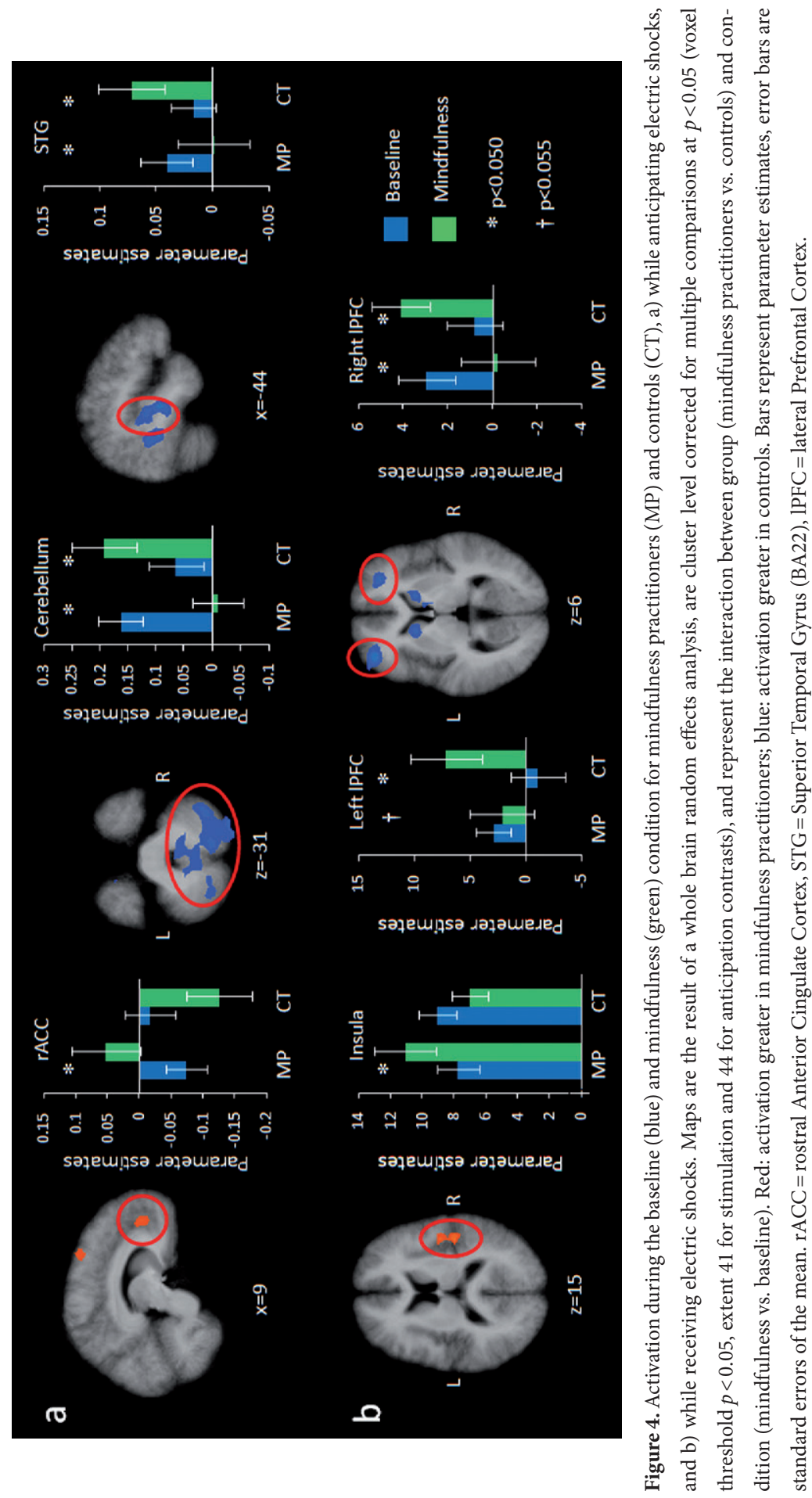


To determine in what brain regions group $\times$ condition interaction effects on brain activity during electric stimulation occurred, a whole brain RFX GLM analysis was performed. The contrast mindfulness $>$ baseline for mindfulness practitioners $>$ controls revealed a significant interaction in right posterior insula extending to secondary somatosensory cortex (S2; Figure 4 and Table 3). Posthoc paired samples t-tests revealed that this interaction was driven by increased activation in mindfulness practitioners $(t(15)=3.31, p=0.005)$ but not in controls $(t(14)=-1.80, p=0.093)$. There were no differences in activation during baseline between mindfulness practitioners and controls in this region $(t(29)=-0.73, p=0.469)$. Activation (mindfulness-baseline) in this cluster was negatively correlated with a decrease in pain unpleasantness in mindfulness practitioners (baseline-mindfulness; $r(14)=-0.529, p=0.035)$, but was positively correlated in controls $(r(13)=0.618$, $p=0.014$; Figure 5).

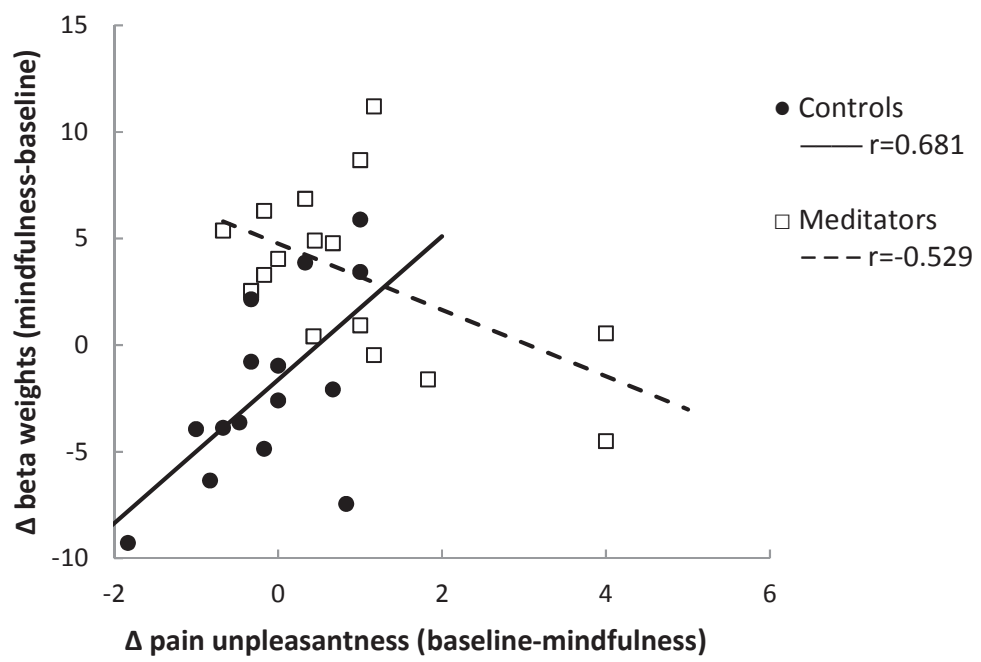

Figure 5. Correlations between reduction in pain unpleasantness during mindfulness and increased brain activity during mindfulness in posterior Insula/S2, for controls (solid line) and mindfulness practitioners (dashed line) separately.

The group group $\times$ condition interaction examined with the contrast mindfulness $>$ baseline for controls $>$ mindfulness practitioners further revealed significant effects in the right and left middle frontal gyrus/lPFC (Figure 4 and Table 3). Post-hoc paired samples t-tests revealed that the interaction in the right $1 \mathrm{PFC}$ was driven by decreased activation in mindfulness practitioners $(t(15)=-2.25$, $p=0.040)$ and increased activation in controls $(t(14)=3.87, p=0.002)$ in the mind- 
fulness compared to the baseline condition. There was no difference in activation during baseline between mindfulness practitioners $(t(29)=1.22, p=0.233)$. The interaction in the left 1 PFC was driven by a trend towards decreased activity in mindfulness practitioners $(t(15)=-2.10, p=0.053$, n.s.) and an increase in controls $(t(14)=3.19, p=0.007)$, and there was also no difference in baseline activity between the groups $(t(29)=0.24, p=0.811)$. The contrast mindfulness $>$ baseline for controls $>$ mindfulness practitioners further revealed clusters in the bilateral cingulate gyrus, bilateral caudate, bilateral cerebellum, left inferior parietal lobule, and left supramarginal gyrus (Table 3).

Table 3. Activation while receiving electric stimulation for the contrast mindfulness $>$ baseline for mindfulness practitioners $>$ controls and controls $>$ mindfulness practitioners (whole brain corrected $p<0.05$, using cluster thresholding with voxel threshold $p<0.05$ and extent 41). Cluster size in $\mathrm{mm}^{3}$, coordinates, and $\mathrm{t}$ - and $p$-values are of peak voxels, BA: Brodman area.

\begin{tabular}{|c|c|c|c|c|c|c|c|c|}
\hline Structure & BA & Side & $\mathbf{X}$ & $\mathrm{Y}$ & $\mathrm{Z}$ & Size & $t$ & $p$ \\
\hline \multicolumn{9}{|l|}{$\begin{array}{l}\text { Mindfulness } \\
\text { practitioners }>\text { Controls }\end{array}$} \\
\hline $\begin{array}{l}\text { Insula } \\
\text { S2 }\end{array}$ & $\begin{array}{l}13 \\
40\end{array}$ & $\begin{array}{l}\mathrm{R} \\
\mathrm{R}\end{array}$ & 45 & -19 & 13 & 1569 & 3.59 & 0.001 \\
\hline \multicolumn{9}{|l|}{$\begin{array}{l}\text { Controls }>\text { Mindfulness } \\
\text { practitioners }\end{array}$} \\
\hline Superior Temporal Gyrus & 39 & $\mathrm{R}$ & 42 & -49 & 28 & 1810 & 3.06 & 0.004 \\
\hline Cerebellar Tonsil & & $\mathrm{R}$ & 33 & -40 & -35 & 1802 & 3.15 & 0.005 \\
\hline $\begin{array}{l}\text { Middle Frontal Gyrus } \\
\text { Lateral Prefrontal Cortex }\end{array}$ & 10 & $\mathrm{R}$ & 27 & 44 & 7 & 1515 & 4.03 & $<0.001$ \\
\hline Caudate Head & & $\mathrm{R}$ & 15 & 14 & 4 & 2269 & 3.83 & $<0.001$ \\
\hline Cingulate Gyrus & 31 & $\begin{array}{l}\mathrm{L} \\
\mathrm{R}\end{array}$ & -3 & -37 & 37 & 5722 & 4.35 & $<0.001$ \\
\hline $\begin{array}{l}\text { Frontal Lobe Paracentral } \\
\text { Lobule }\end{array}$ & 5 & $\mathrm{~L}$ & -3 & -40 & 55 & 3033 & 3.53 & 0.001 \\
\hline Caudate Body & & $\mathrm{L}$ & -15 & 14 & 7 & 1197 & 3.02 & 0.005 \\
\hline $\begin{array}{l}\text { Cerebellum, Posterior } \\
\text { Lobue }\end{array}$ & & $\mathrm{L}$ & -36 & -67 & -38 & 2053 & 3.25 & 0.003 \\
\hline $\begin{array}{l}\text { Middle Frontal Gyrus } \\
\text { Lateral Prefrontal Cortex }\end{array}$ & 10 & $\mathrm{~L}$ & -33 & 50 & 4 & 2093 & 3.87 & $<0.001$ \\
\hline Cerebellum, Culmen & & $\mathrm{L}$ & -30 & -28 & -29 & 1197 & 3.21 & 0.003 \\
\hline Inferior Parietal Lobule & 40 & $\mathrm{~L}$ & -30 & -31 & 37 & 1610 & 4.02 & $<0.001$ \\
\hline Supramarginal Gyrus & 40 & $\mathrm{~L}$ & -51 & -40 & 31 & 7321 & 4.15 & $<0.001$ \\
\hline
\end{tabular}

Note. S2 is secondary somatosensory cortex. 


\section{Anticipation}

Brain regions with group $\times$ condition interaction effects on brain activity during the anticipation of painful stimulation were determined with a RFX GLM. The contrast mindfulness $>$ baseline for mindfulness practitioners $>$ controls revealed a significant interaction in the bilateral medial frontal gyrus, specifically in the region of the rACC and the ventro-medial PFC (vmPFC; Figure 4 and Table 4). The interaction in this region was driven by increased activation during mindfulness in mindfulness practitioners $(t(15)=2.25, p=0.040)$ and no change in controls $(t(14)=-1.65, p=0.121)$. There was no difference in activation during baseline between mindfulness practitioners and controls in this cluster $(t(29)=-1.09, p=0.284)$. The contrast mindfulness $>$ baseline for mindfulness practitioners $>$ controls further revealed significant clusters in the left superior frontal gyrus and left superior temporal gyrus (Table 4).

Table 4. Activation during the anticipation of shock for the contrast mindfulness $>$ baseline for mindfulness practitioners $>$ controls and controls $>$ mindfulness practitioners (whole brain corrected $p<0.05$, using cluster thresholding with voxel threshold $p<0.05$ and extent 44). Cluster size in $\mathrm{mm}^{3}$, coordinates, and $\mathrm{t}$ - and $p$-values are of peak voxels, BA: Brodman area.

\begin{tabular}{|c|c|c|c|c|c|c|c|c|}
\hline Structure & BA & Side & $\mathbf{X}$ & $\mathbf{Y}$ & $\mathrm{Z}$ & Size & $t$ & $p$ \\
\hline \multicolumn{9}{|l|}{$\begin{array}{l}\text { Mindfulness } \\
\text { practitioners }>\text { Controls }\end{array}$} \\
\hline Superior Frontal Gyrus & 6 & $\mathrm{~L}$ & 0 & 11 & 58 & 2563 & 3.22 & 0.003 \\
\hline $\begin{array}{l}\text { Medial Frontal Gyrus } \\
\text { vmPFC } \\
\text { rACC }\end{array}$ & 10 & $\begin{array}{l}\mathrm{R} \\
\mathrm{L} \\
\mathrm{R}\end{array}$ & 9 & 44 & 10 & 1798 & 2.80 & 0.009 \\
\hline Superior Temporal Gyrus & 38 & $\mathrm{~L}$ & -45 & 17 & -26 & 1947 & 3.23 & 0.003 \\
\hline \multicolumn{9}{|l|}{$\begin{array}{l}\text { Controls }>\text { Mindfulness } \\
\text { practitioners }\end{array}$} \\
\hline Superior Temporal Gyrus & 42 & $\mathrm{R}$ & 66 & -34 & 19 & 2112 & 3.89 & $<0.001$ \\
\hline Inferior Temporal Gyrus & 20 & $\mathrm{R}$ & 54 & -31 & -11 & 1222 & 2.96 & 0.006 \\
\hline Cerebellum, Pyramis & & $\mathrm{R}$ & 12 & -70 & -23 & 16471 & 3.84 & $<0.001$ \\
\hline $\begin{array}{l}\text { Uncus } \\
\text { Caudate }\end{array}$ & 28 & $\begin{array}{l}\mathrm{L} \\
\mathrm{L}\end{array}$ & -21 & 5 & -26 & 1230 & 3.75 & $<0.001$ \\
\hline Middle Temporal Gyrus & 39 & $\mathrm{~L}$ & -30 & -58 & 19 & 1547 & 3.17 & 0.004 \\
\hline Superior Temporal Gyrus & 22 & $\mathrm{~L}$ & -45 & -22 & -5 & 4759 & 4.06 & $<0.001$ \\
\hline Temporal Lobe & 37 & $\mathrm{~L}$ & -45 & -46 & -5 & 1931 & 3.75 & $<0.001$ \\
\hline
\end{tabular}

Note. vmPFC is ventromedial Prefrontal Cortex, and rACC is rostral Anterior Cingulate Cortex.

In the contrast mindfulness $>$ baseline for controls $>$ mindfulness practitioners, significant interactions were identified in the cerebellum, left superior temporal gy- 
rus, and left temporal lobe (Table 4 and Figure 4). Post-hoc paired samples t-tests revealed that interactions in cerebellum and left superior temporal gyrus were driven by decreased activation in mindfulness practitioners during mindfulness $(t(15)=-4.11$, $p=0.001$ and $t(15)=-2.24, p=0.041$ respectively) and increased activation in controls $(t(14)=3.28, p=0.005$ and $t(14)=2.70, p=0.017$ respectively). The interaction in the left temporal lobe was driven by a tendency towards decreased activity in mindfulness practitioners $(t(15)=-2.02, p=0.062$, n.s. $)$ and increased activation in controls $(t(14)=2.317, p=0.036)$. There were no differences in activation during baseline between mindfulness practitioners and controls in these regions (cerebellum $t(29)=1.58$, $p=0.126$; left superior temporal gyrus $(t(29)=0.77, p=0.447$; left temporal lobe $(t(29)=1.70, p=0.099)$. Other significant clusters in the contrast mindfulness $>$ baseline for controls $>$ mindfulness practitioners were found in the right superior and inferior temporal gyrus, left uncus, and in the left middle temporal gyrus (Table 4).

\section{Discussion}

The present study investigated the modulation of perceived pain and anticipatory anxiety through mindfulness in experienced mindfulness practitioners. Our finding of unchanged pain intensity and decreased (22\%) pain unpleasantness in experienced Vipassana practitioners and no changes in controls is in line with findings in experienced Zen practitioners (Grant \& Rainville, 2009), experienced Tibetan Buddhism practitioners (Perlman et al., 2010), and participants of a short mindfulness intervention (Zeidan et al., 2010), indicating that mindfulness, regardless of the tradition in which it is taught, has pain attenuating effects. Furthermore our study extended these findings by investigating ratings of anticipatory anxiety. Results showed decreased anticipatory anxiety of $29 \%$ during a state of mindfulness in practitioners but not in controls. Surprisingly, mindfulness practitioners had greater but not significant $(p=0.308)$ anticipatory anxiety than controls during baseline. This might be the result of instructing mindfulness practitioners not to practice mindfulness during the baseline condition, thereby preventing them to use their natural coping strategy to manage anticipatory anxiety.

This study reveals the neural mechanism by which this modulation of pain and anxiety through mindfulness is mediated. Increased activation was found in the rACC/vmPFC in mindfulness practitioners but not in controls while anticipating pain in a state of mindfulness. When receiving the stimuli in a state of mindfulness, activation decreased in the bilateral IPFC and increased in the posterior insula/S2. This finding is striking, as the observed activation pattern is in sharp contrast to previous findings on the successful regulation of pain and anxiety (Ochsner \& Gross, 2005; Wiech, Ploner, et al., 2008). 
Based on a literature review, Wiech, Ploner et al.(2008) proposed a model of cognitive pain modulation according to which modulation is initiated by increased activation of the $\mathrm{PFC}$, resulting in increased activation of the periaqueductal gray (PAG), mediated by rACC activation. This top-down modulation of pain would then result in decreased activation of brain regions involved in pain, including insula/S2 (Wiech, Ploner, et al., 2008). Although increased activation in IPFC and decreased activations in pain related regions as proposed by this model have not been reported consistently (e.g. Bingel, Lorenz, Schoell, Weiller, \& Buchel, 2006; Kong et al., 2006), increases in pain related regions have not been reported thus far. The brain activity pattern underlying pain modulation through mindfulness as reported here is contrary to the patterns described for other known pain coping strategies.

The activation pattern of decreased IPFC activity in combination with increased posterior insula/S2 activity when receiving electric stimulation revealed in the current study is not surprising when considering the two conceptual components of mindfulness: 1) focusing attention on the sensory aspects of the stimulus and 2) the non-judgmental, accepting attitude towards the experience. Based on a study showing that attention towards sensory stimuli results in increased recruitment of the respective neural representation (Gregory et al., 2003), we proposed that focusing attention on the sensory aspects of the stimulus is related to increased activation in the posterior insula, which is thought to be involved in interoceptive and sensory processing (Craig, 2009). The correlation between increased insula activation during mindfulness and reduction in pain unpleasantness suggests that activation in this region is related to the pain attenuating effects of mindfulness. This relation could be explained by Leventhal's theory of dual processing, according to which individuals either process information in an objective/sensory oriented or in a subjective/emotional way (Leventhal, 1982). By activating schemata of objective/sensory aspects of stimuli, instead of subjective/emotional schemata, there will be less "distress" or "suffering" during noxious stimulation (Leventhal, Brown, Shacham, \& Engquist, 1979). However, it remains an open question why correlations between increases in brain activation in the right posterior insula/S2 and decreases in pain unpleasantness were negatively correlated in mindfulness practitioners, but positively correlated in controls.

The second component of mindfulness, the non-judgmental and accepting attitude, could be described as cognitive disengagement, and thus an absence of cognitive control, which we hypothesize is related to the decrease in IPFC activation. That is, in contrast to other pain coping techniques, mindfulness practice is not aiming at cognitively controlling the pain, but rather at "letting go" by reducing this cognitive control mechanism in the prefrontal cortex of the brain. Instead, mindfulness exerts its pain and anxiety modulating effects by an increased sensory processing 
of the pain sensation itself and by replacing typical attempts to exert more cognitive control over the pain with a distinct brain state of cognitive disengagement and nonjudgmental sensory awareness.

The finding of a unique mindfulness brain state comprised of decreased IPFC and increased posterior insula/S2 activity is consistent with findings from a recent EEG study that found decreased frontal top-down control and increased sensory processing in mindfulness practitioners when they were being presented with oddball auditory stimuli during meditation (Cahn \& Polich, 2009). Along the same line as our findings, a previous study showed that experienced Zen practitioners, compared to controls, had greater activation in sensory areas including posterior insula, and decreased activation in lateral (l) PFC during rest when exposed to painful stimuli (Grant et al., 2011). However, this study neither manipulated nor investigated the state of mindfulness and how it modulates pain. As discussed by the authors, it is possible that effects of state mindfulness carried over into the study's rest conditions, because rest and mindfulness conditions were altered in the study design. Our study explicitly investigated and manipulated the state of mindfulness, thereby allowing us to differentiate between the state of mindfulness vs. the non-meditative baseline state. It therefore reveals the neural correlates of mindfulness induced pain attenuation.

Increased activation in the $\mathrm{rACC} / \mathrm{vmPFC}$ in experienced mindfulness practitioners while in a state of mindfulness, as we report here, has been reported previously (Brefczynski-Lewis et al., 2007; Hölzel et al., 2007). Aligned with the role of the rACC in attention regulation in affective contexts (Bush, Luu, \& Posner, 2000), it has been suggested that greater activation in this region is associated with a stronger processing of distracting events while focusing on the object of attention and maintaining a mindful state (Hölzel et al., 2007). The increased rACC/vmPFC activation we reported during the anticipation of pain therefore might be related to the first component of mindfulness, namely focused attention.

Alternatively, our finding of increased rACC activation during the anticipation of pain might be related to the expectation of lower pain (Mobbs et al., 2007; Straube, Schmidt, Weiss, Mentzel, \& Miltner, 2009), or to placebo analgesia (Wager et al., 2004). However, we hypothesize that neither the mechanism of altered expectation nor that of placebo is involved in our study. Expectation and placebo analgesia involve no change or decreased activation in pain related areas (Koyama et al., 2005; Petrovic et al., 2010; Wager et al., 2004), and placebo involves increased activation in IPFC (Petrovic et al., 2010; Wager et al., 2004), whereas we find increased activation in pain related areas and decreased activation in $\mathrm{PFC}$.

Furthermore, activation in the $\mathrm{rACC} / \mathrm{vmPFC}$ has been associated with positive emotions (Wager et al., 2008). Despite studies reporting pain attenuating effects of positive emotions (Roy et al., 2009; Villemure \& Bushnell, 2009), it is unlikely that 
our finding of decreased pain unpleasantness is due to emotion-induced pain attenuation as this involves decreased activation in sensory pain areas, whereas we found increased activation in posterior insula/S2 (Villemure \& Bushnell, 2009).

In contrast to mindfulness practitioners, controls did not experience reduced pain unpleasantness or reduced anticipatory anxiety during the mindfulness condition. Congruently, no changes in activation in the rACC or posterior insula/S2 were found. The identified increase in IPFC activity in controls during mindfulness might reflect that first-time practitioners engage in cognitive control while trying to be mindful. Aligned with this finding, a recent study reported that novice (4 sessions of 20 minutes) mindfulness practitioners engaged in increased cognitive control and decreased sensory processing when down regulating painful stimuli during a state of mindfulness (Zeidan et al., 2011). This discrepancy in modulation mechanisms between experienced mindfulness practitioners, as we report here, and novice practitioners, as reported by Zeidan et al.(2011), has recently also been reported in the context of emotion regulation (Taylor et al., 2011). Alternatively, this discrepancy in modulation mechanisms might be explained by differences in meditation practices (Cahn \& Polich, 2006; Hölzel et al., 2011; Lutz, Dunne, \& Davidson, 2007; Lutz et al., 2008; Manna et al., 2010; Travis \& Shear, 2010).

Like in any study involving self-report, a potential confound in the present study is self-report bias. However, the fact that changes in brain activation are in line with and in part correlated with self-reports, suggests that pain ratings are not only the result of self-report bias and have a neurobiological substrate.

In summary, our data suggest that experienced mindfulness practitioners are able to substantially decrease experienced pain unpleasantness (22\%) and anticipatory anxiety (29\%) during a mindful state. The neural correlates of this modulation involve decreased activation in the IPFC and increased activation in the posterior insula/S2 during painful stimulation, and increased rACC activation during the anticipation of pain. While the emotional aspects of the stimuli were significantly modulated by the mindful state, the pattern of brain activation is in sharp contrast to patterns typically identified in participants successfully modulating pain and anxiety. Our findings suggest that pain and anxiety modulation through mindfulness involves a unique neural mechanism in the brain, characterized by an increased sensory processing of the pain sensation itself and by replacing typical attempts to exert more cognitive control over the pain with a distinct brain state of cognitive disengagement. The identification of this distinct brain state is important as it has implications that bear on the fundamental understanding of pain and emotion regulation. Furthermore, it has clinical implications, due to its potential to empower patients with a new way of regulating pain, and make successful coping possible for those who can rely less on cognitive control. Finally, due to the high prevalence rates of pain conditions and the great burden they place on the general public (Stewart et al., 2003), our findings also have 
societal implications. Further exploration is vital to deepening the understanding and advancing the application of this distinct mechanism. One essential step in this direction would be to directly compare mindfulness to other pain modulation strategies.

\section{FUNDING}

T.G. was supported by the German Academic Exchange Service (DAAD), B.K.H. by a Marie Curie International Outgoing Fellowship within the 7th European Community Framework Programme, and A.T.S. by a grant from the Dutch Organization for Scientific Research (NWO; grant number 452-06-003).

\section{NOTES}

We would like to thank all participants for their effort, Rainer Goebel for his help designing the study, Daniel Stölzel for help with data collection, Carlo Blecker for his help with the electric stimulator, Felix Dücker and Michelle Moerel for their help with data analysis, Armin Heinecke and Douglas Greve for consulting on analysis methods, and Narayan Brach for his help on the manuscript. Conflict of interest: None declared.

\section{REFERENCES}

Apkarian, A. V., Bushnell, M. C., Treede, R. D., \& Zubieta, J. K. (2005). Human brain mechanisms of pain perception and regulation in health and disease. European Journal of Pain, 9(4), 463-484. doi: 10.1016/j.ejpain.2004.11.001

Baer, R. A. (2003). Mindfulness training as a clinical intervention: A conceptual and empirical review. Clinical Psychology-Science and Practice, 10(2), 125-143.

Bantick, S. J., Wise, R. G., Ploghaus, A., Clare, S., Smith, S. M., \& Tracey, I. (2002). Imaging how attention modulates pain in humans using functional MRI. Brain, 125(2), 310319. doi: 10.1093/brain/awf022

Bingel, U., Lorenz, J., Schoell, E., Weiller, C., \& Buchel, C. (2006). Mechanisms of placebo analgesia: rACC recruitment of a subcortical antinociceptive network. Pain, 120(1-2), 8-15. doi: 10.1016/j.pain.2005.08.027

Brefczynski-Lewis, J. A., Lutz, A., Schaefer, H. S., Levinson, D. B., \& Davidson, R. J. (2007). Neural correlates of attentional expertise in long-term meditation practitioners. Proceedings of the National Academy of Sciences of the United States of America, 104(27), 11483-11488. doi: 10.1073/pnas.0606552104 
Brown, C. A., \& Jones, A. K. P. (2010). Meditation experience predicts less negative appraisal of pain: electrophysiological evidence for the involvement of anticipatory neural responses. Pain, 150(3), 428-438. doi: 10.1016/j.pain.2010.04.017

Bush, G., Luu, P., \& Posner, M. I. (2000). Cognitive and emotional influences in anterior cingulate cortex. Trends in Cognitive Sciences, 4(6), 215-222.

Cahn, B. R., \& Polich, J. (2006). Meditation states and traits: EEG, ERP, and neuroimaging studies. Psychological Bulletin, 132(2), 180-211. doi: 10.1037/0033-2909.132.2.180

Cahn, B. R., \& Polich, J. (2009). Meditation (Vipassana) and the P3a event-related brain potential. International Journal of Psychophysiology, 72(1), 51-60. doi: 10.1016/j.ijpsycho.2008.03.013

Craig, A. D. (2009). How do you feel -- now? The anterior insula and human awareness. Nature Reviews Neuroscience, 10(1), 59-70. doi: 10.1038/nrn2555

Creswell, J. D., Way, B. M., Eisenberger, N. I., \& Lieberman, M. D. (2007). Neural correlates of dispositional mindfulness during affect labeling. Psychosomatic Medicine, 69(6), 560565. doi: 10.1097/PSY.0b013e3180f6171f

Derbyshire, S. W. G., Whalley, M. G., \& Oakley, D. A. (2009). Fibromyalgia pain and its modulation by hypnotic and non-hypnotic suggestion: an fMRI analysis. European Journal of Pain, 13(5), 542-550. doi: 10.1016/j.ejpain.2008.06.010

Forman, S. D., Cohen, J. D., Fitzgerald, M., Eddy, W. F., Mintun, M. A., \& Noll, D. C. (1995). Improved assessment of significant activation in functional magnetic resonance imaging (fMRI): use of a cluster-size threshold. Magnetic Resonance Imaging, 33(5), 636647. doi: $10.1002 / \mathrm{mrm} .1910330508$

Goebel, R., Esposito, F., \& Formisano, E. (2006). Analysis of functional image analysis contest (FIAC) data with brainvoyager QX: From single-subject to cortically aligned group general linear model analysis and self-organizing group independent component analysis. Human Brain Mapping, 27(5), 392-401. doi: 10.1002/hbm.20249

Grant, J. A., Courtemanche, J., \& Rainville, P. (2011). A non-elaborative mental stance and decoupling of executive and pain-related cortices predicts low pain sensitivity in Zen meditators. Pain, 152(1), 150-156. doi: 10.1016/j.pain.2010.10.006

Grant, J. A., \& Rainville, P. (2009). Pain sensitivity and analgesic effects of mindful states in zen meditators: A cross-sectional study. Psychosomatic Medicine, 71(1), 106-114. doi: 10.1097/PSY.0b013e31818f52ee

Gregory, L. J., Yaguez, L., Williams, S. C. R., Altmann, C., Coen, S. J., Ng, V., Brammer, M. J., Thompson, D. G., \& Aziz, Q. (2003). Cognitive modulation of the cerebral processing of human oesophageal sensation using functional magnetic resonance imaging. Gut, 52(12), 1671-1677.

Grossman, P., Niemann, L., Schmidt, S., \& Walach, H. (2004). Mindfulness-based stress reduction and health benefits. A meta-analysis. Journal of Psychosomatic Research, 57(1), 35-43. doi: 10.1016/S0022-3999(03)00573-7 
Grossman, P., Tiefenthaler Gilmer, U., Raysz, A., \& Kesper, U. (2007). Mindfulness training as an intervention for fibromyalgia: Evidence of postintervention and 3-year follow-up benefits in weil-being. Psychotherapy and Psychosomatics, 76(4), 226-233.

Hadjistavropoulos, H. D., Hadjistavropoulos, T., \& Quine, A. (2000). Health anxiety moderates the effects of distraction versus attention to pain. Behaviour Research and Therapy, 38(5), 425-438. doi: 10.1016/S0005-7967(99)00044-3

Hart, W. (1987). The art of living: Vipassana-meditation as taught by S.N. Goenka. San Francisco, CA: Harper and Row.

Hofmann, S. G., Sawyer, A. T., Witt, A. A., \& Oh, D. (2010). The effect of mindfulness-based therapy on anxiety and depression: A meta-analytic review. Journal of Consulting and Clinical Psychology, 78(2), 169-183. doi: 10.1037/a0018555

Hölzel, B. K., Lazar, S. W., Gard, T., Schuman-Olivier, Z., Vago, D. R., \& Ott, U. (2011). How Does Mindfulness Meditation Work? Proposing Mechanisms of Action From a Conceptual and Neural Perspective. Perspectives on Psychological Science, 6(6), 537-559. doi: $10.1177 / 1745691611419671$

Hölzel, B. K., Ott, U., Hempel, H., Hackl, A., Wolf, K., Stark, R., \& Vaitl, D. (2007). Differential engagement of anterior cingulate and adjacent medial frontal cortex in adept meditators and non-meditators. Neuroscience Letters, 421(1), 16-21. doi: 10.1016/j. neulet.2007.04.074

Jack, C. R., Bernstein, M. A., Fox, N. C., Thompson, P., Alexander, G., Harvey, D., Borowski, B., Britson, P. J., Whitwell, J. L., Ward, C., Dale, A. M., Felmlee, J. P., Gunter, J. L., Hill, D. L. G., Killiany, R., Schuff, N., Fox-Bosetti, S., Lin, C., Studholme, C., DeCarli, C. S., Krueger, G., Ward, H. A., Metzger, G. J., Scott, K. T., Mallozzi, R., Blezek, D., Levy, J., Debbins, J. P., Fleisher, A. S., Albert, M., Green, R., Bartzokis, G., Glover, G., Mugler, J., \& Weiner, M. W. (2008). The Alzheimer's Disease Neuroimaging Initiative (ADNI): MRI methods. Journal of Magnetic Resonance Imaging, 27(4), 685-691. doi: 10.1002/ jmri.21049

Kabat-Zinn, J. (1990). Full catastrophe living: Using the wisdom of your body and your mind to face stress, pain and illness. New York, NY: Delta.

Kabat-Zinn, J., Lipworth, L., \& Burney, R. (1985). The clinical use of mindfulness meditation for the self-regulation of chronic pain. Journal of Behavioral Medicine, 8(2), 163-190. doi: $10.1007 / \mathrm{BF} 00845519$

Kingston, J., Chadwick, P., Meron, D., \& Skinner, T. C. (2007). A pilot randomized control trial investigating the effect of mindfulness practice on pain tolerance, psychological wellbeing, and physiological activity. Journal of Psychosomatic Research, 62(3), 297-300. doi: 10.1016/j.jpsychores.2006.10.007

Kong, J., Gollub, R. L., Rosman, I. S., Webb, J. M., Vangel, M. G., Kirsch, I., \& Kaptchuk, T. J. (2006). Brain activity associated with expectancy-enhanced placebo analgesia as measured by functional magnetic resonance imaging. The Journal of Neuroscience, 26(2), 381. 
Koyama, T., McHaffie, J. G., Laurienti, P. J., \& Coghill, R. C. (2005). The subjective experience of pain: where expectations become reality. Proceedings of the National Academy of Sciences of the United States of America, 102(36), 12950-12955. doi: 10.1073/ pnas.0408576102

Kross, E., Berman, M. G., Mischel, W., Smith, E. E., \& Wager, T. D. (2011). Social rejection shares somatosensory representations with physical pain. Proceedings of the National Academy of Sciences of the United States of America, 108(15), 6270-6275. doi: 10.1073/pnas.1102693108

Lancaster, J. L., Woldorff, M. G., Parsons, L. M., Liotti, M., Freitas, C. S., Rainey, L., Kochunov, P. V., Nickerson, D., Mikiten, S. A., \& Fox, P. T. (2000). Automated Talairach atlas labels for functional brain mapping. Human Brain Mapping, 10(3), 120-131. doi: 10.1002/1097-0193(200007)10:3<120::AID-HBM30>3.0.CO;2-8

Leventhal, H. (1982). The integration of emotion and cognition: A view from the perceptualmotor theory of emotion. In M. S. Clark \& S. T. TFiske (Eds.), Affect and cognition (pp. 121-156). Hillsdale, NJ: Lawrence Erlbaum Associates, Inc.

Leventhal, H., Brown, D., Shacham, S., \& Engquist, G. (1979). Effects of preparatory information about sensations, threat of pain, and attention on cold pressor distress. Journal of Personality and Social Psychology, 37(5), 688-714. doi: 10.1037//0022-3514.37.5.688

Lu, H. C., Hsieh, J. C., Lu, C. L., Niddam, D. M., Wu, Y. T., Yeh, T. C., Cheng, C. M., Chang, F. Y., \& Lee, S. D. (2010). Neuronal correlates in the modulation of placebo analgesia in experimentally-induced esophageal pain: a 3T-fMRI study. Pain, 148(1), 75-83. doi: 10.1016/j.pain.2009.10.012

Lutz, A., Dunne, J. D., \& Davidson, R. J. (2007). Meditation and the neuroscience of consciousness: An introduction. In P. Zelazo, M. Moscovitch \& E. Thompson (Eds.), The Cambridge handbook of consciousness (pp. 499-554). Cambridge, MA: Cambridge University Press.

Lutz, A., Slagter, H. A., Dunne, J. D., \& Davidson, R. J. (2008). Attention regulation and monitoring in meditation. Trends in Cognitive Sciences, 12(4), 163-169. doi: 10.1016/j. tics.2008.01.005

Manna, A., Raffone, A., Perrucci, M. G., Nardo, D., Ferretti, A., Tartaro, A., Londei, A., Del Gratta, C., Belardinelli, M. O., \& Romani, G. L. (2010). Neural correlates of focused attention and cognitive monitoring in meditation. Brain Research Bulletin, 82(1-2), 46-56. doi: 10.1016/j.brainresbull.2010.03.001

McNeil, D. W., \& Rainwater, A. J. (1998). Development of the Fear of Pain Questionnaire--III. Journal of Behavioral Medicine, 21(4), 389-410. doi: 10.1023/A:1018782831217

Mobbs, D., Petrovic, P., Marchant, J. L., Hassabis, D., Weiskopf, N., Seymour, B., Dolan, R. J., \& Frith, C. D. (2007). When fear is near: Threat imminence elicits prefrontal-periaqueductal gray shifts in humans. Science, 317(5841), 1079-1083.

Ochsner, K. N., \& Gross, J. J. (2005). The cognitive control of emotion. Trends in Cognitive Sciences, 9(5), 242-249. doi: 10.1016/j.tics.2005.03.010 
Oldfield, R. C. (1971). The assessment and analysis of handedness: the Edinburgh inventory. Neuropsychologia, 9(1), 97-113. doi: 10.1016/0028-3932(71)90067-4

Perlman, D. M., Salomons, T. V., Davidson, R. J., \& Lutz, A. (2010). Differential effects on pain intensity and unpleasantness of two meditation practices. Emotion, 10(1), 65-71. doi: 10.1037/a0018440

Petrovic, P., Kalso, E., Petersson, K. M., Andersson, J., Fransson, P., \& Ingvar, M. (2010). A prefrontal non-opioid mechanism in placebo analgesia. Pain, 150(1), 59-65. doi: 10.1016/j.pain.2010.03.011

Petrovic, P., Petersson, K. M., Ghatan, P. H., Stone-Elander, S., \& Ingvar, M. (2000). Pain-related cerebral activation is altered by a distracting cognitive task. Pain, 85(1-2), 19-30.

Price, D. D., McGrath, P. A., Rafii, A., \& Buckingham, B. (1983). The validation of visual analogue scales as ratio scale measures for chronic and experimental pain. Pain, 17(1), 45-56. doi: 10.1016/0304-3959(83)90126-4

Rainville, P., Duncan, G. H., Price, D. D., Carrier, B., \& Bushnell, M. C. (1997). Pain affect encoded in human anterior cingulate but not somatosensory cortex. Science, 277(5328), 968-971. doi: 10.1126/science.277.5328.968

Roelofs, J., Peters, M. L., van der Zijden, M., \& Vlaeyen, J. W. S. (2004). Does fear of pain moderate the effects of sensory focusing and distraction on cold pressor pain in pain-free individuals? Journal of Pain, 5(5), 250-256. doi: 10.1016/j.jpain.2004.04.001

Roy, M., Piche, M., Chen, J. I., Peretz, I., \& Rainville, P. (2009). Cerebral and spinal modulation of pain by emotions. Proceedings of the National Academy of Sciences of the United States of America, 106(49), 20900-20905. doi: 10.1073/pnas.0904706106

Stark, R., Wolf, O. T., Tabbert, K., Kagerer, S., Zimmermann, M., Kirsch, P., Schienle, A., \& Vaitl, D. (2006). Influence of the stress hormone cortisol on fear conditioning in humans: evidence for sex differences in the response of the prefrontal cortex. Neuroimage, 32(3), 1290-1298. doi: 10.1016/j.neuroimage.2006.05.046

Stewart, W. F., Ricci, J. A., Chee, E., Morganstein, D., \& Lipton, R. (2003). Lost productive time and cost due to common pain conditions in the US workforce. Journal of the American Medical Association, 290(18), 2443-2454. doi: 10.1001/jama.290.18.2443

Straube, T., Schmidt, S., Weiss, T., Mentzel, H. J., \& Miltner, W. H. R. (2009). Dynamic activation of the anterior cingulate cortex during anticipatory anxiety. Neuroimage, 44(3), 975-981. doi: 10.1016/j.neuroimage.2008.10.022

Tang, Y. Y., Ma, Y. H., Fan, Y. X., Feng, H. B., Wang, J. H., Feng, S. G., Lu, Q. L., Hu, B., Lin, Y., Li, J., Zhang, Y., Wang, Y., Zhou, L., \& Fan, M. (2009). Central and autonomic nervous system interaction is altered by short-term meditation. Proceedings of the National Academy of Sciences of the United States of America, 106(22), 8865-8870. doi: 10.1073/pnas.0904031106

Taylor, V. A., Grant, J., Daneault, V., Scavone, G., Breton, E., Roffe-Vidal, S., Courtemanche, J., Lavarenne, A. S., \& Beauregard, M. (2011). Impact of mindfulness on the neural 
responses to emotional pictures in experienced and beginner meditators. Neuroimage, 57(4), 1524-1533. doi: 10.1016/j.neuroimage.2011.06.001

Travis, F., \& Shear, J. (2010). Focused attention, open monitoring and automatic self-transcending: Categories to organize meditations from Vedic, Buddhist and Chinese traditions. Consciousness and Cognition, 19(4), 1110-1118. doi: 10.1016/j.concog.2010.01.007

Vanhaudenhuyse, A., Boly, M., Balteau, E., Schnakers, C., Moonen, G., Luxen, A., Lamy, M., Degueldre, C., Brichant, J. F., Maquet, P., Laureys, S., \& Faymonville, M. E. (2009). Pain and non-pain processing during hypnosis: a thulium-YAG event-related fMRI study. Neuroimage, 47(3), 1047-1054. doi: 10.1016/j.neuroimage.2009.05.031

Vaughan, J. T., Garwood, M., Collins, C. M., Liu, W., DelaBarre, L., Adriany, G., Andersen, P., Merkle, H., Goebel, R., Smith, M. B., \& Ugurbil, K. (2001). 7T vs. 4T: RF power, homogeneity, and signal-to-noise comparison in head images. Magnetic Resonance Imaging, 46(1), 24-30. doi: 10.1002/mrm.1156 [pii]

Villemure, C., \& Bushnell, M. C. (2009). Mood influences supraspinal pain processing separately from attention. Journal of Neuroscience, 29(3), 705-715. doi: 10.1523/jneurosci.3822-08.2009

Visscher, K. M., Miezin, F. M., Kelly, J. E., Buckner, R. L., Donaldson, D. I., McAvoy, M. P., Bhalodia, V. M., \& Petersen, S. E. (2003). Mixed blocked/event-related designs separate transient and sustained activity in fMRI. Neuroimage, 19(4), 1694-1708. doi: 10.1016/ s1053-8119(03)00178-2

Wager, T. D., Atlas, L. Y., Leotti, L. A., \& Rilling, J. K. (2011). Predicting individual differences in placebo analgesia: contributions of brain activity during anticipation and pain experience. Journal of Neuroscience, 31(2), 439-452. doi: 10.1523/jneurosci.3420-10.2011

Wager, T. D., Barrett, L. F., Bliss-Moreau, E., Lindquist, K., Duncan, S., Kober, H., Joseph, J., Davidson, M., \& Mize, J. (2008). The neuroimaging of emotion. In M. Lewis \& J. M. Haviland (Eds.), The handbook of emotion (3rd ed., pp. 249-271). New York, NY: The Guilford Press.

Wager, T. D., Rilling, J. K., Smith, E. E., Sokolik, A., Casey, K. L., Davidson, R. J., Kosslyn, S. M., Rose, R. M., \& Cohen, J. D. (2004). Placebo-induced changes in fMRI in the anticipation and experience of pain. Science, 303(5661), 1162-1167. doi: 10.1126/science. 1093065

Walach, H., Buchheld, N., Buttenmüller, V., Kleinknecht, N., \& Schmidt, S. (2004). Empirische Erfassung der Achtsamkeit - Die Konstruktion des Freiburger Fragebogens zur Achtsamkeit (FFA) und weitere Validierungsstudien. In T. Heidenreich \& J. Michalak (Eds.), Achtsamkeit und Akzeptanz in der Psychotherapie. Ein Handbuch. (pp. 729-772). Tübingen, Germany: dgvt-Verlag.

Wiech, K., Farias, M., Kahane, G., Shackel, N., Tiede, W., \& Tracey, I. (2008). An fMRI study measuring analgesia enhanced by religion as a belief system. Pain, 139(2), 467-476. doi: 10.1016/j.pain.2008.07.030 
Wiech, K., Kalisch, R., Weiskopf, N., Pleger, B., Stephan, K. E., \& Dolan, R. J. (2006). Anterolateral prefrontal cortex mediates the analgesic effect of expected and perceived control over pain. Journal of Neuroscience, 26(44), 11501-11509. doi: 10.1523/JNEUROSCI.2568-06.2006

Wiech, K., Ploner, M., \& Tracey, I. (2008). Neurocognitive aspects of pain perception. Trends in Cognitive Sciences, 12(8), 306-313. doi: 10.1016/j.tics.2008.05.005

Zeidan, F., Gordon, N. S., Merchant, J., \& Goolkasian, P. (2010). The effects of brief mindfulness meditation training on experimentally induced pain. Journal of Pain, 11(3), 199209. doi: 10.1016/j.jpain.2009.07.015

Zeidan, F., Martucci, K. T., Kraft, R. A., Gordon, N. S., McHaffie, J. G., \& Coghill, R. C. (2011). Brain mechanisms supporting the modulation of pain by mindfulness meditation. Journal of Neuroscience, 31(14), 5540-5548. doi: 10.1523/JNEUROSCI.5791-10.2011 


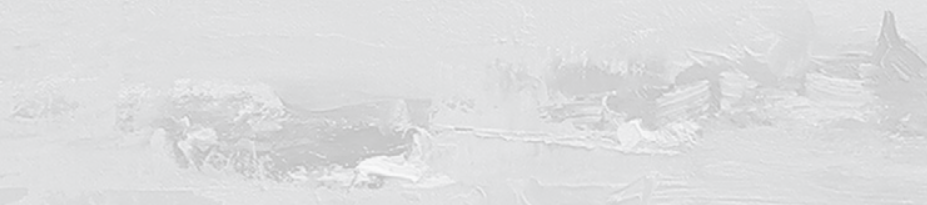


CHAPTER 3

\section{PSYCHOLOGICAL MECHANISMS OF INCREASED WELL-BEING AND RESILIENCE THROUGH YOGA IN YOUNG ADULTS}

Based on: Gard, T., Brach, N., Hölzel, B. K., Noggle, J. J., Conboy, L. A., \& Lazar,

S. W. (2012). Effects of a yoga-based intervention for young adults on quality of life and perceived stress: The potential mediating roles of mindfulness and self-compassion. The Journal of Positive Psychology, 7(3), 165-175. doi: 


\section{AbStRACT}

The purpose of this pilot study was to investigate the effects of a yoga-based program on quality of life, perceived stress, mindfulness, and self-compassion in young adults. These variables were measured in thirty-three self-selected participants of a 4-month residential yoga intervention before and after the program. Fortythree demographically matched controls completed the same questionnaires at two time points with a 4-month interval in-between. Participation in the program predicted increases in quality of life and decreases in perceived stress, mediated by mindfulness and self-compassion. Multiple mediator models revealed that the effect of group on quality of life was simultaneously mediated by mindfulness and self-compassion, while the effect of group on perceived stress was only mediated by self-compassion. These positive effects on perceived stress and quality of life suggest that yoga-based interventions may be of value in cultivating subjective wellbeing in young adults. Furthermore, yoga-based and mindfulness-based interventions may share underlying mechanisms. 


\section{INTRODUCTION}

While the field of psychology has historically focused on the diagnosis and treatment of mental illness, the more recent advent of the positive psychology movement (Seligman \& Csikszentmihalyi, 2000) has led to a burgeoning interest in gaining a deeper understanding of happiness. Happiness is often operationalized as subjective well-being, a concept comprising three components-life satisfaction, positive affect, and negative affect (Diener, 1984, 2000; Diener, Suh, Lucas, \& Smith, 1999). Subjective well-being has been shown to be positively correlated with good health, long life, fulfilling relationships, high income, and work performance (Lyubomirsky, King, \& Diener, 2005). Individuals with high levels of the life satisfaction component of subjective well-being, which can also be conceptualized as quality of life (Frisch, 2012), have been reported to exhibit heightened cognitive and social functioning (Suldo \& Huebner, 2006). Additionally, life satisfaction has been conceptualized as a buffer, or protective psychological strength, that can help individual's mitigate adverse life events without externalizing negative behavior (Suldo \& Huebner, 2004).

Low levels of life satisfaction have been shown to be predictive of both poor work and scholastic performance (Frisch et al., 2005; Judge \& Watanabe, 1993), poor health (Diener, Chan, 2011), substance abuse (Gilman \& Huebner, 2003), aggressive behavior (Valois, Zullig, Huebner, \& Drane, 2001), and peer relationship problems (Gilman \& Huebner, 2000). Furthermore, a negative relationship has been found between life satisfaction and both mental issues health and suicidality in young adults (Valois et al., 2001). While low levels of life satisfaction are related to many negative outcomes, high levels of stress are also well known to negatively impact health (Bekkouche, Holmes, Whittaker, \& Krantz, 2009; Pedersen, Bovbjerg, \& Zachariae, 2009), as well as cognitive (McEwen \& Sapolsky, 1995) and emotional functioning (Lazarus, 2006), and can be a strong contributor to psychopathology (Grant, McMahon, Dufy, Taylor, \& Compas, 2009; Kessler \& Wang, 2008).

There is a substantial body of evidence demonstrating that mindfulness-based programs, such as Mindfulness-based Stress Reduction (MBSR; Kabat-Zinn, 1990), can decrease stress and anxiety (Carmody \& Baer, 2008; Shapiro, Brown, \& Biegel, 2007), while increasing cognitive performance (Jha, Krompinger, \& Baime, 2007; Zeidan, Johnson, Diamond, David, \& Goolkasian, 2010) and psychological well-being (Branstrom, Kvillemo, Brandberg, \& Moskowitz, 2010). Mindfulness is defined as "paying attention in a particular way: on purpose, in the present moment, and nonjudgmentally" (Kabat-Zinn, 1990), and in recent years, its underlying mechanisms have been increasingly studied (Hölzel et al., 2011). Changes in mindfulness have been shown to highly correlate with increased psychological well-being and decreased stress (Carmody \& Baer, 2008), and mediate the relationship between MBSR partici- 
pation and decreases in stress and mental health symptoms (Carmody \& Baer, 2008; Nyklicek \& Kuijpers, 2008). Mindfulness-based programs therefore have great potential to foster resiliency against mental illness and promote psychological well-being.

Similarly, there is growing evidence that yoga also improves mental health, decreasing symptoms such as anxiety and stress, while increasing psychological well-being (Ross \& Thomas, 2010). Although there is some preliminary evidence that yoga increases mindfulness (Conboy, Wilson, \& Braun, 2010; Shelov, Suchday, $\&$ Friedberg, 2009), it's role as a mediator of the effect of yoga on stress and well-being has not yet been investigated.

The Kripalu Center for Yoga and Health developed a 4-month yoga-based residential program to target 18 to 25 year olds, with the aim of providing them with skills to handle the transition to independence and improve their quality of life. The Semester Intensive Program (SI) combines daily yoga practice with a didactic curriculum based on yoga philosophy. Kripalu yoga is a form of classical yoga influenced by the teachings of Swami Kripalu, who emphasized the cultivation of "witness consciousness" and compassion for the self and others (Faulds, 2005).

"Witness consciousness" is defined as "the ability to closely observe what is occurring without reactivity or judgment” (Faulds, 2005), a description that closely matches mindfulness as defined by Kabat-Zinn (1990). Witness consciousness is cultivated through and supported by the practice of five skills during yoga practice, the shorthand term for which is "BRFWA", an acronym for "Breath-Relax-Feel-Watch-Allow" (“Kripalu Yoga 200 Hour Teacher Training Manual," 2011). Conceptually, four of these skills-Breath, Feel, Watch, and Allow-have considerable similarity to the two components of mindfulness: 1) paying attention to the present moment, 2) non-judgment of experience (Kabat-Zinn, 1990). "Breath" refers to focusing attention on the sensation of the breath, which is aligned with the first component of mindfulness. "Feel" refers to increasing awareness of sensations, thoughts, and feelings as they occur, which is an extension of the focus on breath and is also aligned with the focused attention aspect of mindfulness. "Watch" and "Allow" refer to a stance of acceptance and non-judgment respectively, and are aligned with the second component of mindfulness.

Compassion is frequently viewed as another key quality underlying the transformations that accompany contemplative practices. Compassion is at the foundation of Kripalu yoga; the literal translation of the Sanskrit word "kripalu" is "being compassionate" (Faulds, 2005). Self-compassion has been described "as being open to and moved by one's own suffering, experiencing feelings of caring and kindness toward oneself, taking an understanding, nonjudgmental attitude toward one's inadequacies and failures, and recognizing that one's own experience is part of the common human experience" (Neff, 2003). Self-compassion has been shown to predict subjective well-being (Neely, Schallert, Mohammed, Roberts, \& Chen, 2009), mental and physical health (Raque-Bogdan, Ericson, Jackson, Martin, \& Bryan, 2011), and 
scholastic performance (Neff, Hsieh, \& Dejitterat, 2005). Furthermore, self-compassion is thought to counter negative "self-talk", and has been shown to be negatively correlated with self-reported depression and anxiety in both adolescents and young adults (Neff \& McGehee, 2010). Both self-compassion and mindfulness have been identified as mediators of the positive effect of Mindfulness Based Cognitive Therapy (MBCT) on depressive symptoms in patients with recurrent depression (Kuyken et al., 2010). Furthermore, positive correlations between changes in self-compassion and changes in well-being following a MBSR intervention have been reported (Birnie, Speca, \& Carlson, 2010). However, another study found that changes in selfcompassion following a MBSR course predicted changes in perceived stress but not in satisfaction with life (Shapiro, Astin, Bishop, \& Cordova, 2005).

Here we tested the hypothesis that participation in the SI is predictive of increases in quality of life, mindfulness, and self-compassion, with concomitant decreases in perceived stress. Furthermore, we tested whether the effects of participation in the SI program on quality of life and perceived stress are mediated by mindfulness and self-compassion. To test these hypotheses we administered questionnaires measuring quality of life, perceived stress, mindfulness, and self-compassion to SI participants and demographically matched controls before and after the program period.

\section{METHODS}

\section{PARTICIPANTS}

One hundred and one participants were enrolled in the study: fifty-three participants of the SI and forty-eight controls, who did not participate in the program, and were matched for age, gender, and education. Of the fifty-three enrolled SI participants, fifty participants completed the intervention, of which thirty-three (73\% female; $88 \%$ Caucasian; age range 18-26 years, $M=22.06$ years, $S D=2.34 ; M$ education $=14.91$ years, $S D=1.67$ ) completed questionnaires before and after the course period. Of the forty-eight control participants, forty-three (74\% female, 79\% Caucasian; age range 18 - 26 years, $M=21.33$ years, $S D=2.58 ; M$ education $=14.65$ years, $S D=1.59)$ completed both sets of questionnaires.

Participants of the SI were recruited via an invitation letter after registering for the program and did not receive reimbursement for participating in the study. Control participants were recruited from colleges in the Boston area, through oncampus and on-line advertisements, and received $\$ 5$ for completing the first and $\$ 15$ for completing the second questionnaire. All subjects gave informed consent for participation. The study was approved by the Partners Human Research Committee, Massachusetts General Hospital (protocol 2006P001488). 


\section{Semester Intensive Program}

The Kripalu Semester Intensive Program (SI) is a manualized 4-month yoga-based residential educational immersion program for 18-25 year olds. The SI aims to increase subjective and objective well-being. Students had on average 3-5 hours of daily yoga practice comprising postures (asanas), breathing practices (pranayamas), and meditation in addition to 3-5 hours of daily didactic course work concerning the development of life skills and the integration of yoga practice into daily life activities.

Kripalu yoga is a form of classical yoga based on the Yoga Sutra's of Patanjali (Shearer, 2002) and strongly influenced by the teachings of Swami Kripalu, who emphasized the cultivation of "witness consciousness" and compassion for the self and others (Faulds, 2005). These concepts, as well as "BRFWA" ("Kripalu Yoga 200 Hour Teacher Training Manual," 2011), were conveyed throughout the program.

\section{PROCEDURE}

Participants were administered questionnaires pre-program and post-program ( $M \Delta$ time $=112.48$ days, $S D=18.01)$. Control subjects completed the same questionnaires at two time-points within a similar time interval $(M \Delta$ time $=110.78$, $S D=13.00)$. There was no significant difference in the time interval between course participants and controls $(t(55.90)=0.458, p=0.648)$.

\section{MeAsures}

Quality of life was assessed with the 32-item Quality of Life Inventory (QOLI) (Frisch, Cornell, Villanueva, \& Retzlaff, 1992), which assesses an individual's satisfaction in 16 different domains of life (i.e. relationships, work, self-esteem), and the importance they attribute to each of these categories. The QOLI has been shown to have strong test-retest reliability and internal consistency (Frisch et al., 1992).

Perceived stress was measured with the 10-item version of the Perceived Stress Scale (PSS) (Cohen, Kamarck, \& Mermelstein, 1983), a validated and widely used self-report questionnaire for assessing the extent to which situations during the past month have been perceived as stressful. The scale has high internal consistency and test-retest reliability (Cohen et al., 1983).

Mindfulness was assessed with the Five Facet Mindfulness Questionnaire (FFMQ), a 39-item scale (Baer, Smith, Hopkins, Krietemeyer, \& Toney, 2006) designed to measure five facets of mindfulness: Observing (attending to or noticing internal and external stimuli), describing (noting or mentally labeling these stimuli with words), acting with awareness (attending to one's current actions), non-judging of inner experience (refraining from evaluations), and non-reactivity (allowing thoughts 
and feelings to come and go). Responses to the items are given on a 5-point Likerttype scale. The five subscales have shown good internal consistency (Baer et al., 2006). The subscales of the FFMQ are typically not used to calculate a sum score as they don't load on a single higher order factor. However, in order to conduct mediation analyses with only one mediator in the model representing mindfulness, a sum score of the FFMQ was calculated, similar to Carmody and Baer (Carmody \& Baer, 2008).

Self-compassion was measured with the 26-item Self-Compassion Scale (SCS) (Neff, 2003), which assesses one's ability to be forgiving and kind to oneself in difficult circumstances. The SCS includes six subscales-Self-Kindness, Self-Judgment, Common Humanity, Isolation, Mindfulness, and Over-identification-from which a total score of general self-compassion can be derived, as they all load on a single higher order factor. The SCS has been shown to be valid and reliable (Neff, 2003).

\section{Design ANd ANALYsis}

A quasi-experimental pre-post design with an intervention group and a nonrandomized matched control group was employed. To evaluate the effectiveness of a program, data acquired with such a design can be analyzed either with an ANCOVA with the pre time-point as covariate, or with a t-test/ANOVA on the gain (post minus pre) score, which is equivalent to the group $\times$ time interaction in a repeated measures ANOVA (Kenny, 1975). There is no consensus on which method is preferable for quasi-experimental designs, with arguments in favor of an ANCOVA (Van Breukelen, 2006) and against it (Dimitrov \& Rumrill Jr, 2003). Generally, an ANCOVA is preferred because it has greater power than an ANOVA on gain scores. However, if the assumption of no group-effect at pre-test is not met, this method can lead to biased results (Van Breukelen, 2006). Some authors recommend employing both methods of analysis, to have increased confidence if both methods lead to the same conclusion but only differ in effect size (e.g.Van Breukelen, 2006). Here we follow this approach.

ANCOVAs with the post-measurement as dependent variable, group as factor, and pre-measure as covariate were performed. To test the assumption of no group-effects at pre-test, independent samples t-tests (two-tailed) on all dependent variables were calculated. The assumption of homogeneity of regression slopes was tested by running ANCOVAs with group, pre-measure, and the interaction term group $\times$ pre-measure as predictors, and post-measure as the dependent variable. To compare gain (post minus pre) scores between groups, independent samples t-tests were employed. To determine the effect of self-compassion on perceived stress and quality of life after the intervention, two post-hoc regression analyses were conducted on data of SI participants: one regression analysis with PSS-post score as dependent variable and PSS-pre score as covariate and total SCS-pre score as predictor, and one with QOLI-post score as dependent variable and QOLI-pre score as 
covariate and total SCS-pre score as predictor. ANCOVAS, regression analyses, and t-tests (two-tailed) were performed with SPSS 17 (SPSS Inc., Chicago, IL, USA), and significance was defined as $p<0.05$.

To conduct mediation analyses with only one mediator in the model representing mindfulness, similar to Carmody and Baer (Carmody \& Baer, 2008), a sum score of the FFMQ was calculated. Next, residual post scores for total FFMQ, total SCS, PSS, and QOLI were calculated by regressing out respective pre-scores. Mediation models with single and multiple mediators were tested using a macro by Preacher and Hayes (Preacher \& Hayes, 2008) which implements a bootstrapping procedure to create confidence intervals for indirect effects in the mediation model. In contrast to the widely used causal steps method (Baron \& Kenny, 1986), this method focuses on the size and direction of indirect effects of potential mediators rather than on the significance of direct effects (Preacher \& Hayes, 2008). It is recommended above the causal steps method as it has higher power and requires less assumptions (MacKinnon, Lockwood, Hoffman, West, \& Sheets, 2002).

\section{RESULTS}

\section{PARTICIPANT MATCHING}

There were no significant differences between the experimental and control groups on the matching variables of gender $\left(\chi^{2}(1)=0.038, p=0.868\right)$, ethnicity $\left(\chi^{2}(1)=1.022\right.$, $p=0.312)$, age $(t(74)=1.312, p=0.193)$, and education $(t(73)=0.673, p=0.503)$. At the pre time-point there were also no group differences on quality of life, perceived stress, any of the FFMQ subscales, and the SCS subscales overidentification, isolation, and mindfulness (Table 1). There were group differences on total SCS and on the SCS subscales self-judgment, common humanity, and self-kindness (Table 1).

PSS scores of both SI $(M=15.30, S D=5.83)$ and control $(M=17.53, S D=8.14)$ participants fell within the normal range of young adults ages $18-25(M=16.14, S D=6.86)$ (Cohen \& Janicki-Deverts, 2012). QOLI scores of both SI $(M=2.28, S D=1.63)$ and control $(M=1.91, S D=1.37)$ participants were also within the normal range, as compared to an undergraduate population $(M=2.63, S D=1.11)$ (Frisch et al., 1992). 
Table 1. Means, standard deviations, and independent samples t-tests (two-tailed) for all variables at pre-test.

\begin{tabular}{|c|c|c|c|c|c|c|c|}
\hline & \multicolumn{2}{|c|}{ SI } & \multicolumn{2}{|c|}{ Controls } & \multicolumn{3}{|c|}{ t-test } \\
\hline & $M$ & $S D$ & $M$ & $S D$ & $t$ & $d f$ & $p$ \\
\hline FFMQ- Observe & 27.81 & 5.83 & 26.44 & 4.71 & 1.131 & 74 & 0.262 \\
\hline FFMQ- Describe & 27.24 & 6.56 & 27.35 & 5.73 & -0.075 & 74 & 0.940 \\
\hline FFMQ- Non-judge & 27.55 & 6.94 & 26.52 & 6.68 & 0.651 & 74 & 0.517 \\
\hline FFMQ- Non-react & 21.06 & 4.85 & 19.98 & 3.69 & 1.102 & 73 & 0.274 \\
\hline FFMQ- Act with Awareness & 26.45 & 5.26 & 26.26 & 5.62 & 0.152 & 74 & 0.880 \\
\hline SCS- Total Self-Compassion & 3.26 & 0.65 & 2.80 & 0.68 & 2.928 & 72 & 0.005 \\
\hline SCS- Self-judgment & 2.82 & 0.88 & 3.35 & 0.97 & -2.413 & 72 & 0.018 \\
\hline SCS- Over-identification & 2.76 & 0.85 & 3.11 & 1.05 & -1.531 & 72 & 0.130 \\
\hline SCS- Common Humanity & 3.24 & 0.81 & 2.70 & 0.68 & 3.116 & 72 & 0.003 \\
\hline SCS- Isolation & 2.68 & 0.83 & 3.10 & 1.10 & -1.774 & 72 & 0.080 \\
\hline SCS- Self-Kindness & 3.15 & 0.89 & 2.53 & 0.77 & 3.155 & 72 & 0.002 \\
\hline SCS- Mindfulness & 3.43 & 0.75 & 3.12 & 0.70 & 1.808 & 72 & 0.075 \\
\hline Quality of Life Index & 2.28 & 1.63 & 1.91 & 1.37 & 1.057 & 71 & 0.294 \\
\hline Perceived Stress Scale & 15.30 & 5.83 & 17.53 & 8.14 & -1.276 & 69 & 0.206 \\
\hline
\end{tabular}

Note. SI = Semester Intensive participants, FFMQ = Five Facet Mindfulness Questionnaire, SCS Self-compassion Scale.

\section{ANCOVA}

Independent samples t-tests on pre-test scores confirmed the ANCOVA assumption of no group effect at the pre time-point for most variables (Table 1). For total Selfcompassion and the SCS subscales Self-judgment, Common Humanity, and Selfkindness this assumption was not met. The assumption of homogeneity of regression slopes was not met for the FFMQ subscales Non-judge and Acting with Awareness, indicated by significant group $\times$ pre-measure interactions. ANCOVAs with the postmeasurement as dependent variable, group as factor, and pre-measure as covariate revealed significant effects of group for all variables (Table 2). 


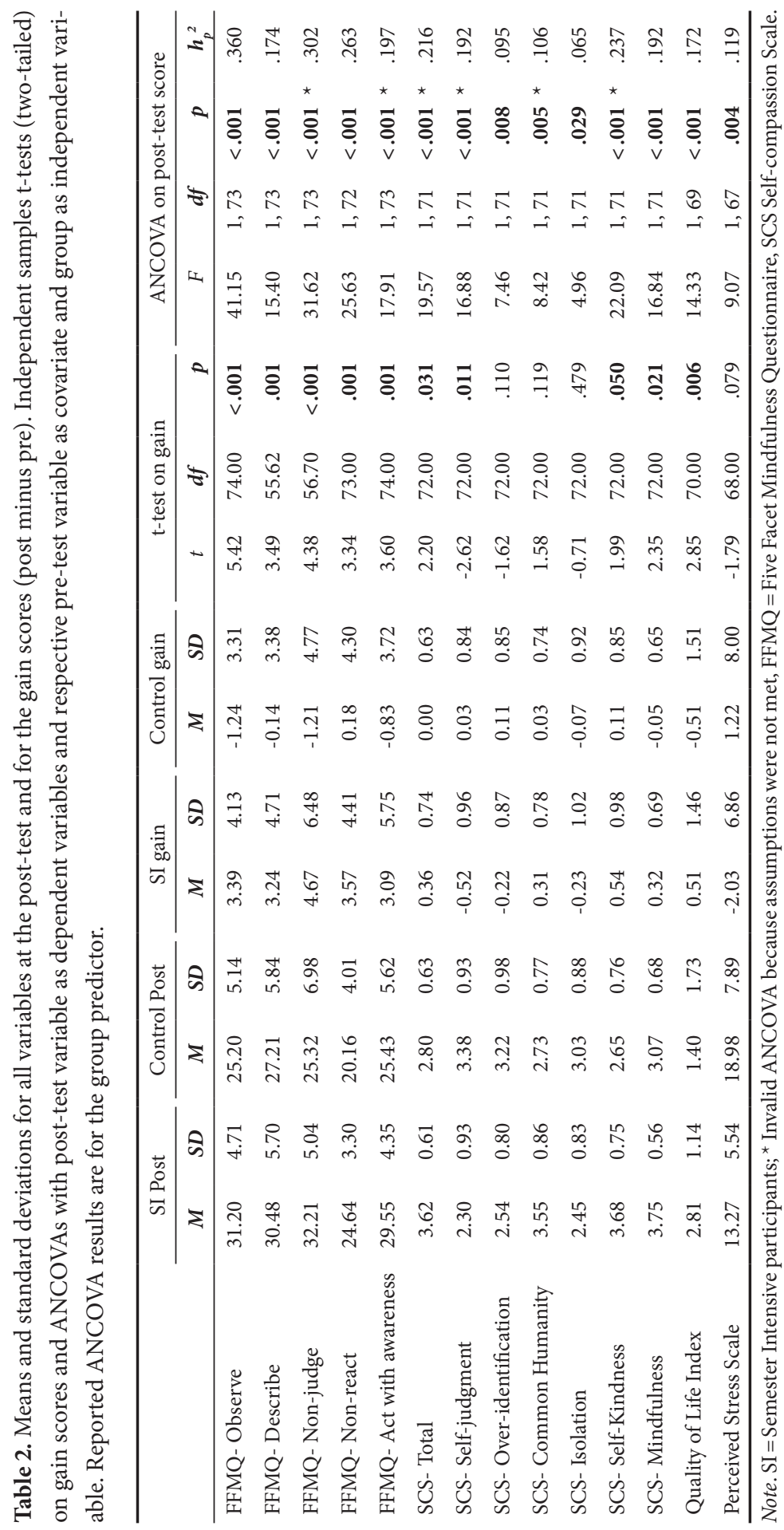




\section{T-TESTS ON GAIN SCORES}

Independent samples t-tests (two-tailed) were also performed on the gain scores (post-test minus pre-test). These tests revealed significant differences in gain scores between SI participants and controls on the Quality of Life Index, all subscales of the FFMQ, total Self-compassion, as well as the Self-judgment, Self-kindness, and Mindfulness subscales of the SCS (Table 2).

For five out of the eight variables for which ANCOVA assumptions were met, ANCOVAs and the t-tests on gain scores led to the same conclusion, namely that participation in SI significantly improved scores. For the SCS subscales Over-identification and Isolation, and for the PSS, the ANCOVAs and t-tests yielded different results but point in the same direction. The ANCOVAs revealed significant groupeffects for all three variables, whereas the t-tests were not significant, or in the case of the PSS only showed a trend towards significance $(p=0.079)$.

Post-hoc regression analyses with PSS-post score as dependent variable and PSS-pre score as covariate and total SCS-pre score as predictor, and with QOLI-post score as dependent variable and QOLI-pre score as covariate and total SCS-pre score as predictor were conducted. Total SCS-pre score was not a significant predictor for PSS $(b=1.02, t(26)=0.51, p=0.617)$, nor for QOLI $(b=-0.10, t(26)=-0.23, p=0.821)$, indicating that post-intervention levels of perceived stress and quality of life did not depend on pre-intervention levels of self-compassion.

\section{Mediation anAlysis}

To test if the effects of group on quality of life and perceived stress were mediated by mindfulness and self-compassion, we used a bootstrapping method with 5000 iterations as described by Preacher and Hayes (Preacher \& Hayes, 2008).

First, we tested four separate mediation models, two with residual QOLI and two with residual PSS as dependent variables. For each of the dependent variables, one model contained total residual SCS and one model contained total residual FFMQ as potential mediator. All models had group (SI versus control) as independent variable. These analyses revealed that the effect of group on quality of life was significantly mediated by mindfulness (95\% CI 0.678 to 1.856 ) and self-compassion (95\% CI 0.271 to 1.344 ). The effect of group on perceived stress was also significantly mediated by mindfulness (95\% CI -9.419 to -3.706$)$ and self-compassion (95\% CI -7.098 to -1.928).

Second, we tested two multiple mediator models. The first model contained group as the independent variable, total residual FFMQ and total residual SCS as potential mediators, and residual QOLI as the dependent variable (Figure 1a). Bootstrapping revealed significant indirect effects for self-compassion and mindfulness. 
95\% confidence intervals for the true effects are 0.105 to 1.114 and 0.109 to 1.115 respectively, indicating that the effect of group on quality of life was mediated by both mindfulness and self-compassion. The indirect effects of mindfulness and selfcompassion did not significantly (95\% CI -0.796 to 0.820 ) differ in magnitude.

The second model was identical to the previous one, but contained residual PSS as the dependent variable (Figure 1b). For this model, bootstrapping revealed a significant indirect effect for self-compassion only. 95\% confidence intervals for the true effects of mindfulness and self-compassion are -4.709 to 0.002 and -6.545 to -1.530 respectively, indicating that the effect of group on perceived stress was only mediated by self-compassion, not by mindfulness. Although the indirect effect of mindfulness was not significant, and that of self-compassion was, the magnitude of both effects were not significantly different (95\% CI -1.891 to 6.192).

It is important to note that the indirect effects of both potential mediators on the dependent variables are the unique effects of each potential mediator above and beyond any other mediator in the model. As the total residual FFMQ and the total residual SCS are strongly correlated $(r(70)=0.711, p<0.001)$, indirect mediation effects for each potential mediator in the model are compromised.
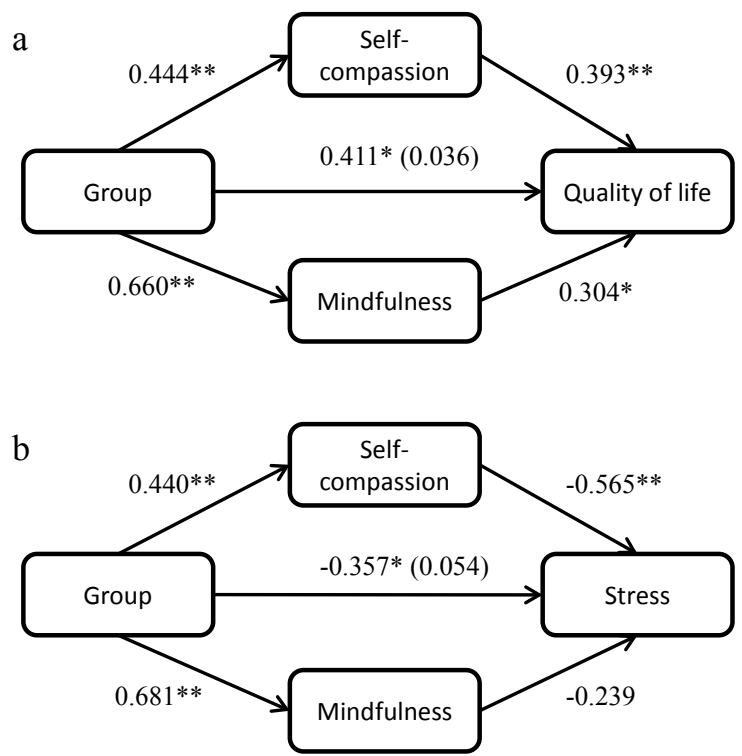

Figure 1. Mediation models for the effect of group (Semester Intensive versus controls) on a) quality of life and b) perceived stress, mediated by self-compassion and mindfulness (the sum of all facets of the five facet mindfulness questionnaire). For potential mediators and outcomes, residual post-scores were used. Values are standardized regression coefficients of direct effects. Between brackets the indirect effect of group on perceived stress. ${ }^{\star} p<0.055,{ }^{* *} p<0.005$. 


\section{DISCUSSION}

This pilot study examined the effects of a 4-month residential yoga-based program on quality of life, perceived stress, mindfulness, and self-compassion. Aligned with our hypothesis, participation in the program significantly predicted increases in quality of life, mindfulness, and self-compassion, along with decreases in perceived stress. Our findings also support that mindfulness and self-compassion mediate the effects of participation in the SI on quality of life and perceived stress.

\section{Quality of Life and Perceived Stress}

Our findings are aligned with previous studies which have shown that yoga can increase quality of life (Thomley, Ray, Cha, \& Bauer, 2011) and decrease stress (Ross \& Thomas, 2010). Some caution must be used in interpreting our results regarding perceived stress, as the t-test just missed significance, though the ANCOVA was significant. However, because both tests point in the same direction, and the ANCOVA has more power, we feel confident concluding that the SI program is effective for reducing perceived stress.

Quality of life is often considered synonymous with the life satisfaction component of subjective well-being (Frisch, 2012). Subjective well-being is known to be related to fulfillment in relationships, longevity, general health, income, and work performance (Lyubomirsky et al., 2005). Individuals with high levels of the life satisfaction have been shown to have increased cognitive and social functioning (Suldo \& Huebner, 2006). In contrast, low levels of the life satisfaction have been reported to predict poor work and academic performance (Frisch et al., 2005; Judge \& Watanabe, 1993), health problems (Diener, Chan, 2011), substance abuse (Gilman \& Huebner, 2003), violent and aggressive behavior (Valois et al., 2001), and problems in relationships with peers (Gilman \& Huebner, 2000). Furthermore, a negative relationship has been found between life satisfaction and both mental health and suicidality in young adults (Valois et al., 2001). Life satisfaction has been described as protective psychological buffer that can help individual's mitigate stressful life events without externalizing negative behavior (Suldo \& Huebner, 2004). High levels of stress have been demonstrated to negatively affect health (Bekkouche et al., 2009; Pedersen et al., 2009), as well as cognitive (McEwen \& Sapolsky, 1995) and emotional functioning (Lazarus, 2006), and are strongly related to psychopathology (Grant et al., 2009; Kessler \& Wang, 2008).

In our study we observed increases in quality of life and decreases in perceived stress following a yoga-based intervention in a young adult population, which represents a demographic with higher rates of mental health difficulties and levels of stress than the general public (Reavley \& Jorm, 2010). According to a recent survey of col- 
lege students, stress was reported to be the number one factor affecting academic performance (Reavley \& Jorm, 2010). By increasing quality of life and decreasing stress, yoga-based programs may have the potential to increase subjective well-being, scholastic performance, and foster resiliency towards mental illness in young adults.

\section{MINDFULNESS}

It is well established that the practice of mindfulness-meditation increases the skill of mindfulness (Carmody \& Baer, 2008; Nyklicek \& Kuijpers, 2008), however relatively little is known about the impact of other contemplative traditions on this skill. Our finding that participation in the SI program predicts an increase in mindfulness is consistent with some recent reports suggesting that yoga-based programs can also increase the skill of mindfulness (Conboy et al., 2010; Shelov et al., 2009). This increase in mindfulness might be attributed to the emphasis on the cultivation of "witness consciousness" in the SI program. As discussed above, "witness consciousness" (Faulds, 2005) has significant conceptual overlap with mindfulness .

Our finding that mindfulness predicted quality of life is aligned with previous research showing that mindfulness has a positive association with both subjective well-being (Branstrom et al., 2010; Brown, Kasser, Ryan, Alex Linley, \& Orzech, 2009; Schutte \& Malouff, 2011) and life satisfaction (Schutte \& Malouff, 2011). Similarly, our finding that mindfulness predicts perceived stress is aligned with recent research (Branstrom et al., 2010). Although not measured in the current study, based previous research showing negative associations between mindfulness and posttraumatic avoidance symptoms, and anxiety (Branstrom et al., 2010), as well positive associations with cognition, attention, working memory, and executive functioning (Jha et al., 2007; Zeidan et al., 2010), one might hypothesize that yoga-based interventions could affect these domains as well.

\section{SELF-COMPASSION}

Thus far, only one uncontrolled pilot study of highly experienced yoga practitioners has assessed the impact of yoga on self-compassion; however, only changes in the Mindfulness subscale of the SCS were observed (Conboy et al., 2010). In contrast, we reported favorable outcomes on all SCS subscales except Common Humanity, along with increased Total Self-compassion. Increases in self-compassion may have resulted from the instruction to students to bring awareness and acceptance to their unique physical attributes as they moved through yoga postures, rather than emphasizing the achievement of a 'perfect' pose.

Our finding that self-compassion predicts quality of life is aligned with previous studies that reported positive associations between self-compassion and well- 
being (Neely et al., 2009; Neff \& McGehee, 2010). Furthermore, our finding that selfcompassion predicts perceived stress is also aligned with previous report (Shapiro et al., 2005). Self-compassion also has been shown to be positively related to mental and physical health (Raque-Bogdan et al., 2011), scholastic performance (Neff et al., 2005), optimism (Neff, Rude, \& Kirkpatrick, 2007), positive affect (Neff et al., 2007), and resilience (Neff \& McGehee, 2010), and negatively to self-reported anxiety and depression (Neff \& McGehee, 2010). Although the aforementioned variables were not measured in the current study, one might hypothesize that yoga-based interventions have the potential to positively affect these variables through increased levels of self-compassion.

\section{Mediation}

Although the effects of yoga-based programs on mindfulness (Conboy et al., 2010; Shelov et al., 2009), quality of life (Thomley et al., 2011), and stress (Ross \& Thomas, 2010) have been reported previously, until now the potential mediating role of mindfulness and self-compassion on outcome has not been investigated. Here we report evidence that the effects of the SI on perceived stress and quality of life are mediated by mindfulness and self-compassion. The mediating role of mindfulness and self-compassion has previously been shown in mindfulness-based programs (Branstrom et al., 2010; Kuyken et al., 2010; Nyklicek \& Kuijpers, 2008). As mindfulnessbased and yoga-based interventions seem to share similar mechanisms, hypotheses about the outcome of yoga-based programs could be based upon existing knowledge of mindfulness-based programs (i.e. that yoga-based interventions could improve depressive symptoms and psychological well-being) (Hollis-Walker \& Colosimo, 2011; Kuyken et al., 2010; Shahar, Britton, Sbarra, Figueredo, \& Bootzin, 2011). Despite this apparent similarity, mindfulness- and yoga-based interventions might have unique mechanisms that need to be further explored.

The effect of the SI on quality of life was mediated by mindfulness and selfcompassion in both single and multiple mediator models. In contrast, while perceived stress was mediated by mindfulness and self-compassion individually in singe mediator models, when both mindfulness and self-compassion were simultaneously entered as potential mediators in the model, only self-compassion significantly mediated the effect of participation in the SI on perceived stress. Although it should be treated with caution because of the high correlation between mindfulness and self-compassion in the present study, our finding that perceived stress was mediated by self-compassion but not mindfulness in the multiple mediator model has very interesting potential theoretical and practical implications. Somewhat related, a recent study found self-compassion to be a better predictor of quality of life than mindfulness, although in a sample from a different population (18 to 73 year olds 
seeking self-help for anxiety, fear, and worry, of which $87.3 \%$ had moderate-severe levels of anxiety or depression) (Van Dam, Sheppard, Forsyth, \& Earleywine, 2011). Further studies with measurements at multiple time-points and larger samples are necessary to determine the relative contributions of mindfulness and self-compassion as mediators of positive outcome.

Finally, care must be used in interpreting the mediation results. Although widely done, it is important to note that causality between mediator and dependent variables can't be inferred when measured at the same time-point (Stone-Romero \& Rosopa, 2008). In addition to the causal models we tested here, other models could also be consistent with the reported covariance pattern.

\section{LIMITATIONS}

As with every quasi-experimental study, the main limitation of our study is the presence of threat to internal validity (Kenny, 1975). While we tried to minimize differences between groups by recruiting a demographically matched control group, a significant limitation of this study lies in the experimental group's pre-existing interest and intention to participate in a four month residential yoga-based intervention. In contrast, controls were not asked about their interest in yoga or participation in other types of self-help programs. It is likely that this difference between groups has affected our results, as a recent study revealed that self-selection, personal commitment, and motivation are all important contributors to the success of happiness interventions (Lyubomirsky, Dickerhoof, Boehm, \& Sheldon, 2011). Furthermore, while the between-group comparisons at the pre time-point demonstrated that the groups did not differ on most of the outcome variables, there were significant baseline differences in total Self-compassion and the SCS subscales Self-judgment, Common Humanity, and Self-kindness. Because of this baseline difference, self-compassion might be a confound in the present study, although, post-hoc regression analyses indicated that self-compassion at the pre-time-point did not predict post intervention QOLI and PSS scores. Additionally, there is the possibility that the groups might have differed on variables that were not measured. While it was impossible for practical reasons to randomly assign participants to the 4-month residential SI, future studies investigating the effect of yoga programs should employ random intervention allocation to rule out group differences.

Although the dropout rate in the SI program was relatively low (3 out of 53 SI participants), 17 out of the 50 course completers did not complete questionnaires at the post time point. This was likely due to the lack of financial compensation for SI participants to complete the questionnaires, and possibly due to the fact that many participants were very busy during this interval, as they were transitioning from this 
intensive residential program to their next steps in life. Another limitation was the absence of an appropriate control program, making it impossible to determine if the improvements in the assessed variables were truly the result of the yoga components of the SI or due to more generic aspects of the program such as social support, healthy diet, and outdoors activities. To rule out this limitation, future studies should employ active control groups.

While the present data are intriguing, future studies will be needed to investigate the effects of shorter, non-residential yoga-programs on subjective well-being and health, which would be more accessible, cost-effective, and feasible interventions. While this pilot study indicates what the possible short-term effects of a residential yoga-based program for young adults might be, the long-term effects are yet to be investigated. In order to evaluate the possible preventive effects of yoga-programs for mental health difficulties in young adults, future studies should specifically recruit individuals that are particularly at risk, and should have a follow-up period that allows for the assessment of long-term effects. Lastly, it would be useful to compare yoga- and mindfulness-based programs in the same study in order to directly compare their effects and underlying mechanisms.

\section{CONCLUSION}

In summary, our data suggests that participation in the yoga-based Kripalu Semester Intensive program results in increases in quality of life, mindfulness, self-compassion, and decreases in perceived stress in young adults. This is the first time that a yoga-based program has been reported to increase self-compassion, and that the effects of such a program on quality of life and perceived stress are mediated by mindfulness and self-compassion.

These preliminarily findings have potential implications for both the cultivation of subjective well-being and the clinical treatment and prevention of mental illness in young adults. Furthermore, our data suggests that yoga-based and mindfulness-based programs might share similar mechanisms, which could create an alternative option for individuals that have interest in acquiring the skills of mindfulness and self-compassion, but are resistant to formal meditation techniques or have a preference for more physically engaging practices. Finally, this similarity makes it possible to generate hypotheses about the effects of yoga-based programs based on the larger body of knowledge about the effects of mindfulness-based programs.

Further investigation of the mechanisms underlying yoga- and mindfulnessbased programs will facilitate the development of more targeted and efficient programs to foster subjective well-being and increase resilience. 


\section{ACKNOWLEDGEMENTS}

This study was supported by grants from two non-profit organizations: the Kripalu Center for Yoga and Health and the Yawkey Foundation. We would like to thank all participants for their efforts. Furthermore we would like to thank Edi Pasalis and Tosca Braun for their input and feedback on the background and content of Kripalu Yoga.

\section{REFERENCES}

Baer, R. A., Smith, G. T., Hopkins, J., Krietemeyer, J., \& Toney, L. (2006). Using self-report assessment methods to explore facets of mindfulness. Assessment, 13(1), 27-45. doi: $10.1177 / 1073191105283504$

Baron, R. M., \& Kenny, D. A. (1986). The moderator-mediator variable distinction in social psychological research: conceptual, strategic, and statistical considerations. Journal of Personality and Social Psychology, 51(6), 1173-1182. doi: 10.1037//0022-3514.51.6.1173

Bekkouche, N. S., Holmes, S., Whittaker, K. S., \& Krantz, D. S. (2009). Stress and the Heart: Psychosocial Stress and Coronary Heart Disease. In R. M. Piscitelli (Ed.), The Handbook of Stress Science: Biology, Psychology, and Health (pp. 385-398). New York, NY: Springer Publishing Company.

Birnie, K., Speca, M., \& Carlson, L. E. (2010). Exploring self-compassion and empathy in the context of mindfulness-based stress reduction (MBSR). Stress and Health, 26(5), 359371. doi: $10.1002 /$ smi. 1305

Branstrom, R., Kvillemo, P., Brandberg, Y., \& Moskowitz, J. T. (2010). Self-report mindfulness as a mediator of psychological well-being in a stress reduction intervention for cancer patients--a randomized study. Annals of Behavioral Medicine, 39(2), 151-161. doi: 10.1007/s12160-010-9168-6

Brown, K. W., Kasser, T., Ryan, R. M., Alex Linley, P., \& Orzech, K. (2009). When what one has is enough: Mindfulness, financial desire discrepancy, and subjective well-being. Journal of Research in Personality, 43(5), 727-736. doi: 10.1016/j.jrp.2009.07.002

Carmody, J., \& Baer, R. A. (2008). Relationships between mindfulness practice and levels of mindfulness, medical and psychological symptoms and well-being in a mindfulness-based stress reduction program. Journal of Behavioral Medicine, 31(1), 23-33. doi: $10.1007 / \mathrm{s} 10865-007-9130-7$

Cohen, S., \& Janicki-Deverts, D. (2012). Who's Stressed? Distributions of Psychological Stress in the United States in Probability Samples from 1983, 2006, and 20091. Journal of Applied Social Psychology, 42(6), 1320-1334. doi: 10.1111/j.1559-1816.2012.00900.x

Cohen, S., Kamarck, T., \& Mermelstein, R. (1983). A global measure of perceived stress. Journal of Health and Social Behavior, 24(4), 385-396. doi: 10.2307/2136404 
Conboy, L. A., Wilson, A., \& Braun, T. (2010). Moving beyond health to flourishing: the effects of yoga teacher training. TheScientificWorldJournal, 10, 788-795. doi: 10.1100/ tsw.2010.87

Diener, E. (1984). Subjective well-being. Psychological Bulletin, 95(3), 542-575. doi: 10.1037/0033-2909.95.3.542

Diener, E. (2000). Subjective well-being: the science of happiness and a proposal for a national index. American Psychologist, 55(1), 34-43. doi: 10.1037//0003-066X.55.1.34

Diener, E., Suh, E. M., Lucas, R. E., \& Smith, H. L. (1999). Subjective well-being: Three decades of progress. Psychological Bulletin, 125(2), 276-302. doi: 10.1037//0033-2909.125.2.276

Dimitrov, D. M., \& Rumrill Jr, P. D. (2003). Pretest-posttest designs and measurement of change. Work, 20(2), 159-165.

Faulds, R. (2005). Kripalu yoga: a guide to practice on and off the mat. New York, NY: Bantam.

Frisch, M. B. (2012). Quality of Life Well-Being in General Medicine, Mental Health and Coaching. In K. C. Land, M. J. Sirgy \& A. C. Michalos (Eds.), Handbook of Social Indicators and Quality of Life Research (pp. 239-263). Dordrecht, The Netherlands: Springer.

Frisch, M. B., Clark, M. P., Rouse, S. V., Rudd, M. D., Paweleck, J. K., Greenstone, A., \& Kopplin, D. A. (2005). Predictive and treatment validity of life satisfaction and the quality of life inventory. Assessment, 12(1), 66-78. doi: 10.1177/1073191104268006

Frisch, M. B., Cornell, J., Villanueva, M., \& Retzlaff, P. J. (1992). Clinical validation of the Quality of Life Inventory: a measure of life satisfaction for use in treatment planning and outcome assessment. Psychological Assessment, 4(1), 92-101. doi: 10.1037//10403590.4.1.92

Gilman, R., \& Huebner, E. S. (2000). Review of life satisfaction measures for adolescents. Behaviour Change, 17(3), 178-195. doi: 10.1375/bech.17.3.178

Gilman, R., \& Huebner, S. (2003). A review of life satisfaction research with children and adolescents. School Psychology Quarterly, 18(2), 192-205.

Grant, K. E., McMahon, S. D., Dufy, S., Taylor, J. J., \& Compas, B. E. (2009). Stressors and Mental Health Problems in Childhood and Adolescence. In R. M. Piscitelli (Ed.), The Handbook of Stress Science: Biology, Psychology, and Health (pp. 359-372). New York, NY: Springer Publishing Company.

Hollis-Walker, L., \& Colosimo, K. (2011). Mindfulness, self-compassion, and happiness in non-meditators: A theoretical and empirical examination. Personality and Individual Differences, 50(2), 222-227. doi: 10.1016/j.paid.2010.09.033

Hölzel, B. K., Lazar, S. W., Gard, T., Schuman-Olivier, Z., Vago, D. R., \& Ott, U. (2011). How Does Mindfulness Meditation Work? Proposing Mechanisms of Action From a Conceptual and Neural Perspective. Perspectives on Psychological Science, 6(6), 537-559. doi: $10.1177 / 1745691611419671$ 
Jha, A. P., Krompinger, J., \& Baime, M. J. (2007). Mindfulness training modifies subsystems of attention. Cognitive, Affective, \& Behavioral Neuroscience, 7(2), 109-119. doi: 10.3758/CABN.7.2.109

Judge, T. A., \& Watanabe, S. (1993). Another look at the job-satisfaction life satisfaction relationship. Journal of Applied Psychology, 78(6), 939-948. doi: 10.1037//00219010.78.6.939

Kabat-Zinn, J. (1990). Full catastrophe living: Using the wisdom of your body and your mind to face stress, pain and illness. New York, NY: Delta.

Kenny, D. A. (1975). A quasi-experimental approach to assessing treatment effects in the nonequivalent control group design. Psychological Bulletin, 82(3), 345-362. doi: 10.1037//0033-2909.82.3.345

Kessler, R. C., \& Wang, P. S. (2008). The descriptive epidemiology of commonly occurring mental disorders in the United States. Annual Review of Public Health, 29(1), 115-129. doi: 10.1146/annurev.publhealth.29.020907.090847

. Kripalu Yoga 200 Hour Teacher Training Manual. (2011). Stockbridge, MA: Kripalu Center for Yoga and Health.

Kuyken, W., Watkins, E., Holden, E., White, K., Taylor, R. S., Byford, S., Evans, A., Radford, S., Teasdale, J. D., \& Dalgleish, T. (2010). How does mindfulness-based cognitive therapy work? Behaviour Research and Therapy, 48(11), 1105-1112. doi: 10.1016/j. brat.2010.08.003

Lazarus, R. S. (2006). Stress and emotion: A new synthesis. New York, NY: Springer Publishing Company.

Lyubomirsky, S., Dickerhoof, R., Boehm, J. K., \& Sheldon, K. M. (2011). Becoming happier takes both a will and a proper way: an experimental longitudinal intervention to boost well-being. Emotion, 11(2), 391-402. doi: 10.1037/a0022575

Lyubomirsky, S., King, L., \& Diener, E. (2005). The benefits of frequent positive affect: does happiness lead to success? Psychological Bulletin, 131(6), 803-855. doi: 10.1037/00332909.131.6.803

MacKinnon, D. P., Lockwood, C. M., Hoffman, J. M., West, S. G., \& Sheets, V. (2002). A comparison of methods to test mediation and other intervening variable effects. Psychological methods, 7(1), 83-104. doi: 10.1037/1082-989X.7.1.83

McEwen, B. S., \& Sapolsky, R. M. (1995). Stress and cognitive function. Current Opinion in Neurobiology, 5(2), 205-216. doi: 10.1016/0959-4388(95)80028-X

Neely, M. E., Schallert, D. L., Mohammed, S. S., Roberts, R. M., \& Chen, Y. J. (2009). Selfkindness when facing stress: The role of self-compassion, goal regulation, and support in college students' well-being. Motivation and Emotion, 33(1), 88-97. doi: 10.1007/ s11031-008-9119-8

Neff, K. D. (2003). The development and validation of a scale to measure self-compassion. Self and Identity, 2(3), 223-250. doi: 10.1080/15298860309027 
Neff, K. D., Hsieh, Y. P., \& Dejitterat, K. (2005). Self-compassion, achievement goals, and coping with academic failure. Self and Identity, 4(3), 263-287. doi: 10.1080/13576500444000317

Neff, K. D., \& McGehee, P. (2010). Self-compassion and psychological resilience among adolescents and young adults. Selfand Identity, 9(3),225-240. doi: 10.1080/15298860902979307

Neff, K. D., Rude, S. S., \& Kirkpatrick, K. L. (2007). An examination of self-compassion in relation to positive psychological functioning and personality traits. Journal of Research in Personality, 41(4), 908-916. doi: 10.1016/j.jrp.2006.08.002

Nyklicek, I., \& Kuijpers, K. F. (2008). Effects of mindfulness-based stress reduction intervention on psychological well-being and quality of life: Is increased mindfulness indeed the mechanism? Annals of Behavioral Medicine, 35(3), 331-340. doi: 10.1007/s12160008-9030-2

Pedersen, A. F., Bovbjerg, D. H., \& Zachariae, R. (2009). Stress and Susceptibility to Infectious Disease. In R. M. Piscitelli (Ed.), The Handbook of Stress Science: Biology, Psychology, and Health (pp. 425-446). New York, NY: Springer Publishing Company.

Preacher, K. J., \& Hayes, A. F. (2008). Asymptotic and resampling strategies for assessing and comparing indirect effects in multiple mediator models. Behavior Research Methods, 40(3), 879-891. doi: 10.3758/BRM.40.3.879

Raque-Bogdan, T. L., Ericson, S. K., Jackson, J., Martin, H. M., \& Bryan, N. A. (2011). Attachment and mental and physical health: self-compassion and mattering as mediators. Journal of Counseling Psychology, 58(2), 272-278. doi: 10.1037/a0023041

Reavley, N., \& Jorm, A. F. (2010). Prevention and early intervention to improve mental health in higher education students: a review. Early Intervention in Psychiatry, 4(2), 132-142. doi: 10.1111/j.1751-7893.2010.00167.x

Ross, A., \& Thomas, S. (2010). The health benefits of yoga and exercise: a review of comparison studies. The Journal of Alternative and Complementary Medicine, 16(1), 3-12. doi: 10.1089/acm.2009.0044

Schutte, N. S., \& Malouff, J. M. (2011). Emotional intelligence mediates the relationship between mindfulness and subjective well-being. Personality and Individual Differences, 50(7), 1116-1119. doi: 10.1016/j.paid.2011.01.037

Seligman, M. E. P., \& Csikszentmihalyi, M. (2000). Positive psychology. An introduction. American Psychologist, 55(1), 5-14. doi: 10.1037//0003-066X.55.1.5

Shahar, B., Britton, W. B., Sbarra, D. A., Figueredo, A. J., \& Bootzin, R. R. (2011). Mechanisms of Change in Mindfulness-Based Cognitive Therapy for Depression: Preliminary Evidence from a Randomized Controlled Trial. International Journal of Cognitive Therapy, 3(4), 402-418. doi: 10.1521/ijct.2010.3.4.402

Shapiro, S. L., Astin, J. A., Bishop, S. R., \& Cordova, M. (2005). Mindfulness-Based Stress Reduction for Health Care Professionals: Results From a Randomized Trial. International Journal of Stress Management, 12(2), 164-176. doi: 10.1037/1072-5245.12.2.164

Shapiro, S. L., Brown, K. W., \& Biegel, G. M. (2007). Teaching self-care to caregivers: Effects of mindfulness-based stress reduction on the mental health of therapists in training. 
Training and Education in Professional Psychology, 1(2), 105-115. doi: 10.1037/19313918.1.2.105

Shearer, A. (2002). The yoga sutras of Patanjali. New York, NY: Harmony.

Shelov, D. V., Suchday, S., \& Friedberg, J. P. (2009). A pilot study measuring the impact of yoga on the trait of mindfulness. Behavioural and Cognitive Psychotherapy, 37(5), 595-598. doi: $10.1017 /$ S1352465809990361

Stone-Romero, E. F., \& Rosopa, P. J. (2008). The relative validity of inferences about mediation as a function of research design characteristics. Organizational Research Methods, 11(2), 326-352. doi: 10.1177/1094428107300342

Suldo, S. M., \& Huebner, E. S. (2004). Does life satisfaction moderate the effects of stressful life events on psychopathological behavior during adolescence? School Psychology Quarterly, 19(2), 93-105. doi: 10.1521/scpq.19.2.93.33313

Suldo, S. M., \& Huebner, E. S. (2006). Is Extremely High Life Satisfaction during Adolescence Advantageous? Social Indicators Research, 78(2), 179-203. doi: 10.1007/s11205-0058208-2

Thomley, B. S., Ray, S. H., Cha, S. S., \& Bauer, B. A. (2011). Effects of a brief, comprehensive, yoga-based program on quality of life and biometric measures in an employee population: a pilot study. Explore (New York, NY), 7(1), 27-29. doi: 10.1016/j.explore.2010.10.004

Valois, R. F., Zullig, K. J., Huebner, E. S., \& Drane, J. W. (2001). Relationship between life satisfaction and violent behaviors among adolescents. American Journal of Health Behavior, 25(4), 353-366. doi: 10.5993/AJHB.25.4.1

Van Breukelen, G. J. P. (2006). ANCOVA versus change from baseline had more power in randomized studies and more bias in nonrandomized studies. Journal of Clinical Epidemiology, 59(9), 920-925. doi: 10.1016/j.jclinepi.2006.02.007

Van Dam, N. T., Sheppard, S. C., Forsyth, J. P., \& Earleywine, M. (2011). Self-compassion is a better predictor than mindfulness of symptom severity and quality of life in mixed anxiety and depression. Journal of anxiety disorders, 25(1), 123-130. doi: 10.1016/j. janxdis.2010.08.011

Zeidan, F., Johnson, S. K., Diamond, B. J., David, Z., \& Goolkasian, P. (2010). Mindfulness meditation improves cognition: evidence of brief mental training. Consciousness and Cognition, 19(2), 597-605. doi: 10.1016/j.concog.2010.03.014 



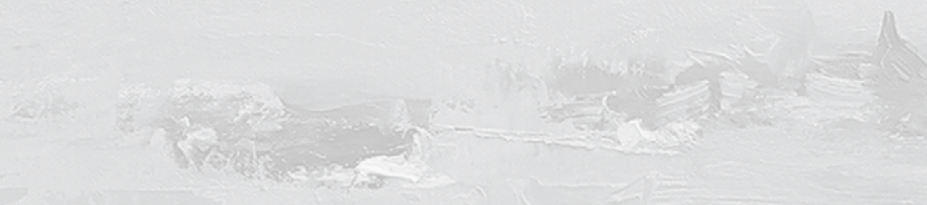


ChAPTER 4

\section{THE POTENTIAL EFFECTS OF MEDITATION ON AGE-RELATED COGNITIVE DECLINE}

Based on: Gard, T., Hölzel, B. K., \& Lazar, S. W. (2014). The potential effects of meditation on age-related cognitive decline: a systematic review. Annals of the New York Academy of Sciences, 1307(1), 89-103. doi: 10.1111/nyas.12348 


\section{AbStract}

Background: With a rapidly aging society it becomes increasingly important to counter normal age related decline in cognitive functioning. Growing evidence suggests that cognitive training programs may have the potential to counter-act this decline. Based on a growing body of research that shows that meditation has positive effects on cognition in younger and middle-aged adults, meditation may be able to off-set normal age related cognitive decline or even enhance cognitive function in older adults. Here we review studies investigating the effects of meditation on age related cognitive decline. Methods: Web of Science (1900-present), PsychInfo (1597-present), MEDLINE (1950-present), and CABI (1910-present) have been searched to identify original studies investigating the effects of meditation on cognition and cognitive decline in the context of aging. Results: Twelve studies were included in the review, of which six RCTs. Studies involved a wide variety of meditation techniques and reported preliminary positive effects on attention, memory, executive function, processing speed, and general cognition. However, most studies had high risk of bias and small sample sizes. Reported drop-out rates were low and compliance rates high. Conclusion: Meditation interventions for older adults are feasible and preliminary evidence suggests that meditation can off-set age-related cognitive decline. 


\section{INTRODUCTION}

The world population is rapidly aging, in part due to increases in life expectancy and the aging baby boom generation getting older (Administration on Aging, 2012; United Nations, 2002). In the United States the population of persons 65 years and older has grown by $18 \%$ in the last decade and is expected to almost double to 79 million in 2040, making up 20\% of the US population (Administration on Aging, 2012).

While aging is associated with increased social satisfaction and increased well-being (for reviews see (Charles \& Carstensen, 2010; Mather \& Carstensen, 2005; Scheibe \& Carstensen, 2010)), it is also well established that normal healthy aging is accompanied by decline in cognitive function (Salthouse, 2009b; Tucker-Drob, 2011; Wilson, Beckett, Bennett, Albert, \& Evans, 1999) and related declines in neural structure and activity (Morrison \& Hof, 1997; Persson et al., 2006; Salat et al., 2004). The decline in cognition is rather specific. While crystallized mental capabilities such as vocabulary increase steadily until mid-life, remain relatively stable throughout mid-life and then only slowly decline at an older age, fluid capabilities, speed and memory decrease sooner and faster with aging (Salthouse, 2004; Salthouse, 2009a). The decline can progress to mild cognitive impairment (MCI) and dementia, which are characterized by limitations of daily functioning and typically result in a reduced quality of life. Therefore cognitive decline is an often feared aspect of aging. It is not only a burden for the affected individual but also for relatives and society (Deary et al., 2009; Plassman, Williams, Burke, Holsinger, \& Benjamin, 2010). Some preliminary literature has suggested that a number of life style factors can affect the rate of normal decline (for reviews see (Fotuhi, Do, \& Jack, 2012; Kramer \& Erickson, 2007; Plassman et al., 2010)). A variety of cognitive training programs (Belleville et al., 2011; Nyberg et al., 2003; Willis et al., 2006) and aerobic exercise (Brown, Peiffer, \& Martins, 2013; Colcombe et al., 2004) have also recently been suggested to slow cognitive decline. However, based on the limited body of research trials, no clear recommendations can be established so far, and further rigorous research is needed to more clearly address this question (Daviglus et al., 2010).

A growing body of research suggests that meditation can enhance various cognitive functions including attention, memory, and executive function (Cranson et al., 1991; Jha, Krompinger, \& Baime, 2007; Jha, Stanley, Kiyonaga, Wong, \& Gelfand, 2010; Tang et al., 2007; Zeidan, Johnson, Diamond, David, \& Goolkasian, 2010), and that it positively affects brain function and structure relevant to cognition (Allen et al., 2012; Brefczynski-Lewis, Lutz, Schaefer, Levinson, \& Davidson, 2007; Gard, Hölzel, et al., 2012; Hölzel et al., 2011; Hölzel et al., 2007; Lazar et al., 2005; Pagnoni, 2012). Despite this evidence, the effects of meditation on cognition and cognitive decline in aging have not been extensively studied. Here we will review what is currently known about this young field at the intersection of gerontology 
and contemplative sciences. While we focus on the effects of meditation on cognitive decline in this review, a review of the effects of meditation on brain function and structure in aging has been done by Luders (2014).

\section{METHODS}

This systematic review followed the guidelines of the Preferred Reporting Items for Systematic Reviews and Meta-Analysis (PRISMA) statement (Moher, Liberati, Tetzlaff, Altman, \& The, 2009).

\section{ELIGIBILITY CRITERIA}

As the field of contemplative gerontology is still in its infancy and part of our aim was to provide a broad overview of the attempts that have been made to investigate the effect of meditation on age related cognitive decline rather than drawing firm conclusions about this relationship, eligibility criteria were kept rather broad. Original studies of all designs investigating the effects of meditation on cognition and cognitive decline in the context of aging were eligible. The focus was on formal meditation or interventions describing formal meditation as part of their curriculum but without substantial exercise components, to avoid exercise as a confound (Brown et al., 2013). Therefore studies involving mind-body interventions such as yoga and tai chi were not considered eligible, even though yoga for example clearly involves meditation (Gard, Brach, et al., 2012). Reports had to be written in English and were required to be published in peer reviewed journals.

\section{STUDY SEARCH AND SELECTION}

Studies were identified by searching the databases Web of Science (1900-present), CABI (1910-present), PsychInfo (1597-present) and MEDLINE (1950-present) without restrictions. To avoid excluding potentially relevant articles at the search stage a relatively broad search strategy was used. The query "(Meditation OR Mindfulness) AND Aging AND Decline" was used in the "topic" fieled of Web of Scinece, CABI and MEDLINE and in "all fields" in PsychInfo. The search was not restricted to also include "cognition" or related search terms as we also wanted to identify studies that did not primarily focus on cognition but still included some measures of it. Searches were first conducted on May $29^{\text {th }}, 2013$ and last updated on November $14^{\text {th }}, 2013$. In addition to database searches, additional relevant studies were identified from the 
reference lists of examined articles. Eligibility of articles was assessed based on the eligibility criteria, first on the level of title, abstract and source, then on the basis the full article (Figure 1). Search and study selection were conducted by TG.

\section{DATA EXTRACTION AND RISK OF BIAS ASSESSMENT}

A data extraction form was developed in which data on study design, population characteristics, intervention characteristics, and study results are summarized (Table 1). Risk of bias was assessed with the Cochrane risk assessment tool (Higgins et al., 2011) (Table 2). Data extraction was conducted by TG, risk of bias evaluation by TG and $\mathrm{BKH}$.

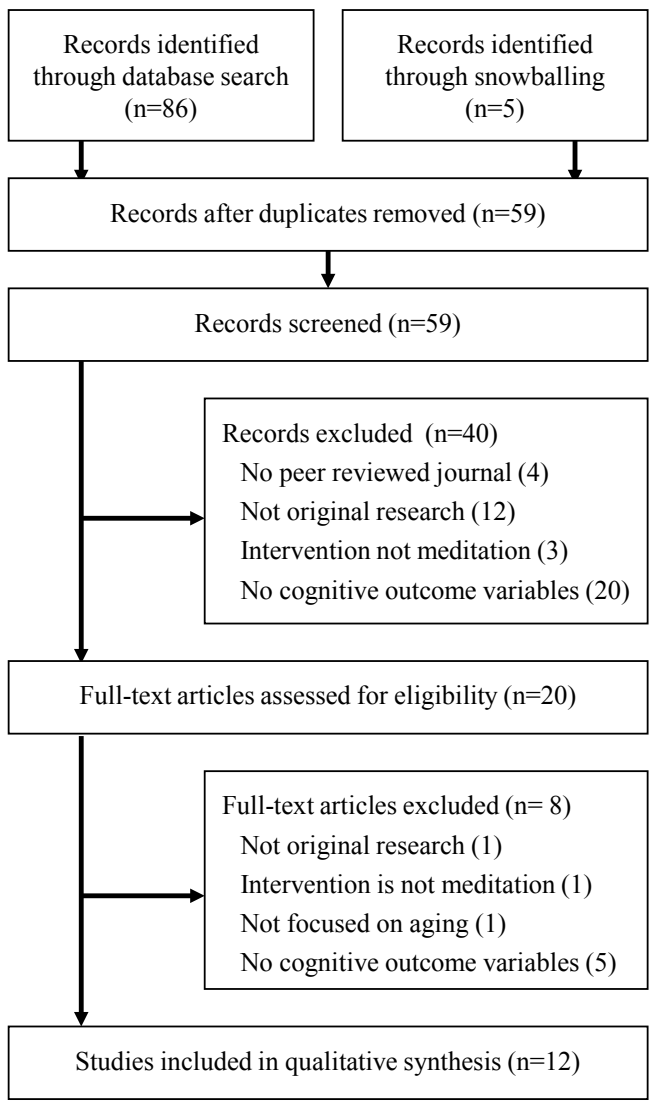

Figure 1. Study search and selection. 


\section{Results}

Literature search resulted in a total of 91 records, 86 through the databases (WebIS 30, CABI 2, Medline 37, Psychinfo 17), and 5 through snowballing examined articles. After screening and full-text assessment, 12 articles were included in the qualitative synthesis (Figure 1). Characteristics and results of individual studies are summarized below and in Table 1.

Results of risk of bias assessment are presented in Table 2. For all ratings, consensus was reached between the two evaluators. Each individual study will first be summarized briefly, before characteristics and findings will be discussed in an integrative way.

Alexander et al., (1989) investigated the effects of Transcendental Meditation (TM), a program that used techniques developed by Ellen Langer which was termed 'mindfulness' (MFL; Langer, 1992; Langer \& Moldoveanu, 2000) (though it should be noted that this form of mindfulness does not utilize meditation and is different than the "mindfulness" popularized by Jon Kabat-Zinn (1990)), and a mental relaxation (MR) condition on a number of health related and cognitive variables. Cognitive function was assessed with the Dementia Screening Test (DST; Farmer et al., 1987), the word-color Stroop interference test (Stroop, 1992) and the Overlearned Verbal Task (see (Alexander et al., 1989)) which is intended to measure cognitive flexibility. It should be mentioned here that the OVT was developed for the study, but no validation data was reported. The DST total score and the Associative Learning and Word Fluency subtest scores were used as outcome measures. Seventy-three older (mean age 80.7 years) participants with normal to poor cognitive functioning were randomized to the four conditions such that the TM, MFL and MR group had 20, 21, and 21 participants respectively and the no-intervention (NT) control group 11. All three interventions lasted for 12 weeks and comprised 30 minutes of individual teaching per week and 2x20 minutes of home practice per day. The TM practice involves focusing on a mantra and "a specific procedure for using it mentally without effort" (Alexander et al., 1989), to turn "inwards towards subtler levels of a thought until the mind transcends the subtlest state of thought and arrives at the source of thought" (Yogi, 1969, p. 470) which is experienced as content-free pure consciousness (Alexander et al., 1989). The mindfulness intervention was meant to increase mindfulness as defined by Langer (Langer, 1992; Langer \& Moldoveanu, 2000). According to this definition mindfulness is described as "a general style or mode of functioning through which the individual actively engages in reconstructing the environment through creating new categories or distinctions, thus directing attention to new contextual cues that may be consciously controlled or manipulated as appropriate" (Alexander et al., 1989). To increase mindfulness participants were trained in two tasks, a word-production, and a creative mental activity task. The word production task 
Effects of meditation on cognition in aging

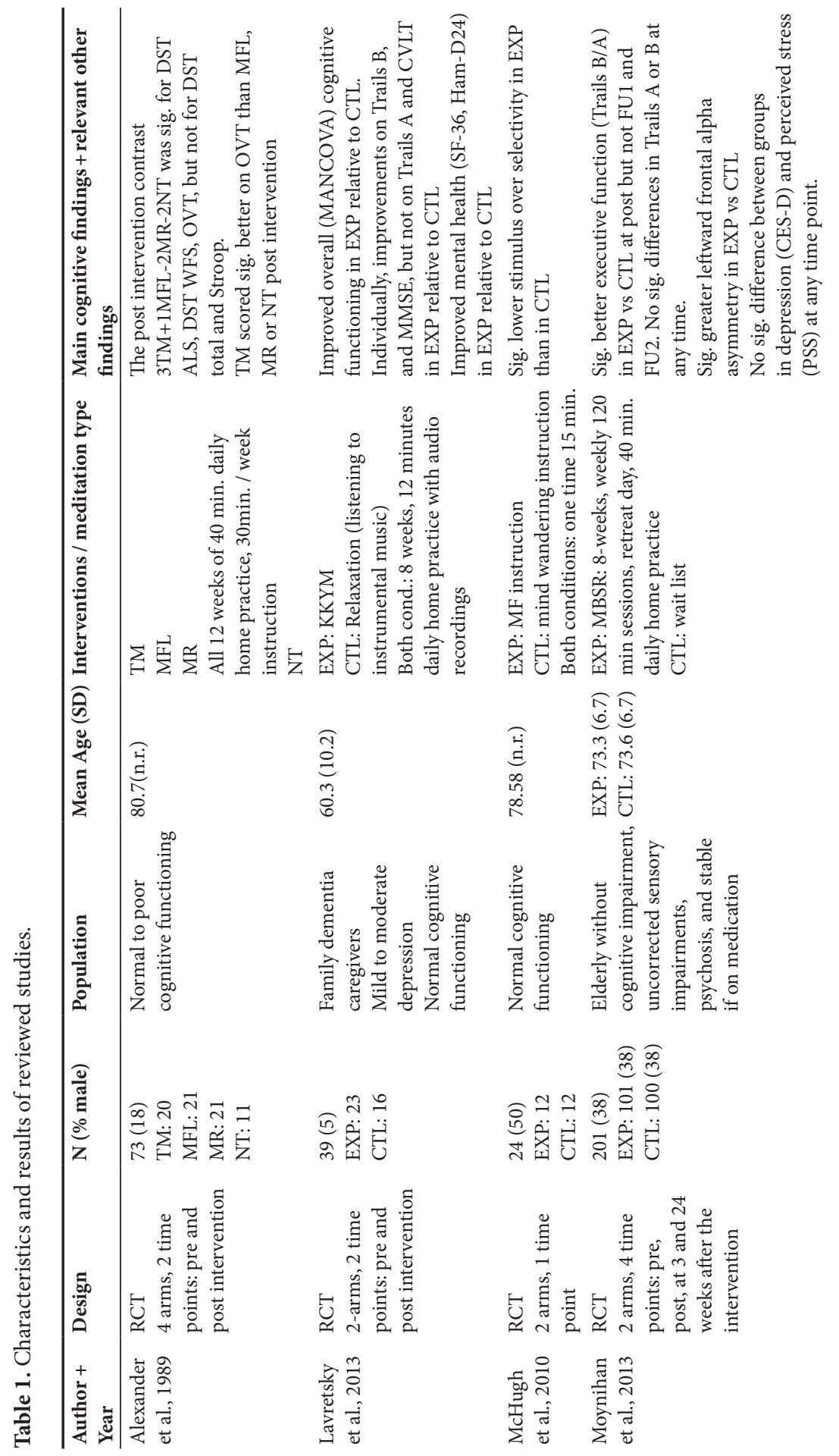




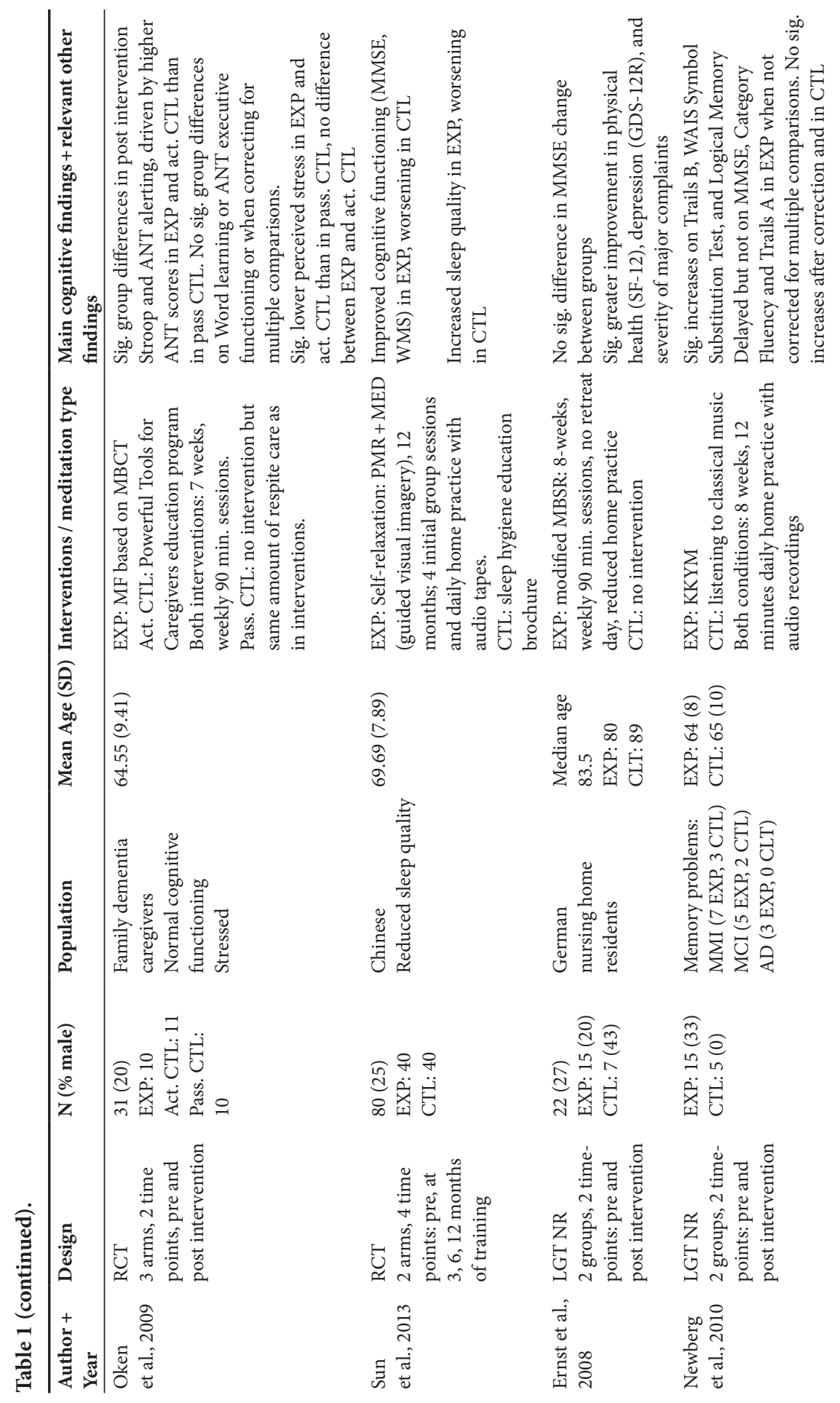




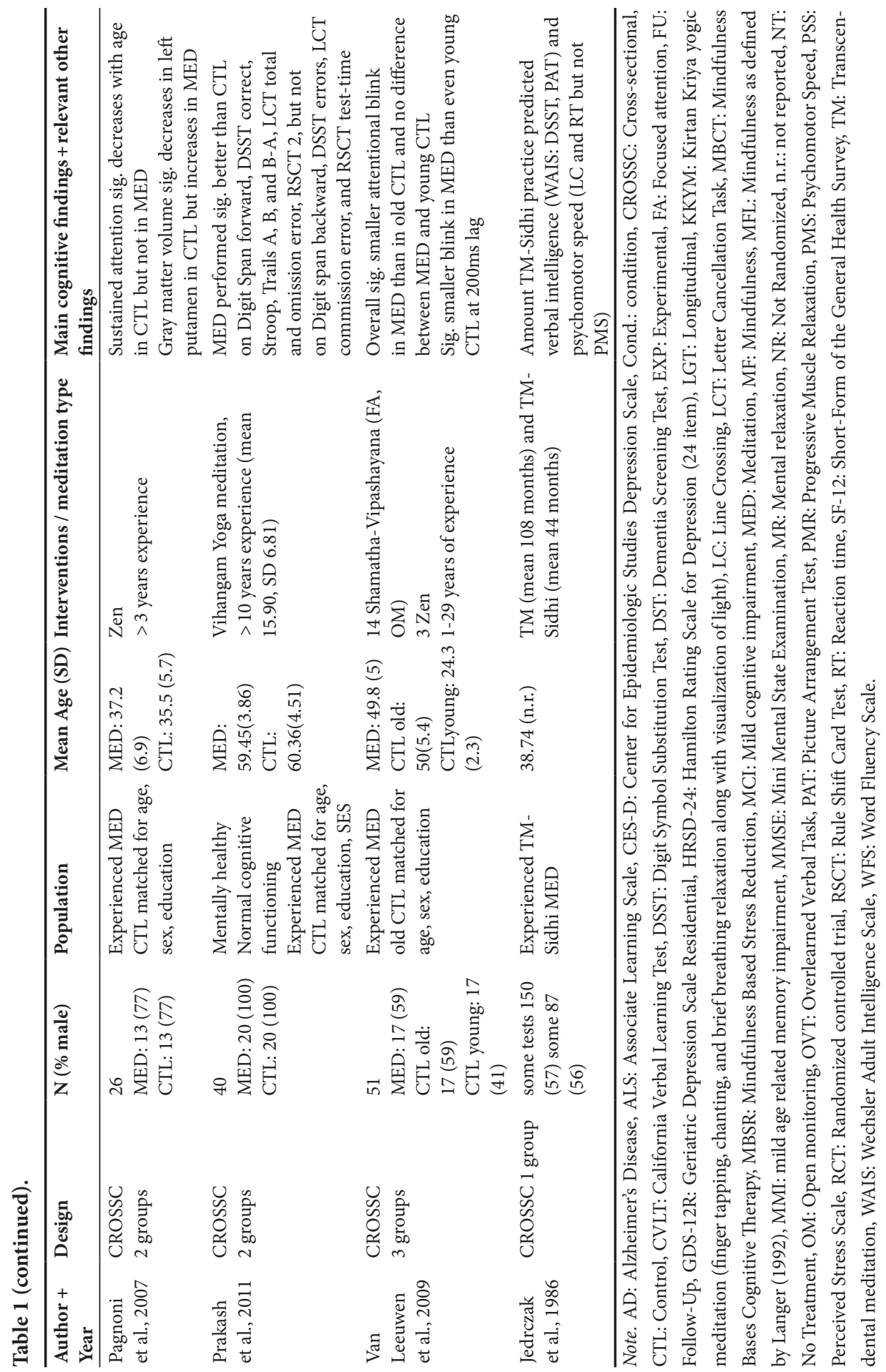




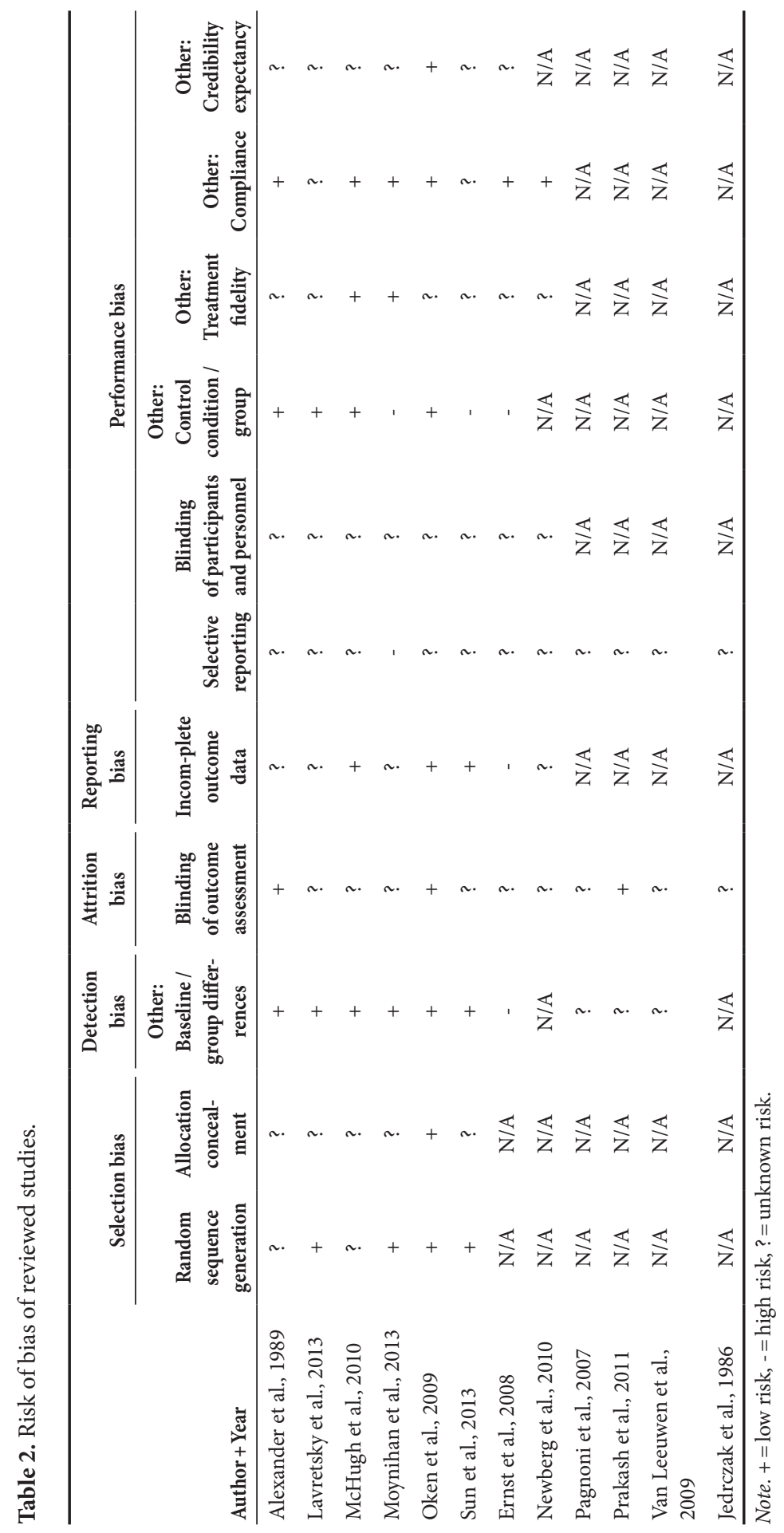


consisted of thinking of a word and finding a new word that begins with the last letter of the previous word. Difficulty was added throughout the intervention by restricting words to specific categories such as animals or foods. For the creative mental activity task, participants were asked to think in new ways about things. For example to think of new uses of an object or to argue against one's usual opinion regarding certain topics. In the mental relaxation condition, participants were asked to sit with eyes closed, as in the other two conditions, and to silently repeat a self-chosen mental stimulus. Each week a new stimulus could be chosen. To test the main hypothesis that TM would have the strongest effect on outcome variables, followed by MFL as compared to MR and NT, a contrast with contrast weights 3, 1, -2, and -2 for the respective conditions was tested. This contrast was significant for the following outcome variables: mental health, systolic blood pressure, and ratings of behavioral flexibility, perceived control, perceived age, and treatment efficacy. Most impressively, groups also significantly differed in survival rate at 36 month follow-up. This was driven by a greater survival rate in TM than in MR and NT and greater survival of MFL than MR. For the cognitive variables, the main contrast was not significant for DST total and there only was a trend towards significance $(p<0.10)$ for the Stroop Test. However, the contrast was significant for the Associate Learning Scale, OVT, and Word Fluency, indicating that TM and MFL combined resulted in increased performance on these tests compared to MR and NT combined. Follow-up tests revealed that the TM group had significantly greater improvement than the NT group on the Associate Learning Scale and significantly greater improvements than MFL, MR and NT on the OVT. A strength of the study is that interventions were matched for form (sitting eyes closed) and time spent. Furthermore expectancy of the effectiveness of the intervention, instructor likability and competence were assessed and did not differ among groups, and all teachers believed that their intervention was the most effective one. A weakness of the study is that the sample size was rather small for a 4-arm study. The authors did not report whether and how they corrected for multiple comparisons. This study also included participants with compromised cognitive functions, however it is not reported how many participants were impaired, how severe the impairment was and whether results were driven by the impaired participants or not.

Lavretsky et al., (2013) investigated the effects of Kirtan Kriya, a form of yogic meditation, on mental health, cognition, and telomerase activity in older (mean age 60.3, SD 10.2 years) family dementia caregivers with mild depression. Participants were randomized to either the Kirtan Kriya or a relaxation condition. Both interventions lasted for eight weeks and took the form of 12 minutes daily home practice with audio recordings. The Kirtan Kriya, which is a meditative practice from the Kundalini Yoga tradition, comprised mudras (finger gestures), chanting of a mantra, and a short breathing relaxation accompanied by the visualization of light. The relaxation condition consisted of listening to instrumental music. Men- 
tal health, cognition and telomerase activity were assessed before and after the interventions. Mental health was assessed with the mental health scale of the SF-36 (Ware Jr \& Sherbourne, 1992) and the Hamilton Rating Scale for Depression (Hamilton, 1960); cognitive functioning with the Mini-Mental State Examination (MMSE; Folstein, Folstein, \& McHugh, 1975) and the Trail A (attention, processing speed) and B (executive function) trail making tests (Reitan, 1958). The researchers reported that the number of responders (improvement of $\geq 50 \%$ ) on both mental health variables was greater in the experimental condition than in the control condition. Furthermore, when all the tests were combined (MANCOVA analysis), there were significant group differences in change of cognitive function. When analyzed individually (ANCOVAs) there was a significantly greater improvement on the MMSE and Trails $B$ in the Kirtan Kriya condition than in the relaxation condition. The same was true for the telomerase activity. These findings suggest that Kirtan Kriya is more effective than relaxation alone in improving mental health and cognition in older dementia caregivers. Again, in this study it is not clear if the effects on cognition were directly dependent on the meditation or the result of reductions in depression and improvements in mental health in general.

McHugh et al., (2010) studied the effects of a 15 minute mindfulness intervention on stimulus over-selectivity in mentally healthy older adults. Stimulus overselectivity refers to hyper-attentiveness to limited stimuli in the environment while ignoring others. This attentional abnormality is common in Autism Spectrum Disorders, and recently it has been shown to also increase with age (McHugh \& Reed, 2007). Twenty-four older participants (mean age 78.58 years) first completed a battery of psychometric tests including the MMSE (Folstein et al., 1975), Trails A and B (Reitan, 1958), and others to ensure normal cognitive function and to evaluate group differences on these baseline measures. Participants were then randomized to either a 15 minute mindfulness or a 15 minute mind wandering intervention. The instruction for the mindfulness intervention was "Focus on the actual sensations of breath entering and leaving the body. There is no need to think about the breath - just experience the sensations of it. When you notice that your awareness is no longer on the breath, gently bring your awareness back to the sensations of breathing" and for the mind wandering condition "Simply think about whatever comes to mind. Let your mind wander freely without trying to focus on anything in particular " (McHugh et al., 2010). Participants of the meditation intervention had significantly lower stimulus over-selectivity than those of the mind wandering condition, indicating that a short mindfulness intervention can decrease this age-related attention-bias. These findings seem impressive as the intervention was very brief. However, as the authors acknowledge, testing was done immediately after the intervention / induction, and it would be interesting and relevant for future studies to investigate longer-term effects of mindfulness interventions on stimulus over-selectivity. 
Moynihan et al., (2013) investigated the effects of MBSR on executive function, frontal alpha asymmetry, and immune function in a community sample of relatively healthy older adults (mean age 73.4, SD 6.7 years). 108 participants were randomized to MBSR and 112 to a wait list control (WLC) group. Of those, 201 participants completed measurements before the intervention, right after the intervention and 3- and 24 weeks after completion of the course. MBSR participants had a significantly lower Trails (Reitan, 1958) B/A ratio than WLCs immediately after the intervention, indicating improved executive function. This effect was not maintained at the follow-up time-points and there were no significant group differences on Trails A and B at any time-point. MBSR participants also had greater left lateralized frontal alpha asymmetry than WLC right after the intervention. Furthermore the MBSR group had significant increases in mindfulness as assessed with the MAAS (Brown \& Ryan, 2003), after the intervention and after 24 weeks of follow-up. Depression as measured with the Center for Epidemiologic Studies Depression Scale (CES-D-R; Lewinsohn, Seeley, Roberts, \& Allen, 1997)and perceived stress as assessed with the Perceived Stress Scale (PSS; Cohen, Kamarck, \& Mermelstein, 1983) were not affected by the intervention. Against expectations, immune response at the 24-week follow-up was lower in the MBSR group than in the WLC group. Despite the fact that this study is the largest RCT that we have reviewd here, it also has several limitations. The control group did not receive any intervention, some subjects were randomized pair-wise, and baseline differences were present in perceived stress, depression and mindfulness.

Oken et al., (2010) investigated the effects of a mindfulness meditation intervention on older family dementia caregivers. Thirty-one participants with normal cognitive functioning (mean age $=64.55, S D=9.41$ ) and some stress were included in the study. Participants were randomized to either a mindfulness training, the Powerful Tools for Caregivers (PTC) education program (Services, 2006), or did not participate in any program but received the same amount of respite care as participants of the interventions. Both programs lasted for 7 weeks, consisted of weekly 90 minute sessions and involved daily homework. The mindfulness intervention was based on the Mindfulness Based Cognitive Therapy (MBCT) protocol (Segal, Williams, \& Teasdale, 2002) and comprised psycho-education, mindfulness practice, and group discussions. The PTC is based on the Chronic Disease Self-Management Program (Lorig \& Holman, 2003) and comprised of weekly lectures and the development of self-care tools by the participants. Before and after the intervention, a large number of measurements were taken, including the primary outcome measure caregiver perceived stress as evaluated with the reaction rating of the Revised Memory and Behavior Problems Checklist (RMBPC; Teri et al., 1992). Other measures included mood, fatigue, self-efficacy, mindfulness, cortisol, cytokines and of most interest for this review, cognitive function. Cognitive function was assessed with a 10word list learning task (Rosen, Mohs, \& Davis, 1984), Stroop Test (Perret, 1974), 
and a shortened Attention Network Test (ANT; Fan, McCandliss, Sommer, Raz, \& Posner, 2002), that included only cued/non-cued and congruent/incongruent conditions to calculate an alerting and executive control score. In addition, participants rated expectancy and intervention credibility. The researchers reported significantly lower caregiver perceived stress in the mindfulness and education group after the intervention than in the respite only group, while there were no differences between the mindfulness and education group. When correcting for multiple comparisons, there were no group differences on any of the secondary outcome measures at the post time-point. However when not correcting for multiple comparisons, group differences were significant on the Stroop Test and on the ANT alerting score (reaction time non cued-cued). The group difference in ANT alerting score was driven by higher scores in the meditation and education groups than in the respite only group. The comparison between the meditation and the education groups was not reported, nor any post-hoc test for the Stroop Test. While this pilot study had a rather small sample size, it had a solid design with an active comparison condition. A further strength of the study is the measurement of credibility and expectancy. This study suggests that mindfulness is superior to respite care in reducing caregiver perceived stress. However, the absence of a difference in perceived stress between the mindfulness and the active control condition suggests that stress reduction was not specific to the mindfulness intervention in this study. The fact that the effects of mindfulness and education on executive function and alerting attention did not survive when correcting for multiple comparisons might be due to the small sample size. Furthermore, it is not clear whether the effects were directly or indirectly, mediated by stress.

Sun et al., (2013) studied the effects of self-relaxation on quality of sleep and cognitive functions in older people with reduced quality of sleep (Pittsburg Sleep Quality Index, PSQI $>5$ ). Eighty Chinese community-dwelling older adults (mean age 69.69, SD 7.89 years) without mental illness that could potentially result in cognitive impairment, were randomized to either a self-relaxation intervention or a sleep hygiene education condition. The sleep hygiene education condition included only a brochure with descriptions / explanations of healthy and unhealthy sleep habits and the instruction to maintain healthy habits and avoid unhealthy ones. The self-relaxation condition on the other hand was comprised of a 12-month program of progressive muscle relaxation and guided imagery meditation. The 12-month program consisted of four group sessions of 90 minutes during the first month and 3x30 minutes daily home practice with audio tapes and weekly phone interviews for the remaining 11 months. Before the intervention, and at month 3, 6 and 12, sleep quality and cognitive functions were assessed. Sleep quality was assessed with the PSQI (Buysse, Reynolds III, Monk, Berman, \& Kupfer, 1989) and the Epworth Sleepiness Scale (Johns, 1994), and cognitive function was assessed with the MMSE (Folstein et al., 1975) and the number memory, picture memory, associative memory, and un- 
derstanding memory subtests of the Wechsler Memory Scale-Chinese Revised (Gong, 1989). The authors reported significant group by time interactions that were driven by decreased quality of sleep and cognitive function over time in the control group, but increases in the experimental group. These results suggest that the self-relaxation program can not only off-set the decline in sleep quality and cognition (that occurred in the control group during the year) but even enhance these. Unfortunately it is not clear if the positive effect on cognitive function was direct or indirect, mediated by improvements in sleep quality. Furthermore, it is not clear how much of the effectiveness of the self-relaxation intervention can be attributed to its meditation component.

Ernst et al., (2008) conducted a feasibility study to investigate the effects of a mindfulness-based stress reduction (MBSR; Kabat-Zinn, 1990) program on the quality of life of German nursing home residents. Fifteen of the 22 participants (median age 83.5) completed assessments before and after an 8-week modified MBSR program while seven controls did not participate in any intervention but completed assessments with an interval of 8 weeks. The modification of the original MBSR program included shortening of the weekly sessions to 90 minutes, simplification of physical practices, reduction of homework, and removal of the retreat day. Perprotocol analysis (only including the 9 completers and 7 controls), revealed significantly greater improvement in the experimental group than in the control group in physical health as measured with the Short-Form of the General Health Survey (SF-12; Gandek et al., 1998), depression as measured with the Geriatric Depression Scale Residential (GDS-12R; Sutcliffe et al., 2000), and in severity of major complaints. There were no differences in change between the groups regarding mental health as assessed with the SF-12 (Gandek et al., 1998), intensity of pain, satisfaction with life, activities of daily living as measured with the Barthel Index (Heuschmann et al., 2005; Mahoney \& Barthel, 1965), and cognition as measured with the MMSE (Folstein et al., 1975). Although the difference in MMSE change was not significant, there seemed to be no change (median pre 29, post 29) in the experimental group but a decline (median pre 27, post 24) in the control group. The study has several limitations, including a small sample size, no randomization, no active control intervention, a relatively high dropout rate of $40 \%$, and baseline differences between de groups in age and in nursing status.

Newberg et al., (2010) conducted a study to investigate the effects of Kirtan Kriya on cerebral blood flow and cognition in older participants (mean age 64, SD 8 years) with memory problems ranging from normal age related memory impairment $(n=7)$, to mild cognitive impairment (MCI, $n=5)$ to Alzheimer's disease $(A D, n=3)$. Participants underwent Single-photon emission computed tomography (SPECT) scans while listening to neutral information (baseline) or while doing a guided meditation before and after an 8 week meditation intervention. Before and after the intervention, participants' cognitive performance was assessed with the 
MMSE (Folstein et al., 1975), Category Fluency task (see Newberg et al., 2010), Trails A and B (Reitan, 1958), Digit Symbol Substitution Test (DSST) of the Wechsler Adult Intelligence Scale (WAIS; Wechsler, 1955), and a Logical Memory task (see Newberg et al., 2010). The meditation intervention consisted of daily practice of a 12 -minute guided Kirtan Kriya meditation for eight weeks. Five additional participants were recruited to participate in a music listening control intervention, but this group was not used for statistical comparisons with the Kirtan Kriya group and so we won't discuss it further. After the intervention participants had increased blood flow in frontal and parietal brain regions, specifically in right inferior-, bilateral superior frontal, right superior parietal, right sensorimotor, and the right dorsolateral prefrontal cortex (DLPFC) in a baseline scan. During the meditation scan there was a decreased blood flow in right DLPFC. In terms of cognitive performance, participants showed significant improvements on Trails B (Reitan, 1958), WAIS Symbol Substitution Test (Wechsler, 1955), Logical Memory Delayed (see Newberg et al., 2010) when not correcting results for multiple comparisons. With correction for multiple comparisons, there only was a significant improvement on the Category Fluency test. These findings suggest that an 8-week Kirtan Kriya intervention might improve cognitive function and increase cerebral blood flow in brain regions associated with cognitive functions in older adults with memory impairment. Unfortunately the study is lacking statistical comparison with a control group and it is not clear whether the improvements are driven by participants with normal age related memory problems or by those with MCI or AD.

Pagnoni et al., (2007) investigated the effects of age on gray matter volume and on sustained attention in 13 experienced Zen meditators and 13 controls that were matched for age, gender, and education. Participants were middle aged (meditators average 37.2, SD 6.9 years; controls average 35.5, SD 5.7 years). To determine gray matter volume, participants underwent structural MRI scanning. Furthermore they completed the Rapid Visual Information Processing (RVIP) task from the CANTAB battery (Sahakian \& Owen, 1992) to asses sustained attention capacity. This task involved rapid presentation of numbers on a screen and responding to specific target sequences. Performance was evaluated in terms of reaction time and A', a sensitivity index which indicates the ability to detect targets correctly while taking errors into account. The researchers reported a significant group $\times$ age interaction for reaction time which was driven by a significant decrease in performance (i.e. increase in reaction time) with age in the controls but not in the meditators. While the same pattern was found for A', the group $\times$ age interaction only showed a trend towards significance here. Similarly, a significant group $\times$ age interaction was reported for gray matter volume in the left putamen, which also was driven by decreases in controls and a borderline significant increase in meditators. For total gray matter volume group $\times$ age interaction and follow up tests followed the same pattern but only showed a trend to- 
wards significance. This study suggests an off-set in the decline in sustained attention and gray matter volume. However, as the authors acknowledge, the cross-sectional design and the small sample size are clear limitations.

Prakash et al. (2012) investigated cognitive performance in 20 older (mean age 59.45, SD 3.86) Vihangam Yoga meditators as compared to 20 age- (mean age 60.36, SD 4.51), gender- and education-matched controls. Vihangam Yoga meditation involves focusing attention on an external visual object. Meditators had an average meditation practice of 15.40 years (SD 1.18). They performed significantly better than controls on the Digit Span Forward Test, which is a measure of working memory (Wechsler, 1955), Trail making Test A, B and B-A (Reitan, 1958), Stroop Test color reading and color word interference (Stroop, 1992), Digit Symbol number correct, a measure of information processing speed (Wechsler, 1955), Letter Cancellation total and omission errors, measures of sustained attention (Dawson \& TannerCohen, 1997), and errors on the Rule Shift test, another measure of executive function. Groups did not differ on Digit Span backward, Stroop word reading, Digit Symbol errors, Letter Cancellation Commission errors, and time on the Rule Shift test. While a strength of the study is the well-matched sample, even including socioeconomic status (SES), the cross-sectional design and relatively small sample size are weaknesses. It is also not reported if and how correction for multiple comparisons was done, which is of particular importance with the large number of statistical tests performed here.

Van Leeuwen et al., (2009) investigated attentional blink in experienced meditators and non-meditators in a cross-sectional study. For this study 17 middle-aged (mean age 49.8, SD 5.0 years) meditators with 1-29 years of meditation experience, were compared to 17 age-, sex- and education-matched adults (mean age 50, SD 5.4 years) without meditation experience and 17 young adults (mean age 24.3, SD 2.3) without meditation experience. Thirteen of the meditators were trained in Shamatha and Vipassana, also referred to as focused attention and open monitoring (Lutz, Slagter, Dunne, \& Davidson, 2008), and three were trained in Zazen. In the attentional blink task letters are rapidly presented on a screen and in this stream of letters, two numbers were presented with a lag of 100 to $700 \mathrm{~ms}$ in increments of 100 (lag 1-7) between the numbers. The task was to correctly identify the first and the second number. The main outcome measure of this study was the proportion correctly identified second numbers. When considering all 7 lags, meditators outperformed age-matched controls while there was no difference between meditators and younger controls. On lag2 meditators even outperformed younger controls. The authors conclude that "the practice of meditation aids in overcoming age-related attentional deficits in the temporal domain"(van Leeuwen et al., 2009). While these results are impressive, an obvious limitation of the study that the authors also acknowledge is the cross-sectional design of it, which does not allow for causal inferences. 
Jedrczak, Toomey, and Clements (1986) studied nonverbal intelligence and perceptual motor speed in a group of TM practitioners who also practiced the TM Sidhi program, which is described as an extension of the TM program. This preliminary cross-sectional study did not include a control group, but was simply correlational. The Digit Symbol Substitution Test (DSST) and Picture Arrangement Test of the WAIS subscales (Wechsler, 1955) were employed to test nonverbal intelligence. Perceptual motor-speed was tested with the line crossing task (Botwinick \& Storandt, 1973), a reaction task to a visual stimulus, and the psychomotor speed variable of the Test of Behavioral Rigidity (Schaie \& Parham, 1975). The sample consisted of 87 participants who completed all five tests and 150 participants who completed only the three group administered tests (DSST, line crossing, and psychomotor speed). Participants were in the age range of 20 to 79 years (mean age 38.74 years) and had practiced TM Sidhi for a mean of 44.07 months and TM for 108.39 months (no standard deviations provided). Multiple regression analyses controlling for age, sex, education, motivation and TM practice time revealed that TM-Sidhi practice time significantly predicted nonverbal intelligence (both WAIS tests) as well as two of the tests for perceptual-motor speed, the line crossing and simple reaction time tests. Psychomotor speed was not predicted by TM-Sidhi meditation practice. Due to its strong methodological limitations, including the absence of a control group, the study has very limited relevance.

\section{DISCUSSION}

Here we reviewed twelve studies investigating the effects of meditation on age-related cognitive decline and cognition in middle aged and older adults.

\section{DIFFERENT TYPES OF MEDITATION}

The studies reviewed here employed a wide range of meditation techniques, ranging from mantra based meditations such as TM (Alexander et al., 1989), KKYM (Lavretsky et al., 2013; Newberg et al., 2010), meditations that involve focusing on a visual object (Prakash et al., 2012), to Buddhist based mindfulness practices including Shamata-Vipassana (van Leeuwen et al., 2009), Zen (Pagnoni \& Cekic, 2007) and non-secularized forms including MBCT (Oken et al., 2010), MBSR (Ernst et al., 2008; Moynihan et al., 2013), and others (McHugh et al., 2010).Two studies did not clearly describe what the meditation techniques they used involved (Jedrczak, 1986; Sun et al., 2013). Researchers that investigate different meditation traditions 
have not referenced each other's work much in the past. Relating findings from different techniques to one-another seems important though to better understand the exact mechanisms underlying their effects. The conference that lead to this volume was a positive example of bringing research on the different meditation traditions together. Six of the twelve reviewed studies utilized mindfulness meditation, which represents the largest category. Something that all of the reviewed meditation practice have in common is that they involve attention training.

\section{SUMMARY OF EVIDENCE}

With this common ground of focused attention it makes sense that there is overlap in outcome measures and results between the different studies. The authors used a variety of neuropsychological tests to investigate the effect of meditation on a range of cognitive domains, including attention, memory, executive function, and processing speed. The most commonly used tests were the Mini Mental State Examination (Ernst et al., 2008; Lavretsky et al., 2013; Newberg et al., 2010; Sun et al., 2013), the Trail Making Task (Lavretsky et al., 2013; Moynihan et al., 2013; Newberg et al., 2010; Prakash et al., 2012), the Stroop Test (Alexander, DeLong, \& Strick, 1986; Oken et al., 2010; Prakash et al., 2012), and Digit Symbol Substitution Test (Jedrczak, 1986; Newberg et al., 2010; Prakash et al., 2012). Although three of the reviewed studies also reported meditation related changes in brain structure (Pagnoni \& Cekic, 2007) and function (Moynihan et al., 2013; Newberg et al., 2010) that are consistent with the changes in cognition, we have restricted this review to the cognitive findings. Eileen Luders has previously reviewed the effects of meditation on the aging brain (Luders, 2014). In the future, it will be important to increasingly bring these areas together and to establish what neural changes underlie the effects of meditation on cognitive function. While a few studies have begun to investigate this relationship (Moynihan et al., 2013; Newberg et al., 2010; Pagnoni \& Cekic, 2007), it is still too early to come to clear conclusions.

While the here reviewed studies form the beginning of an emerging field at the intersection of meditation research and gerontology and provide a first orientation in this field, the results so far must be evaluated with caution. Only six of the twelve reviewed studies were RCT and even of these six studies only one study had more "low" risk of bias ratings than "unclear" or "high" (Oken et al., 2010, see Table 2). However, this study which was best evaluated in terms of risk of bias suffered from low precision due to the small sample size. The categorization of the results into general cognition, attention, executive function, memory, and processing speed in the following sections is not rigid, as not all tests fit clearly or exclusively into one category. 


\section{General cognition}

Two studies, one involving Kirtan Kriya Yoga Meditation and one involving selfrelaxation including guided visual imagery based meditation, revealed significant improvements in overall cognitive function (Lavretsky et al., 2013; Sun et al., 2013). However, three others, involving TM, KKYM, and MBSR did not find significant effects of meditation on overall cognitive function (Alexander et al., 1989; Ernst et al., 2008; Newberg et al., 2010). Both Newberg et al. (2010) and Lavretsky et al. (2013) studied the same intervention protocol for KKYM and used the same instrument (MMSE) to measure overall cognitive function. However Lavretsky et al. (2013) investigated individuals with mild depression but normal cognitive function, while Newberg et al. (2010) studied older adults with memory problems. These data may suggest that KKYM may be more useful for preserving normal functioning than for countering declines related to dementia.

\section{Attention}

The clearest significant finding in a more specific cognitive domain was improved attention related to mindfulness meditation (McHugh et al., 2010; Pagnoni \& Cekic, 2007; van Leeuwen et al., 2009). This conclusion is based on two cross-sectional studies (Pagnoni \& Cekic, 2007; van Leeuwen et al., 2009) and one study with a brief mindfulness induction (McHugh et al., 2010). A longitudinal study with a 7-week mindfulness intervention also found improvements in attention when compared to a passive control group, but not after correcting for multiple comparisons, or when compared to an active intervention (Oken et al., 2010). That older Vipassana meditators outperformed younger non-meditators on attention suggests that mindfulness meditation not only increases cognitive reserve or resilience but perhaps even enhances attentional capabilities (van Leeuwen et al., 2009). Significant improvements in attention were also reported for Vihangam Yoga meditation (Prakash et al., 2012).

\section{Executive function}

Executive function was significantly improved as the result of KKYM (Lavretsky et al., 2013), Vihangam Yoga Meditation (Prakash et al., 2012), and mindfulness (MBSR) (Moynihan et al., 2013). Other studies also reported positive effects of KKYM (Newberg et al., 2010), mindfulness (MBCT; Oken et al., 2010) and TM (Alexander et al., 1986) on executive functions. However, when correcting for multiple comparisons, these findings were no longer significant, or the correction was not reported.

\section{Memory}

One RCT suggested memory improvement as the result of a self-relaxation meditation program (Sun et al., 2013). A cross-sectional study showed that Vihangam Yoga 
Meditation practitioners performed better on Digit Span Forward but not Backward than matched controls (Prakash et al., 2012). This study also revealed unclear group differences on the DSST, which is thought to involve memory. Jedrczak et al. (1986) found a correlaton between TM-Sidhi practice and DSST performance, which may be related to the memory component of the test. KKYM (Newberg et al., 2010) also had positive effects on memory but not significantly after correcting for multiple comparisons. Alexander et al. (1989) reported significant effects of TM on memory and verbal fluency but did not report multiple comparison correction.

\section{Processing speed}

The DSST that involves memory also involves processing speed. Hence, the study of Prakash et al. (2012) involving Vihangam Yoga Meditation practitioners is also inconclusive regarding processing speed. The effects of KKYM (Newberg et al., 2010) on this task also might be related to processing speed but did not hold after correcting for multiple comparisons. Besides a positive relationship between TM-Sidhi practice and DSST performance Jedrczak et al. (1986) also reported a positive relation between practice and two of three measures of psychomotor speed.

\section{LIMITATIONS}

As mentioned before, the field of contemplative gerontology is in its infancy which is clearly reflected in the limitations of the reviewed studies. Only half of the studies were RCTs and even these studies had high risk of bias (Table 2). Most studies also had small sample sizes, resulting in imprecision. Furthermore, the large number of outcome variables and multiple control groups are problematic. In combination with the small sample sizes they resulted in underpowered studies that often did not reveal significant findings after correcting for multiple comparisons. Interestingly, the studies investigating mindfulness were mainly cross-sectional with only one or two outcome measures per study.

While the reviewed studies have investigated specific cognitive domains, the question remains how changes in these domains impact the real life of elderly. Therefore it might be of value to also have direct measures of quality of life and real life functioning or to measure the higher order cognitive variable of intelligence which has real life relevance (Deary, 2012; Gray \& Thompson, 2004). As it has been suggested that meditation might not only increase quality of life by reducing cognitive decline but by learning how to successfully cope with it (Petkus \& Wetherell, 2013), future studies might also want to explore that possibility.

Future studies will also need to elucidate potential mediators and moderators of improved cognition following meditation, e.g. reductions in stress, or depressive and anxiety symptoms. Depression is very common in old age (Luppa et al., 2012), 
and depressive symptoms have been linked to impaired cognitive performance (Reppermund et al., 2011). Through an increase in glucocorticoid levels, chronic stress and depression can significantly impact cognition by altering prefrontal, amygdaloidal, and hippocampal functioning (Lupien, Maheu, Tu, Fiocco, \& Schramek, 2007; Lupien et al., 1999). Meditation reliably reduces stress (Chiesa \& Serretti, 2009) and improves depressive and anxiety symptoms (Hofmann, Sawyer, Witt, \& Oh, 2010). We have found in adults that improvements in stress reduction and anxiety are associated with alterations of the structure and function of fronto-limbic regions (Hölzel et al., 2010; Hölzel et al., 2013). Future research should therefore investigate whether a reduction in stress and improvements in mental health serve as mediating variables for the impact of meditation on cognition in older adults, determine their relative impact as compared to direct training of attentional performance, and investigate as neural correlates stress hormone levels, brain volume and functioning. While some of the studies that were reviewed here have investigated changes in depression, stress, and other mental health variables in the elderly (Ernst et al., 2008; Lavretsky et al., 2013; Moynihan et al., 2013; Oken et al., 2010), it has not been established how such changes relate to cognitive improvements. It will be also important to more thoroughly differentiate between different types of meditation and their relative impact on these mediating as well as on outcome variables.

Furthermore, to really allow causal inference, future studies should employ longitudinal designs. Particularly RCTs with long-term follow-up measures are required to investigate if improvements in cognitive functions are lasting and how much they depend on continuous meditation practice.

An important conclusion that can be drawn from the published studies is that meditation interventions for the elderly are feasible. First of all, dropout rates were mostly low. Five of the seven reviewed intervention studies reported drop-out rates, which were 5\% (Moynihan et al., 2013), 9\% (Lavretsky et al., 2013), 20\% (Oken et al., 2010), 33.5\% (Alexander et al., 1989), and 40\% (Ernst et al., 2008). Secondly, compliance rates were exceptionally high. The four studies that reported them found intervention compliance rates of 75\% (Newberg et al., 2010), 88\% (Oken et al., 2010), 88\% (Ernst et al., 2008), and 98\% (attended more than 5 out of 8 classes; Moynihan et al., 2013). However, in one study it was noted that an AD patient with an MMSE of 16 was not able to properly perform the meditation, indicating that a certain level of cognitive function is required to practice meditation, at least KKYM (Newberg et al., 2010). This is not surprising as meditation relies on cognitive functions, and this limitation should be taken into consideration when designing future meditation based interventions for the elderly. 


\section{CONCLUSION}

This review of the literature on the effects of meditation on age related cognitive decline revealed that although this field is still young and small, the effects of a wide range of practices have been investigated. While most studies were small, underpowered pilot studies, they provide preliminary evidence that a variety of meditation techniques may be able to off-set age-related cognitive decline and perhaps even increase cognitive capabilities in older adults. Furthermore these studies show that it is feasible to effectively teach these techniques to the elderly. Future studies should continue to use rigorous RCT designs with active control groups, but with sufficiently large samples and long-term follow up measures. While the neuropsychological measures used so far should be good predictors of quality of life and real life functioning, more direct measures of these variables might help to investigate the true relevance of these interventions for the elderly. As a next step investigating the (neural) mechanisms of preservation and enhancement of cognition in aging through meditation is of great interest.

\section{ACKNOWLEDGEMENTS}

There was no dedicated funding for this review. While working on the review, S.W.L. was supported by R01AT006344 and R01AT006464, B.K.H. by the Kusala foundation, Germany, and T.G. by the Kripalu Center for Yoga and Health, and the Brach Family Charitable Foundation.

\section{CONFLICT OF INTEREST}

The authors declare no conflicts of interest. 


\section{REFERENCES}

Administration on Aging. (2012). A Profile of Older Americans. June 18. http://www.aoa.gov/ AoARoot/Aging_Statistics/Profile/2012/docs/2012profile.pdf

Alexander, C. N., Langer, E. J., Newman, R. I., Chandler, H. M., \& Davies, J. L. (1989). Transcendental meditation, mindfulness, and longevity: an experimental study with the elderly. Journal of Personality and Social Psychology, 57(6), 950-964. doi: 10.1037//00223514.57.6.950

Alexander, G. E., DeLong, M. R., \& Strick, P. L. (1986). Parallel organization of functionally segregated circuits linking basal ganglia and cortex. Annual Review of Neuroscience, 9(1), 357-381. doi: 10.1146/annurev.ne.09.030186.002041

Allen, M., Dietz, M., Blair, K. S., van Beek, M., Rees, G., Vestergaard-Poulsen, P., Lutz, A., \& Roepstorff, A. (2012). Cognitive-affective neural plasticity following active-controlled mindfulness intervention. The Journal of Neuroscience, 32(44), 15601-15610. doi: 10.1523/JNEUROSCI.2957-12.2012

Belleville, S., Clement, F., Mellah, S., Gilbert, B., Fontaine, F., \& Gauthier, S. (2011). Trainingrelated brain plasticity in subjects at risk of developing Alzheimer's disease. Brain, 134, 1623-1634. doi: 10.1093/brain/awr037

Botwinick, J., \& Storandt, M. (1973). Speed functions, vocabulary ability, and age. Perceptual and Motor Skills, 36(3), 1123-1128. doi: 10.2466/pms.1973.36.3c.1123

Brefczynski-Lewis, J. A., Lutz, A., Schaefer, H. S., Levinson, D. B., \& Davidson, R. J. (2007). Neural correlates of attentional expertise in long-term meditation practitioners. Proceedings of the National Academy of Sciences of the United States of America, 104(27), 11483-11488. doi: 10.1073/pnas.0606552104

Brown, B. M., Peiffer, J. J., \& Martins, R. N. (2013). Multiple effects of physical activity on molecular and cognitive signs of brain aging: can exercise slow neurodegeneration and delay Alzheimer's disease? Molecular Psychiatry, 18(8), 864-874. doi: 10.1038/ mp.2012.162

Brown, K. W., \& Ryan, R. M. (2003). The benefits of being present: mindfulness and its role in psychological well-being. Journal of Personality and Social Psychology, 84(4), 822-848. doi: 10.1037/0022-3514.84.4.822

Buysse, D. J., Reynolds III, C. F., Monk, T. H., Berman, S. R., \& Kupfer, D. J. (1989). The Pittsburgh Sleep Quality Index: a new instrument for psychiatric practice and research. Psychiatry research, 28(2), 193-213. doi: 10.1016/0165-1781(89)90047-4

Charles, S. T., \& Carstensen, L. L. (2010). Social and Emotional Aging. Annual Review of Psychology, 61(1), 383-409. doi: 10.1146/annurev.psych.093008.100448

Chiesa, A., \& Serretti, A. (2009). Mindfulness-based stress reduction for stress management in healthy people: a review and meta-analysis. The Journal of Alternative and Complementary Medicine, 15(5), 593-600. doi: 10.1089/acm.2008.0495 
Cohen, S., Kamarck, T., \& Mermelstein, R. (1983). A global measure of perceived stress. Journal of Health and Social Behavior, 24(4), 385-396. doi: 10.2307/2136404

Colcombe, S. J., Kramer, A. F., Erickson, K. I., Scalf, P., McAuley, E., Cohen, N. J., Webb, A., Jerome, G. J., Marquez, D. X., \& Elavsky, S. (2004). Cardiovascular fitness, cortical plasticity, and aging. Proceedings of the National Academy of Sciences of the United States of America, 101(9), 3316-3321. doi: 10.1073/pnas.0400266101

Cranson, R. W., Orme-Johnson, D. W., Gackenbach, J., Dillbeck, M. C., Jones, C. H., \& Alexander, C. N. (1991). Transcendental meditation and improved performance on intelligence-related measures: A longitudinal study. Personality and Individual Differences, 12(10), 1105-1116. doi: 10.1016/0191-8869(91)90040-i

Daviglus, M. L., Bell, C. C., Berrettini, W., Bowen, P. E., Connolly, J. E. S., Cox, N. J., DunbarJacob, J. M., Granieri, E. C., Hunt, G., McGarry, K., Patel, D., Potosky, A. L., SandersBush, E., Silberberg, D., \& Trevisan, M. (2010). National Institutes of Health Stateof-the-Science Conference Statement: preventing alzheimer disease and cognitive decline. Annals of Internal Medicine, 153(3), 176-181. doi: 10.7326/0003-4819-153-3201008030-00260

Dawson, D. R., \& TannerCohen, C. (1997). Visual scanning patterns in an adult Chinese population: Preliminary normative data. Occupational Therapy Journal of Research, 17(4), 264-279.

Deary, I. J. (2012). Intelligence. Annual Review of Psychology, 63, 453-482. doi: 10.1146/annurev-psych-120710-100353

Deary, I. J., Corley, J., Gow, A. J., Harris, S. E., Houlihan, L. M., Marioni, R. E., Penke, L., Rafnsson, S. B., \& Starr, J. M. (2009). Age-associated cognitive decline. British Medical Bulletin, 92(1), 135-152. doi: 10.1093/bmb/ldp033

Ernst, S., Welke, J., Heintze, C., Gabriel, R., Zollner, A., Kiehne, S., Schwantes, U., \& Esch, T. (2008). Effects of mindfulness-based stress reduction on quality of life in nursing home residents: a feasibility study. Forschende Komplementarmedizin, 15(2), 74-81. doi: 10.1159/000121479

Fan, J., McCandliss, B. D., Sommer, T., Raz, A., \& Posner, M. I. (2002). Testing the efficiency and independence of attentional networks. Journal of cognitive neuroscience, 14(3), 340-347. doi: 10.1162/089892902317361886

Farmer, M. E., White, L. R., Kittner, S. J., Kaplan, E., Moes, E., McNamara, P., Wolz, M. M., Wolf, P. A., \& Feinleib, M. (1987). Neuropsychological test performance in Framingham: a descriptive study. Psychological Reports, 60(3), 1023-1040. doi: 10.2466/ pr0.1987.60.3c.1023

Folstein, M. F., Folstein, S. E., \& McHugh, P. R. (1975). Mini-Mental State: a practical method for grading the cognitive state of patients for the clinician. Journal of Psychiatric Research, 12(3), 189-198. doi: 10.1016/0022-3956(75)90026-6

Fotuhi, M., Do, D., \& Jack, C. (2012). Modifiable factors that alter the size of the hippocampus with ageing. Nature Reviews Neurology, 8(4), 189-202. doi: 10.1038/nrneurol.2012.27 
Gandek, B., Ware, J. E., Aaronson, N. K., Apolone, G., Bjorner, J. B., Brazier, J. E., Bullinger, M., Kaasa, S., Leplege, A., Prieto, L., \& Sullivan, M. (1998). Cross-validation of item selection and scoring for the SF-12 Health Survey in nine countries: results from the IQOLA Project. Journal of Clinical Epidemiology, 51(11), 1171-1178. doi: 10.1016/ S0895-4356(98)00109-7

Gard, T., Brach, N., Hölzel, B. K., Noggle, J. J., Conboy, L. A., \& Lazar, S. W. (2012). Effects of a yoga-based intervention for young adults on quality of life and perceived stress: The potential mediating roles of mindfulness and self-compassion. The Journal of Positive Psychology, 7(3), 165-175. doi: 10.1080/17439760.2012.667144

Gard, T., Hölzel, B. K., Sack, A. T., Hempel, H., Lazar, S. W., Vaitl, D., \& Ott, U. (2012). Pain attenuation through mindfulness is associated with decreased cognitive control and increased sensory processing in the brain. Cerebral Cortex, 22(11), 2692-2702. doi: 10.1093/cercor/bhr352

Gong, Y. (1989). Handbook of Wechsler Memory Scale-Revised. Changsha, China: Hunan Medical College.

Gray, J. R., \& Thompson, P. M. (2004). Neurobiology of intelligence: science and ethics. Nature Reviews Neuroscience, 5, 471-482. doi: 10.1038/nrn1405

Hamilton, M. (1960). A rating scale for depression. Journal of neurology, neurosurgery, and psychiatry, 23(1), 56-62. doi: 10.1136/jnnp.23.1.56

Heuschmann, P., Kolominsky-Rabas, P., Nolte, C., Hünermund, G., Ruf, H.-U., Laumeier, I., Meyrer, R., Alberti, T., Rahmann, A., \& Kurth, T. (2005). Untersuchung der Reliabilität der deutschen Version des Barthel-Index sowie Entwicklung einer postalischen und telefonischen Fassung für den Einsatz bei Schlaganfall-Patienten. Fortschritte der Neurologie Psychiatrie, 73(02), 74-82.

Higgins, J. P., Altman, D. G., Gotzsche, P. C., Juni, P., Moher, D., Oxman, A. D., Savovic, J., Schulz, K. F., Weeks, L., Sterne, J. A., Cochrane Bias Methods, G., \& Cochrane Statistical Methods, G. (2011). The Cochrane Collaboration's tool for assessing risk of bias in randomised trials. British Medical Journal, 343, d5928. doi: 10.1136/bmj.d5928

Hofmann, S. G., Sawyer, A. T., Witt, A. A., \& Oh, D. (2010). The effect of mindfulness-based therapy on anxiety and depression: A meta-analytic review. Journal of Consulting and Clinical Psychology, 78(2), 169-183. doi: 10.1037/a0018555

Hölzel, B. K., Carmody, J., Evans, K. C., Hoge, E. A., Dusek, J. A., Morgan, L., Pitman, R. K., \& Lazar, S. W. (2010). Stress reduction correlates with structural changes in the amygdala. Social Cognitive and Affective Neuroscience, 5(1), 11-17. doi: 10.1093/scan/ nsp034

Hölzel, B. K., Carmody, J., Vangel, M., Congleton, C., Yerramsetti, S. M., Gard, T., \& Lazar, S. W. (2011). Mindfulness practice leads to increases in regional brain gray matter density. Psychiatry Research: Neuroimaging, 191(1), 36-43. doi: 10.1016/j. pscychresns.2010.08.006 
Hölzel, B. K., Hoge, E. A., Greve, D. N., Gard, T., Creswell, J. D., Brown, K. W., Barrett, L. F., Schwartz, C., Vaitl, D., \& Lazar, S. W. (2013). Neural mechanisms of symptom improvements in generalized anxiety disorder following mindfulness training. NeuroImage: Clinical, 2(0), 448-458. doi: 10.1016/j.nicl.2013.03.011

Hölzel, B. K., Ott, U., Hempel, H., Hackl, A., Wolf, K., Stark, R., \& Vaitl, D. (2007). Differential engagement of anterior cingulate and adjacent medial frontal cortex in adept meditators and non-meditators. Neuroscience Letters, 421(1), 16-21. doi: 10.1016/j. neulet.2007.04.074

Jedrczak, A., Toomey M, Clements, G. (1986). The TM-Sidhi Program, age, and brief tests of perceptual-motor speed and nonverbal intelligence. Journal of Clinical Psychology, 42(1), 161-164. doi: 10.1002/1097-4679(198601)42:1\%3C161::AIDJCLP2270420127\%3E3.0.CO;2-W

Jha, A. P., Krompinger, J., \& Baime, M. J. (2007). Mindfulness training modifies subsystems of attention. Cognitive, Affective, \& Behavioral Neuroscience, 7(2), 109-119. doi: 10.3758/ CABN.7.2.109

Jha, A. P., Stanley, E. A., Kiyonaga, A., Wong, L., \& Gelfand, L. (2010). Examining the protective effects of mindfulness training on working memory capacity and affective experience. Emotion, 10(1), 54-64. doi: 10.1037/a0018438

Johns, M. W. (1994). Sleepiness in different situations measured by the Epworth Sleepiness Scale. Sleep, 17(8), 703-710.

Kabat-Zinn, J. (1990). Full Catastrophe Living. New York, NY: Delta Publishing.

Kramer, A. F., \& Erickson, K. I. (2007). Capitalizing on cortical plasticity: Influence of physical activity on cognition and brain function. Trends in Cognitive Sciences, 11(8), 342-348. doi: 10.1016/j.tics.2007.06.009

Langer, E. J. (1992). Matters of mind: Mindfulness/mindlessness in perspective. Consciousness and Cognition, 1(3), 289-305. doi: 10.1016/1053-8100(92)90066-J

Langer, E. J., \& Moldoveanu, M. (2000). The construct of mindfulness. Journal of Social Issues, 56(1), 1-9. doi: 10.1111/0022-4537.00148

Lavretsky, H., Epel, E. S., Siddarth, P., Nazarian, N., St Cyr, N., Khalsa, D. S., Lin, J., Blackburn, E., \& Irwin, M. R. (2013). A pilot study of yogic meditation for family dementia caregivers with depressive symptoms: effects on mental health, cognition, and telomerase activity. International Journal of Geriatric Psychiatry, 28(1), 57-65. doi: 10.1002/ gps.3790

Lazar, S. W., Kerr, C. E., Wasserman, R. H., Gray, J. R., Greve, D. N., Treadway, M. T., McGarvey, M., Quinn, B. T., Dusek, J. A., Benson, H., Rauch, S. L., Moore, C. I., \& Fischl, B. (2005). Meditation experience is associated with increased cortical thickness. Neuroreport, 16(17), 1893-1897. doi: 10.1097/01.wnr.0000186598.66243.19

Lewinsohn, P. M., Seeley, J. R., Roberts, R. E., \& Allen, N. B. (1997). Center for Epidemiologic Studies Depression Scale (CES-D) as a screening instrument for depression 
among community-residing older adults. Psychology and aging, 12(2), 277-287. doi: 10.1037//0882-7974.12.2.277

Lorig, K. R., \& Holman, H. R. (2003). Self-management education: history, definition, outcomes, and mechanisms. Annals of Behavioral Medicine, 26(1), 1-7. doi: 10.1207/ S15324796ABM2601_01

Luders, E. (2014). Exploring age-related brain degeneration in meditation practitioners. Annals of the New York Academy of Sciences, 1307(1), 82-88. doi: 10.1111/nyas.12217

Lupien, S. J., Maheu, F., Tu, M., Fiocco, A., \& Schramek, T. E. (2007). The effects of stress and stress hormones on human cognition: Implications for the field of brain and cognition. Brain and Cognition, 65(3), 209-237. doi: 10.1016/j.bandc.2007.02.007

Lupien, S. J., Nair, N. P. V., Briere, S., Maheu, F., Tu, M. T., Lemay, M., McEwen, B. S., \& Meaney, M. J. (1999). Increased cortisol levels and impaired cognition in human aging: implication for depression and dementia in later life. Reviews in the Neurosciences, 10(2), 117-140. doi: 10.1515/REVNEURO.1999.10.2.117

Luppa, M., Sikorski, C., Luck, T., Ehreke, L., Konnopka, A., Wiese, B., Weyerer, S., Koenig, H. H., \& Riedel-Heller, S. G. (2012). Age- and gender-specific prevalence of depression in latest-life -- systematic review and meta-analysis. Journal of Affective Disorders, 136(3), 212-221. doi: 10.1016/j.jad.2010.11.033

Lutz, A., Slagter, H. A., Dunne, J. D., \& Davidson, R. J. (2008). Attention regulation and monitoring in meditation. Trends in Cognitive Sciences, 12(4), 163-169. doi: 10.1016/j. tics.2008.01.005

Mahoney, F. I., \& Barthel, D. W. (1965). Functional Evaluation: The Barthel Index. Maryland state medical journal, 14, 61-65.

Mather, M., \& Carstensen, L. L. (2005). Aging and motivated cognition: the positivity effect in attention and memory. Trends in Cognitive Sciences, 9(10), 496-502. doi: 10.1016/j. tics.2005.08.005

McHugh, L., \& Reed, P. (2007). Age trends in stimulus overselectivity. Journal of the Experimental Analysis of Behavior, 88(3), 369-380. doi: 10.1901/jeab.2007.88-369

McHugh, L., Simpson, A., \& Reed, P. (2010). Mindfulness as a potential intervention for stimulus over-selectivity in older adults. Research in Developmental Disabilities, 31(1), 178184. doi: 10.1016/j.ridd.2009.08.009

Moher, D., Liberati, A., Tetzlaff, J., Altman, D. G., \& The, P. G. (2009). Preferred Reporting Items for Systematic Reviews and Meta-Analyses: The PRISMA Statement. PLoS Med, 6(7), e1000097. doi: 10.1371/journal.pmed.1000097

Morrison, J. H., \& Hof, P. R. (1997). Life and death of neurons in the aging brain. Science, 278(5337), 412-419. doi: 10.1126/science.278.5337.412

Moynihan, J. A., Chapman, B. P., Klorman, R., Krasner, M. S., Duberstein, P. R., Brown, K. W., \& Talbot, N. L. (2013). Mindfulness-based stress reduction for older adults: effects on executive function, frontal alpha asymmetry and immune function. Neuropsychobiology, 68(1), 34-43. doi: 10.1159/000350949 
Newberg, A. B., Wintering, N., Khalsa, D. S., Roggenkamp, H., \& Waldman, M. R. (2010). Meditation effects on cognitive function and cerebral blood flow in subjects with memory loss: a preliminary study. Journal of Alzheimer's Disease, 20(2), 517-526. doi: 10.3233/JAD-2010-1391

Nyberg, L., Sandblom, J., Jones, S., Neely, A. S., Petersson, K. M., Ingvar, M., \& Backman, L. (2003). Neural correlates of training-related memory improvement in adulthood and aging. Proceedings of the National Academy of Sciences of the United States of America, 100(23), 13728-13733. doi: 10.1073/pnas.1735487100

Oken, B. S., Fonareva, I., Haas, M., Wahbeh, H., Lane, J. B., Zajdel, D., \& Amen, A. (2010). Pilot controlled trial of mindfulness meditation and education for dementia caregivers. The Journal of Alternative and Complementary Medicine, 16(10), 1031-1038. doi: 10.1089/ acm.2009.0733

Pagnoni, G. (2012). Dynamical properties of BOLD activity from the ventral posteromedial cortex associated with meditation and attentional skills. The Journal of Neuroscience, 32(15), 5242-5249. doi: 10.1523/JNEUROSCI.4135-11.2012

Pagnoni, G., \& Cekic, M. (2007). Age effects on gray matter volume and attentional performance in Zen meditation. Neurobiology of Aging, 28(10), 1623-1627. doi: 10.1016/j. neurobiolaging.2007.06.008

Perret, E. (1974). The left frontal lobe of man and the suppression of habitual responses in verbal categorical behaviour. Neuropsychologia, 12(3), 323-330. doi: 10.1016/00283932(74)90047-5

Persson, J., Nyberg, L., Lind, J., Larsson, A., Nilsson, L. G., Ingvar, M., \& Buckner, R. L. (2006). Structure-function correlates of cognitive decline in aging. Cerebral Cortex, 16(7), 907-915. doi: 10.1093/cercor/bhj036

Petkus, A. J., \& Wetherell, J. L. (2013). Acceptance and Commitment Therapy With Older Adults: Rationale and Considerations. Cognitive and Behavioral Practice, 20(1), 47-56. doi: 10.1016/j.cbpra.2011.07.004

Plassman, B. L., Williams, J. W., Burke, J. R., Holsinger, T., \& Benjamin, S. (2010). Systematic review: factors associated with risk for and possible prevention of cognitive decline in later life. Annals of Internal Medicine, 153(3), 182-193. doi: 10.7326/0003-4819-153-3201008030-00258

Prakash, R., Rastogi, P., Dubey, I., Abhishek, P., Chaudhury, S., \& Small, B. J. (2012). Longterm concentrative meditation and cognitive performance among older adults. Aging Neuropsychology and Cognition, 19(4), 479-494. doi: 10.1080/13825585.2011.630932

Reitan, R. M. (1958). Validity of the Trail Making Test as an Indicator of Organic Brain Damage. Perceptual and Motor Skills, 8(3), 271-276. doi: 10.2466/pms.1958.8.3.271

Reppermund, S., Brodaty, H., Crawford, J. D., Kochan, N. A., Slavin, M. J., Trollor, J. N., Draper, B., \& Sachdev, P. S. (2011). The relationship of current depressive symptoms and past depression with cognitive impairment and instrumental activities of daily living 
in an elderly population: the Sydney Memory and Ageing Study. Journal of Psychiatric Research, 45(12), 1600-1607. doi: 10.1016/j.jpsychires.2011.08.001

Rosen, W. G., Mohs, R. C., \& Davis, K. L. (1984). A new rating scale for Alzheimer's disease. The American journal of psychiatry, 141(11), 1356-1364.

Sahakian, B., \& Owen, A. (1992). Computerized assessment in neuropsychiatry using CANTAB: discussion paper. Journal of the Royal Society of Medicine, 85(7), 399.

Salat, D. H., Buckner, R. L., Snyder, A. Z., Greve, D. N., Desikan, R. S., Busa, E., Morris, J. C., Dale, A. M., \& Fischl, B. (2004). Thinning of the cerebral cortex in aging. Cerebral Cortex, 14(7), 721-730. doi: 10.1093/cercor/bhh032

Salthouse, T. A. (2004). Localizing age-related individual differences in a hierarchical structure. Intelligence, 32(6), 541-561. doi: 10.1016/j.intell.2004.07.003

Salthouse, T. A. (2009a). Decomposing age correlations on neuropsychological and cognitive variables. Journal of the International Neuropsychological Society, 15(5), 650-661. doi: $10.1017 /$ S1355617709990385

Salthouse, T. A. (2009b). When does age-related cognitive decline begin? Neurobiology of Aging, 30(4), 507-514. doi: 10.1016/j.neurobiolaging.2008.09.023

Schaie, K. W., \& Parham, I. (1975). Manual for the test of behavioral rigidity. 2nd revised edition), Consulting Psychologists Press, Palo Alto, CA.

Scheibe, S., \& Carstensen, L. L. (2010). Emotional aging: recent findings and future trends. The Journals of Gerontology Series B: Psychological Sciences and Social Sciences, 65(2), 135144. doi: 10.1093/geronb/gbp132

Segal, Z. V., Williams, J. M. G., \& Teasdale, J. D. (2002). Mindfulness-based cognitive therapy for depression: A new approach to preventing relapse. New York, NY: The Guilford Press.

Services, L. (2006). The Caregiver Helpbook: Powerful Tools for Caregivers. Portland, OR: Legacy Health Systems.

Stroop, J. R. (1992). Studies of interference in serial verbal reactions. Journal of Experimental Psychology, 121(1), 15-23. doi: 10.1037/0096-3445.121.1.15

Sun, J., Kang, J., Wang, P., \& Zeng, H. (2013). Self-relaxation training can improve sleep quality and cognitive functions in the older: a one-year randomised controlled trial. Journal of clinical nursing, 22(9-10), 1270-1280. doi: 10.1111/jocn.12096

Sutcliffe, C., Cordingley, L., Burns, A., Mozley, C. G., Bagley, H., Huxley, P., \& Challis, D. (2000). A new version of the geriatric depression scale for nursing and residential home populations: the geriatric depression scale (residential) (GDS-12R). International Psychogeriatrics, 12(02), 173-181. doi: 10.1017/S104161020000630X

Tang, Y. Y., Ma, Y. H., Wang, J., Fan, Y. X., Feng, S. G., Lu, Q. L., Yu, Q. B., Sui, D., Rothbart, M. K., Fan, M., \& Posner, M. I. (2007). Short-term meditation training improves attention and self-regulation. Proceedings of the National Academy of Sciences of the United States of America, 104(43), 17152-17156. doi: 10.1073/pnas.0707678104 
Teri, L., Truax, P., Logsdon, R., Uomoto, J., Zarit, S., \& Vitaliano, P. P. (1992). Assessment of behavioral problems in dementia: the revised memory and behavior problems checklist. Psychology and aging, 7(4), 622-631. doi: 10.1037//0882-7974.7.4.622

Tucker-Drob, E. M. (2011). Global and domain-specific changes in cognition throughout adulthood. Developmental Psychology, 47(2), 331-343. doi: 10.1037/a0021361

United Nations. (2002). World population ageing, 1950-2050. New York, NY: United Nations

van Leeuwen, S., Müller, N. G., \& Melloni, L. (2009). Age effects on attentional blink performance in meditation. Consciousness and Cognition, 18(3), 593-599. doi: 10.1016/j. concog.2009.05.001

Ware Jr, J. E., \& Sherbourne, C. D. (1992). The MOS 36-item short-form health survey (SF-36):

I. Conceptual framework and item selection. Medical Care, 473-483.

Wechsler, D. (1955). Manual for the Wechsler Adult Intelligence Scale.

Willis, S. L., Tennstedt, S. L., Marsiske, M., Ball, K., Elias, J., Koepke, K. M., Morris, J. N., Rebok, G. W., Unverzagt, F. W., Stoddard, A. M., \& Wright, E. (2006). Long-term effects of cognitive training on everyday functional outcomes in older adults. Journal of the American Medical Association, 296(23), 2805-2814. doi: 10.1001/jama.296.23.2805

Wilson, R. S., Beckett, L. A., Bennett, D. A., Albert, M. S., \& Evans, D. A. (1999). Change in cognitive function in older persons from a community population: relation to age and Alzheimer disease. Archives of Neurology, 56(10), 1274-1279. doi: 10.1001/archneur.56.10.1274

Yogi, M. M. (1969). On the Bhagavad-Gita: A new translation and commentary. Harmondswortb, United Kingdom: Penguin Books.

Zeidan, F., Johnson, S. K., Diamond, B. J., David, Z., \& Goolkasian, P. (2010). Mindfulness meditation improves cognition: evidence of brief mental training. Consciousness and Cognition, 19(2), 597-605. doi: 10.1016/j.concog.2010.03.014 


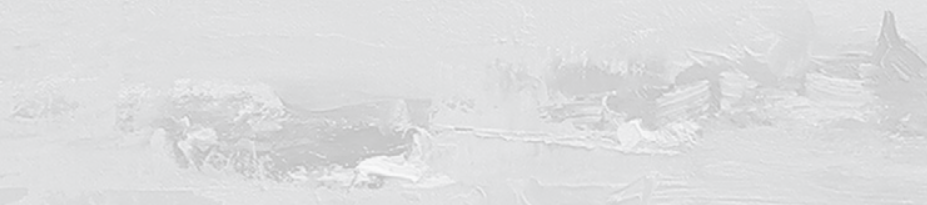


ChAPTER 5

NEURAL AND PSYCHOLOGICAL MECHANISMS OF OFFSET AGE-RELATED DECLINE IN FLUID INTELLIGENCE IN YOGIS AND MEDITATORS

Based on: Gard, T., Taquet, M., Dixit, R., Hoelzel, B. K., de Montjoye, Y.-A., Brach, N.,

Salat, D., Dickerson, B. C., Gray, J. R., \& Lazar, S. (2014). Fluid intelligence and brain functional organization in aging yoga and meditation practitioners. Frontiers in Aging Neuroscience, 6, 76. doi: 10.3389/fnagi.2014.00076 


\section{AbStract}

Numerous studies have documented the normal age-related decline of neural structure, function, and cognitive performance. Preliminary evidence suggests that meditation may reduce decline in specific cognitive domains and in brain structure. Here we extended this research by investigating the relation between age and fluid intelligence and resting state brain functional network architecture using graph theory, in middle-aged yoga and meditation practitioners, and matched controls. Fluid intelligence declined slower in yoga practitioners and meditators combined than in controls. Resting state functional networks of yoga practitioners and meditators combined were more integrated and more resilient to damage than those of controls. Furthermore, mindfulness was positively correlated with fluid intelligence, resilience, and global network efficiency. These findings reveal the possibility to increase resilience and to slow the decline of fluid intelligence and brain functional architecture and suggest that mindfulness plays a mechanistic role in this preservation. 


\section{INTRODUCTION}

Neural structure, function, and cognitive performance naturally decline as individuals age (de Chastelaine, Wang, Minton, Muftuler, \& Rugg, 2011; Morrison \& Hof, 1997; Persson et al., 2006; Salat et al., 2004). However, research suggests that a variety of cognitive training programs (Anguera et al., 2013; Belleville et al., 2011; Nyberg et al., 2003; Willis et al., 2006) and aerobic exercise (Colcombe et al., 2004; Holzschneider, Wolbers, Roeder, \& Hoetting, 2012) can improve cognitive performance and associated brain function in older adults. This suggests that older adults can still undergo beneficial neuroplastic changes through changes in behavior. Besides specific cognitive abilities, even the higher level construct of fluid intelligence, i.e., the set of abilities involved in coping with novel environments and abstract reasoning (Sternberg, 2008), has recently been shown to be trainable through working memory training (Jaeggi, Buschkuehl, Jonides, \& Perrig, 2008), and related to changes in brain function (Jausovec \& Jausovec, 2012). However, generalizability of working memory training is not unequivocal (Melby-Lervag \& Hulme, 2013) and so far training-induced improvements in fluid intelligence and associated brain function have been demonstrated only in young people. Their effects on older individuals remain to be investigated.

There is growing evidence that meditation could potentially reduce age-related decline in cognition and brain function (for a review see Gard, Hölzel, \& Lazar, 2014). For example, older meditators have been shown to outperform age-matched participants on an attentional blink task (van Leeuwen, Müller, \& Melloni, 2009) and on tasks assessing attention, short-term memory, perceptual speed, and executive functioning (Prakash et al., 2012). Pagnoni and Cekic (2007) reported that the typical negative correlation between age and sustained attention was not present in Zen meditators. At the neural level, two studies found negative correlations between age and gray matter volume in controls, but not in age-matched meditation practitioners (Lazar et al., 2005; Pagnoni \& Cekic, 2007). Another study found a less prominent age-related decline in fractional anisotropy in multiple white matter tracts in meditators compared to controls (Luders, Clark, Narr, \& Toga, 2011). These findings suggest that meditation practice may be able to reduce normal age-related cognitive decline and neuro-degeneration. However, a limitation of these studies is that, although groups were matched for sex, age, and education, other important factors including exercise and cognitive engagement (Fotuhi, Do, \& Jack, 2012; Kramer \& Erickson, 2007; Plassman, Williams, Burke, Holsinger, \& Benjamin, 2010; Wilson, Segawa, Boyle, \& Bennett, 2012) were not controlled for. Furthermore, these studies focused on specific cognitive functions, mostly attention, as opposed to higher level constructs such as fluid intelligence, which could have broader implications due to its high predictive value of real life behavior (Deary, 2012; Gray \& Thompson, 2004). 
There is growing evidence that yoga can also enhance cognition (Chattha, Nagarathna, Padmalatha, \& Nagendra, 2008; Kyizom, Singh, Singh, Tandon, \& Kumar, 2010; Rocha et al., 2012; Subramanya \& Telles, 2009) and brain function (Streeter et al., 2010) in younger adults. With only one publication, the literature regarding the effects of yoga on cognition in older people is sparse and equivocal (Oken et al., 2006). The various yoga and meditation traditions share some similarities, but differ in practices as well as theoretical orientation (Goleman, 1996). Few scientific studies have directly compared practitioners of different traditions to determine similarities and differences in either the benefits or mechanisms underlying improved cognition or health.

To investigate the impact of yoga and meditation practices on brain function, we have employed graph theoretical methods to assess group differences in resting state brain connectivity. These graph methods have been successfully used to reveal a negative relation between age and network integration (Achard \& Bullmore, 2007), and a positive one between fluid intelligence and both network integration and segregation (Langer et al., 2012; van den Heuvel, Stam, Kahn, \& Hulshoff Pol, 2009). However, the effects of training on functional brain network architecture have not yet been studied in the context of aging.

Graph-based analysis also provides novel ways to simulate the effect of agingrelated brain damage, and the brain's resilience to this damage (Achard, Salvador, Whitcher, Suckling, \& Bullmore, 2006). Resilience analysis has been used to simulate neuronal death (Rubinov, McIntosh, Valenzuela, \& Breakspear, 2009), and it has been speculated that the dynamic impact of brain lesions is related to cognition and behavior (Alstott, Breakspear, Hagmann, Cammoun, \& Sporns, 2009). While structural brain networks of Alzheimer's patients have been shown to be less resilient against targeted attacks than networks of healthy controls (He, Chen, \& Evans, 2008), network resilience has not yet been assessed in populations that display above average cognitive function at older age.

Here we used graph theoretical methods to investigate the effect of age on resting state functional brain connectivity and fluid intelligence in yoga and meditation practitioners, and in controls. The three groups were demographically well matched and we controlled for variables that might influence age-related decline. We hypothesized that yoga and meditation practitioners would be less subject to age-related declines in fluid intelligence and the resting state network properties of small-worldness and integration. No age-related decline in network segregation was expected in any of the groups (Meunier, Achard, Morcom, \& Bullmore, 2009). Furthermore, we investigated differences in the resilience of brain functional networks between the three groups. Finally, we assessed the relationship between mindfulness, fluid intelligence and resting state network resilience and integration. 


\section{METHODS}

\section{PARTICIPANTS}

Forty-seven participants, 16 yoga practitioners, 16 meditation practitioners, and 15 controls were recruited. Groups were matched for age, gender, education, race, and handedness. All participants self-reported being physically and mentally healthy. Individuals with current or past neurological conditions and individuals taking any medication for psychiatric or neurological conditions were excluded. Participants were also free of dementia as assessed with the Mini-Mental State Examination (Folstein, Folstein, \& McHugh, 1975). Yoga practitioners were trained in the Kripalu Yoga tradition (Faulds, 2005) and had an average of 13,534 ( $S D=9,950)$ hours of yoga experience. Meditators were trained in insight meditation (Goldstein \& Kornfield, 2001) and had an average of 7,458 $(S D=5,734)$ hours of meditation experience. Controls had no experience with yoga or meditation. Participants were compensated with $\$ 100$ and provided written informed consent. The study was approved by the Partners Human Research Committee, Massachusetts General Hospital (protocol 2005P001392).

\section{BEHAVIORAL MEASURES}

Fluid intelligence, comprising a variety of cognitive skills, was measured with the odd items of the Raven's Advanced Progressive Matrices (APM) (Raven, 2000; Raven, Raven, \& Court, 1998). Verbal intelligence, which is a form of crystallized intelligence (Deary, Penke, \& Johnson, 2010), was assessed with the American version of the National Adult Reading Test (AMNART; Grober \& Sliwinski, 1991), cognitive functioning was assessed with the Mini-Mental State Examination (Folstein et al., 1975), and mindfulness with the Five Facet Mindfulness Questionnaire (FFMQ; Baer, Smith, Hopkins, Krietemeyer, \& Toney, 2006). To simplify analyses the sum score of the 5 subscales has been used, following the example of Carmody and Bear (2008). Furthermore, it was recorded for how many hours per week participants engaged in physical exercise, and cognitive activities including reading, writing, solving puzzles, and playing board and card games.

\section{IMAGE ACQUISITION}

Imaging data was collected on a Siemens 1.5 Tesla Avanto MRI scanner (Erlagen, Germany) at the Martinos Center for Biomedical Imaging. Structural images were acquired using a T1-weighted magnetization prepared rapid acquisition gradient 
echo (MPRAGE) sequence (128 sagittal slices, slice thickness $=1.33 \mathrm{~mm}, \mathrm{TR}=2.73 \mathrm{~s}$, $\mathrm{TE}=3.39 \mathrm{~ms}$, flip angle $=7^{\circ}$, field of view $=256 \times 256 \mathrm{~mm}^{2}$, matrix $=192 \times 192 \mathrm{~mm}^{2}$ ). A 5 minute functional resting state scan was acquired using a gradient echo $\mathrm{T} 2{ }^{*}$ weighted sequence $\left(\mathrm{TR}=2.5 \mathrm{~s}, \mathrm{TE}=40 \mathrm{~ms}\right.$, flip angle $=90^{\circ}$, field of view $=320 \mathrm{~mm}$, matrix $\left.=64^{\prime} 64 \mathrm{~mm}^{2}\right)$. Twenty two horizontal slices with $1 \mathrm{~mm}$ gap, parallel to the inter-commissural plane (voxel size: $3.13 \times 3.13^{\prime} 5 \mathrm{~mm}^{3}$ ) were acquired inter-leaved.

\section{PROCEDURE AND ANALYSIS}

Though it is expected that fluid intelligence declines with age, the model of this decline is not known a priori. A simple linear regression model would predict that fluid intelligence reaches negative values after a certain age, which is not consistent with the positive Raven's score. We therefore investigated different regression models which can be summarized by the general relation

$$
\mathrm{f}(F)=A \times \mathrm{g}(\text { age })+B
$$

in which $F$ is fluid intelligence measured by the Raven's score and $\mathrm{f}$ and $\mathrm{g}$ are two functions (equation 1). We limited the analysis to $\mathrm{f}$ and $\mathrm{g}$ being either the identity, the logarithm or the inverse. These functions bring flexibility in the scale and proportionality of the relation between age and intelligence. Furthermore, they are all strictly increasing or decreasing functions, which is necessary to interpret A and B in terms of a decline. To select which of these models best represent the data, a model selection based on the Akaike information criterion (AIC) was carried out in the control group, the same way Dosenbach et al. (2010) selected their model of brain maturity. The parameter $\mathrm{A}$ of the regression indicates the rate at which intelligence declines with age. The parameter $\mathrm{B}$, the generalized intercept, provides insight into the absolute value of the fluid intelligence. Group differences in parameters A and B were tested with permutation tests with 10,000 permutations. Permutation tests were one-sided except for the comparisons between yoga practitioners and meditators. Curve fitting and parameter comparisons were conducted with Matlab R2009a (The MathWorks Inc. Natick, MA, USA). This method was also used to investigate the relationship between age and the graph measures.

Relationships between mindfulness and other variables were tested with Pearson product-moment correlations. ANOVAs were conducted to compare the three groups in different variables. Significant ANOVAs were followed up by independent samples t-tests (two-tailed) to compare groups pair-wise. Whenever the assumption of homogeneity of variances was not met for ANOVAs, Welch's test of equality of means (Welch, 1951) was used. These analyses were done with SPSS 17 (SPSS Inc., Chicago, IL, USA). 


\section{Imaging}

\section{Data preprocessing}

Resting state data was slice time corrected, realigned, coregistered to individual T1-weighted images, normalized, and spatially smoothed with a $5 \mathrm{~mm}$ kernel using SPM8 (Wellcome Department of Cognitive Neurology, London, UK; www.fil. ion.ucl.ac.uk/spm/). Next, the first 8 image acquisitions of the resting functional time series were discarded to allow for stabilization of the MR signal. The remaining 112 volumes were further preprocessed using the Connectivity toolbox (http://www. nitrc.org/projects/conn; Whitfield-Gabrieli et al., 2011). Mean white matter signal, mean CSF signal, 6 motion parameters, and the first order motion derivative were regressed out of the data. Finally, the residual time series were band-pass filtered with a window of $0.008-0.09 \mathrm{~Hz}$.

\section{Anatomical parcellation and time series extraction}

Resting state scans were parcellated into 116 regions of interest (ROIs; 90 cortical and subcortical, and 26 cerebellar) using the Automated Anatomical Labeling (AAL; Tzourio-Mazoyer et al., 2002) template in the Wake Forest University (WFU) Pickatlas version 2.5 (Maldjian, Laurienti, Kraft, \& Burdette, 2003).

For each ROI, the preprocessed time-series was extracted, resulting in a 116 (ROIs) $\times 112$ (volumes) time-series matrix for each subject. These matrices were used to generate bivariate correlation matrices for each subject. Time-series extraction was done with the Connectivity toolbox.

\section{Network analysis}

Graph theory has recently been introduced in neuroscience to characterize the brain network (Bullmore \& Sporns, 2009). In graph theory, networks are represented as a set of nodes connected by edges. Edges can be either weighted (to encode the strength of the connection) or unweighted. The weights can then be used to define a network distance that increases when the connection strength decreases. A path in a graph is a set of edges through which two distant nodes are connected. When different paths connect two nodes, the shortest path is the one with the smallest network distance. In this study, graphs were built with the 116 ROIs as nodes and the correlation between their mean BOLD time series as edge weights. To capture more of the richness of the available data, we used weighted graphs (Newman, 2004; Saramäki, Kivelä, Onnela, Kaski, \& Kertesz, 2007). Negative correlations were thresholded out. The functional distance was computed as the inverse of the correlation (Rubinov \& Sporns, 2010).

To analyze the functional networks in terms of their integration and segregation, four graph measures were computed: characteristic path length, global efficiency, clustering coefficient and small-worldness. The mathematical definition of these measures can be found in (Rubinov \& Sporns, 2010). Here, we summarize their use 
and interpretation. The characteristic path length is the average of the shortest path length between all pairs of nodes. This measure is primarily driven by longer paths. In particular, if two nodes are disconnected, their shortest path will be infinite, and so will be the characteristic path length. The latter is therefore a measure of integration of functionally distant brain regions. The global efficiency is the average of the inverse of the path length between all pairs of nodes. This measure is mostly driven by shorter paths. It is therefore a measure of integration between functionally close brain regions. The clustering coefficient measures how likely two nodes that are strongly connected to a third one are also strongly connected to each other, forming a strongly connected triangle in the network. As such, it is a measure of segregation, which is the ability to perform specialized tasks in a densely connected network. These three measures were normalized by their mean over 500 surrogate networks created by randomly shuffling the edges. This normalization eliminates the potential effect of a global difference between connection strengths in the different groups. A fourth measure, small-worldness, can be computed as the ratio between the normalized clustering coefficient and the characteristic path length. Small-world property of a network defines how well the network finds a trade-off between a highly integrated network (as seen in random graphs) and a highly segregated network (as seen in a regular lattice).

\section{Resilience}

Functional networks can also be characterized by their resilience to attacks (Achard et al., 2006). Whether attacks represent actual lesions in the cortex or simulate the normal degenerescence of aging neural units, a resilient brain network will be less affected by them. In practice, attacks to the functional networks are simulated by removing nodes and computing some network property of the resulting damaged network. Two types of attacks are considered: random failures where nodes are removed randomly and targeted attacks where the removed node is chosen based on its degree centrality. Degree centrality refers to how important the node is in facilitating functional integration and is defined as the sum of the weights of all edges that connect to the node (Rubinov \& Sporns, 2010). Physiologically, targeted attacks may better simulate neurodegenerescence, as highly connected nodes tend to be more metabolically active, making them more vulnerable (Alstott et al., 2009). The property computed after each attack can be the characteristic path length or the global efficiency (Achard et al., 2006; Albert, Jeong, \& Barabási, 2000). However, global efficiency is usually preferred since it can be computed even if the network is disconnected, while the characteristic path length goes to infinity in that case (Rubinov \& Sporns, 2010). Here we reported statistical group comparisons of resilience to targeted network damage of 15 nodes (i.e. the 15 nodes with the greatest degree centrality were removed) in terms of global efficiency. However, results were similar 
for the other sizes of attacks (3-30 nodes in steps of 3). All network measures were computed using NetworkX, a set of open-source tools written in Python (Hagberg, Schult, \& Swart, 2008)

\section{RESULTS}

\section{SUBJECT CHARACTERISTICS}

Importantly for this study, yoga practitioners, meditators, and controls were matched for age, gender, education, race, and handedness (Table 1). Groups also did not significantly differ in the potentially confounding variables verbal intelligence, current number of hours spent exercising, and current number of hours spent engaged in cognitive activities such as reading, writing, and board and card game playing (Table 1).

Table 1. Group comparisons of matching variables and other potential confounders.

\begin{tabular}{|c|c|c|c|c|c|c|c|c|c|}
\hline & \multicolumn{2}{|c|}{ Controls } & \multicolumn{2}{|c|}{$\begin{array}{c}\text { Yoga } \\
\text { practitioners }\end{array}$} & \multicolumn{2}{|c|}{ Meditators } & \multicolumn{3}{|c|}{ ANOVA / $\chi^{2}$-test } \\
\hline & $M / \%$ & $S D$ & $M / \%$ & $S D$ & $M / \%$ & $S D$ & $F / \chi^{2}$ & $d f$ & $p$ \\
\hline Age (years) & 52.93 & 9.84 & 49.38 & 7.79 & 54.06 & 8.15 & 1.29 & 2,44 & 0.286 \\
\hline $\begin{array}{l}\text { Education } \\
\text { (years) }\end{array}$ & 17.27 & 1.98 & 17.31 & 2.41 & 18.44 & 2.58 & 1.26 & 2,44 & 0.293 \\
\hline $\begin{array}{l}\text { AMNART } \\
\text { VIQ }\end{array}$ & 120.73 & 7.65 & 123.27 & 4.67 & 125.60 & 4.70 & $2.34^{\mathrm{a}}$ & 2,27 & 0.115 \\
\hline $\begin{array}{l}\text { Exercise } \\
\text { (h/wk) }\end{array}$ & 4.79 & 4.53 & 6.98 & 5.57 & 6.48 & 4.16 & 0.72 & 2,36 & 0.496 \\
\hline $\begin{array}{l}\text { Read/Write/ } \\
\text { Play (h/wk) }\end{array}$ & 23.75 & 8.89 & 21.07 & 15.76 & 13.27 & 11.41 & 2.13 & 2,34 & 0.134 \\
\hline $\begin{array}{l}\text { Gender } \\
\text { (\% female) }\end{array}$ & $60 \%$ & & $69 \%$ & & $63 \%$ & & 0.28 & 2 & 0.871 \\
\hline $\begin{array}{l}\text { Handedness } \\
\text { (\% right) }\end{array}$ & $87 \%$ & & $88 \%$ & & $88 \%$ & & 0.01 & 2 & 0.997 \\
\hline $\begin{array}{l}\text { Race } \\
\text { (\% white) }\end{array}$ & $100 \%$ & & $100 \%$ & & $100 \%$ & & & & \\
\hline
\end{tabular}

Note. ${ }^{\text {a }}$ Welch test, AMNART $=$ American National Reading Test. 


\section{AGE RELATED DECLINE IN FLUID INTELLIGENCE}

The best fitting model for the relation between age and the APM score was a loglinear model including the inverse age (equation 2; Figure 1).

$$
\log (F)=A / \operatorname{age}+\log \left(F_{f}\right)
$$

Where $A$ corresponds to the rate at which fluid intelligence declines, and $F_{f}$ expresses the plateau that fluid intelligence reaches at advanced ages.

Coefficient A was significantly lower for yoga practitioners and meditators considered as a single group than for controls (permutation test; $p=0.040$ ). The difference was mostly driven by the difference between yoga practitioners and controls (permutation test; $p=0.057$ ) and only slightly by the difference between meditators and controls (permutation test; $p=0.092$ ). There was no significant difference in decline rate between yoga practitioners and meditators $(p=0.190)$. In this model, the intercept $\mathrm{B}=\log \left(\mathrm{F}_{\mathrm{f}}\right)$ indicates the final plateau value that is reached at advanced ages. It is another characteristic of the decline profile and we can therefore expect it to be larger for yoga practitioners and meditators. Post-hoc permutation tests revealed that this parameter was significantly higher in yoga practitioners and meditators considered as a single group as compared to controls $(p=0.019)$. This difference was mainly driven by the difference between yoga practitioners and controls $(p=0.032)$ and only in part by the difference between meditators and controls $(p=0.070)$. There was no significant difference between yoga practitioners and meditators $(p=0.140)$.

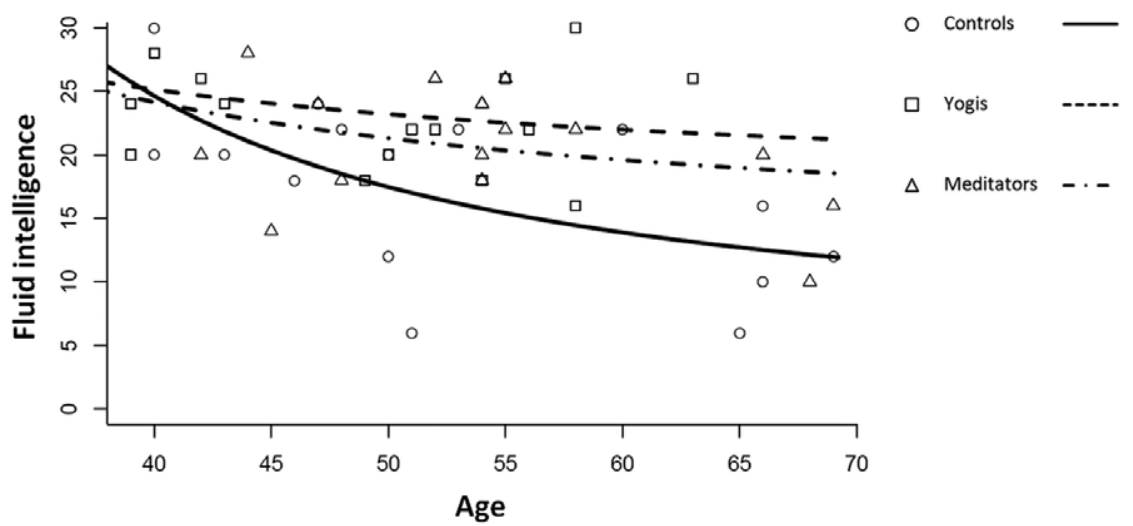

Figure 1. Relation between age, measured in years and fluid intelligence measured with the Raven's Advanced Progressive Matrices for controls, yoga practitioners, and meditators. Lines represent log-linear regression lines for the three groups following the function $\log (F)=A$ /age $+\log \left(F_{f}\right)$. 
Possibly as a result of the slower decline of fluid intelligence in yoga practitioners and meditators as compared to controls, we found a significant main effect for group $\left(F(2,44)=4.827, p=0.013, \eta_{p}{ }^{2}=0.180\right)$ in a one-way ANOVA with group (controls, meditators, yoga practitioners) as factor, and Raven's APM score as dependent variable. Post-hoc t-tests revealed that yoga practitioners $(M=23.500$, $S D=4.761)$ had significantly higher Raven's APM scores than controls $(M=17.333$, $S D=6873 ; t(29)=2.920, p=0.007)$, while their scores did not significantly differ from those of meditators $(M=20.750, S D=4.782 ; t(30)=1.630, p=0.114)$. Meditators and controls did not significantly differ in Raven's APM scores $(t(29)=1.615, p=0.117)$. When considered as a single group, yoga practitioners and meditators had significantly higher Raven's APM scores than controls $(t(45)=2.741, p=0.009)$.

Together, these findings are consistent with the hypothesis that yoga practitioners and meditators combined had a lower rate of decline of fluid intelligence than controls, which was mostly driven by a reduced decline in yoga practitioners. This apparent reduced decline might be the cause for the greater fluid intelligence that we observed in our combined group of older yoga practitioners and meditators. Furthermore, our model predicts that fluid intelligence will not decline beyond a certain level and that this is higher for yoga practitioners and meditators than for controls.

\section{INTEGRATION AND SEGREGATION OF RESTING STATE NETWORKS}

To compare the brain functional network architecture of yoga practitioners, meditators and controls (for a visualization of the network creation see Figure 2) in terms of small-worldness, characteristic path length, global efficiency and clustering coefficient, ANOVAs were conducted. Significant group differences were found in normalized characteristic path length $(F(2,44)=4.482, p=0.017, \eta \mathrm{p} 2=0.169$; Figure $3 \mathrm{~b}$ ) and normalized small-worldness $(F(2,44)=3.487, p=0.039, \eta p 2=0.137$; Figure $3 c)$, and a trend towards significance in normalized global efficiency $(F(2,44)=3.148$, $p=0.053, \eta p 2=0.125)$. However, there were no significant group differences in the normalized clustering coefficient $(F(2,44)=1.956, p=0.153$, n.s.; Figure 3a). Post-hoc independent samples t-tests revealed that yoga practitioners and meditators each had significantly shorter characteristic path length than controls $(t(29)=-2.652, p=0.014$ and $t(23.34)=-2.100, p=0.047$, respectively). This was also true when considered as a single group $(t(20.33)=-2.562, p=0.018)$. There was no difference between yoga practitioners and meditators $(t(30)=-0.782, p=0.440$; Figure $3 b)$. Yoga practitioners also had significantly greater global efficiency than controls $(t(29)=2.249, p=0.032)$, while the difference between meditators and controls showed a trend towards significance $(t(29)=1.893, p=0.068)$. Combined, yoga practitioners and meditators had significantly greater global efficiency than controls $t(45)=2.428, p=0.019$ ), 
A
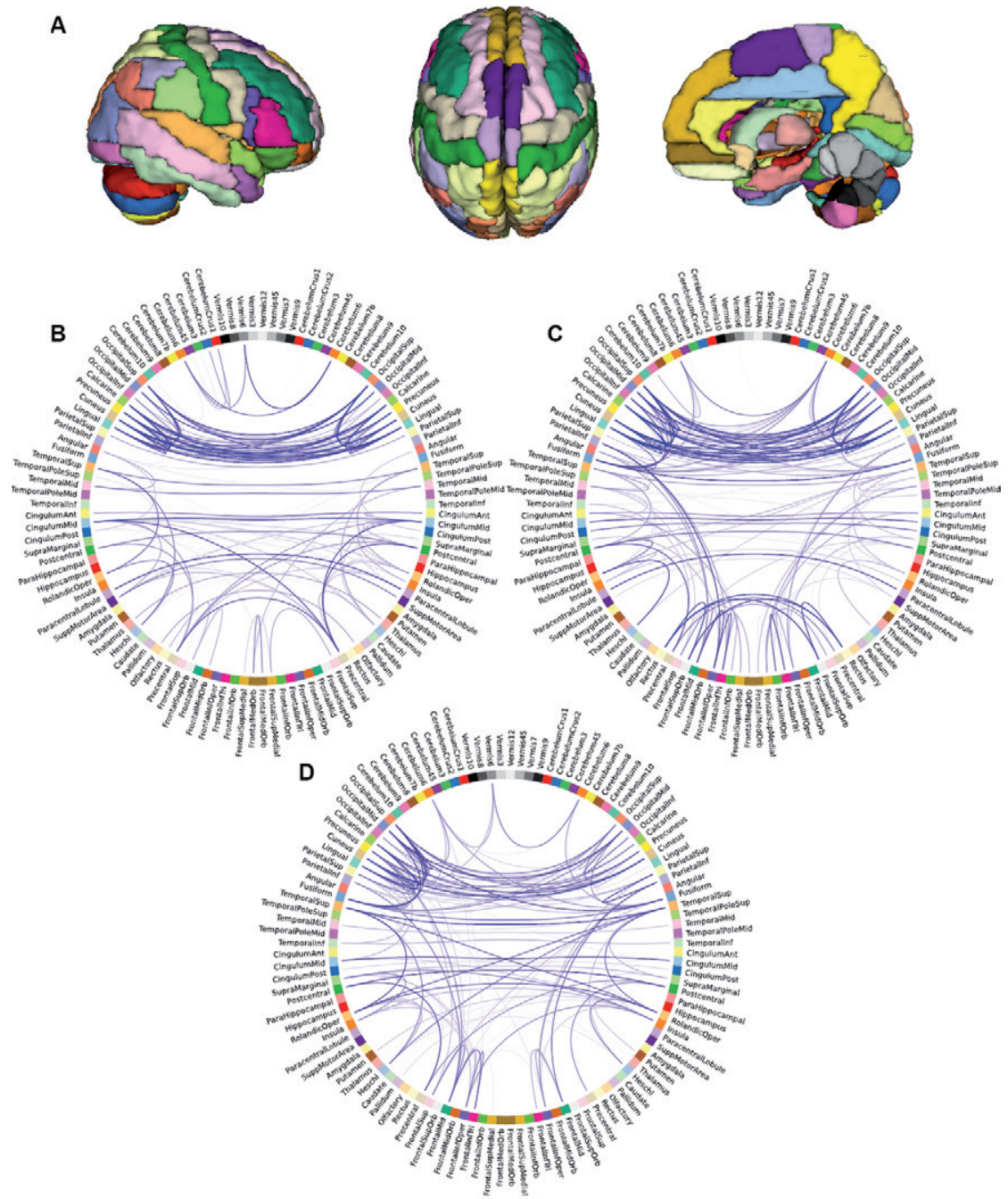

Figure 2. Visualization of network creation. Parcellation of brain into 116 regions (a), and structure of weighted resting state functional networks of a representative control (b), yoga practitioner (c), and meditator (d). Networks depicted were thresholded $(r \geq 0.5)$ for illustrative purposes only. Opacity of the lines represents strength of the correlation (more saturated is stronger), relative to the strength of the strongest correlation. 
while there was no significant difference between yoga practitioners and meditators $(t(30)=-0.701, p=0.489)$. Furthermore, post-hoc independent samples t-tests revealed that yoga practitioners had significantly greater small-worldness than controls $(t(29)=2.297, p=0.029)$. Meditators had borderline significant greater smallworldness than controls $(t(23.60)=1.899, p=0.070)$. Yoga practitioners and meditators together had significantly greater small-worldness than controls $t(19.84)=2.261$, $p=0.035)$, while there was no difference between yoga practitioners and meditators $(t(30)=0.535, p=0.596)$.

Attempts to find the best fitting function for the relationship between age and each of the graph measures revealed that although all models had poor fit, the linear regression model was the best fitting model (all $p>0.050$ ). None of the slopes or intercepts differed significantly between any of the groups for any of the graph measures (all $p>0.050$ ). These findings indicate that although no group differences in age-related decline were found in network integration or segregation, yoga practitioners and meditators combined had greater network integration but not segregation than controls. Again, this difference was mostly driven by the yoga practitioners.

\section{RESILIENCE OF RESTING STATE NETWORKS}

We assessed the resilience of the functional networks to targeted damage (Achard et al., 2006), by removing nodes from the networks in the order of their degree centrality. An ANOVA with group as factor and change in normalized global efficiency after removal of 15 nodes, revealed a significant group effect $(F(2,44)=6.979$, $p=0.002, \eta_{\mathrm{p}}{ }^{2}=0.241$; Figure 4). Post-hoc independent samples t-tests revealed that this group difference was driven by a smaller decrease in yoga practitioners than in controls $(t(29)=3.749, p=0.001)$ and meditators $(t(30)=2.161, p=0.039)$, and no significant difference was found between meditators and controls $(t(29)=1.594$, $p=0.122$ ). When yoga practitioners and meditators were considered as a single group, attacks resulted into a significantly smaller decrease in global efficiency than in controls $(t(45)=2.964, p=0.005)$. These findings indicate that considered as one group, yoga practitioners and meditators have more resilient networks than controls, but when considered separately, yoga practitioners have more resilient networks than controls and meditators. 
A

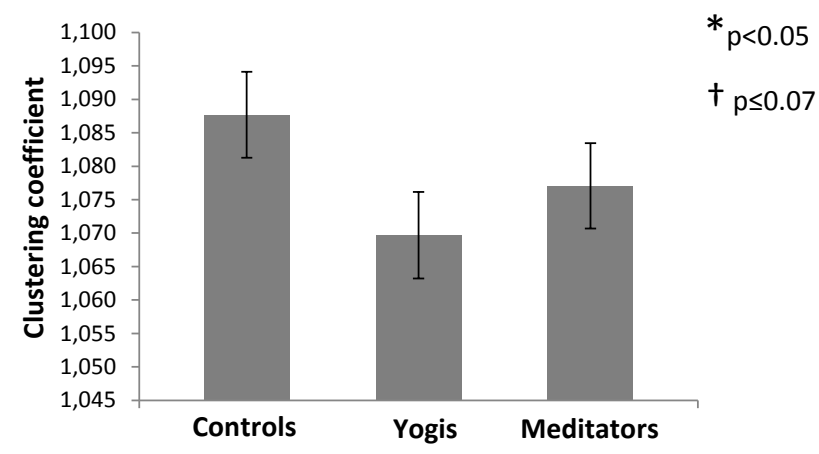

B

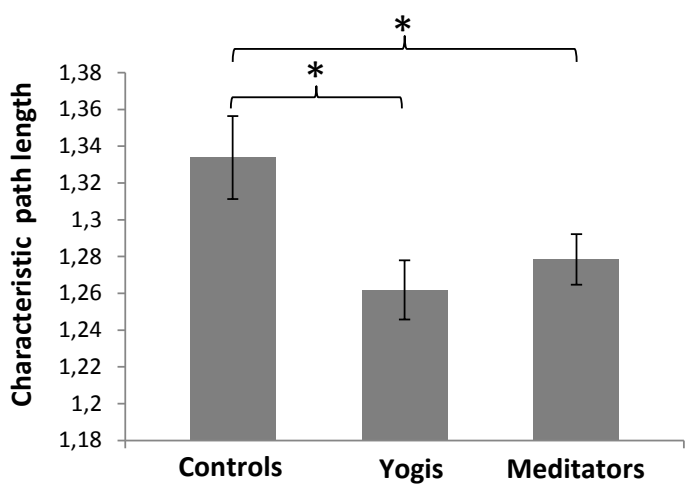

C

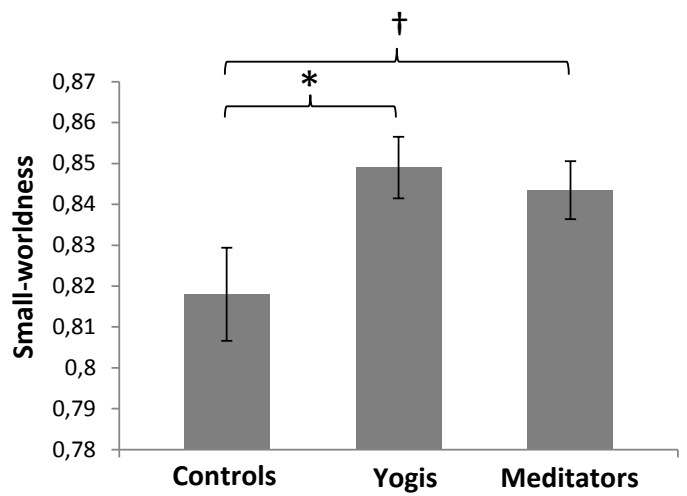

Figure 3. Mean of normalized clustering coefficient (a), normalized characteristic path length (b) and small-worldness (c) for controls, yoga practitioners, and meditators, based on weighted resting state brain functional networks. Error bars represent the standard error of the mean. P-values are based on two-tailed independent samples t-tests. 


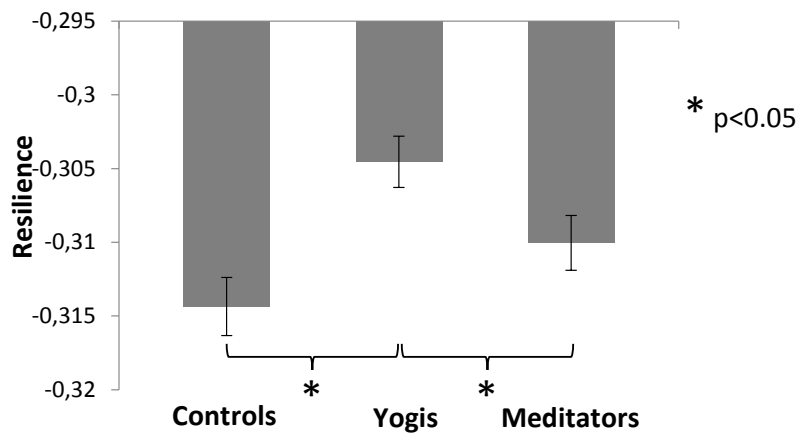

Figure 4. Mean of functional network resilience, measured as the change in global efficiency after removal of the 15 nodes with the highest degree centrality. Less decrease means higher resilience. Error bars represent the standard error of the mean. P-values are based on two-tailed independent samples t-tests.

\section{MINDFULNESS, INTELLIGENCE AND NETWORK INTEGRATION}

The three groups differed in sum score of the FFMQ $(F(2,44)=5.544, p=0.007$, $\left.\eta_{\mathrm{p}}{ }^{2}=0.201\right)$. This group difference was driven by significantly greater scores in yoga practitioners $(M=19.780, S D=2.576 ; t(29)=3.006, p=0.005)$ and meditators $(M=19.053$, $S D=2.190 ; t(29)=2.426, p=0.022)$ than in controls $(M=16.826, S D=2.894)$. There was no significant difference between yoga practitioners and meditators $(t(30)=0.860$, $p=0.396$ ). To investigate the relationship between mindfulness and fluid intelligence, the correlation between the sum score of the FFMQ and the age corrected sum score of the Raven's APM was calculated. This correlation was significant $(r(45)=0.292$, $p=0.046)$ and still approached significance after removing an outlier on mindfulness $(r(44)=0.287, p=0.053$; Figure $5 a)$. Mindfulness was also significantly correlated with network resilience as defined in the previous section $(\mathrm{r}(45)=0.329, p=0.024)$, and still approached significance after removing an outlier on mindfulness $(\mathrm{r}(44)=0.270$, $p=0.070$; Figure $5 b$ ). Furthermore, mindfulness was positively related to network integration as reflected in a positive correlation of mindfulness with normalized global efficiency $(\mathrm{r}(45)=0.367, p=0.011)$ and a negative correlation with normalized characteristic path length $\mathrm{r}(45)=-0.356, p=0.014)$. Both correlations remained significant after removing an outlier on mindfulness $(\mathrm{r}(44)=0.325, p=0.028$; Figure $5 \mathrm{c}$, and $\mathrm{r}(44)=-0.309, p=0.037$; Figure $5 \mathrm{~d}$, respectively). Together these findings indicate that individuals who are more mindful have higher fluid intelligence and more integrated and resilient resting state brain networks. 

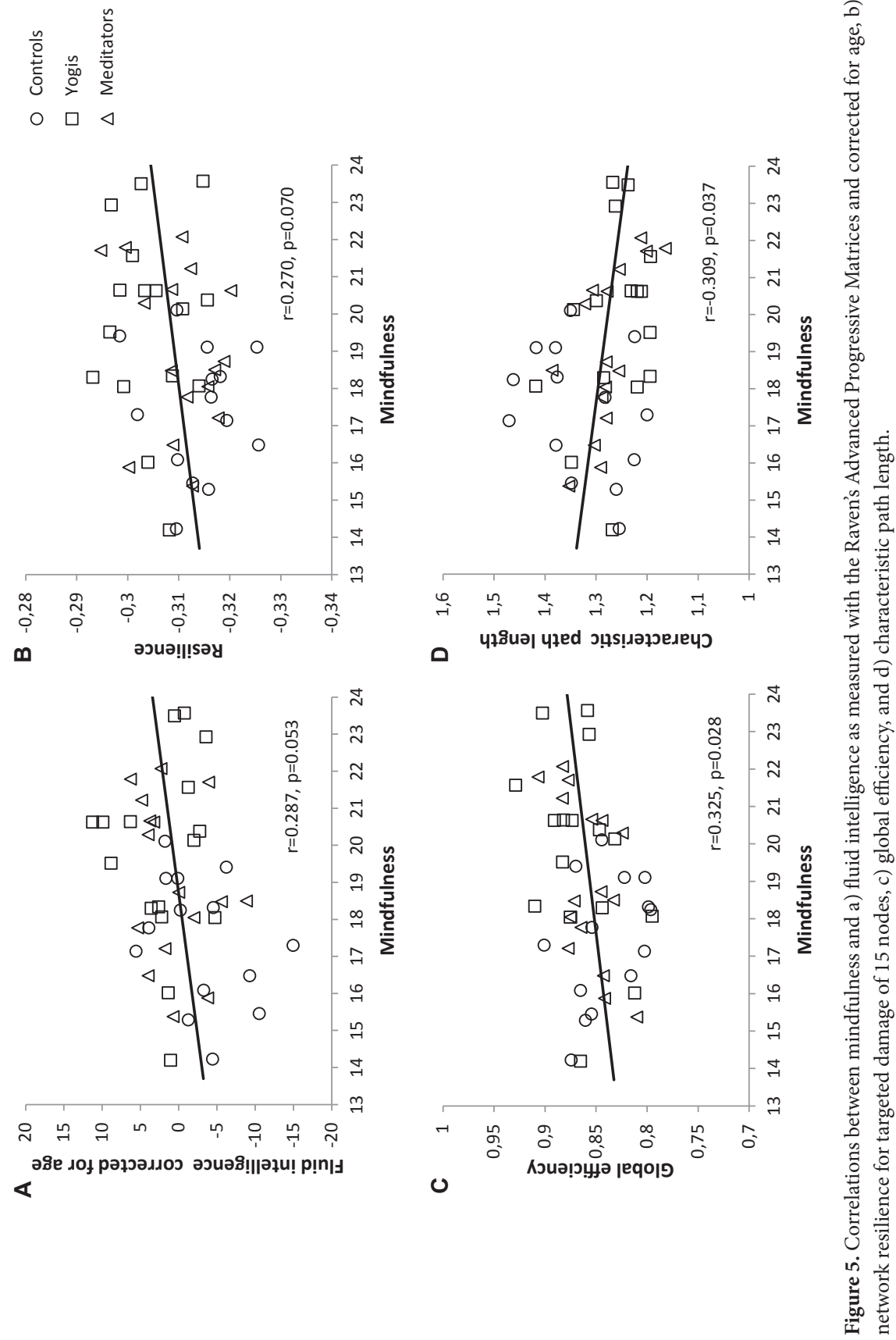

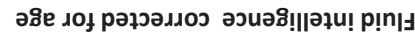
$\varangle$

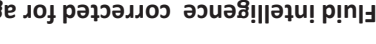




\section{DISCUSSION}

In this study we investigated age-related decline in fluid intelligence and resting state functional brain network properties in older yoga practitioners, meditators, and controls. Importantly, the groups were well-matched demographically and did not significantly differ in several factors that impact brain function, including age, gender, education, crystallized intelligence, and average hours of physical exercise and cognitive engagement in daily life. Aligned with our hypothesis, the apparent rate of age-related decline in fluid intelligence was lower in yoga practitioners and meditators combined as compared to controls. Congruent with this finding, resting state functional brain networks of yoga practitioners and meditators combined were more resilient to damage than those of controls and had a stronger small-world architecture. This difference in small-worldness was driven by greater network integration rather than segregation. Interestingly, mindfulness was positively related to fluid intelligence as well as network resilience and integration. These findings link behavioral training to reduced decline in fluid intelligence and greater functional brain network integration and robustness in older adults. In addition, the correlation between mindfulness and network integration, resilience, and fluid intelligence suggests that mindfulness plays a mechanistic role in this preservation and advances our understanding of the involved constructs.

\section{SLOWER DECLINE OF FLUID INTELLIGENCE}

Consistent with our hypothesis of off-set age-related decline in yoga and meditation practitioners, decline parameters of the function describing the relationship between age and fluid intelligence were smaller in yoga practitioners and meditators combined than in controls. Presumably because of this apparent slower decline, the group averages of fluid intelligence were higher in the combined group of yoga practitioners and meditators than in the age-matched controls. These findings are consistent with previous studies which indicated that older meditators have better attentional performance than non-meditators (Prakash et al., 2012; van Leeuwen et al., 2009), and that meditators don't show the normal negative correlation between sustained attention and age (Pagnoni \& Cekic, 2007). Our results extend these earlier findings by revealing a reduced cognitive aging effect in yoga practitioners and meditators on the higher level construct fluid intelligence. This extension is important as fluid intelligence is a broader construct than attention and predicts meaningful behavior in the real world (Deary et al., 2010; Sternberg, 2008).

The question that these findings raise is what variables mediate the effect of meditation and yoga on fluid intelligence? The positive correlation between mind- 
fulness and fluid intelligence we reported here suggests that mindfulness is one of these variables. Our finding is congruent with previous studies that have shown that both mindfulness (Anicha, Ode, Moeller, \& Robinson, 2012; Moore \& Malinowski, 2009) and fluid intelligence (Colzato, Van Wouwe, Lavender, \& Hommel, 2006) are related to cognitive flexibility, thereby linking the two constructs.

\section{RESILIENT BRAIN FUNCTIONAL NETWORKS}

Resilience can be studied in terms of change in brain network properties after simulated aging-related brain damage. Our analysis revealed that resting state functional brain networks of yoga practitioners and meditators together had greater resilience to simulated damage than those of controls. This finding is aligned with our finding of greater resilience to age-related cognitive decline. While decreased network resilience of structural brain networks has been reported in Alzheimer's patients (He et al., 2008), our data reveal conditions that may enhance network resilience. Although it is tempting to speculate that these network findings might translate to biological brain resilience, this link has not yet been established.

\section{GREATER SMALL-WORLDNESS THROUGH MORE INTEGRATION}

Recent studies have shown that experienced meditators have altered resting state functional connectivity within the default mode network (Jang et al., 2011; Taylor et al., 2013), and increased connectivity between the posterior cingulate and the dorsal anterior cingulate and dorsolateral prefrontal cortices (Brewer et al., 2011). The current study extends these findings by demonstrating differences in graph theoretical global network properties, thereby capturing more of the full complexity of the functional network architecture.

We found between-group differences in small-worldness, characteristic path length, and global efficiency, but not in clustering coefficient. Yoga practitioners and meditators combined had significantly shorter characteristic path length and greater global efficiency and greater small-worldness than controls. Elevated small-worldness of the yoga practitioners and meditators was driven by higher network integration (characteristic path length and global efficiency), rather than by increased network segregation (clustering coefficient). Hence, aging yoga practitioners and meditators have a more small-world like resting state functional brain network architecture compared to controls by having stronger integrative connections, efficiently integrating information from distributed brain regions, rather than having more groups of highly connected local brain regions for specialized information processing. 
Long distance $\gamma$-synchrony has long been hypothesized to be a mechanism for large scale network integration related to coherent cognition, behavior, and consciousness (Rodriguez et al., 1999; Singer, 1993; Varela, Lachaux, Rodriguez, \& Martinerie, 2001), and a recent study revealed that long-distance synchronization between brain regions, especially in the $\beta(16-32 \mathrm{~Hz})$ and $\gamma(32-63 \mathrm{~Hz})$ bands is related to cognition and network integration as measured by global efficiency (Kitzbichler, Henson, Smith, Nathan, \& Bullmore, 2011). Interestingly, increased long-distance gamma (25-42 Hz) synchrony has been related to meditation, with a significant group (meditators vs. controls) by condition (meditation vs. baseline) interaction (Lutz, Greischar, Rawlings, Ricard, \& Davidson, 2004). Our finding of shorter characteristic path length in yoga and meditation practitioners than in controls extends this finding by revealing group differences in network integration during rest and by demonstrating altered network integration in yoga practitioners.

We did not find a significant decline of any of the network properties with age, and no differences in decline between groups. The absence of a decline in clustering coefficient is in agreement with a previous study that did not find a difference in modularity, another measure of network segregation, between young and old healthy subjects (Meunier et al., 2009).

Although we did not find the expected negative correlation between age and network integration, probably due to our relatively small sample size and the relatively narrow age range (39-69 years), growing evidence suggests that there is an age related decline of integration in functional networks (Achard \& Bullmore, 2007). Achard and Bullmore (2007) found that young $(M=24.7$ years) participants had greater global efficiency than old ( $M=66.5$ years) participants. Thus, with a more integrated, more efficient network organization as compared to controls, yoga practitioners and meditators might be viewed as having a younger, less-degraded brain network organization. These findings indicate that it might be possible to reduce age related decline in functional network integration through meditation and yoga practice.

Mindfulness is related to fluid intelligence and brain functional network resilience and integration

The correlation between fluid intelligence and mindfulness that we report here is congruent with previous studies linking both variables to cognitive flexibility (Anicha et al., 2012; Colzato et al., 2006; Moore \& Malinowski, 2009). We also found a positive correlation between mindfulness and global efficiency, as well as a negative correlation between mindfulness and characteristic path length. Together, these findings are aligned with previous reports of negative correlations between characteristic path length and fluid intelligence (Langer et al., 2012; van den Heuvel et al., 2009). Similarly, using diffusion tensor imaging (DTI) tractography derived 
networks, Li et al. (2009) reported a positive correlation between global efficiency and intelligence, and a negative relation between characteristic path length and intelligence. Wen et al. (2011) reported positive correlations between global efficiency and processing speed, visuospatial ability, and executive function. The correlation of mindfulness with measures of network resilience, network integration and fluid intelligence suggests that mindfulness plays a central role in the prevention of age related cognitive and neural decline.

\section{YOGA PRACTITIONERS VS. MEDITATORS}

To date, much of the neuroimaging literature regarding mind-body practices has focused on mindfulness meditation. However there are numerous yoga and meditation traditions, as well as other mind-body practices such as tai chi. Although there are important philosophical differences between different Eastern traditions, there are also numerous similarities (Goleman, 1996). Previous longitudinal studies that have directly compared different styles of meditation or yoga have reported both convergent and divergent findings. Wolever et at. (2012) failed to show a difference between a yoga-based and a mindfulness-based intervention on a number of psychological and physiological variables, though both practices showed greater improvements on perceived stress, sleep quality, and aspects of heart rate variability in a workplace setting than a control condition. However, other studies have found between-group differences between mindfulness and relaxation interventions on various scales and tests, including rumination (Jain et al., 2007), and emotional interference, psychological well-being, and negative affect (Ortner, Kilner, \& Zelazo, 2007).

In the current study we recruited individuals whose main practice was either Kripalu yoga or Vipassana (a.k.a. mindfulness) meditation. Mindfulness plays a central role in both of these traditions (Carmody \& Baer, 2008; Gard et al., 2012; Nyklicek \& Kuijpers, 2008; Shelov, Suchday, \& Friedberg, 2009; Wolever et al., 2012), though in Kripalu the concept of mindfulness is referred to as "witness consciousness" (Faulds, 2005); and see Gard et al. (Gard et al., 2012) for a comparison of these concepts). The two groups did not differ significantly on any of our metrics, except for network resilience which suggests these practices have similar effects on brain network organization and cognitive functioning. The significantly greater resilience in yoga practitioners than in meditators and the overall trend for larger differences between yoga practitioners and controls with meditators in between likely due to the fact that the yoga group had almost twice as much life-time hours of practice as the meditation group. 


\section{LIMITATIONS}

It is important to note that a variety of factors are thought to influence the rate of normal age-related decreases in brain structure and function including gender, cognitive engagement and physical exercise (Fotuhi et al., 2012; Plassman et al., 2010; Wilson et al., 2012). Therefore we matched yoga practitioners, meditators and controls for age, gender, race, handedness, and education, and additionally compared them on verbal intelligence, current exercise, and cognitive spare time engagement (reading, writing, playing games). Although groups did not significantly differ on any of these variables, there might be other confounding variables that we did not control for.

Since the presented study has a cross-sectional design it has important limitations, such that causality can not be established. For example, people endowed with higher fluid intelligence and greater brain functional network integration may be more interested in practicing yoga and meditation. While our present study with highly experienced yoga practitioners and meditators revealed interesting and encouraging findings, future longitudinal studies with larger sample sizes and individuals without prior experience with these mind-body techniques will be required to establish causality.

\section{CONCLUSION}

We have provided evidence that is in line with the hypothesis that age-related decline in fluid intelligence is slower in yoga practitioners and meditators and that these practitioners have more efficient and resilient functional brain networks than matched controls. Furthermore, we reported no significant differences between yoga practitioners and meditators on most of the assessed variables and found that mindfulness, which is a key skill developed through meditation and yoga practice, was positively correlated with fluid intelligence and global brain network efficiency and resilience. These findings are of theoretical importance as they provide insight into the global brain functional network architecture of yoga practitioners and meditators and provide a potential mechanism for the preserved intellectual capacity in mindfulness practitioners. Furthermore, these findings have potential practical implications with a rapidly aging world population and increasing life expectancies (Administration on Aging, 2012; United Nations, 2002). Longitudinal research is needed to establish causality between the practice of yoga and meditation and reduced decline of intelligence and functional brain network architecture. 


\section{ACKNOWLEDGEMENTS}

This study was funded by NIH award R21AT003673 and the Kripalu Center for Yoga and Health, and was made possible by the resources provided by Shared Instrumentation Grants 1S10RR023401, S10RR019307, and 1S10RR023043.We also would like to thank all participants for their contribution.

\section{REFERENCES}

Achard, S., \& Bullmore, E. (2007). Efficiency and cost of economical brain functional networks. Plos Computational Biology, 3, 174-183. doi: 10.1371/journal.pcbi.0030017

Achard, S., Salvador, R., Whitcher, B., Suckling, J., \& Bullmore, E. (2006). A resilient, lowfrequency, small-world human brain functional network with highly connected association cortical hubs. The Journal of Neuroscience, 26(1), 63-72. doi: 10.1523/JNEUROSCI.3874-05.2006

Administration on Aging. (2012). A Profile of Older Americans. June 18. http://www.aoa.gov/ AoARoot/Aging_Statistics/Profile/2012/docs/2012profile.pdf

Albert, R., Jeong, H., \& Barabási, A. L. (2000). Error and attack tolerance of complex networks. Nature, 406(6794), 378-382. doi: 10.1038/35019019

Alstott, J., Breakspear, M., Hagmann, P., Cammoun, L., \& Sporns, O. (2009). Modeling the impact of lesions in the human brain. Plos Computational Biology, 5(6), e1000408. doi: 10.1371/journal.pcbi.1000408

Anguera, J. A., Boccanfuso, J., Rintoul, J. L., Al-Hashimi, O., Faraji, F., Janowich, J., Kong, E., Larraburo, Y., Rolle, C., Johnston, E., \& Gazzaley, A. (2013). Video game training enhances cognitive control in older adults. Nature, 501(7465), 97-101. doi: 10.1038/nature12486

Anicha, C. L., Ode, S., Moeller, S. K., \& Robinson, M. D. (2012). Toward a cognitive view of trait mindfulness: distinct cognitive skills predict its observing and nonreactivity facets. Journal of personality, 80(2), 255-285. doi: 10.1111/j.1467-6494.2011.00722.x

Baer, R. A., Smith, G. T., Hopkins, J., Krietemeyer, J., \& Toney, L. (2006). Using self-report assessment methods to explore facets of mindfulness. Assessment, 13(1), 27-45. doi: $10.1177 / 1073191105283504$

Belleville, S., Clement, F., Mellah, S., Gilbert, B., Fontaine, F., \& Gauthier, S. (2011). Trainingrelated brain plasticity in subjects at risk of developing Alzheimer's disease. Brain, 134, 1623-1634. doi: 10.1093/brain/awr037

Brewer, J. A., Worhunsky, P. D., Gray, J. R., Tang, Y.-Y., Weber, J., \& Kober, H. (2011). Meditation experience is associated with differences in default mode network activity and connectivity. Proceedings of the National Academy of Sciences of the United States of America, 108(50), 20254-20259. doi: 10.1073/pnas.1112029108 
Bullmore, E., \& Sporns, O. (2009). Complex brain networks: graph theoretical analysis of structural and functional systems. Nature Reviews Neuroscience, 10(3), 186-198. doi: $10.1038 / \mathrm{nrn} 2575$

Carmody, J., \& Baer, R. A. (2008). Relationships between mindfulness practice and levels of mindfulness, medical and psychological symptoms and well-being in a mindfulnessbased stress reduction program. Journal of Behavioral Medicine, 31(1), 23-33. doi: 10.1007/s10865-007-9130-7

Chattha, R., Nagarathna, R., Padmalatha, V., \& Nagendra, H. R. (2008). Effect of yoga on cognitive functions in climacteric syndrome: a randomised control study. BJOG: An International Journal of Obstetrics and Gynaecology, 115(8), 991-1000. doi: 10.1111/j.14710528.2008.01749.x

Colcombe, S. J., Kramer, A. F., Erickson, K. I., Scalf, P., McAuley, E., Cohen, N. J., Webb, A., Jerome, G. J., Marquez, D. X., \& Elavsky, S. (2004). Cardiovascular fitness, cortical plasticity, and aging. Proceedings of the National Academy of Sciences of the United States of America, 101(9), 3316-3321. doi: 10.1073/pnas.0400266101

Colzato, L. S., Van Wouwe, N. C., Lavender, T. J., \& Hommel, B. (2006). Intelligence and cognitive flexibility: fluid intelligence correlates with feature "unbinding" across perception and action. Psychonomic Bulletin \& Review, 13(6), 1043-1048. doi: 10.3758/bf03213923

de Chastelaine, M., Wang, T. H., Minton, B., Muftuler, L. T., \& Rugg, M. D. (2011). The effects of age, memory performance, and callosal integrity on the neural correlates of successful associative encoding. Cerebral Cortex, 21(9), 2166-2176. doi: 10.1093/cercor/bhq294

Deary, I. J. (2012). Intelligence. Annual Review of Psychology, 63, 453-482. doi: 10.1146/annurev-psych-120710-100353

Deary, I. J., Penke, L., \& Johnson, W. (2010). The neuroscience of human intelligence differences. Nature Reviews Neuroscience, 11(3), 201-211. doi: 10.1038/nrn2793

Dosenbach, N. U. F., Nardos, B., Cohen, A. L., Fair, D. A., Power, J. D., Church, J. A., Nelson, S. M., Wig, G. S., Vogel, A. C., \& Lessov-Schlaggar, C. N. (2010). Prediction of individual brain maturity using fMRI. Science, 329(5997), 1358-1361.

Faulds, R. (2005). Kripalu yoga: a guide to practice on and off the mat. New York, NY: Bantam.

Folstein, M. F., Folstein, S. E., \& McHugh, P. R. (1975). Mini-Mental State: a practical method for grading the cognitive state of patients for the clinician. Journal of Psychiatric Research, 12(3), 189-198. doi: 10.1016/0022-3956(75)90026-6

Fotuhi, M., Do, D., \& Jack, C. (2012). Modifiable factors that alter the size of the hippocampus with ageing. Nature Reviews Neurology, 8(4), 189-202. doi: 10.1038/nrneurol.2012.27

Gard, T., Brach, N., Hölzel, B. K., Noggle, J. J., Conboy, L. A., \& Lazar, S. W. (2012). Effects of a yoga-based intervention for young adults on quality of life and perceived stress: The potential mediating roles of mindfulness and self-compassion. The Journal of Positive Psychology, 7(3), 165-175. doi: 10.1080/17439760.2012.667144 
Gard, T., Hölzel, B. K., \& Lazar, S. W. (2014). The potential effects of meditation on age-related cognitive decline: a systematic review. Annals of the New York Academy of Sciences, 1307(1), 89-103. doi: 10.1111/nyas.12348

Goldstein, J., \& Kornfield, J. (2001). Seeking the heart of wisdom: The path of insight meditation. Boston, MA: Shambhala Publications.

Goleman, D. (1996). The Meditative Mind: The Varieties of Meditative Experience. New York, NY: J. P. Tarcher.

Gray, J. R., \& Thompson, P. M. (2004). Neurobiology of intelligence: science and ethics. Nature Reviews Neuroscience, 5, 471-482. doi: 10.1038/nrn1405

Grober, E., \& Sliwinski, M. (1991). Development and validation of a model for estimating premorbid verbal intelligence in the elderly. Journal of Clinical and Experimental Neuropsychology, 13(6), 933-949. doi: 10.1080/01688639108405109

Hagberg, A. A., Schult, D. A., \& Swart, P. J. (2008). Exploring Network Structure, Dynamics, and Function using NetworkX. Paper presented at the Proceedings of the 7th Python in Science Conference, Pasadena, CA.

He, Y., Chen, Z., \& Evans, A. (2008). Structural insights into aberrant topological patterns of large-scale cortical networks in Alzheimer's disease. The Journal of Neuroscience, 28(18), 4756-4766. doi: 10.1523/JNEUROSCI.0141-08.2008

Holzschneider, K., Wolbers, T., Roeder, B., \& Hoetting, K. (2012). Cardiovascular fitness modulates brain activation associated with spatial learning. Neuroimage, 59(3), 3003-3014. doi: 10.1016/j.neuroimage.2011.10.021

Jaeggi, S. M., Buschkuehl, M., Jonides, J., \& Perrig, W. J. (2008). Improving fluid intelligence with training on working memory. Proceedings of the National Academy of Sciences of the United States of America, 105(19), 6829-6833. doi: 10.1073/pnas.0801268105

Jain, S., Shapiro, S. L., Swanick, S., Roesch, S. C., Mills, P. J., Bell, I., \& Schwartz, G. E. (2007). A randomized controlled trial of mindfulness meditation versus relaxation training: effects on distress, positive states of mind, rumination, and distraction. Annals of Behavioral Medicine, 33(1), 11-21. doi: 10.1207/s15324796abm3301_2

Jang, J. H., Jung, W. H., Kang, D. H., Byun, M. S., Kwon, S. J., Choi, C. H., \& Kwon, J. S. (2011). Increased default mode network connectivity associated with meditation. Neuroscience Letters, 487(3), 358-362. doi: 10.1016/j.neulet.2010.10.056

Jausovec, N., \& Jausovec, K. (2012). Working memory training: Improving intelligence - Changing brain activity. Brain and Cognition, 79(2), 96-106. doi: 10.1016/j.bandc.2012.02.007

Kitzbichler, M. G., Henson, R. N. A., Smith, M. L., Nathan, P. J., \& Bullmore, E. T. (2011). Cognitive effort drives workspace configuration of human brain functional networks. The Journal of Neuroscience, 31(22), 8259-8270. doi: 10.1523/JNEUROSCI.0440-11.2011

Kramer, A. F., \& Erickson, K. I. (2007). Capitalizing on cortical plasticity: Influence of physical activity on cognition and brain function. Trends in Cognitive Sciences, 11(8), 342-348. doi: 10.1016/j.tics.2007.06.009 
Kyizom, T., Singh, S., Singh, K. P., Tandon, O. P., \& Kumar, R. (2010). Effect of pranayama \& yoga-asana on cognitive brain functions in type 2 diabetes-P3 event related evoked potential (ERP). Indian Journal of Medical Research, 131(5), 636-640.

Langer, N., Pedroni, A., Gianotti, L. R. R., Haenggi, J., Knoch, D., \& Jaencke, L. (2012). Functional brain network efficiency predicts intelligence. Human Brain Mapping, 33(6), 1393-1406. doi: 10.1002/hbm.21297

Lazar, S. W., Kerr, C. E., Wasserman, R. H., Gray, J. R., Greve, D. N., Treadway, M. T., McGarvey, M., Quinn, B. T., Dusek, J. A., Benson, H., Rauch, S. L., Moore, C. I., \& Fischl, B. (2005). Meditation experience is associated with increased cortical thickness. Neuroreport, 16(17), 1893-1897. doi: 10.1097/01.wnr.0000186598.66243.19

Li, Y., Liu, Y., Li, J., Qin, W., Li, K., Yu, C., \& Jiang, T. (2009). Brain anatomical network and intelligence. Plos Computational Biology, 5(5), e1000395. doi: 10.1371/journal. pcbi. 1000395

Luders, E., Clark, K., Narr, K. L., \& Toga, A. W. (2011). Enhanced brain connectivity in longterm meditation practitioners. Neuroimage, 57(4), 1308-1316. doi: 10.1016/j.neuroimage.2011.05.075

Lutz, A., Greischar, L. L., Rawlings, N. B., Ricard, M., \& Davidson, R. J. (2004). Long-term meditators self-induce high-amplitude gamma synchrony during mental practice. Proceedings of the National Academy of Sciences of the United States of America, 101(46), 16369-16373. doi: 10.1073/pnas.0407401101

Maldjian, J. A., Laurienti, P. J., Kraft, R. A., \& Burdette, J. H. (2003). An automated method for neuroanatomic and cytoarchitectonic atlas-based interrogation of fMRI data sets. Neuroimage, 19(3), 1233-1239. doi: 10.1016/s1053-8119(03)00169-1

Melby-Lervag, M., \& Hulme, C. (2013). Is working memory training effective? A meta-analytic review. Developmental Psychology, 49(2), 270-291. doi: 10.1037/a0028228

Meunier, D., Achard, S., Morcom, A., \& Bullmore, E. (2009). Age-related changes in modular organization of human brain functional networks. Neuroimage, 44(3), 715-723. doi: 10.1016/j.neuroimage.2008.09.062

Moore, A., \& Malinowski, P. (2009). Meditation, mindfulness and cognitive flexibility. Consciousness and Cognition, 18(1), 176-186. doi: 10.1016/j.concog.2008.12.008

Morrison, J. H., \& Hof, P. R. (1997). Life and death of neurons in the aging brain. Science, 278(5337), 412-419. doi: 10.1126/science.278.5337.412

Newman, M. E. J. (2004). Analysis of weighted networks. Physical Review, 70(5), 056131. doi: 10.1103/PhysRevE.70.056131

Nyberg, L., Sandblom, J., Jones, S., Neely, A. S., Petersson, K. M., Ingvar, M., \& Backman, L. (2003). Neural correlates of training-related memory improvement in adulthood and aging. Proceedings of the National Academy of Sciences of the United States of America, 100(23), 13728-13733. doi: 10.1073/pnas.1735487100 
Nyklicek, I., \& Kuijpers, K. F. (2008). Effects of mindfulness-based stress reduction intervention on psychological well-being and quality of life: Is increased mindfulness indeed the mechanism? Annals of Behavioral Medicine, 35(3), 331-340. doi: 10.1007/s12160-008-9030-2

Oken, B. S., Zajdel, D., Kishiyama, S., Flegal, K., Dehen, C., Haas, M., Kraemer, D. F., Lawrence, J., \& Leyva, J. (2006). Randomized, controlled, six-month trial of yoga in healthy seniors: effects on cognition and quality of life. Alternative Therapies in Health and Medicine, 12(1), 40-47.

Ortner, C. N. M., Kilner, S. J., \& Zelazo, P. D. (2007). Mindfulness meditation and reduced emotional interference on a cognitive task. Motivation and Emotion, 31, 271-283.

Pagnoni, G., \& Cekic, M. (2007). Age effects on gray matter volume and attentional performance in Zen meditation. Neurobiology of Aging, 28(10), 1623-1627. doi: 10.1016/j. neurobiolaging.2007.06.008

Persson, J., Nyberg, L., Lind, J., Larsson, A., Nilsson, L. G., Ingvar, M., \& Buckner, R. L. (2006). Structure-function correlates of cognitive decline in aging. Cerebral Cortex, 16(7), 907-915. doi: 10.1093/cercor/bhj036

Plassman, B. L., Williams, J. W., Burke, J. R., Holsinger, T., \& Benjamin, S. (2010). Systematic review: factors associated with risk for and possible prevention of cognitive decline in later life. Annals of Internal Medicine, 153(3), 182-193. doi: 10.7326/0003-4819-153-3201008030-00258

Prakash, R., Rastogi, P., Dubey, I., Abhishek, P., Chaudhury, S., \& Small, B. J. (2012). Longterm concentrative meditation and cognitive performance among older adults. Aging Neuropsychology and Cognition, 19(4), 479-494. doi: 10.1080/13825585.2011.630932

Raven, J. (2000). The Raven's progressive matrices: change and stability over culture and time. Cognitive Psychology, 41(1), 1-48. doi: 10.1006/cogp.1999.0735

Raven, J., Raven, J. C., \& Court, J. H. (1998). Manual for Raven's Advanced Progressive Matrices. Oxford, United Kingdom: Oxford Psychologists Press.

Rocha, K. K. F., Ribeiro, A. M., Rocha, K. C. F., Sousa, M. B. C., Albuquerque, F. S., Ribeiro, S., \& Silva, R. H. (2012). Improvement in physiological and psychological parameters after 6 months of yoga practice. Consciousness and Cognition, 21(2), 843-850. doi: 10.1016/j.concog.2012.01.014

Rodriguez, E., George, N., Lachaux, J. P., Martinerie, J., Renault, B., \& Varela, F. J. (1999). Perception's shadow: long-distance synchronization of human brain activity. Nature, 397(6718), 430-433. doi: 10.1038/17120

Rubinov, M., McIntosh, A. R., Valenzuela, M. J., \& Breakspear, M. (2009). Simulation of neuronal death and network recovery in a computational model of distributed cortical activity. American Journal of Geriatric Psychiatry, 17(3), 210-217. doi: 10.1097/ JGP.0b013e318187137a

Rubinov, M., \& Sporns, O. (2010). Complex network measures of brain connectivity: uses and interpretations. Neuroimage, 52(3), 1059-1069. doi: 10.1016/j.neuroimage.2009.10.003 
Salat, D. H., Buckner, R. L., Snyder, A. Z., Greve, D. N., Desikan, R. S., Busa, E., Morris, J. C., Dale, A. M., \& Fischl, B. (2004). Thinning of the cerebral cortex in aging. Cerebral Cortex, 14(7), 721-730. doi: 10.1093/cercor/bhh032

Saramäki, J., Kivelä, M., Onnela, J. P., Kaski, K., \& Kertesz, J. (2007). Generalizations of the clustering coefficient to weighted complex networks. Physical Review E, 75(2), 27105. doi: 10.1103/PhysRevE.75.027105

Shelov, D. V., Suchday, S., \& Friedberg, J. P. (2009). A pilot study measuring the impact of yoga on the trait of mindfulness. Behavioural and Cognitive Psychotherapy, 37(5), 595-598. doi: $10.1017 /$ S1352465809990361

Singer, W. (1993). Synchronization of cortical activity and its putative role in information processing and learning. Annual review of physiology, 55(1), 349-374. doi: 10.1146/annurev.ph.55.030193.002025

Sternberg, R. J. (2008). Increasing fluid intelligence is possible after all. Proceedings of the National Academy of Sciences of the United States of America, 105(19), 6791-6792. doi: 10.1073/pnas.0803396105

Streeter, C. C., Whitfield, T. H., Owen, L., Rein, T., Karri, S. K., Yakhkind, A., Perlmutter, R., Prescot, A., Renshaw, P. F., Ciraulo, D. A., \& Jensen, J. E. (2010). Effects of yoga versus walking on mood, anxiety, and brain GABA levels: a randomized controlled MRS study. The Journal of Alternative and Complementary Medicine, 16(11), 1145-1152. doi: 10.1089/acm.2010.0007

Subramanya, P., \& Telles, S. (2009). Effect of two yoga-based relaxation techniques on memory scores and state anxiety. BioPsychoSocial Medicine, 3, 8. doi: 10.1186/1751-0759-3-8

Taylor, V. A., Daneault, V., Grant, J., Scavone, G., Breton, E., Roffe-Vidal, S., Courtemanche, J., Lavarenne, A. S., Marrelec, G., Benali, H., \& Beauregard, M. (2013). Impact of meditation training on the default mode network during a restful state. Social Cognitive and Affective Neuroscience, 8(1), 4-14. doi: 10.1093/scan/nsr087

Tzourio-Mazoyer, N., Landeau, B., Papathanassiou, D., Crivello, F., Etard, O., Delcroix, N., Mazoyer, B., \& Joliot, M. (2002). Automated Anatomical Labeling of Activations in SPM Using a Macroscopic Anatomical Parcellation of the MNI MRI Single-Subject Brain. Neuroimage, 15(1), 273-289. doi: 10.1006/nimg.2001.0978

United Nations. (2002). World population ageing, 1950-2050. New York, NY: United Nations van den Heuvel, M. P., Stam, C. J., Kahn, R. S., \& Hulshoff Pol, H. E. (2009). Efficiency of functional brain networks and intellectual performance. Journal of Neuroscience, 29(23), 7619-7624. doi: 10.1523/JNEUROSCI.1443-09.2009

van Leeuwen, S., Müller, N. G., \& Melloni, L. (2009). Age effects on attentional blink performance in meditation. Consciousness and Cognition, 18(3), 593-599. doi: 10.1016/j. concog.2009.05.001

Varela, F., Lachaux, J. P., Rodriguez, E., \& Martinerie, J. (2001). The brainweb: phase synchronization and large-scale integration. Nature Reviews Neuroscience, 2(4), 229-239. doi: $10.1038 / 35067550$ 
Welch, B. L. (1951). On the Comparison of Several Mean Values: An Alternative Approach. Biometrika, 38(3/4), 330-336. doi: 10.2307/2332579

Wen, W., Zhu, W., He, Y., Kochan, N. A., Reppermund, S., Slavin, M. J., Brodaty, H., Crawford, J., Xia, A., \& Sachdev, P. (2011). Discrete neuroanatomical networks are associated with specific cognitive abilities in old age. The Journal of Neuroscience, 31(4), 12041212. doi: 10.1523/JNEUROSCI.4085-10.2011

Whitfield-Gabrieli, S., Moran, J. M., Nieto-Castanon, A., Triantafyllou, C., Saxe, R., \& Gabrieli, J. D. (2011). Associations and dissociations between default and self-reference networks in the human brain. Neuroimage, 55(1), 225-232. doi: 10.1016/j.neuroimage.2010.11.048

Willis, S. L., Tennstedt, S. L., Marsiske, M., Ball, K., Elias, J., Koepke, K. M., Morris, J. N., Rebok, G. W., Unverzagt, F. W., Stoddard, A. M., \& Wright, E. (2006). Long-term effects of cognitive training on everyday functional outcomes in older adults. Journal of the American Medical Association, 296(23), 2805-2814. doi: 10.1001/jama.296.23.2805

Wilson, R. S., Segawa, E., Boyle, P. A., \& Bennett, D. A. (2012). Influence of late-life cognitive activity on cognitive health. Neurology, 78(15), 1123-1129. doi: 10.1212/ WNL.0b013e31824f8c03

Wolever, R. Q., Bobinet, K. J., McCabe, K., Mackenzie, E. R., Fekete, E., Kusnick, C. A., \& Baime, M. (2012). Effective and viable mind-body stress reduction in the workplace: a randomized controlled trial. Journal of Occupational Health Psychology, 17(2), 246258. doi: $10.1037 / \mathrm{a} 0027278$ 



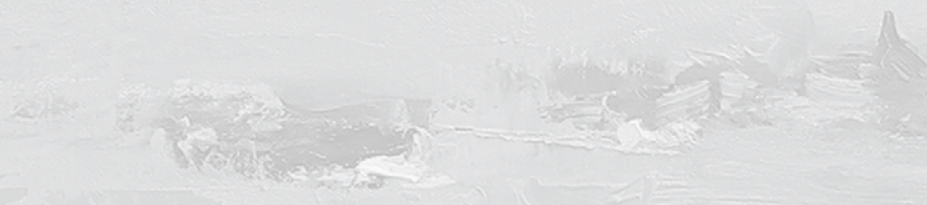


CHAPTER 6

GREATER CAUDATE CONNECTIVITY

IN AGING YOGIS AND MEDITATORS AS POTENTIAL MEDIATOR OF INCREASED

BEHAVIORAL FLEXIBILITY,

MENTAL HEALTH, AND WELL-BEING

Based on: Gard, T. , Maxime, T. ${ }^{*}$, Rohan, D., Britta, K. H., Dickerson, B. C., \& Lazar, S. W. (in revision). Greater widespread functional connectivity of the caudate in older adults who practice kripalu yoga and vipassana meditation than in controls. 


\section{ABSTRACT}

There has been a growing interest in understanding how contemplative practices affect brain functional organization. However, most studies have restricted their exploration to predefined networks. Furthermore, scientific comparisons of different contemplative traditions are largely lacking.

Here we explored differences in whole brain resting state functional connectivity between experienced yoga practitioners, experienced meditators and matched controls. Analyses were repeated in an independent sample of experienced meditators and matched controls.

Analyses utilizing Network Based Statistics revealed difference components for yoga practitioners $>$ controls and meditators $>$ controls in which the right caudate was a central node. Follow up analyses revealed that yoga practitioners and meditators had significantly greater degree centrality in the caudate than controls. This greater degree centrality was not driven by single connections but by greater connectivity between the caudate and numerous brain regions. Findings of greater caudate connectivity in meditators than in controls was replicated in an independent dataset.

These findings suggest that yoga and meditation practitioners have stronger functional connectivity within basal ganglia cortico-thalamic feedback loops than non-practitioners. Although we could not provide evidence for its mechanistic role, this greater connectivity might be related to the often reported effects of meditation and yoga on behavioral flexibility, mental health and well-being. 


\section{INTRODUCTION}

There is a growing interest in the neural correlates of meditation practice. While initial studies focused on the meditative state or the effects of meditation on brain activation during a specific task, more recent studies also have investigated the effect of ongoing regular meditation experience on the resting state of the brain (Brewer et al., 2011; Jang et al., 2011; Kilpatrick et al., 2011; Taylor et al., 2013). These studies have provided first insights in how meditation affects functional brain connectivity at rest. An important limitation of these studies is that they only investigate differences in connectivity between nodes of the default mode network (Buckner, Andrews-Hanna, \& Schacter, 2008) without accounting for the complex network structure that these connections underpin. Recent models of the brain as a complex network has furthered the understanding of its resting state and provided robust methods to compare its properties amongst subjects based on graph theory. These methods refrain from comparing the fMRI signal at every voxel, thereby increasing the statistical power of group comparisons. Therefore this approach is particularly useful for studying the brain resting state between groups of healthy subjects, for which differences may be subtle.

Further, the above-mentioned studies focused only on practitioners of meditation. There is much theoretical debate about how various contemplative practices may be similar or different, both in terms of mechanisms and effects. There is a growing interest in understanding how different contemplative practices compare (Brewer et al., 2011). A study directly comparing different practices may therefore provide invaluable insights into the neural processes involved and provide concrete evidence as to how these practices differ, or not.

In this study, we investigate local differences in the brain resting state functional networks of individuals with extensive meditation or yoga practice compared to demographically matched controls. Unlike previous studies, we use a data-driven approach to reliably identify the differences in networks between the groups across the entire brain, without limiting ourselves to any a priori sub-network or region. To strengthen confidence in the main finding, we repeated analyses with a second, independent dataset of experienced meditators and controls. 


\section{MATERIALS AND MethodS}

\section{PARTICIPANTS}

The first study consisted of forty-seven participants: 16 yoga practitioners, 16 meditation practitioners, and 15 controls. The three groups were matched for age, gender, education, race, and handedness. Yoga practitioners were primarily trained in the Kripalu Yoga (Faulds, 2005) tradition and had an average of 13,534 $(S D=9,950)$ hours of yoga experience. Meditators were primarily trained in Vipassana (a.k.a. insight or mindfulness) meditation (Goldstein \& Kornfield, 2001) and had an average of 7,458 hours $(S D=5,734)$ of meditation experience. Controls had less than 4 yoga or meditation classes in the past year and less than 10 classes in their lifetime. See Table 1 for the demographic characteristics of each group. Participants provided written informed consent and were compensated $\$ 100$ for their time. The study was approved by the Partners Human Research Committee, Massachusetts General Hospital (protocol 2005P001392). Other data from these subjects has been published elsewhere (T. Gard et al., 2014).

For the replication study we used data of a subset of individuals who participated in a previously published study (Lazar et al., 2005). Resting state BOLD data was available for 13 Vipassana meditation practitioners and 16 controls with little or no meditation experience (less than 4 classes in the past year and less than 10 classes in their lifetime). Meditators had an average experience of 4,831 $(S D=3,738)$ hours. See Table 2 for the demographic characteristics of each group. Participants provided written informed consent and were compensated $\$ 100$ for their time. The study was approved by the Partners Human Research Committee, Massachusetts General Hospital (protocol 2000p-001392).

\section{IMAGE ACQUISITION}

For the original study data was collected on a Siemens 1.5 Tesla Avanto MRI scanner (Erlagen, Germany) at the Martinos Center for Biomedical Imaging. Structural images were acquired using a T1-weighted magnetization prepared rapid acquisition gradient echo (MPRAGE) sequence (128 sagittal slices, slice thickness $=1.33 \mathrm{~mm}, \mathrm{TR}=2.73 \mathrm{~s}, \mathrm{TE}=3.39 \mathrm{~ms}$, flip angle $=7^{\circ}$, field of view $=256 \times 256 \mathrm{~mm}$, matrix $=192 \times 192 \mathrm{~mm}$ ). A 5 minute functional resting state scan was acquired using a gradient echo $\mathrm{T} 2{ }^{\star}$-weighted sequence $\left(\mathrm{TR}=2.5 \mathrm{~s}, \mathrm{TE}=40 \mathrm{~ms}, \mathrm{FA}=90^{\circ}\right.$, field of view $=320 \times 320 \mathrm{~mm}$, matrix $\left.=64^{\prime} 64 \mathrm{~mm}\right)$. Twenty five sagittal slices with $1 \mathrm{~mm}$ gap (voxel size: $3.13 \times 3.13^{\prime} 5 \mathrm{~mm}$ ) were acquired inter-leaved.

For the replication study data was collected on a Siemens 1.5 Tesla Sonata MRI scanner (Erlagen, Germany) at the Martinos Center for Biomedical Imaging. Structural 
images were acquired using a T1-weighted magnetization prepared rapid acquisition gradient echo (MPRAGE) sequence ( 128 sagittal slices, slice thickness $=1.33 \mathrm{~mm}, \mathrm{TR}=2.73 \mathrm{~s}$, $\mathrm{TE}=3.39 \mathrm{~ms}$, flip angle $=7^{\circ}$, field of view $=256 \times 256 \mathrm{~mm}$, matrix $=192 \times 192 \mathrm{~mm}$ ). A 6.7 minute functional resting state scan was acquired using a gradient echo $\mathrm{T} 2{ }^{*}$ weighted sequence $\left(\mathrm{TR}=4 \mathrm{~s}, \mathrm{TE}=40 \mathrm{~ms}, \mathrm{FA}=90^{\circ}\right.$, field of view $=320 \times 320 \mathrm{~mm}$, matrix $=64^{\prime} 64 \mathrm{~mm}$ ). Twenty five sagittal slices with $1 \mathrm{~mm}$ gap (voxel size: $3.13 \times 3.13^{\prime} 5 \mathrm{~mm}$ ) were acquired inter-leaved. Participants of both the original and the replication study were instructed not to meditate during the resting state scan.

\section{ANALYSIS}

\section{DEMOGRAPHICS}

To test if groups were successfully demographically matched for age and education, ANOVAs and independent sample t-tests (two-tailed) were conducted for the original and the replication study respectively. To evaluate comparability on gender, handedness and race, $\chi^{2}$-tests were conducted for both studies.

\section{DATA PREPROCESSING}

For both studies resting state data were slice time corrected, realigned, coregistered to individual T1-weighted images, normalized, and spatially smoothed with at $5 \mathrm{~mm}$ kernel using SPM8 (Wellcome Department of Cognitive Neurology, London, UK; www.fil.ion.ucl.ac.uk/spm/). Next, in the original study the first 8 volumes of the functional time series were discarded to allow for stabilization of the MR signal. The remaining 112 volumes were further preprocessed using the Connectivity toolbox (http://www.nitrc.org/projects/conn; Whitfield-Gabrieli et al., 2010). In the replication study the first 5 volumes were discarded and the remaining 95 were further processed in the same way as the data from the original study. Mean white matter signal, mean CSF signal, 6 motion parameters, and the first order motion derivative were regressed out of the data. Finally, the residual time series were band-pass filtered with a window of 0.008-0.09 Hz.

\section{ANATOMICAL PARCELLATION AND TIME SERIES EXTRACTION}

Resting state scans were parcellated into 116 regions of interest (ROIs; 90 cortical and subcortical, and 26 cerebellar) using the Automated Anatomical Labeling (AAL; Tzourio-Mazoyer et al., 2002) template in the Wake Forest University (WFU) Pickatlas version 2.5 (Maldjian, Laurienti, Kraft, \& Burdette, 2003). 
For each ROI, the average (of all voxels in the ROI) preprocessed time-series was extracted, resulting in a 116 (ROIs) $\times 112$ (volumes) time-series matrix for each subject. These matrices were used to generate bivariate correlation matrices for each subject. Time-series extraction was done with the Connectivity toolbox (http://www. nitrc.org/projects/conn; Whitfield-Gabrieli et al., 2010).

\section{NetWORK ANALYSIS}

Due to methodological constraints in analyzing networks with both positive and negative weights (Schwarz \& McGonigle, 2011), correlation matrices were thresholded such that only positive correlations remained. As a result, the basis for the network analyses were each subject's weighted, undirected network (or "graph"), with 116 nodes and positive weighted edges. Network analyses were done using NetworkX (Hagberg, Schult, \& Swart, 2008). We chose to analyze weighted networks instead of binary networks, as binarization results in loss of valuable information (Barrat, Barthelemy, Pastor-Satorras, \& Vespignani, 2004) and weighted network analyses have been shown to be more reliable (Wang et al., 2011).

\section{Network Based Statistics}

To explore differences in resting state brain functional connectivity between yoga practitioners, meditators and controls, while considering the entire brain network, we employed Network-Based Statistics (NBS). NBS is a solution to the multiple comparison problem that occurs when comparing many edges in a network. NBS assumes that edges contributing to population differences tend to appear in connected components (Zalesky et al., 2010). Introducing this assumption decreases the number of comparisons and unveils clusters of edges that significantly differ between the groups.

More specifically, we used the NBS method for the comparisons yoga practitioners $>$ controls, meditators $>$ controls and yoga practitioners versus (two-sided test) meditators. For the comparisons involving controls we used one-sided tests, based on previous studies that found greater resting stage connectivity in meditators compared to controls (Brewer et al., 2011). Much like cluster-based statistics, NBS requires a threshold on the $t$-statistics (or equivalently on the $p$-value) of individual edge differences. Connected components are subsequently defined in the binary network of supra-threshold edges. To explore spatially small, hence interpretable, subnetworks, we used a relatively severe initial threshold of $p<0.00005$.

\section{Degree centrality}

Network-based statistics limits the number of comparisons by automatically and reliably identifying subnetworks of interests. To further investigate the central role that the caudate (central node of the detected subnetworks) plays in the functional 
networks for yoga practitioners $>$ controls and meditators $>$ controls, degree centrality of the caudate was computed for each subject (equation 1). Degree centrality was chosen as it is conceptually the simplest measure of nodal importance in a network. Degree centrality is defined as:

$$
C_{D}(v)=\frac{\operatorname{deg}(v)}{n-1}
$$

where $\operatorname{deg}(v)$ is the weighted degree of the node $\mathrm{v}$ and $\mathrm{n}$ is the total number of nodes in the network. A larger degree centrality therefore implies that the node is more connected to the rest of the network.

We compared the degree centrality of controls, meditators and yoga practitioners for the left and right caudate nuclei. Since the assumption of homogeneity of variances was not met, we used a Welch's test to assess the equality of means in the population. The test was followed up by independent two-tailed t-tests comparing yoga practitioners, meditators and controls pairwise. To validate the findings from these analyses, we tested the hypothesis that meditators have greater degree centrality than controls (independent samples t-test, one-tailed) in an independent dataset of 13 meditators and 16 controls.

\section{Individual edges}

To follow up the finding of greater degree centrality of the caudate in yoga practitioners and meditators vs. controls, connectivity between the caudate and each of the 115 other nodes in the network was compared between yoga practitioners and controls and meditators and controls. To do so, correlation coefficients were Fisher-transformed (equation 2) to obtain normally distributed values which were used for the second-level node-wise analysis.

$$
z=\frac{1}{2} \ln \frac{1+r}{1-r}=\operatorname{arctanh}(r)
$$

Where $r$ represents the correlation coefficient value.

Then, independent samples t-tests (two-tailed) were calculated for each edge for yoga practitioners vs. controls, and meditators vs. controls. Correction for multiple comparisons was done using the False Discovery Rate (FDR; $\mathrm{q}<0.5$; Genovese, Lazar, \& Nichols, 2002). Fisher transformation, and the node-wise analysis was done with the Connectivity toolbox (http://www.nitrc.org/projects/ conn; Whitfield-Gabrieli et al., 2010). Again, to validate the findings from this analysis we repeated the above analyses on an independent dataset of 13 meditators and 16 controls. 


\section{COGNITIVE ASSESSMENT}

Due to the role of the caudate in aging and cognitive functioning, the relation between degree centrality in the left and right caudates and age and fluid intelligence was explored in the original sample. This was done by calculating Pearson product moment correlations over the merged groups. Fluid intelligence was measured with the odd items of the Raven's Advanced Progressive Matrices (APM) (Raven, 2000; Raven, Raven, \& Court, 1998).

\section{RESULTS}

To test the success of participant matching in both the original as well as in the replication data set, ANOVAs, t-tests and $\chi^{2}$-test were conducted. There were no significant differences in age, education, gender, handedness and race between yoga practitioners, meditators and controls in the original data set (Table 1). In the replication data set there also were no differences on these variables between meditators and controls (Table 2).

Table 1. Comparison of demographic variables between controls, yogis, and meditators for the original dataset.

\begin{tabular}{|c|c|c|c|c|c|c|c|c|c|}
\hline & \multicolumn{2}{|c|}{ Controls } & \multicolumn{2}{|c|}{$\begin{array}{c}\text { Yoga } \\
\text { practitioners }\end{array}$} & \multicolumn{2}{|c|}{ Meditators } & \multicolumn{3}{|c|}{ ANOVA / $\chi^{2}$-test } \\
\hline & $M / \%$ & $S D$ & $M / \%$ & $S D$ & $M / \%$ & $S D$ & $F / \chi^{2}$ & $d f$ & $p$ \\
\hline Age (years) & 52.93 & 9.84 & 49.38 & 7.79 & 54.06 & 8.15 & 1.29 & 2,44 & 0.286 \\
\hline Education (years) & 17.27 & 1.98 & 17.31 & 2.41 & 18.44 & 2.58 & 1.26 & 2,44 & 0.293 \\
\hline Gender (\% female) & $60 \%$ & & $69 \%$ & & $63 \%$ & & 0.28 & 2 & 0.871 \\
\hline Handedness (\% right) & $87 \%$ & & $88 \%$ & & $88 \%$ & & 0.01 & 2 & 0.997 \\
\hline Race (\% white) & $100 \%$ & & $100 \%$ & & $100 \%$ & & & & \\
\hline
\end{tabular}


Table 2. Comparison of demographic variables between controls, and meditators for the replication dataset.

\begin{tabular}{|c|c|c|c|c|c|c|c|}
\hline & \multicolumn{2}{|c|}{ Controls } & \multicolumn{2}{|c|}{ Meditators } & \multicolumn{3}{|c|}{ t-test $/ \chi^{2}$-test } \\
\hline & $M / \%$ & $S D$ & $M / \%$ & $S D$ & $t / \chi^{2}$ & $d f$ & $p$ \\
\hline Age (years) & 36.00 & 7.67 & 38.15 & 7.85 & 0.74 & 27 & 0.463 \\
\hline Education (years) & 17.13 & 1.77 & 17.54 & 1.85 & 0.59 & 26 & 0.559 \\
\hline Gender (\% female) & $44 \%$ & & $31 \%$ & & 0.51 & 1 & 0.474 \\
\hline Handedness (\% right) & $100 \%$ & & $100 \%$ & & & & \\
\hline Race (\% white) & $100 \%$ & & $100 \%$ & & & & \\
\hline
\end{tabular}

\section{NETWORK BASED STATISTICS}

To compare whole brain resting state networks of yoga practitioners, meditators, and controls, the Network Based Statistic (NBS; Zalesky et al., 2010), a novel approach to correct edgewise connectivity for multiple comparisons, was used. At the stringent initial $p$-threshold of $p<0.00005$, this approach revealed a significant $(p=0.031)$ difference component for the comparison yoga practitioners $>$ controls. This component was comprised of three nodes and two edges, with the right caudate serving as the central node, connected to the left parahippocampal gyrus and the left interior temporal gyrus. The comparisons meditators $>$ controls and yoga practitioners versus (two tailed test) meditators did not reveal significant difference components. Although not significant, it is striking to note that the largest difference component for meditators > controls was comprised of the same two connected nodes, namely the right caudate and the left parahippocampal gyrus as in the difference network for yoga practitioners $>$ controls.

\section{Degree Centrality Caudate}

To further investigate the central role of the caudate in the identified components, we calculated the degree centrality of the right and left caudate for each participant's weighted network and compared it between groups. Welch's test of equality of means, which is an alternative to ANOVA when the assumption of homogeneity of variances is not met (Welch, 1951), revealed that the mean degree centrality was different for yoga practitioners, meditators, and controls in the right $(F(2,24.576)=14.587$, $p<0.001)$ and in the left caudate $(F(2,23.785)=5.867, p=0.008)$. Post-hoc independent samples t-tests (two-tailed) revealed that this effect in the left caudate was driven by greater weighted degree in yoga practitioners $(M=0.132, S D=0.088$; $t(18.390)=2.171, p=0.038)$ and meditators $(M=0.148, S D=0.088 ; t(19.362)=2.801$, $p=0.009)$ than in controls $(M=0.081, S D=0.029$; Figure $1 \mathrm{a})$. There was no signifi- 
cant difference between yoga practitioners and meditators $(t(30)=0.490, p=0.628)$. The effect in the right caudate also was driven by greater weighted degree in yoga practitioners $(M=0.153, S D=0.072 ; t(19.318)=3.472, p=0.003)$ and meditators $(M=0.176, S D=0.073 ; t(19.224)=4.641, p<0.001)$ than in controls $(M=0.086$, $S D=0.027$; Figure $1 \mathrm{~b})$. There was no significant difference between yoga practitioners and meditators $(t(30)=0.916, p=0.367)$. Degree centrality of the left and right caudates were not significantly correlated with age $(\mathrm{r}(45)=0.033, p=0.823$ and $r(45)=-064, p=0.671$ respectively) or fluid intelligence $(r(45)=0.130, p=0.385$ and $\mathrm{r}(45)=0.043, p=0.776$ respectively).

These findings were replicated in an independent dataset of 13 meditators and 16 controls. Meditators $(M=0.130, S D=0.067)$ had significantly greater degree centrality in the left caudate than controls $(M=0.065, S D=0.028 ; t(15.269)=3.238$, $p=0.003$; Figure 1c). In the right caudate meditators $(M=1.463, S D=0.089)$ also had greater degree centrality than controls $(M=0.090, S D=0.049 ; t(17.746)=2.021$, $p=0.028$; Figure 1d).

\section{INDIVIDUAL EDGES}

To find out by what edges the greater centrality in yoga practitioners and meditators as compared to controls was driven, the average connectivity between the caudate and all 115 other brain regions was compared pairwise between yoga practitioners, meditators and controls. Yoga practitioners and meditators had stronger connectivity to a large number of brain regions as compared to controls, while there were no differences between yoga practitioners and meditators (Figure 2 A-D).

The finding of greater connectivity between the caudate and a large number of brain regions in meditators than in controls was replicated in the independent dataset (Figure $2 \mathrm{E}-\mathrm{F}$ ). 
(a)

Left Caudate

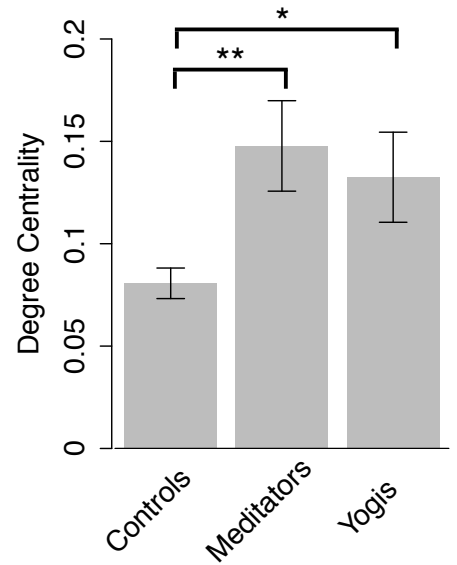

(c)

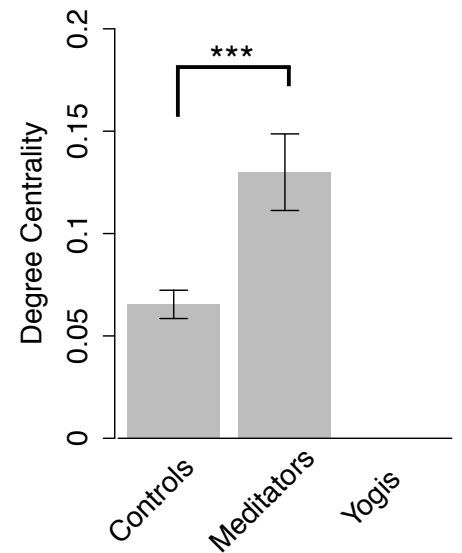

(b) Right Caudate

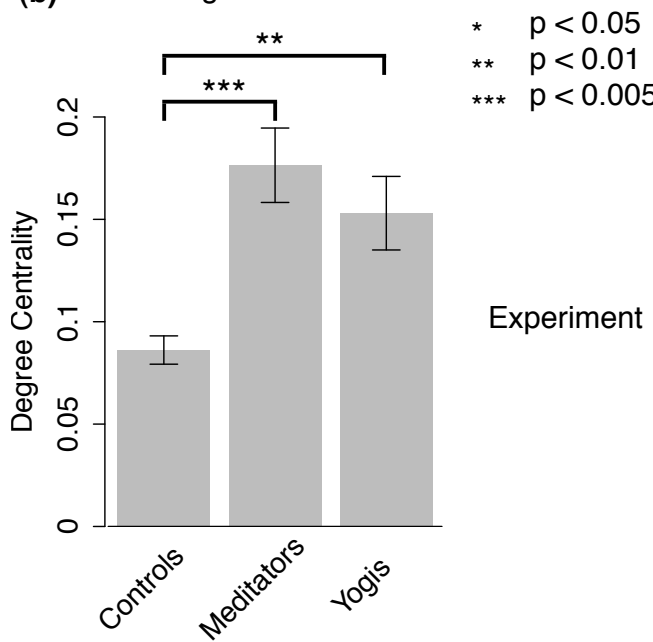

(d)

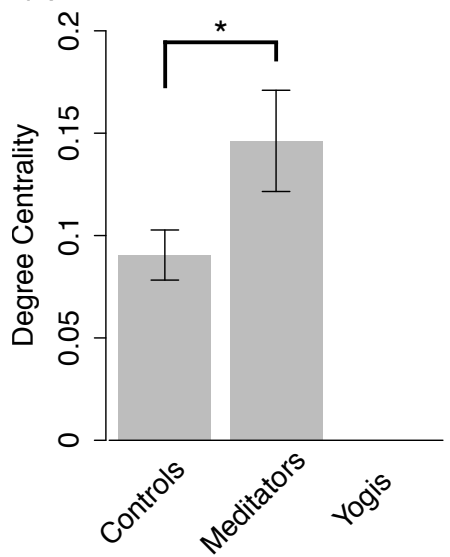

Replication

Figure 1. Degree centrality in left and right caudate in the original experiment (a and b) and in the replication study ( $\mathrm{c}$ and d). Error bars represent standard error of the mean. P-values are based on independent samples t-tests. 

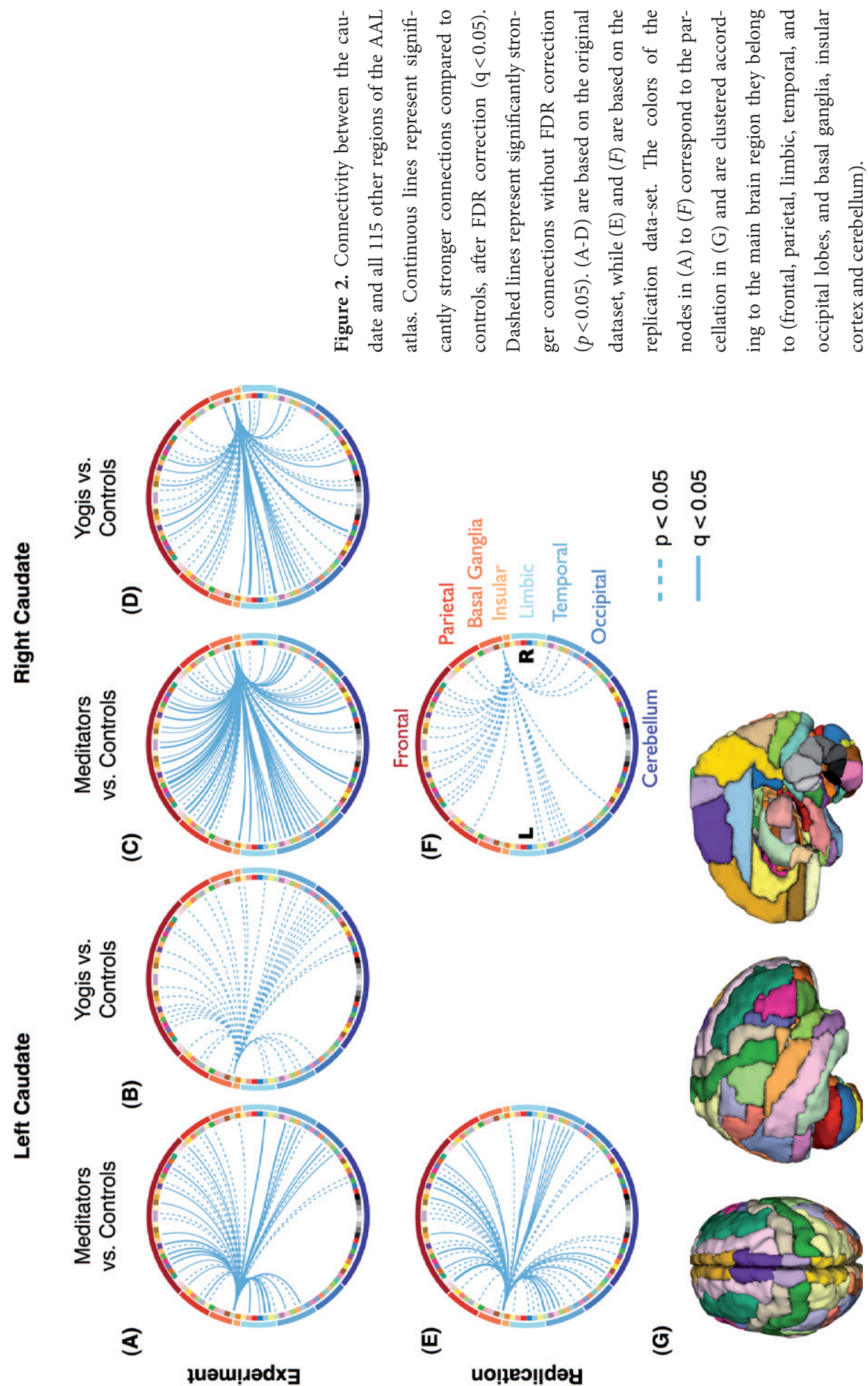


\section{DISCUSSION}

Here we investigated differences in resting state networks between yoga practitioners, meditators and controls. Our data revealed that the caudate was a hub in the difference network (i.e. the network whose edges represent the differences between the groups) between yoga practitioners and controls. Not only was the caudate a hub in the difference network, yoga practitioners and meditators also had greater degree centrality in the caudate than controls. Further post-hoc analyses revealed this greater degree centrality was not driven by a specific connection but rather by widespread stronger connectivity between the caudate and multiple regions across the rest of the brain.

This finding of widespread stronger connectivity of the caudate in both yoga practitioners and meditators is consistent with overlapping theoretical mechanisms involved in both practices. Both Kripalu Yoga and Vipassana theoretically and empirically foster mindfulness, thereby sharing a key aspect (Chiesa, 2010; Faulds, 2005; Gard et al., 2012; Perelman et al., 2012). This overlap between the practices might also be the reason why we did not find significant differences in resting state brain networks between yoga practitioners and meditators. With a larger sample size it might be possible to identify more subtle differences in resting state network organization between yoga practitioners and meditators. It will also be interesting to test contemplative traditions that do not emphasize mindfulness.

This is, to our knowledge, the first study revealing greater resting state functional connectivity between the caudate and a variety of brain regions in experienced yoga practitioners and meditators as compared to controls. Our finding of greater degree centrality in the caudate of meditators is particularly strong as it was replicated in an independent sample, collected at a different time, on a different scanner and with different scanning parameters. Remarkably, despite these technological differences, not only the statistical significance of the differences but also the magnitude of these differences were replicated (Figure 1).

Although not much is known about the role of the caudate in meditation, this structure has been reported in several meditation-related brain imaging studies. Structural brain imaging studies revealed increased gray matter volume/density in the caudate after completion of 8-week mindfulness-based interventions (Farb, Segal, \& Anderson, 2013; Pickut et al., 2013), while dispositional mindfulness in nonmeditators has been reported to be negatively correlated with caudate volume (Taren, Creswell, \& Gianaros, 2013).

Functional studies have revealed increased activity in this region during the state of meditation. Lazar et al. (2000) for example found increased caudate activation during kundalini silent mantra meditation as compared to a silent random word generation task in experienced kundalini meditation practitioners. Dickenson et al. (2013) reported increased caudate activity in novice mediators during mindful breath 
awareness as compared to mind wandering. Another study that assessed activity during different phases in the interplay between mindful awareness and mind wandering in moderately experienced meditators revealed increased caudate activity during the attention shifting phase, when attention was shifted to the breath, as compared to mind wandering phase (Hasenkamp, Wilson-Mendenhall, Duncan, \& Barsalou, 2012). Brefczynski-Lewis et al. (2007) also investigated different phases of the meditation process but in Tibetan Buddhist meditators with different levels of experience. They reported increased caudate activity only during the startup phase (first 10sec) of a concentrative meditation in the most experienced meditators (greater than 37,000 hours experience), while the less experienced long term meditators (10,000-24,000 hours) also had increased caudate activity during the continuation phase of the meditation session. Another study that included a mix of Tibetan Buddhist and Zen meditators reported increased caudate activation during continuous meditation as compared to rest, although the analysis was not corrected for multiple comparisons (Baerentsen et al., 2010). The involvement of the caudate in the meditative state as compared to rest has further been confirmed by a meta analysis that included studies with a wide variety of meditation practices (Sperduti, Martinelli, \& Piolino, 2012).

Despite clear differences on the surface, different meditation techniques seem to have some overlap in their neural basis, including in the caudate. However, one study investigating experienced Kria Yoga practitioners reported decreased activation of caudate during meditation (guided imagery) as compared to rest (Lou et al., 1999). This discrepancy might be due to that specific meditation practice, or to the fact that just before the experiment in the scanner started, participants had practiced an intense form of concentrative meditation for two hours. Methodological differences between this early and the more recent studies may be another reason.

Increased caudate activity has also been reported at rest in novices after completing a short integrative body-mind meditation training (Tang et al., 2009). Furthermore, a sample of experienced meditators from a variety of traditions, including Tibetan Buddhist meditators and Franciscan nuns, have been shown to have greater caudate activity at rest than matched controls (Newberg et al., 2010).

The state of meditation has also been investigated in terms of brain connectivity. Baerentsen et al. (2010) performed Independent Component Analysis (ICA) on the fMRI time-series during sustained meditation. This analysis revealed a number of components including one large component comprising the caudate, the lateral prefrontal cortex, the precentral gyrus, the insula, the temporal gyrus, the parahippocampal gyrus, the fusiform gyrus, the ligual gyrus, and the cerebellum. Our findings are aligned with this finding of a meditation-related network that involves the caudate, alongside frontal and temporal brain regions. We extend the finding by revealing this network in both meditators and yoga practitioners, at rest, and by revealing the central role of the caudate in this network. 
Most studies so far have only reported meditation related caudate activity as a side finding and have not attempted to interpret it extensively. However, the role of the caudate in meditation has been discussed in a number of theoretical accounts. In these theories the caudate is discussed as a key component of the basal gangliathalamocortical circuits. These segregated circuits originate in functionally related cortical regions that send excitatory glutamergic projections to specific parts of the striatum, which then send converging projections to the pallidus and substantia nigra through a direct net-inhibitory and an indirect net-excitatory pathway. Both pathways to the basal ganglia output regions are mostly GABAergic and are modulated by dopaminergic projections from the midbrain, resulting in net inhibition of the neurons in the output regions. The latter have GABAeric projections to specific thalamic nuclei which project back (glutamergic) to the main prefrontal area that fed the loop and after which the loop is named. In three out of the five known loops, the oculomotor-, dorsolateral prefrontal-, and lateral orbitofrontal loops, the caudate is the central striatal component (Alexander \& Crutcher, 1990; Alexander, DeLong, \& Strick, 1986). In the oculomotor loop the caudate receives input from the frontal eyefields, the dorsolateral prefrontal cortex and the posterior parietal cortex, and in the dorsolateral prefrontal loop from the posterior parietal cortex and the arcuate premotor area. In the lateral orbitofrontal loop it receives input from the superior and inferior temporal gyrus and from the anterior cingulate cortex (Alexander et al., 1986).

These frontal-subcortical loops have been related to a variety of human behaviors, including alterations in emotion and cognition as a result of lesions (Cummings, 1993). As Graybiel (2000) noted "Under conditions of circuit dysfunction, at one extreme excessive and repetitive actions or thoughts could result, and the other extreme poverty of movement or thought could be the result." A recent metaanalysis has related caudate functional connectivity in particular to cognition, emotion, action and perception (Robinson et al., 2012).

With its broad converging cortical input, its gating function on the thalamus and its modulation by the dopaminergic reward system, the basal ganglia are implicated in reinforcement learning: learning to take actions that maximize reward (Braunlich \& Seger, 2013). Two types of reinforcement learning can be distinguished: model-based or goal-directed and model-free or habitual learning. The former involves value based and contingency learning and results in behavioral flexibility. The latter involves simple stimulus response learning and although low in computational cost it is not adaptive in changing environments (Braunlich \& Seger, 2013; Doll, Simon, \& Daw, 2012; Schwabe \& Wolf, 2011). While both types of learning utilize dopamine mediated reward prediction error signaling from the ventral tegmental area and the substantia nigra (Schultz, Dayan, \& Montague, 1997), goal directed learning is mediated by the caudate and habitual learning by 
the putamen (Braunlich \& Seger, 2013). Indeed, a recent study revealed that flexible goal-directed behavior was predicted by white matter structural connectivity between caudate and ventromedial prefrontal cortex while non-adaptive habitual behavior was predicted by connectivity between the putamen and the premotor cortex (de Wit et al., 2012). This finding combined with our finding of greater widespread caudate connectivity in yoga practitioners and meditators might suggest that the positive association between mindfulness and cognitive and behavioral flexibility (Anicha, Ode, Moeller, \& Robinson, 2012; Carmody, Baer, Lykins, \& Olendzki, 2009 ) is mediated by connectivity between caudate and prefrontal cortex. Interestingly, stress which can be reduced through meditation and yoga (Carmody \& Baer, 2008; Gard et al., 2012), has been shown to result in a shift from goal-directed to habitual behavior (Schwabe \& Wolf, 2011).

Some theoretical models of meditation and yoga incorporate basal gangliathalamocortical circuits. In the model of Vago and Silbersweig (2012) for example, these loops are closely related to the experiential enactive self (EES) network, one of four networks that they hypothesize to underlie self-awareness, self-regulation, and self-transcendence through mindfulness. The EES refers to a non-conscious sensoryaffective-motor learning network that Vago and Silbersweig (2012) hypothesized to support attention regulation and awareness of sensory and mental activity. In a more recent paper, Vago (2014) explicitly extends this view to habits of minds. Similarly Gard et al. (2014) have proposed that yoga practice also involves basal ganglia corticothalamic circuits involved in extinction learning to unlearn old, maladaptive behavioral patterns and to establish new, adaptive ones. Travis \& Wallace (1999) proposed that the state of meditation is initiated by a "neural switch" network involving frontal brain regions and is further maintained by a "maintenance" network that involves basal ganglia cortico-thalamic feedback loops. Similarly Newberg and Iverson (2003) in their neurochemical model of meditation proposed that meditation is initiated by frontal brain regions and maintained by basal ganglia cortico-thalamic feedback loops. The involvement of these frontal-subcortical loops in this model is supported by the finding of increased dopamine release in the striatum during the yoga nidra meditation (Kjaer et al., 2002) and increased GABA levels in the thalamus after yoga practice (Streeter et al., 2007; Streeter et al., 2010). However, in contrast to these models, a recent fMRI study (Baerentsen et al., 2010) did not find evidence for the frontal involvement but rather increased brain activity in the putamen at the onset of meditation. During sustained meditation, increased activation in the caudate was reported. Based on these findings, the previously proposed models and their own meta-analysis, Sperduti et al.(2012) proposed a three component model for the state of meditation comprising an "interference control system", a "thoughts monitoring system", and a "self monitoring system". It is the interference control system that would support both the switching to and the maintenance of the meditative state through in- 
volvement of the putamen and the caudate as part of a basal ganglia cortico-thalamic feedback system. Sperduti et al. (2012) note that their model is based on increased brain activation during meditation as compared to baseline and suggest that it should be further validated with other methods including functional connectivity.

The fact that greater connectivity was not driven by single strong connections but by wide-spread connections including those to frontal, temporal and parietal regions, further suggests that yoga practitioners and meditators have more efficient basal ganglia cortico-thalamic feedback loops than controls. This enhanced basal ganglia cortico-thalamic feedback loop functioning even during a state of rest might be the result of repeated involvement of these loops during the state of meditation as proposed in the models of Sperduti et al. (2012), Newberg and Iversen (2003), Travis and Wallace (1999), Vago and Silbersweig (2012), and Gard et al.(2014). This lasting change in basal ganglia cortico-thalamic feedback loops might be of clinical relevance as disturbances in these loops have been associated with mental health disorders, e.g. autism (Turner, Frost, Linsenbardt, McIlroy, \& Muller, 2006), obsessive compulsive disorder (Harrison et al., 2009), schizophrenia (Salvador et al., 2010; Simpson, Kellendonk, \& Kandel, 2010), and depression (Bluhm et al., 2009). This combined with our finding of increased connectivity between caudate and several brain regions, and the fact that mindfulness based interventions have been shown to improve mental health (Grossman, Niemann, Schmidt, \& Walach, 2004), leads to the hypothesis that improved mental health due to mindfulness may be mediated in part by connectivity in caudate.

Normal aging and mild cognitive impairment are also both associated with decreased caudate connectivity ((Agosta et al., 2013; Klostermann, Braskie, Landau, O’Neil, \& Jagust, 2012; Morbelli et al., 2012; Podell et al., 2012), but see (Tomasi \& Volkow, 2012)), and caudate dopamine D1 receptor density (Rieckmann, Karlsson, Fischer, \& Backman, 2011). Although we did not find a significant correlation between age and degree centrality in the caudate in the current samples, the greater degree centrality in caudate in yoga and meditation practitioners may be the result of decreased age-related decline rather than an increased caudate connectivity due to practice. Interestingly, studies have shown that the greater caudate-frontal connectivity in younger subjects is associated with better working memory performance (Klostermann et al., 2012; Podell et al., 2012) and that the shape and volume of the striatum are related to intelligence (Burgaleta et al., 2014; MacDonald, Ganjavi, Collins, Evans, \& Karama, 2014). These findings, combined with our previous finding in the current sample that age-related decline in fluid intelligence is offset in yoga and meditation practitioners (T. Gard et al., 2014), suggest that decreased age-related decline in fluid intelligence in yoga and meditation practitioners may be mediated in part by increased caudate connectivity. However, we did not find a significant correlation between fluid intelligence and degree centrality in caudate, possibly due to power limitations. 


\section{LIMITATIONS}

This study has several limitations. The design is cross sectional so no inference about the causality of the greater caudate connectivity can be made. Furthermore, although instructed to rest and not to meditate, there is no objective way to verify that participants were not actively meditating during the resting state scan. Lastly, as participants in the first sample as well as half of the participants in the replication study are of middle age, it is not clear if greater caudate connectivity is the result of a meditation-related increase or an offset of age-related decline. This limitation of potential age-related effects is a problem in many studies with experienced yoga and meditation practitioners as many practitioners with extensive practice tend to be older.

\section{CONCLUSION}

In summary, we have demonstrated in two independent datasets that yoga practitioners and meditators have greater degree centrality in the caudate than matched controls. Post-hoc analyses of both datasets revealed that the greater connectivity of the caudate was driven by wide spread connectivity to most of the cerebrum, including frontal, temporal and parietal brain regions.

These findings provide evidence for the previously hypothesized involvement of basal ganglia cortico-thalamic feedback loops in meditation (Sperduti et al., 2012) and yoga (Tim Gard et al., 2014). At the same time they extend these hypotheses by revealing stronger caudate connectivity not only in meditators but also in yoga practitioners. There have been relatively few neuroimaging studies of yoga practitioners and no studies directly comparing yoga and meditation practitioners, thus these data provide important information suggesting that different contemplative practices may have some similarities at the neural level. The current study was relatively small and was cross-sectional in design, so further studies with larger sample sizes and longitudinal designs are necessary to reveal the more subtle differences between the two. Our findings also extend previous hypotheses involvement of basal ganglia corticothalamic feedback loops during a state of meditation by providing support for increased connectivity in these loops during rest. This increased connectivity in these loops could be a potential mechanism accounting for improved behavioral flexibility, mental health and well-being that is associated with yoga and meditation. Further research is required to test this hypothesis. 


\section{ACKNOWLEDGEMENTS}

This study was funded by NIH award R21AT003673 and awards from the Kripalu Institute for Extraordinary Living, Sarah Hancock, and Jeff Walker. The project was made possible by the resources provided by Shared Instrumentation Grants 1S10RR023401, S10RR019307, and 1S10RR023043. We also would like to thank all participants for their contribution.

\section{REFERENCES}

Agosta, F., Sala, S., Valsasina, P., Meani, A., Canu, E., Magnani, G., Cappa, S. F., Scola, E., Quatto, P., Horsfield, M. A., Falini, A., Comi, G., \& Filippi, M. (2013). Brain network connectivity assessed using graph theory in frontotemporal dementia. Neurology, 81(2), 134-143. doi: 10.1212/WNL.0b013e31829a33f8

Alexander, G. E., \& Crutcher, M. D. (1990). Functional architecture of basal ganglia circuits: neural substrates of parallel processing. Trends in Neurosciences, 13(7), 266-271. doi: 10.1016/0166-2236(90)90107-L

Alexander, G. E., DeLong, M. R., \& Strick, P. L. (1986). Parallel organization of functionally segregated circuits linking basal ganglia and cortex. Annual Review of Neuroscience, 9(1), 357-381. doi: 10.1146/annurev.ne.09.030186.002041

Anicha, C. L., Ode, S., Moeller, S. K., \& Robinson, M. D. (2012). Toward a cognitive view of trait mindfulness: distinct cognitive skills predict its observing and nonreactivity facets. Journal of personality, 80(2), 255-285. doi: 10.1111/j.1467-6494.2011.00722.x

Baerentsen, K. B., Stodkilde-Jorgensen, H., Sommerlund, B., Hartmann, T., DamsgaardMadsen, J., Fosnaes, M., \& Green, A. C. (2010). An investigation of brain processes supporting meditation. Cognitive processing, 11(1), 57-84. doi: 10.1007/s10339-0090342-3

Barrat, A., Barthelemy, M., Pastor-Satorras, R., \& Vespignani, A. (2004). The architecture of complex weighted networks. Proceedings of the National Academy of Sciences of the United States of America, 101(11), 3747-3752. doi: 10.1073/pnas.0400087101

Bluhm, R., Williamson, P., Lanius, R., Theberge, J., Densmore, M., Bartha, R., Neufeld, R., \& Osuch, E. (2009). Resting state default-mode network connectivity in early depression using a seed region-of-interest analysis: decreased connectivity with caudate nucleus. Psychiatry and Clinical Neurosciences, 63(6), 754-761. doi: 10.1111/j.14401819.2009.02030.x

Braunlich, K., \& Seger, C. (2013). The basal ganglia. Wiley Interdisciplinary Reviews: Cognitive Science, 4(2), 135-148.

Brefczynski-Lewis, J. A., Lutz, A., Schaefer, H. S., Levinson, D. B., \& Davidson, R. J. (2007). Neural correlates of attentional expertise in long-term meditation practitioners. Pro- 
ceedings of the National Academy of Sciences of the United States of America, 104(27), 11483-11488. doi: 10.1073/pnas.0606552104

Brewer, J. A., Worhunsky, P. D., Gray, J. R., Tang, Y.-Y., Weber, J., \& Kober, H. (2011). Meditation experience is associated with differences in default mode network activity and connectivity. Proceedings of the National Academy of Sciences of the United States of America, 108(50), 20254-20259. doi: 10.1073/pnas.1112029108

Buckner, R. L., Andrews-Hanna, J. R., \& Schacter, D. L. (2008). The brain's default network Anatomy, function, and relevance to disease Year in Cognitive Neuroscience 2008 (Vol. 1124, pp. 1-38). Oxford, United Kingdom: Blackwell Publishing.

Burgaleta, M., Macdonald, P. A., Martinez, K., Roman, F. J., Alvarez-Linera, J., Gonzalez, A. R., Karama, S., \& Colom, R. (2014). Subcortical regional morphology correlates with fluid and spatial intelligence. Human Brain Mapping, 35(5), 1957-1968. doi: 10.1002/ hbm. 22305

Carmody, J., \& Baer, R. A. (2008). Relationships between mindfulness practice and levels of mindfulness, medical and psychological symptoms and well-being in a mindfulnessbased stress reduction program. Journal of Behavioral Medicine, 31(1), 23-33. doi: 10.1007/s10865-007-9130-7

Carmody, J., Baer, R. A., Lykins, E. L. B., \& Olendzki, N. (2009). An empirical study of the mechanisms of mindfulness in a mindfulness-based stress reduction program. Journal of Clinical Psychology, 65(6), 613-626. doi: 10.1002/jclp.20579

Chiesa, A. (2010). Vipassana meditation: systematic review of current evidence. The Journal of Alternative and Complementary Medicine, 16(1), 37-46. doi: 10.1089/acm.2009.0362

Cummings, J. L. (1993). Frontal-subcortical circuits and human behavior. Archives of Neurology, 50(8), 873-880. doi: 10.1001/archneur.1993.00540080076020

de Wit, S., Watson, P., Harsay, H. A., Cohen, M. X., van de Vijver, I., \& Ridderinkhof, K. R. (2012). Corticostriatal connectivity underlies individual differences in the balance between habitual and goal-directed action control. Journal of Neuroscience, 32(35), 12066-12075. doi: 10.1523/jneurosci.1088-12.2012

Dickenson, J., Berkman, E. T., Arch, J., \& Lieberman, M. D. (2013). Neural correlates of focused attention during a brief mindfulness induction. Social Cognitive and Affective Neuroscience, 8(1), 40-47. doi: 10.1093/scan/nss030

Doll, B. B., Simon, D. A., \& Daw, N. D. (2012). The ubiquity of model-based reinforcement learning. Current Opinion in Neurobiology, 1075-1081. doi: 10.1016/j.conb.2012.08.003

Farb, N. A., Segal, Z. V., \& Anderson, A. K. (2013). Attentional modulation of primary interoceptive and exteroceptive cortices. Cerebral Cortex, 23(1), 114-126. doi: 10.1093/ cercor/bhr385

Faulds, R. (2005). Kripalu yoga: a guide to practice on and off the mat. New York, NY: Bantam. Gard, T., Brach, N., Hölzel, B. K., Noggle, J. J., Conboy, L. A., \& Lazar, S. W. (2012). Effects of a yoga-based intervention for young adults on quality of life and perceived stress: The 
potential mediating roles of mindfulness and self-compassion. The Journal of Positive Psychology, 7(3), 165-175. doi: 10.1080/17439760.2012.667144

Gard, T., Noggle, J., Park, C., Vago, D. R., \& Wilson, A. (2014). Potential self-regulatory mechanisms of yoga for psychological health. Name: Frontiers in Human Neuroscience, 8, 770. doi: $10.3389 /$ fnhum.2014.00770

Gard, T., Taquet, M., Dixit, R., Holzel, B. K., de Montjoye, Y. A., Brach, N., Salat, D. H., Dickerson, B. C., Gray, J. R., \& Lazar, S. W. (2014). Fluid intelligence and brain functional organization in aging yoga and meditation practitioners. Front Aging Neurosci, 6, 76. doi: 10.3389/fnagi.2014.00076

Genovese, C. R., Lazar, N. A., \& Nichols, T. (2002). Thresholding of Statistical Maps in Functional Neuroimaging Using the False Discovery Rate. Neuroimage, 15(4), 870-878.

Goldstein, J., \& Kornfield, J. (2001). Seeking the heart of wisdom: The path of insight meditation. Boston, MA: Shambhala Publications.

Graybiel, A. M. (2000). The basal ganglia. Current Biology, 10(14), 509-511. doi: 10.1016/ S0960-9822(00)00593-5

Grossman, P., Niemann, L., Schmidt, S., \& Walach, H. (2004). Mindfulness-based stress reduction and health benefits. A meta-analysis. Journal of Psychosomatic Research, 57(1), 35-43. doi: 10.1016/S0022-3999(03)00573-7

Hagberg, A. A., Schult, D. A., \& Swart, P. J. (2008). Exploring Network Structure, Dynamics, and Function using NetworkX. Paper presented at the Proceedings of the 7th Python in Science Conference, Pasadena, CA.

Harrison, B. J., Soriano-Mas, C., Pujol, J., Ortiz, H., Lopez-Sola, M., Hernandez-Ribas, R., Deus, J., Alonso, P., Yucel, M., Pantelis, C., Menchon, J. M., \& Cardoner, N. (2009). Altered corticostriatal functional connectivity in obsessive-compulsive disorder. Archives of General Psychiatry, 66(11), 1189-1200. doi: 10.1001/archgenpsychiatry.2009.152

Hasenkamp, W., Wilson-Mendenhall, C. D., Duncan, E., \& Barsalou, L. W. (2012). Mind wandering and attention during focused meditation: a fine-grained temporal analysis of fluctuating cognitive states. Neuroimage, 59(1), 750-760. doi: 10.1016/j.neuroimage.2011.07.008

Jang, J. H., Jung, W. H., Kang, D. H., Byun, M. S., Kwon, S. J., Choi, C. H., \& Kwon, J. S. (2011). Increased default mode network connectivity associated with meditation. Neuroscience Letters, 487(3), 358-362. doi: 10.1016/j.neulet.2010.10.056

Kilpatrick, L. A., Suyenobu, B. Y., Smith, S. R., Bueller, J. A., Goodman, T., Creswell, J. D., Tillisch, K., Mayer, E. A., \& Naliboff, B. D. (2011). Impact of mindfulness-based stress reduction training on intrinsic brain connectivity. Neuroimage, 56(1), 290-298. doi: 10.1016/j.neuroimage.2011.02.034

Kjaer, T. W., Bertelsen, C., Piccini, P., Brooks, D., Alving, J., \& Lou, H. C. (2002). Increased dopamine tone during meditation-induced change of consciousness. Cognitive Brain Research, 13(2), 255-259. doi: 10.1016/s0926-6410(01)00106-9 
Klostermann, E. C., Braskie, M. N., Landau, S. M., O’Neil, J. P., \& Jagust, W. J. (2012). Dopamine and frontostriatal networks in cognitive aging. Neurobiol Aging, 33(3), 623 e615624. doi: 10.1016/j.neurobiolaging.2011.03.002

Lazar, S. W., Bush, G., Gollub, R. L., Fricchione, G. L., Khalsa, G., \& Benson, H. (2000). Functional brain mapping of the relaxation response and meditation. Neuroreport, 11(7), 1581-1585. doi: 10.1097/00001756 20000515000041

Lazar, S. W., Kerr, C. E., Wasserman, R. H., Gray, J. R., Greve, D. N., Treadway, M. T., McGarvey, M., Quinn, B. T., Dusek, J. A., Benson, H., Rauch, S. L., Moore, C. I., \& Fischl, B. (2005). Meditation experience is associated with increased cortical thickness. Neuroreport, 16(17), 1893-1897. doi: 10.1097/01.wnr.0000186598.66243.19

Lou, H. C., Kjaer, T. W., Friberg, L., Wildschiodtz, G., Holm, S., \& Nowak, M. (1999). A O15-H2O PET study of meditation and the resting state of normal consciousness. Human Brain Mapping, 7(2), 98-105.

MacDonald, P. A., Ganjavi, H., Collins, D. L., Evans, A. C., \& Karama, S. (2014). Investigating the relation between striatal volume and IQ. Brain Imaging and Behavior, 8(1), 52-59. doi: 10.1007/s11682-013-9242-3

Maldjian, J. A., Laurienti, P. J., Kraft, R. A., \& Burdette, J. H. (2003). An automated method for neuroanatomic and cytoarchitectonic atlas-based interrogation of fMRI data sets. Neuroimage, 19(3), 1233-1239. doi: 10.1016/s1053-8119(03)00169-1

Morbelli, S., Drzezga, A., Perneczky, R., Frisoni, G. B., Caroli, A., van Berckel, B. N., Ossenkoppele, R., Guedj, E., Didic, M., Brugnolo, A., Sambuceti, G., Pagani, M., Salmon, E., \& Nobili, F. (2012). Resting metabolic connectivity in prodromal Alzheimer's disease. A European Alzheimer Disease Consortium (EADC) project. Neurobiology of Aging, 33(11), 2533-2550. doi: 10.1016/j.neurobiolaging.2012.01.005

Newberg, A. B., \& Iversen, J. (2003). The neural basis of the complex mental task of meditation: neurotransmitter and neurochemical considerations. Medical Hypotheses, 61(2), 282291. doi: 10.1016/s0306-9877(03)00175-0

Newberg, A. B., Wintering, N., Waldman, M. R., Amen, D., Khalsa, D. S., \& Alavi, A. (2010). Cerebral blood flow differences between long-term meditators and non-meditators. Consciousness and Cognition, 19(4), 899-905. doi: 10.1016/j.concog.2010.05.003

Perelman, A. M., Miller, S. L., Clements, C. B., Rodriguez, A., Allen, K., \& Cavanaugh, R. (2012). Meditation in a Deep South Prison: A Longitudinal Study of the Effects of Vipassana. Journal of Offender Rehabilitation, 51(3), 176-198. doi: 10.1080/10509674.2011.632814

Pickut, B. A., Van Hecke, W., Kerckhofs, E., Marien, P., Vanneste, S., Cras, P., \& Parizel, P. M. (2013). Mindfulness based intervention in Parkinson's disease leads to structural brain changes on MRI: a randomized controlled longitudinal trial. Clin Neurol Neurosurg, 115(12), 2419-2425. doi: 10.1016/j.clineuro.2013.10.002

Podell, J. E., Sambataro, F., Murty, V. P., Emery, M. R., Tong, Y., Das, S., Goldberg, T. E., Weinberger, D. R., \& Mattay, V. S. (2012). Neurophysiological correlates of age-related 
changes in working memory updating. Neuroimage, 62(3), 2151-2160. doi: 10.1016/j. neuroimage.2012.05.066

Raven, J. (2000). The Raven's progressive matrices: change and stability over culture and time. Cognitive Psychology, 41(1), 1-48. doi: 10.1006/cogp.1999.0735

Raven, J., Raven, J. C., \& Court, J. H. (1998). Manual for Raven's Advanced Progressive Matrices. Oxford, United Kingdom: Oxford Psychologists Press.

Rieckmann, A., Karlsson, S., Fischer, H., \& Backman, L. (2011). Caudate dopamine D1 receptor density is associated with individual differences in frontoparietal connectivity during working memory. The Journal of Neuroscience, 31(40), 14284-14290. doi: 10.1523/ JNEUROSCI.3114-11.2011

Robinson, J. L., Laird, A. R., Glahn, D. C., Blangero, J., Sanghera, M. K., Pessoa, L., Fox, P. M., Uecker, A., Friehs, G., Young, K. A., Griffin, J. L., Lovallo, W. R., \& Fox, P. T. (2012). The functional connectivity of the human caudate: an application of meta-analytic connectivity modeling with behavioral filtering. Neuroimage, 60(1), 117-129. doi: 10.1016/j. neuroimage.2011.12.010

Salvador, R., Sarro, S., Gomar, J. J., Ortiz-Gil, J., Vila, F., Capdevila, A., Bullmore, E., McKenna, P. J., \& Pomarol-Clotet, E. (2010). Overall brain connectivity maps show cortico-subcortical abnormalities in schizophrenia. Human Brain Mapping, 31(12), 2003-2014. doi: 10.1002/hbm.20993

Schultz, W., Dayan, P., \& Montague, P. R. (1997). A neural substrate of prediction and reward. Science, 275(5306), 1593-1599. doi: 10.1126/science.275.5306.1593

Schwabe, L., \& Wolf, O. T. (2011). Stress-induced modulation of instrumental behavior: from goal-directed to habitual control of action. Behavioural Brain Research, 219(2), 321328. doi: 10.1016/j.bbr.2010.12.038

Schwarz, A. J., \& McGonigle, J. (2011). Negative edges and soft thresholding in complex network analysis of resting state functional connectivity data. Neuroimage, 55(3), 11321146. doi: 10.1016/j.neuroimage.2010.12.047

Simpson, E. H., Kellendonk, C., \& Kandel, E. (2010). A possible role for the striatum in the pathogenesis of the cognitive symptoms of schizophrenia. Neuron, 65(5), 585-596. doi: 10.1016/j.neuron.2010.02.014

Sperduti, M., Martinelli, P., \& Piolino, P. (2012). A neurocognitive model of meditation based on activation likelihood estimation (ALE) meta-analysis. Consciousness and Cognition, 21(1), 269-276. doi: 10.1016/j.concog.2011.09.019

Streeter, C. C., Jensen, J. E., Perlmutter, R. M., Cabral, H. J., Tian, H., Terhune, D. B., Ciraulo, D. A., \& Renshaw, P. F. (2007). Yoga asana sessions increase brain GABA levels: a pilot study. The Journal of Alternative and Complementary Medicine, 13(4), 419-426. doi: $10.1089 / \mathrm{acm} .2007 .6338$

Streeter, C. C., Whitfield, T. H., Owen, L., Rein, T., Karri, S. K., Yakhkind, A., Perlmutter, R., Prescot, A., Renshaw, P. F., Ciraulo, D. A., \& Jensen, J. E. (2010). Effects of yoga versus walking on mood, anxiety, and brain GABA levels: a randomized controlled MRS 
study. The Journal of Alternative and Complementary Medicine, 16(11), 1145-1152. doi: 10.1089/acm.2010.0007

Tang, Y. Y., Ma, Y. H., Fan, Y. X., Feng, H. B., Wang, J. H., Feng, S. G., Lu, Q. L., Hu, B., Lin, Y., Li, J., Zhang, Y., Wang, Y., Zhou, L., \& Fan, M. (2009). Central and autonomic nervous system interaction is altered by short-term meditation. Proceedings of the National Academy of Sciences of the United States of America, 106(22), 8865-8870. doi: 10.1073/ pnas.0904031106

Taren, A. A., Creswell, J. D., \& Gianaros, P. J. (2013). Dispositional mindfulness co-Varies with smaller amygdala and caudate volumes in community adults. PLoS One, 8(5), e64574. doi: 10.1371/journal.pone.0064574

Taylor, V. A., Daneault, V., Grant, J., Scavone, G., Breton, E., Roffe-Vidal, S., Courtemanche, J., Lavarenne, A. S., Marrelec, G., Benali, H., \& Beauregard, M. (2013). Impact of meditation training on the default mode network during a restful state. Social Cognitive and Affective Neuroscience, 8(1), 4-14. doi: 10.1093/scan/nsr087

Tomasi, D., \& Volkow, N. D. (2012). Aging and functional brain networks. Molecular Psychiatry, 17(5), 549-558. doi: 10.1038/mp.2011.81

Travis, F., \& Wallace, R. K. (1999). Autonomic and EEG patterns during eyes-closed rest and transcendental meditation (TM) practice: the basis for a neural model of TM practice. Consciousness and Cognition, 8(3), 302-318. doi: 10.1006/ccog.1999.0403

Turner, K. C., Frost, L., Linsenbardt, D., McIlroy, J. R., \& Muller, R. A. (2006). Atypically diffuse functional connectivity between caudate nuclei and cerebral cortex in autism. Behavioral and brain functions, 2, 34. doi: 10.1186/1744-9081-2-34

Tzourio-Mazoyer, N., Landeau, B., Papathanassiou, D., Crivello, F., Etard, O., Delcroix, N., Mazoyer, B., \& Joliot, M. (2002). Automated Anatomical Labeling of Activations in SPM Using a Macroscopic Anatomical Parcellation of the MNI MRI Single-Subject Brain. Neuroimage, 15(1), 273-289. doi: 10.1006/nimg.2001.0978

Vago, D. R. (2014). Mapping modalities of self-awareness in mindfulness practice: a potential mechanism for clarifying habits of mind. In S. Sequeira (Ed.), Advances in Meditation Research: Neuroscience and Clinical Applications (Vol. 1307, pp. 28-42).

Vago, D. R., \& Silbersweig, D. A. (2012). Self-awareness, self-regulation, and self-transcendence (S-ART): a framework for understanding the neurobiological mechanisms of mindfulness. Frontiers in Human Neuroscience, 25(6), 296. doi: 10.3389/fnhum.2012.00296

Wang, J. H., Zuo, X. N., Gohel, S., Milham, M. P., Biswal, B. B., \& He, Y. (2011). Graph theoretical analysis of functional brain networks: test-retest evaluation on short- and longterm resting-state functional MRI data. PLoS One, 6(7), e21976. doi: 10.1371/journal. pone.0021976

Welch, B. L. (1951). On the Comparison of Several Mean Values: An Alternative Approach. Biometrika, 38(3/4), 330-336. doi: 10.2307/2332579 
Whitfield-Gabrieli, S., Moran, J. M., Nieto-Castañón, A., Triantafyllou, C., Saxe, R., \& Gabrieli, J. D. E. (2010). Associations and dissociations between default and self-reference networks in the human brain. Neuroimage, 55(1), 225-232. doi: 10.1016/j.neuroimage.2010.11.048

Zalesky, A., Fornito, A., \& Bullmore, E. T. (2010). Network-based statistic: identifying differences in brain networks. Neuroimage, 53(4), 1197-1207. doi: 10.1016/j.neuroimage.2010.06.041 


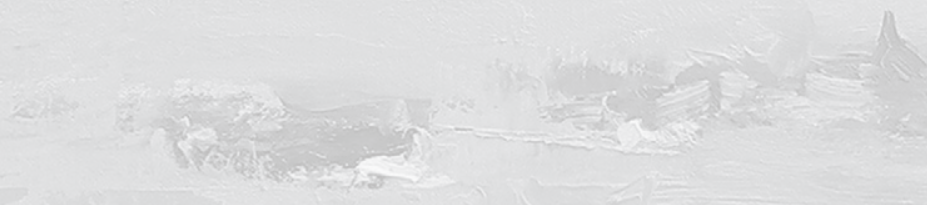


ChAPTER 7

General discussion 

This thesis focused on the neural and psychological mechanisms of mindfulness meditation and yoga in domains that are of particular relevance for society namely pain management, resilience building in young adults, and aging. While the studies covered different domains and used different methods and levels of analysis, all studies have in common that they relate to how meditation and yoga can increase well-being. The study in chapter 2, which investigated the neural correlates of pain modulation through a state of mindfulness can be viewed as the most fundamental of the five. The reason is the close relationship between pain and well-being and because a very specific neural mechanism was identified of how pain and thus well-being can be modulated. This study revealed that experienced mindfulness meditators are able to reduce the unpleasantness and anticipatory anxiety of pain in a unique way, involving increased sensory bottom-up and reduced cognitive elaborative top-down processing. This is aligned with two important components of the practice of mindfulness; namely focusing on the experience in the present moment (pain) in a non-judging (cognitive/elaborative) way. The findings are also consistent with the Buddhist saying "pain is inevitable, suffering is optional" and the metaphor of the first and the second dart in which the first dart refers to the inevitable physical component of pain, and the second dart to the optional, added suffering. With this strong alignment of behavioral findings, neural findings, meditation practice, and Buddhist psychology, this study contributes to the foundation of contemplative neuroscience. Interesting fundamental questions that our study raised that yet need to be answered are how the neural mechanisms of pain modulation through mindfulness are different from other pain modulation strategies in a direct comparison, and what the differences between beginning and expert meditators are, when assessed in the same study. To address the big societal relevance of pain due to the large number of people suffering from it and the huge costs associated with it, new studies are needed to focus on the neural mechanisms of pain modulation through mindfulness in patient populations.

While chapter 2 investigated a phenomenon as fundamental to well-being as pain, chapter 3 focused on increasing well-being and resilience in young adults. As described in the introduction, although yoga and meditation have much in common and reached the West around the same time, research on yoga started flourishing a bit later than research on meditation. In chapter 3 we explicitly focused on yoga and found in a longitudinal study that yoga can reduce perceived stress and increase quality of life in young adults, thereby increasing well-being and resilience for mental illness in this at risk group. These improvements were mediated by mindfulness and self-compassion, and consequently reveal a similar mechanism of action as known from mindfulness meditation based interventions. This finding is congruent with the historical overlap between yoga and mindfulness meditation as outlined in the introduction. Given the complexity of yoga programs, for future research it would be particularly interesting to disentangle the effects of different components. 
Chapter 4-6 addressed the growing problem of cognitive and neural decline in the rapidly aging society. Chapter 4 is a systematic review of the effects of meditation on age-related cognitive decline. The review revealed that the field of meditation research has grown to such an extent that sub-fields started forming, including the field that we label contemplative gerontology. We reported that although many studies need methodological improvements, there is preliminary evidence that different forms of meditation can off-set age-related cognitive decline in a variety of domains. In chapter 5, we followed the recommendations of chapter 4 and investigated the potential neural and psychological mechanisms of off-set age-related decline in fluid intelligence in yoga and meditation practitioners. Findings indeed demonstrated offset decline in fluid intelligence in the practitioners. Yoga and meditation practitioners also had more resilient and integrated functional resting state brain networks than controls. Mindfulness played a potential mechanistic role as it was correlated with these variables. This finding is aligned with the mechanistic role of mindfulness that was revealed in chapter 3 . Also the absence of differences between yoga and meditation practitioners in chapter 5 is aligned with the overlap in mechanisms between both practices as discussed in the introduction and in chapter 3 . Chapter 6 revealed greater connectivity between caudate and a wide range of brain regions in yoga and meditation practitioners. This suggests greater caudate-mediated basal ganglia cortico-thalamic loops efficiency, which might meditate the behavioral flexibility, mental health, and well-being, as discussed in chapter 2 and 3.

This thesis addressed several themes, including differences and commonalities between yoga and meditation, their effects on stress and resilience across life span, and the mechanistic role of mindfulness. The differences and commonalities between yoga and meditation were addressed in chapter 3, 5 and 6 . It seems that there are no differences between the two practices, but this might be due to the relatively small sample sizes and due to the fact that mindfulness meditation and Kripalu yoga that were investigated in this thesis also have a strong conceptual overlap.

Another topic is that of resilience. While chapter 3 investigated yoga as a way to foster resilience at young age, chapter 5 and 6 investigated enhanced resilience at older age as the result of long-term practice. Our data is in support of the hypothesis that yoga can increase resilience in young adults and that yoga and meditation practice result in greater resilience at older age. Our findings suggest that stress and mindfulness play important roles in fostering resilience. Chapter 3 revealed reduced perceived stress after participation in a yoga-based program, which may result in greater resilience to illness as stress is a predictor of health (Bekkouche, Holmes, Whittaker, \& Krantz, 2009; Pedersen, Bovbjerg, \& Zachariae, 2009). In chapter 5 we reported greater resilience to age-related decline in fluid intelligence and network integration in yoga and meditation practitioners as compared to controls. Furthermore, practitioners' brain networks were more resilient to simulated damage. This 
greater resilience in practitioners might be related to reduced levels of stress, as stress is known to affect cognitive and brain function (Kim \& Diamond, 2002). The resilience in caudate mediated basal-ganglia thalamo-cortical loop efficiency suggested in chapter 6 also is related to low stress (Schwabe \& Wolf, 2011). Mindfulness was revealed as a potential psychological mechanism of reduced stress and increased resilience in chapter 3 and 5. Chapter 2 revealed the neural mechanism of how the state of mindfulness modulates processing of a stressor, namely a painful electric stimulus.

Furthermore this thesis reflects the rapid development of the fields of meditation and yoga research. While these fields started as separate fields with scattered studies, now sub-fields start to emerge focusing on different contexts or areas of application such as pain, young adults, and aging. At the same time that more diversification of sub-fields takes place, there is growing interest in comparing different types of contemplative techniques and traditions as reflected in chapter 3-6. Diversification also is taking place with regard to research methods and designs. Chapter 5 and 6 are examples where novel and advanced analysis techniques were applied to investigate the mechanisms of yoga and meditation from a different angle than has been done before. The growing interest and wider acceptance of the field will make it easier for yoga and meditation researchers to establish collaborations with experts in other areas to further enhance the field. Chapter 5 and 6 are good examples of such a collaboration, in which meditation researchers have worked side by side with wellestablished experts in aging neuroscience and mathematicians to use complex methods not seen in contemplative neuroscience before. Rigorous research designs such as RCTs with active control groups and large samples are increasingly used in the field of contemplative sciences. However, for some questions including what the differences in (neural) mechanisms between beginning and experienced meditators are, these rigorous designs render impractical as it takes several years to decades to become a highly experienced yoga or meditation practitioner.

In conclusion, this thesis revealed several psychological and neural mechanisms for the positive effects of mindfulness meditation and yoga on resilience and human well-being across domains. These mechanisms were similar for yoga and meditation. Self-compassion and mindfulness were revealed as important psychological mechanisms. Important neural mechanisms that this thesis revealed are increased bottom-up sensory and less top-down evaluative processing in the brain, as well as greater global efficiency or integration of resting state functional brain networks. Furthermore, greater functional connectivity of the caudate, an important integrative hub in the brain, was revealed as a potential mechanism for the effects of yoga and mindfulness meditation on human well-being.

While this thesis provided insights in these mechanisms from different angles and at different levels, many questions are yet to be answered in the growing field of contemplative sciences and multidisciplinary collaborations and creativity are 
required to find answers. This thesis contributed to the young field of contemplative sciences by answering and raising important questions and by providing a good example of multidisciplinary collaboration and application of innovative methods. Furthermore, some of the publications that this thesis is comprised of were well received in the media and the wider community and I hope that the knowledge that this thesis provides will ultimately contribute to decreased suffering and increased human well-being.

\section{REFERENCES}

Bekkouche, N. S., Holmes, S., Whittaker, K. S., \& Krantz, D. S. (2009). Stress and the Heart: Psychosocial Stress and Coronary Heart Disease. In R. M. Piscitelli (Ed.), The Handbook of Stress Science: Biology, Psychology, and Health (pp. 385-398). New York, NY: Springer Publishing Company.

Kim, J. J., \& Diamond, D. M. (2002). The stressed hippocampus, synaptic plasticity and lost memories. Nature Reviews Neuroscience, 3(6), 453-462. doi: 10.1038/nrn849

Pedersen, A. F., Bovbjerg, D. H., \& Zachariae, R. (2009). Stress and Susceptibility to Infectious Disease. In R. M. Piscitelli (Ed.), The Handbook of Stress Science: Biology, Psychology, and Health (pp. 425-446). New York, NY: Springer Publishing Company.

Schwabe, L., \& Wolf, O. T. (2011). Stress-induced modulation of instrumental behavior: from goal-directed to habitual control of action. Behavioural Brain Research, 219(2), 321328. doi: 10.1016/j.bbr.2010.12.038 



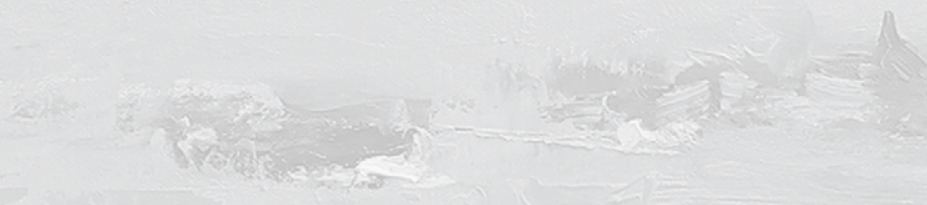




\section{VALORIZATION ADDENDUM}





\section{INTRODUCTION}

The thesis "The neural and psychological mechanisms of yoga and mindfulness meditation" to which this valorization addendum belongs, investigated the neural and psychological mechanisms of mindfulness meditation and yoga in domains that are of particular relevance for society namely pain management, resilience building in young adults, and aging. Yoga and mindfulness meditation both are ancient practices that are concerned with fostering sustainable well-being (Feuerstein, 2008; McWilliams, 2014; Sengupta, 2012; Wallace \& Shapiro, 2006). These ancient practices find many applications in modern society to increase well-being in health and disease (Chiesa \& Serretti, 2009; Goyal et al., 2014). While the studies that are part of the thesis covered different domains and used different methods and levels of analysis, they all have in common that they indeed relate to how meditation and yoga can increase sustainable well-being or eudemonia.

With such a topic, valorization of the knowledge gained by this thesis is obvious and an integral part of the thesis. In the following, part of what already has been discussed in the thesis will be reiterated. First valorization of the thesis as a whole will be discussed before valorization of the individual chapters will be discussed in more detail. The general part assesses the relevance of the gained knowledge, target groups for whom the knowledge is relevant, possible activities and products to which this knowledge can be translated, the level of innovation of these applications, and implementation of the valorization plan. The part on individual chapters will elaborate more specifically on the relevance and innovation aspects of the gained knowledge.

\section{General}

Broadly speaking, the knowledge that was revealed in this thesis can be divided in two parts: 1) the effect of yoga and mindfulness meditation on well-being and 2) the mechanisms that underlie these effects. Each part of knowledge has its own valorization. Although part one was not the main focus of this thesis, it is inherent to part two; studies that investigate the mechanisms of how yoga and mindfulness meditation affect well-being also result in knowledge about the effects of these practices on well-being.

The support that we found for the positive effects of yoga and mindfulness meditation on well-being, is of value and relevant to anyone interested in practical tools to increase human well-being and foster a flourishing society. In particular it may be interesting for people who are professionally concerned with enhancing well-being, such as clinicians and coaches who are not yet working with yoga and 
mindfulness meditation, but see the opportunity of new tools now. Others who are working with these practices already may benefit from our findings as they provide credibility to their practice.

The second part of knowledge gained through this thesis, the psychological and neural mechanisms of yoga and mindfulness meditation forms the core of this thesis. This knowledge is of direct value and relevance to teachers and practitioners of these practices. Having a better understanding of the practice one teaches or practices is useful as it increases credibility of the benefits of these practices. The uniqueness of the mechanisms that were revealed may be of value to clinicians as it suggests that yoga and mindfulness meditation really add something to other known interventions. In the longer run, understanding the psychological and neural mechanisms of mindfulness meditation and yoga also creates value for patients and clinicians in that it may contribute to the improvement of existing interventions and the development of new treatment procedures that capitalize on these mechanisms.

Products and activities that this mechanistic knowledge can be translated to include the development of novel teaching materials for teachers and teacher-trainers of yoga and mindfulness-based interventions, information materials for patients and clinicians and continuing education offers for clinicians. Furthermore, the revealed mechanisms can be used to develop new interventions for a variety of clinical disorders or to enhance well-being in healthy people. These interventions could be mindfulness-based behavioral interventions which use the in this thesis identified brain activation patterns and network architecture as success-indicators to further optimize the intervention. The identified brain activation patterns and network architecture can also be used for technology-based interventions such as neurofeedback and brain stimulation. Neurofeedback applications would initially be based on functional magnetic resonance imaging (fMRI) with translational possibilities to electroencephalography (EEG) and near-infrared spectroscopy (NIRS).

The innovation of updated teaching- and patient-materials as well as continuing education offers lies in the novelty and uniqueness of the revealed mechanisms and by supporting a shift from purely "evidence based" interventions to "mechanisms based" interventions; the novel materials not only emphasize that interventions work, but also show how they work. The innovation of the development of new interventions lies in the approach of directly targeting brain mechanisms, and particularly the newly identified mechanisms that were revealed in this thesis. Although meditation-based neurofeedback is already being used, these applications are not much science based and exclusively use EEG with its low spatial resolution. We provide science-based targets with high spatial resolution. A further innovation is that, if technology allows for it, we have network-based measures that could be used for feedback. 
The valorization strategy has already been partially implemented. To facilitate updating of teaching materials for yoga and mindfulness teachers and teacher trainers, and to facilitate updated patient and clinician information materials, relevant parties were informed in various ways. Clinicians were informed through journals of medical professional associations, including Ärtzteblatt and Report Psychologie and presentations at clinical grand rounds such as the Department of Anesthesia of Massachusetts General Hospital. Furthermore, the gained knowledge was disseminated at various European and American accredited continuing education events for clinicians as well as yoga and mindfulness teachers and educators, including the Annual conference of the Center for Mindfulness at the University of Massachusetts Medical School. Patients were targeted through newsletters of patient associations such as Deutsch Schmerzliga. The general audience could learn about the studies through mainstream newspaper, radio and television outlets including Huffington Post, USA Today, Stern, Deutschlandfunk, and 3sat(Scobel).

The improvement or development of interventions that rely on the in this thesis identified mechanisms is on my long-term research agenda. An important first step to more directly target the identified mechanisms is to disentangle skill and strategy involved in these mechanisms (Gard, 2014). This is exactly what is on my short-term research agenda and a research proposal regarding this topic in currently in preparation.

\section{CHAPTER 2}

Chapter 2 investigated the neural mechanisms of pain modulation through mindfulness using functional magnetic resonance imaging (fMRI). Mindfulness practitioners were able to strongly reduce pain unpleasantness and anticipatory anxiety through the state of mindfulness. In the brain this reduction in pain unpleasantness was associated with increased activation in the right posterior insula and decreased activation in the lateral prefrontal cortex. These findings revealed a unique mechanism of pain modulation through mindfulness, comprising increased sensory and decreased cognitive evaluative processing. The major novelty of this study is that it is the first study that revealed such a pattern of pain modulation during the state of mindfulness as compared to a state of rest.

As discussed in the general part of this document, there is great value in the finding that mindfulness meditation involves a unique mechanism for pain modulation as it suggests the potential for effective application in situations where other methods are not effective and it provides targets for the improvement of old and the development of new treatments. 
Although the study in chapter 2 involved acute experimental pain it may generalize to chronic pain. This would be of great value relevance to patients, clinicians and society because chronic pain is an important problem for society as it has high prevalence and poses a huge burden in the form of reduced well-being to patients and in terms of financial costs to society. Estimates of prevalence rates are ranging from around $20 \%$ to more than $70 \%$ (Breivik, Collett, Ventafridda, Cohen, \& Gallacher, 2006; Gureje, Von Korff, Simon, \& Gater, 1998; Tsang et al., 2008; Wenig, Schmidt, Kohlmann, \& Schweikert, 2009). In the US the prevalence of chronic pain has been estimated to be $43 \%$ (Tsang et al., 2008), meaning that over 116 million Americans are suffering from this condition, which is more than the number of Americans affected by heart disease, cancer and diabetes combined (IOM, 2011; Pizzo \& Clark, 2012). In Germany the estimated annual cost of back pain is $€ 49$ billion, while in the US the annual cost of chronic pain is estimated to be up to $\$ 635$ billion (Gaskin $\&$ Richard, 2012). In addition to the high prevalence and the huge burden to patients and society, chronic pain is difficult to treat (Turk, Wilson, \& Cahana, 2011) and has been conceptualized as public health challenge by the Institute of Medicine of the National Academies (2011).

\section{Chapter 3}

Chapter 3 investigated the effects of a yoga intervention on perceived stress and quality of life, as well as its underlying psychological mechanisms, in young adults who are in the challenging transition to college life. Participation in the yoga-based intervention resulted in reduced perceived stress and increased quality of life in young adults, thereby increasing well-being and resilience for mental illness in this at risk group. Well-being is negatively related to a number of variables, including mental health and suicidality in young adults (Valois, Zullig, Huebner, \& Drane, 2001), while high levels of stress on the other hand contributes to psychopathology (Grant, McMahon, Dufy, Taylor, \& Compas, 2009). College is a high risk period as young adults are particularly vulnerable to mental health problems and the transition to college is a challenging period (Conley, Travers, \& Bryant, 2013; Reavley \& Jorm, 2010). Despite the opportunity to support young adults in this critical phase of life, not many interventions have been developed and tested to foster well-being and resilience in this group, as opposed to children (Conley et al., 2013; Durlak, Weissberg, Dymnicki, Taylor, \& Schellinger, 2011; Reavley \& Jorm, 2010). Therefore the knowledge regarding the effects of yoga in young adults is relevant for this group as well as for providers of preventative health care and wellness providers who are interested in targeting this group. In the end prevention of (mental) illness in young adults will be of benefit for society as well. 
An innovative aspect of this study is that it is the first time that a yoga-based program has been reported to increase self-compassion, and that the effects of such a program on quality of life and perceived stress are mediated by mindfulness and self-compassion. These findings suggests that yoga-based and mindfulness-based programs might share mechanisms, which could be of value to individuals that have interest in acquiring the skills of mindfulness and self-compassion, but are resistant to formal meditation techniques or have a preference for more physically engaging practices. Knowledge about the similarity in mechanisms may also be of value relevance to teachers and developers of interventions that rely on mindfulness and self-compassion. Finally, and mostly of interest to researchers, this similarity makes it possible to generate hypotheses about the effects of yoga-based programs based on the larger body of knowledge about the effects of mindfulness-based programs. Eventually, the mechanistic knowledge gained in this chapter may contribute to the development of more targeted and efficient programs to foster well-being and increase resilience.

\section{CHAPTER 4-6}

Chapter 4-6 focused on the growing problem of cognitive and neural decline in the rapidly aging society. The world population is rapidly aging, due to increases in life expectancy and the aging baby boom generation (Administration on Aging, 2012; United Nations, 2002). In Germany for instance more than $20 \%$ of the population is already older than 65 (Statistisches_Bundesamt, 2014). It is no surprise that the European Commission regards aging as one of the greatest social and economic challenges of the $21^{\text {st }}$ century (European_Commission, 2014).

It is a well-established that normal healthy aging is accompanied by decline in cognitive function (Salthouse, 2009; Tucker-Drob, 2011; Wilson, Beckett, Bennett, Albert, \& Evans, 1999) and related declines in neural structure and activity (Morrison \& Hof, 1997; Persson et al., 2006; Salat et al., 2004). The decline can progress to mild cognitive impairment (MCI) and dementia, which are characterized by limitations of daily functioning and typically result in a reduced quality of life. Therefore cognitive decline is an often feared aspect of aging. It is not only a burden for the affected individual but also for relatives and society (Deary et al., 2009; Plassman, Williams, Burke, Holsinger, \& Benjamin, 2010).

The literature review in chapter 4 suggested that there is preliminary evidence that different forms of meditation can off-set age-related cognitive decline in a variety of domains. Chapter 5 investigated the neural and psychological mechanisms of offset age-related decline in fluid intelligence in yoga and meditation practitioners. Fluid intelligence, which has high real-life relevance, indeed declined slower in yoga and 
meditation practitioners than in controls. Global network analyses of resting state brain functional connectivity data, acquired with $\mathrm{fMRI}$, revealed that the functional brain networks of the practitioners were more integrated and more resilient to damage than those of controls. It should be noted here that aging is typically associated with decreases in brain functional network integration (Achard \& Bullmore, 2007). There were no differences in decline rate and network integration between yoga and mindfulness practitioners. Mindfulness was positively correlated with fluid intelligence and network integration and resilience, suggesting a mechanistic role in preserving cognition and brain function. Chapter 6 revealed that yoga and meditation practitioners had greater connectivity between the caudate and a wide range of brain regions while aging and mild cognitive impairment are associated with decreased caudate connectivity (Agosta et al., 2013; Klostermann, Braskie, Landau, O’Neil, \& Jagust, 2012; Morbelli et al., 2012; Podell et al., 2012).

The finding of off-set decline in fluid intelligence in yoga and mindfulnessmeditation practitioners is of value and relevance to aging individuals, their family, clinicians and society as a whole. Similarly, greater functional network integration, resilience and caudate connectivity in yoga and meditation practitioners than in controls is of value these groups as it they have been positively associated with cognitive function and negatively with aging (Achard \& Bullmore, 2007; Agosta et al., 2013; Klostermann et al., 2012; Langer et al., 2012; Morbelli et al., 2012; Podell et al., 2012; van den Heuvel, Stam, Kahn, \& Hulshoff Pol, 2009). Knowledge about the neural and mechanisms that were revealed in these chapters may in future be used to enhance and develop interventions to reduce age-related cognitive decline and transition to dementia.

The studies in chapter 5 and 6 are particularly innovative as they were a collaboration between fields and used novel analysis methods that had not been used in contemplative neuroscience before.

\section{REFERENCES}

Achard, S., \& Bullmore, E. (2007). Efficiency and cost of economical brain functional networks. Plos Computational Biology, 3, 174-183. doi: 10.1371/journal.pcbi.0030017

Administration on Aging. (2012). A Profile of Older Americans. June 18. http://www.aoa.gov/ AoARoot/Aging_Statistics/Profile/2012/docs/2012profile.pdf

Agosta, F., Sala, S., Valsasina, P., Meani, A., Canu, E., Magnani, G., Cappa, S. F., Scola, E., Quatto, P., Horsfield, M. A., Falini, A., Comi, G., \& Filippi, M. (2013). Brain network connectivity assessed using graph theory in frontotemporal dementia. Neurology, 81(2), 134-143. doi: 10.1212/WNL.0b013e31829a33f8 
Breivik, H., Collett, B., Ventafridda, V., Cohen, R., \& Gallacher, D. (2006). Survey of chronic pain in Europe: prevalence, impact on daily life, and treatment. European Journal of Pain, 10(4), 287-333. doi: 10.1016/j.ejpain.2005.06.009

Chiesa, A., \& Serretti, A. (2009). Mindfulness-based stress reduction for stress management in healthy people: a review and meta-analysis. The Journal of Alternative and Complementary Medicine, 15(5), 593-600. doi: 10.1089/acm.2008.0495

Conley, C. S., Travers, L. V., \& Bryant, F. B. (2013). Promoting psychosocial adjustment andsStress management in first-Year college students: the benefits of engagement in a psychosocial wellness seminar. Journal of American College Health, 61(2), 75-86. doi: $10.1080 / 07448481.2012 .754757$

Deary, I. J., Corley, J., Gow, A. J., Harris, S. E., Houlihan, L. M., Marioni, R. E., Penke, L., Rafnsson, S. B., \& Starr, J. M. (2009). Age-associated cognitive decline. British Medical Bulletin, 92(1), 135-152. doi: 10.1093/bmb/ldp033

Durlak, J. A., Weissberg, R. P., Dymnicki, A. B., Taylor, R. D., \& Schellinger, K. B. (2011). The Impact of enhancing students' social and emotional learning: a meta-analysis of school-based universal interventions. Child Development, 82(1), 405-432. doi: 10.1111/j.1467-8624.2010.01564.x

European_Commission. (2014). Retrieved June 2nd, 2014, from http://ec.europa.eu/health/ ageing/policy/index_en.htm

Feuerstein, G. (2008). The yoga tradition: its history, literature, philosophy, and practice (3 Ed.). Prescott, AZ: Hohm Press

Gard, T. (2014). Different neural correlates of facing pain with mindfulness: Contributions of strategy and skill: Comment on "Facing the experience of pain: A neuropsychological perspective" by Fabbro and Crescentini. Physics of Life Reviews(0). doi: 10.1016/j. plrev.2014.07.003

Gaskin, D. J., \& Richard, P. (2012). The economic costs of pain in the United States. The Journal of Pain, 13(8), 715-724. doi: 10.1016/j.jpain.2012.03.009

Goyal, M., Singh, S., Sibinga, E. M., Gould, N. F., Rowland-Seymour, A., Sharma, R., Berger, Z., Sleicher, D., Maron, D. D., Shihab, H. M., Ranasinghe, P. D., Linn, S., Saha, S., Bass, E. B., \& Haythornthwaite, J. A. (2014). Meditation programs for psychological stress and well-being: a systematic review and meta-analysis. JAMA internal medicine, 174(3), 357-368. doi: 10.1001/jamainternmed.2013.13018

Grant, K. E., McMahon, S. D., Dufy, S., Taylor, J. J., \& Compas, B. E. (2009). Stressors and Mental Health Problems in Childhood and Adolescence. In R. M. Piscitelli (Ed.), The Handbook of Stress Science: Biology, Psychology, and Health (pp. 359-372). New York, NY: Springer Publishing Company.

Gureje, O., Von Korff, M., Simon, G. E., \& Gater, R. (1998). Persistent pain and well-being: a World Health Organization Study in Primary Care. Journal of the American Medical Association, 280(2), 147-151. doi: 10.1001/jama.280.2.147 
IOM. (2011). Relieving pain in America: A blueprint for transforming prevention, care, education, and research. Washington, DC: The National Academies Press.

Klostermann, E. C., Braskie, M. N., Landau, S. M., O’Neil, J. P., \& Jagust, W. J. (2012). Dopamine and frontostriatal networks in cognitive aging. Neurobiol Aging, 33(3), 623 e615624. doi: 10.1016/j.neurobiolaging.2011.03.002

Langer, N., Pedroni, A., Gianotti, L. R. R., Haenggi, J., Knoch, D., \& Jaencke, L. (2012). Functional brain network efficiency predicts intelligence. Human Brain Mapping, 33(6), 1393-1406. doi: 10.1002/hbm.21297

McWilliams, S. (2014). Foundations of Mindfulness and Contemplation: Traditional and Contemporary Perspectives. International Journal of Mental Health and Addiction, 12(2), 116-128. doi: 10.1007/s11469-014-9486-1

Morbelli, S., Drzezga, A., Perneczky, R., Frisoni, G. B., Caroli, A., van Berckel, B. N., Ossenkoppele, R., Guedj, E., Didic, M., Brugnolo, A., Sambuceti, G., Pagani, M., Salmon, E., \& Nobili, F. (2012). Resting metabolic connectivity in prodromal Alzheimer's disease. A European Alzheimer Disease Consortium (EADC) project. Neurobiology of Aging, 33(11), 2533-2550. doi: 10.1016/j.neurobiolaging.2012.01.005

Morrison, J. H., \& Hof, P. R. (1997). Life and death of neurons in the aging brain. Science, 278(5337), 412-419. doi: 10.1126/science.278.5337.412

Persson, J., Nyberg, L., Lind, J., Larsson, A., Nilsson, L. G., Ingvar, M., \& Buckner, R. L. (2006). Structure-function correlates of cognitive decline in aging. Cerebral Cortex, 16(7), 907-915. doi: 10.1093/cercor/bhj036

Pizzo, P. A., \& Clark, N. M. (2012). Alleviating suffering 101--pain relief in the United States. The New England journal of medicine, 366(3), 197-199. doi: 10.1056/NEJMp1109084

Plassman, B. L., Williams, J. W., Burke, J. R., Holsinger, T., \& Benjamin, S. (2010). Systematic review: factors associated with risk for and possible prevention of cognitive decline in later life. Annals of Internal Medicine, 153(3), 182-193. doi: 10.7326/0003-4819-153-3201008030-00258

Podell, J. E., Sambataro, F., Murty, V. P., Emery, M. R., Tong, Y., Das, S., Goldberg, T. E., Weinberger, D. R., \& Mattay, V. S. (2012). Neurophysiological correlates of age-related changes in working memory updating. Neuroimage, 62(3), 2151-2160. doi: 10.1016/j. neuroimage.2012.05.066

Reavley, N., \& Jorm, A. F. (2010). Prevention and early intervention to improve mental health in higher education students: a review. Early Intervention in Psychiatry, 4(2), 132-142. doi: 10.1111/j.1751-7893.2010.00167.x

Salat, D. H., Buckner, R. L., Snyder, A. Z., Greve, D. N., Desikan, R. S., Busa, E., Morris, J. C., Dale, A. M., \& Fischl, B. (2004). Thinning of the cerebral cortex in aging. Cerebral Cortex, 14(7), 721-730. doi: 10.1093/cercor/bhh032

Salthouse, T. A. (2009). When does age-related cognitive decline begin? Neurobiology of Aging, 30(4), 507-514. doi: 10.1016/j.neurobiolaging.2008.09.023 
Sengupta, P. (2012). Health impacts of yoga and pranayama: a state-of-the-art review. Int J Prev Med, 3(7), 444-458.

Statistisches_Bundesamt. (2014). Retrieved June 2nd, 2014, from https://www-genesis.destatis.de

Tsang, A., Von Korff, M., Lee, S., Alonso, J., Karam, E., Angermeyer, M. C., Borges, G. L. G., Bromet, E. J., de Girolamo, G., \& de Graaf, R. (2008). Common chronic pain conditions in developed and developing countries: gender and age differences and comorbidity with depression-anxiety disorders. The Journal of Pain, 9(10), 883-891. doi: 10.1016/j.jpain.2008.05.005

Tucker-Drob, E. M. (2011). Global and domain-specific changes in cognition throughout adulthood. Developmental Psychology, 47(2), 331-343. doi: 10.1037/a0021361

Turk, D. C., Wilson, H. D., \& Cahana, A. (2011). Treatment of chronic non-cancer pain. Lancet, 377(9784), 2226-2235. doi: 10.1016/S0140-6736(11)60402-9

United Nations. (2002). World population ageing, 1950-2050. New York, NY: United Nations

Valois, R. F., Zullig, K. J., Huebner, E. S., \& Drane, J. W. (2001). Relationship between life satisfaction and violent behaviors among adolescents. American Journal of Health Behavior, 25(4), 353-366. doi: 10.5993/AJHB.25.4.1

van den Heuvel, M. P., Stam, C. J., Kahn, R. S., \& Hulshoff Pol, H. E. (2009). Efficiency of functional brain networks and intellectual performance. Journal of Neuroscience, 29(23), 7619-7624. doi: 10.1523/JNEUROSCI.1443-09.2009

Wallace, B. A., \& Shapiro, S. L. (2006). Mental balance and well-being: building bridges between Buddhism and Western psychology. American Psychologist, 61(7), 690-701. doi: 10.1037/0003-066X.61.7.690

Wenig, C. M., Schmidt, C. O., Kohlmann, T., \& Schweikert, B. (2009). Costs of back pain in Germany. European Journal of Pain, 13(3), 280-286. doi: 10.1016/j.ejpain.2008.04.005

Wilson, R. S., Beckett, L. A., Bennett, D. A., Albert, M. S., \& Evans, D. A. (1999). Change in cognitive function in older persons from a community population: relation to age and Alzheimer disease. Archives of Neurology, 56(10), 1274-1279. doi: 10.1001/archneur.56.10.1274 


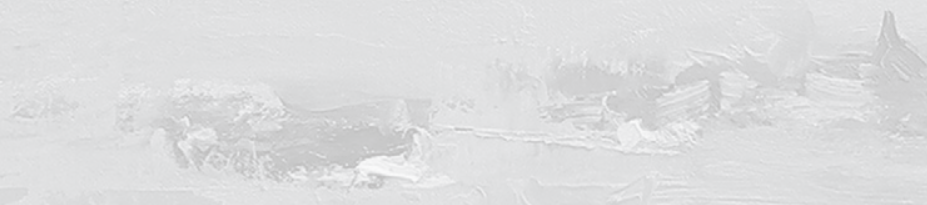




\section{SUMMARY}



This thesis investigated the neural and psychological mechanisms of yoga and mindfulness meditation. In chapter 1 a brief historical and philosophical background of yoga and Buddhism, in which mindfulness meditation is rooted, was provided. This review showed that both practices that have a long history of over 2500 years and are deeply concerned with achieving sustainable well-being. It also showed that both practices have much more in common, including ethical and concentrative components.

Furthermore, the current popularity of these practices in the West and the rapidly growing scientific interest in these practices were discussed. Because of the broad effects and applications of mindfulness meditation and yoga, their neural and psychological mechanisms were investigated in three distinct areas that are particularly relevant to human well-being and society, namely: 1) chronic pain, 2) well-being and resilience at young age, and 3) aging.

Chapter 2 investigated the neural mechanisms of pain modulation through mindfulness using functional magnetic resonance imaging (fMRI). Mindfulness practitioners were able to strongly reduce pain unpleasantness and anticipatory anxiety through the state of mindfulness. In the brain this reduction in pain unpleasantness was associated with increased activation in the right posterior insula and decreased activation in the lateral prefrontal cortex. These findings reveal a unique mechanism of pain modulation through mindfulness, comprising increased sensory and decreased cognitive evaluative processing.

Chapter 3 was concerned with the mechanisms of how yoga can increase resilience and well-being in young adults who are in the challenging transition to college life. Participation in a 4-month residential yoga-based intervention resulted in reduced perceived stress and increased quality of life in young adults, thereby increasing well-being and resilience for mental illness in this at risk group. These positive effects of the yoga intervention were mediated by self-compassion and mindfulness. This suggests that yoga- and mindfulness-based interventions have overlapping psychological mechanisms.

Chapter 4-6 focused on the growing problem of cognitive and neural decline in the rapidly aging society. In chapter 4 the literature on the effects of a variety of meditation techniques on age-related cognitive decline was reviewed. Although many reviewed studies had methodological limitations, there is preliminary evidence that different forms of meditation can off-set age-related cognitive decline in a variety of domains. Chapter 4 concluded with the recommendations to use more reallife relevant measures of cognitive functioning and to conduct research that investigates the psychological and neural mechanisms of the positive effects of meditation on cognition in aging.

Chapter 5, followed these recommendations of chapter 4 and investigated the neural and psychological mechanisms of off-set age-related decline in fluid intelligence in yoga and meditation practitioners. Fluid intelligence, which has high 
real-life relevance, indeed declined slower in yoga and meditation practitioners than in controls. Global network analyses of resting state brain functional connectivity data, acquired with fMRI, revealed that the functional brain networks of the practitioners were more integrated and more resilient to damage than those of controls. There were no differences in decline rate and network integration between yoga and mindfulness practitioners. Mindfulness was positively correlated with fluid intelligence and network integration and resilience, suggesting a mechanistic role in preserving cognition and brain function.

While chapter 5 investigated global network properties of resting state functional brain networks of aging yoga and meditation practitioners as compared to controls, in chapter 6 local differences in network architecture between the three groups were investigated. The study revealed that yoga and meditation practitioners had greater connectivity between the caudates and a wide range of brain regions than the control subjects. There were no differences in local network architecture between yoga and meditation practitioners. This finding of greater caudate connectivity in meditators than in controls was replicated in an independent sample. These findings suggest greater caudate-mediated basal ganglia cortico-thalamic loops efficiency, which might meditate the positive effects of yoga and mindfulness meditation on behavioral flexibility, mental health, and well-being.

Chapter 7 integrated the previous chapters. The chapters share several themes including differences and commonalities between yoga and meditation, their effects on well-being, stress and resilience, and the mechanistic roles of mindfulness and brain functioning. These themes were addressed in different contexts, with different methods, and at different levels of analysis. Furthermore, the diversification of the field of contemplative sciences was described and the need for collaboration within this field and with other disciplines was expressed.

In conclusion, this thesis revealed several psychological and neural mechanisms for the positive effects of mindfulness meditation and yoga on resilience and human well-being across domains. Identified mechanisms include increases in mindfulness, sensory processing, caudate connectivity and global resting state functional brain network integration. With these findings and the questions that these studies raised, this thesis has provided a valuable contribution to the field of contemplative sciences and in the end hopefully also to the aim of increasing human well-being. 



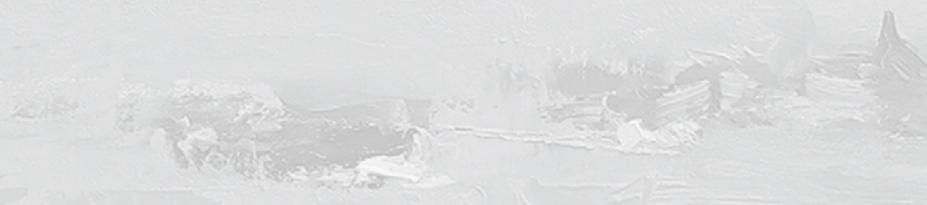


SAMENVATTING 

In dit proefschrift werden de psychologische en de neuronale mechanismen van yoga en mindfulness meditatie onderzocht. In hoofdstuk 1 werd een beknopt overzicht van de historische en de filosofische achtergrond van yoga en van het Boeddhisme, waarin mindfulness meditatie zijn wortels heeft, gegeven. Uit dit overzicht kwam naar voren dat beide systemen een geschiedenis van meer dan 2500 jaar hebben en dat hun kern het realiseren van bestendig welzijn is. De twee systemen hebben nog veel meer gemeenschappelijk, zoals een sterke ethische- en concentratie-component.

Verder werd er besproken dat yoga en mindfulness meditatie momenteel erg populair zijn in de westerse wereld en dat zij steeds meer wetenschappelijk worden bestudeerd. Vanwege hun brede effecten en toepasbaarheid, werden hun neuronale en psychologische effecten in drie verschillende maar maatschappelijk bijzonder relevante gebieden onderzocht, namelijk: 1) pijn bestrijding, 2) welbevinden en weerbaarheid op jonge leeftijd en 3 ) veroudering.

In hoofdstuk 2 werden de neuronale mechanismen van pijnmodulatie door mindfulness met behulp van functionele magneetresonantie tomografie (fMRI) onderzocht. Mediterenden waren in staat de mate waarin de pijn als onaangenaam wordt ervaren en de anticiperende angst voor de pijn tijdens een staat van mindfulness sterk te reduceren. In de hersenen ging de verminderde pijnbeleving gepaard met een verhoogde activatie in de posteriore insula en een verminderde activatie in de laterale prefrontale cortex. Deze bevindingen laten leggen een uniek mechanisme van pijnmodulatie bloot, dat bestaat uit verhoogde sensorische en een verlaagde cognitieve, evaluatieve verwerking.

Hoofdstuk 3 hield zich bezig met de mechanismen die aan een verhoogd welbevinden en een verhoogde weerbaarheid in jong volwassenen door yoga ten grondslag liggen. De studie met jonge volwassenen, die zich in de moeilijke transitie naar de universiteit bevonden, liet zien dat participatie in een 4 maanden durende residentiële yoga interventie leidde tot een toename in de levenskwaliteit en een vermindering in stress. Er was dus een toename in welbevinden en weerbaarheid voor geestelijke ziektes in deze risico groep. Deze positieve effecten werden door zelf-compassie en mindfulness gemedieerd. Deze bevindingen laten zien dat yoga- en mindfulness-gebaseerde interventies op overlappende psychologische mechanismen berusten.

Hoofdstuk 4-6 zijn gericht op het steeds groter wordende probleem van cognitieve en neuronale veroudering in een snel vergrijzende maatschappij. Hoofdstuk 4 geeft een overzicht van de literatuur betreffende de effecten van verschillende vormen van meditatie op cognitieve veroudering. Hoewel veel van de besproken studies methodologische problemen hadden, zijn er aanwijzingen dat meditatie cognitieve veroudering in verschillende domeinen kan verminderen. In hoofdstuk 4 wordt verder aanbevolen om in toekomstige studies cognitief functioneren met maten te me- 
ten die meer alledaagse relevantie hebben. Tevens wordt de aanbeveling gegeven de psychologische en neuronale mechanismen van de positieve effecten van meditatie op cognitieve veroudering te onderzoeken.

Hoofdstuk 5 volgde deze aanbevelingen en onderzocht de psychologische en neuronale mechanismen van een verminderde afname in fluide intelligentie in ouderen die meditatie en yoga beoefenen. Fluide intelligentie heeft een hoge alledaagse relevantie en de afname in deze capaciteit was inderdaad kleiner bij de ouderen met veel ervaring in yoga of meditatie dan bij controle personen zonder die ervaring maar een vergelijkbaar gezonde levensstijl. Met fMRI werd de hersenactiviteit tijdens rust gemeten. Globale netwerkanalyses van deze fMRI data lieten zien dat de hersen netwerken van ouderen die mediteren of yoga beoefenen meer geïntegreerd zijn en meer bestendig tegen gesimuleerde beschadiging zijn dan die van controle personen. Er waren geen verschillen in afname in fluide intelligentie en in de integratie van de functionele hersen netwerken tussen de ouderen die yoga beoefenden en degenen die mediteerden. Mindfulness was positief gecorreleerd met zowel intelligentie als ook netwerk integratie en netwerk bestendigheid, en lijkt daarmee een rol te spelen in het mechanisme van het behouden van cognitie en brein functie.

Terwijl in hoofdstuk 5 de globale netwerk eigenschappen van de functionele hersennetwerken van ouderen die yoga en meditatie praktiseren in vergelijking met controles werden onderzocht, werden in hoofdstuk $\mathbf{6}$ de lokale netwerk verschillen tussen de drie groepen onderzocht. Uit de studie kwam naar voren dat de yogis en mediterenden een grotere mate aan connectiviteit tussen de nuclues caudatus en een groot aantal andere hersengebieden dan de controlegroep hadden. Er waren geen verschillen in lokale netwerkconnectiviteit tussen de yogis en de mediterenden. Wat de bevindingen bijzonder sterk maakt is dat nucleus caudatus connectiviteit in mediterenden in een onafhankelijke steekproef werd gerepliceerd. Deze resultaten wijzen op een mogelijk verhoogde efficiëntie van basal ganglia cortico-thalamische circuits die wellicht de positieve effecten van yoga en mindfulness meditatie op behaviorele flexibiliteit, geestelijke gezondheid en welzijn mediëren.

In hoofdstuk 7 werden de voorgaande hoofdstukken geïntegreerd. De hoofdstukken hebben verschillende onderwerpen gemeenschappelijk zoals de overeenkomsten en verschillen tussen yoga en mindfulness meditatie, hun effecten op welzijn, stress en weerbaarheid en rol van hersenfunctie en mindfulness als mediatoren. Deze onderwerpen werden in verschillende contexten, met verschillende methodes en op verschillende niveaus onderzocht. Verder werd de diversificatie van het onderzoeksgebied van de contemplatieve wetenschappen beschreven en de noodzaak tot verdere samenwerking binnen dit onderzoeksgebied en met andere onderzoeksgebieden benadrukt.

Concluderend heeft dit proefschrift de psychologische en neuronale mechanismen van de positieve effecten van mindfulness meditatie en yoga op de weerbaar- 
heid en het welzijn van de mens binnen verschillende domeinen blootgelegd. Tot de gevonden mechanismen behoren toename in mindfulness, in de sensorische verwerking in de hersenen, nucleus caudatus connectiviteit en integratie van de functionele hersennetwerken tijdens rust. Met deze bevindingen en de verdere vragen die de studies hebben opgeworpen, heeft dit proefschrift een waardevolle bijdrage aan het onderzoeksgebied van de contemplatieve wetenschappen geleverd en uiteindelijk hopelijk ook aan het doel van verhoogd welzijn van de mensheid. 


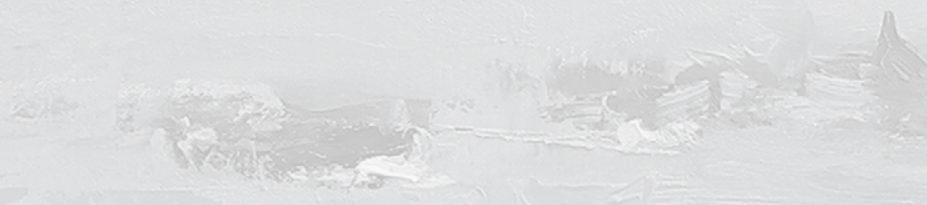




\section{ZUSAMMENFASSUNG}



Diese Doktorarbeit befasst sich mit den psychologischen und neuronalen Mechanismen von Yoga und Achtsamkeitsmeditation. In Kapitel 1 wurde eine Übersicht des historischen und philosophischen Hintergrunds von Yoga und vom Buddhismus, in dem die Achtsamkeitsmeditation ihre Wurzeln hat, präsentiert. Beide Systeme gibt es seit über 2500 Jahren und ihr Kern besteht darin, nachhaltiges Wohlempfinden zu realisieren. Die beiden Systeme haben noch viel mehr gemeinsam, wie zum Beispiel starke ethische- und Konzentrations-Komponenten.

Des Weiteren wurden die Beliebtheit von Yoga und Achtsamkeitsmeditation im Westen und das wachsende wissenschaftliche Interesse an diesen Systemen diskutiert. Wegen ihrer weit gefächerten Effekte und ihren vielen Anwendungsmöglichkeiten, wurden die psychologischen und neuronalen Mechanismen von Yoga und Achtsamkeit in dieser Dissertation in drei unterschiedlichen, jedoch gesellschaftlich wichtigen Bereichen untersucht, nämlich: 1) Schmerzbewältigung, 2) Wohlbefinden und Widerstandsfähigkeit bei jungen Menschen und 3) Alterung.

In Kapitel 2 wurden die neuronalen Mechanismen von Schmerzmodulation durch Achtsamkeit mittels funktioneller Magnetresonanztomographie (fMRT) untersucht. Achtsamkeits-Meditierende waren in der Lage ihr Empfinden durch einen Zustand der Achtsamkeit so zu verändern, dass Schmerzen als weniger unangenehm empfunden wurden und die Angst vor den Schmerzen verringert war. Im Gehirn ging das verringerte Schmerzempfinden mit einer erhöhten Aktivität in der posterioren Insula und einer verringerten Aktivität im lateralen präfrontalen Cortex einher. Diese Befunde weisen einen einzigartigen Schmerzmodulationsmechanismus durch Achtsamkeit auf, der sich durch erhöhte sensorische und verringerte kognitive, evaluative Verarbeitung kennzeichnet.

Kapitel 3 befasste sich mit den Mechanismen, die einem erhöhten Wohlbefinden und einer erhöhten Widerstandsfähigkeit bei Jung-Erwachsenen durch Yoga zugrunde liegen. Die Studie mit jungen Probanden, die gerade im schwierigen Übergang von der Schule zur Universität waren zeigte, dass die Teilnahme an einem 4-monatigen Yoga-basierten Programm zu einer erhöhten Lebensqualität und geringerem Stressempfinden führte. Diese positiven Effekte wurden durch Selbstmitgefühl und Achtsamkeit vermittelt. Diese Ergebnisse zeigen in Kombination mit früheren Studien zur Achtsamkeitsmeditation, dass Yoga und Achtsamkeitsmeditation gemeinsame Wirkmechanismen haben.

Kapitel 4-6 befasste sich mit dem wachsenden Problem der kognitiven und neuronalen Alterung durch eine schnell alternde Gesellschaft. Kapitel 4 ist eine Literaturübersicht von Studien, die die Effekte verschiedener Arten der Meditation auf kognitive Alterung untersucht haben. Trotz der methodologischen Probleme weisen die besprochenen Studien darauf hin, dass Meditation eine kognitive Alterung in vielen Bereichen verringern kann. Zuletzt wurde empfohlen, kognitive Kapazitä- 
ten mit alltagsrelevanteren Massen zu erheben und die psychologischen und neuronalen Mechanismen von den positiven Effekten von Meditation auf die kognitive Alterung zu untersuchen.

In Kapitel 5 wurden diese Empfehlungen befolgt und werden die psychologischen und neuronalen Mechanismen von verringerter Abnahme der fluiden Intelligenz bei älteren Yoga- und Meditations-Übenden untersucht. Fluide Intelligenz hat eine hohe Alltagsrelevanz, und die Abnahme dieser Fähigkeit war tatsächlich geringer bei alternden Yoga- und Mediations-Übenden im Vergleich zu Kontrollprobanden ohne diese Praxis, aber mit einem vergleichbar gesunden Lebensstil. Mittels fMRT wurden die Hirnaktivität während eines Ruhezustands bei allen Probanden gemessen. Globale Netzwerkanalysen dieser fMRT-Daten zeigten, dass die Hirnnetzwerke der alternden Yoga- und Meditations-Praktizierenden besser integriert und robuster gegen Beschädigungen waren als die von Kontrollprobanden. Es gab jedoch keine Unterschiede zwischen der Gruppe von Yoga Praktizierenden und den Meditierenden, was die Abnahme der fluiden Intelligenz und die Integration der Hirnnetzwerke betrifft. Achtsamkeit war mit sowohl der fluiden Intelligenz wie auch mit der Integration und der Robustheit der funktionellen Hirnnetzwerke korreliert und weist somit auf einen psychologischen Mechanismus hin.

Während in Kapitel 5 die globalen Netzwerk Eigenschaften der funktionellen Hirnnetzwerke von älteren Yogis und meditierenden und Kontrollprobanden untersucht wurden, wurden in Kapitel 6 die lokalen Unterschiede in diesen Netzwerken zwischen den drei Gruppen untersucht. Meditierende und Yogis hatten eine stärkere Konnektivität zwischen dem Caudatus und vielen verschiedenen anderen Hirnregionen als die Kontrollprobanden. Es gab jedoch keine Unterschiede zwischen Yogis und Meditierenden. Was diese Befunde besonders stark macht ist, dass die erhöhte Caudatus Konnektivität in Meditierenden im Vergleich zu Kontrollprobanden in einer unabhängigen Stichprobe repliziert wurde. Diese Befunde weisen auf eine erhöhte Effizienz der fronto-striato-thalamischen Regelschleifen hin, die möglicherweise den positiven Effekten von Yoga und Achtsamkeitsmeditation auf Verhaltensflexibilität, geistige Gesundheit und Wohlempfinden zugrunde liegt.

In Kapitel 7 wurden die vorangehenden Kapitel integriert. Die Kapitel hatten mehrere gemeinsame Themen, wie die Unterschiede und Gemeinsamkeiten von Yoga und Achtsamkeitsmeditation, ihre Effekte auf Wohlbefinden, Stress und Widerstandsfähigkeit, sowie die Rolle von Achtsamkeit und Hirnfunktion als Mediatoren. Diese Themen wurden in unterschiedlichen Kontexten, mit unterschiedlichen Methoden und auf verschiedenen Ebenen untersucht. Des Weiteren wurde die Diversifikation des Forschungsbereichs der kontemplativen Wissenschaften thematisiert und auf die Notwendigkeit weiterer Zusammenarbeit innerhalb dieses Fachbereichs und mit anderen Fachbereichen betont. 
Zusammengefasst hat diese Doktorarbeit die psychologischen und neuronalen Mechanismen der positiven Effekte von Yoga und Achtsamkeitsmeditation auf die Widerstandsfähigkeit und das Wohlbefinden in verschiedenen Bereichen aufgewiesen. $\mathrm{Zu}$ den gefunden Mechanismen gehören die Zunahme in Achtsamkeit, der sensorischen Verarbeitung in Gehirn, Caudatus Konnektivität und eine erhöhte Integration der funktionellen Hirnnetzwerke während es Ruhezustands. Mit diesen Befunden und den weiteren Fragen, die aufgeworfen wurden, hat diese Doktorarbeit einen wichtigen Beitrag zum Forschungsgebiet der kontemplativen Wissenschaften geliefert und letzten Endes hoffentlich auch zum Ziel eines erhöhten Wohlbefindens der Menschheit beigetragen. 


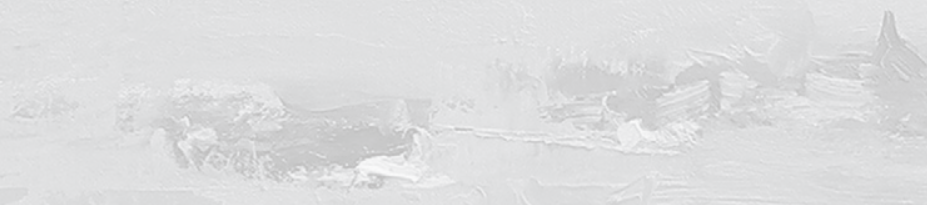


ACKNOWLEDGEMENTS 

In this dissertation I focused on the effects and mechanisms of yoga and mindfulness meditation. One variable that is closely related to yoga and mindfulness meditation, but that I did not discuss, is gratitude. Instead of going into a theoretical discussion about gratitude here, I will use the opportunity of writing this section to practice it.

It was literary quite a journey to complete this dissertation; an intercontinental journey that provided me with the opportunity to experience three different countries and their cultures in depth, to work in very exciting places, and most importantly to meet many interesting and lovely people, to make new friends, and to strengthen old friendships. I am truly grateful for this journey and to all people that were part of it.

At the very beginning of this journey was my deep wish to investigate the neural mechanisms of yoga and mindfulness meditation. Rainer Goebel was the first person I asked for advice about how to fulfill this wish. Rainer, I am very grateful that you were enthusiastic about my interest and supportive in following it. Connecting me to Ulrich Ott and advising me on how to apply for a research scholarship was only your first instance of support. Thank you so much for all of your support.

The contact with Ulrich Ott and Prof. Vaitl was fruitful and an exciting time at the Bender Institute of Neuroimaging in Gießen, Germany began. Prof. Vaitl and Uli, thank you so much for all the support, opportunities and freedom you gave me. Both of you are real pioneers and working with you was a pleasure and enrichment. Uli, you were always there when needed, your accurate and inventive solutions of problems were very helpful. Prof. Vaitl, thank you so much for your generosity and trust, it has been a true honor to work with you. I am also grateful to Hannes and Britta; without the two of you my project in Gießen would not have been possible. Britta, Gießen was where we first met and ever since you have become a very dear friend, colleague, and supervisor. I enjoyed your kind, humble and sharp presence during the entire journey and I am looking forward to many more adventures to come. I also would like to thank my other colleagues at the BION, in particular my office mates Katrin, Ingo, and Karen; talking to you was always interesting and inspiring. Carlo, playing with the electro stimulator and the scanner was not only important to make the study succeed, it also was a lot of fun. Sara and Arjen, my dear friends, what would the weekends have been without you? Work hard, party hard, is a formula that really works, we have proven that. This really was a special time, thanks to all of you.

Although my time at the department of Clinical Psychological Science at Maastricht University was not really part of the journey that led to this dissertation, I want to express my gratitude to my super nice colleagues, particularly from the first floor of UNS 50 and 40 for all the good times. Jeanine, you were an amazing office mate. 
Thanks for your enthusiasm and the many philosophical conversations. You left this world much too early. Armin, thanks for teaching me so much about BrainVoyager. Alex, this was the first time we met and I was right away impressed by how relaxed and supportive you are. Thanks for your optimism and support along the journey and for teaching me how to present data in a clear and impactful way.

Britta, I am very grateful that you invited me to visit you in Boston. This visit turned into a personally and professionally enriching stay of over four years. Sara, thanks for having me in your lab and for giving me so many opportunities and so much freedom. Your creativity, vision and kindness are a true source inspiration for me. My dear colleagues and friends from the Lazar-Lab, thanks for the wonderful times inside and outside the lab. I'll never forget our extended scan sessions and lovely lab lunches in the park, and Nar, our late-night writing sessions and trips to Cape Cod, Sita, the many visits to Walden Pond and the Esplanade, Jan, your humor, Vincent, how fast wishes can become reality, and Tom and Pop, your playfulness and activism. I am also deeply grateful to our Sangha. Doug, Britta, Krista, Keeril, and Daniel, thanks for so many enlightening meetings and discussions that not only fostered my personal development and were supportive while working on my dissertation, but also facilitated my research. Krista and Doug my dear friends, thanks for the countless fun and inspiring activities. I am glad that we still manage to see each other regularly, despite the distance. My deep gratitude also goes to my personal- and studyMBSR- and MBCT teachers; Laurie, Zayda, and Carolyn, thanks for your presence. Thanks to the Kripalu team, including Edi, Angela, and Stephen, for the fruitful collaboration. Maxime, it was a pleasure to work with you and to learn from you. I hope we can celebrate our next paper with a Belgian beer again. Dave, Liz, Cathy, Gaelle, Zev, Sara and Britta, the meetings of our Boston Meditation Research Group were always fun and tasty (thanks Liz) and deepened and broadened my understanding of the field that we work in. I am also very grateful to the Mind \& Life Institute and its community for being a source of inspiration and connection. I could go on endlessly as so many people touched my heart in this important period of my life and directly or indirectly contributed to this dissertation; thanks to all of you.

Back in Maastricht, I was warmly welcomed by Alex and his Vision, Awareness \& Cognition group. Alex, I am very grateful for your openness and support and for having me join your group. Alex, Teresa, Nina, Christianne, Katie, Tom, Felix, Franzi, Sanne, Rosanne, Tahnee, Helen, Lukas, Geraldine, Dennis, and Jeannette, thanks for being such nice colleagues and for providing a good environment for finishing my dissertation. I am also grateful to my office mates, the "Belgian and the Bulgarian guy", for the pleasant microclimate. Thanks Dimo and Bert. 
Thanks Madelon, Hugo, Martin, Elia, Anne, and Antoine for being members of the assessment committee and the opposition. Without you this defense would not have been possible.

I would like to thank all study-participants for their invaluable contributions. Without you we would not have gained the knowledge that is bundled in this dissertation. Interacting with you and the many long conversations we had after the testingsession were also personally enriching for me. Thank you. Without financial support this dissertation also would not have been possible. Thanks DAAD, Kripalu, Brach Family Foundation, Yawkey Foundation, and NIH.

My dear friends on the European continent, I am glad that our friendship is so longlasting and did not suffer from the wideness of the Atlantic Ocean. Luckily we are in the same time-zone again and the dissertation is finished. Thanks for being who you are, for all the good times, and for your support. Thanks Arend for being my paranymph.

Karin und Wolfgang, Ihr wart bis vor kurzem die besten Eltern die es gibt, jetzt sind Marasha und ich es natürlich. Im Ernst, ich kann mir keine besseren Eltern als Euch vorstellen und habe Euch ein grundlegendes Gefühl von Vertrauen und Sicherheit zu verdanken. Mit dieser Grundlage war es kein Problem, mich in die Abenteuer zu stürzen, die zu dieser Dissertation geführt haben. Meine lieben Geschwister, Fritz und Lilli, ich finde es super schön, dass wir immer für einander da sind und so viel Spaß mit einander haben. Lilli, danke, dass Du bereit bist, als meine Paranymphe zu fungieren. Ich möchte mich auch bei meinen vielen, lieben Onkeln und Tanten, insbesondere bei Renate und Burkhard für die Unterstützung in Gießen, und bei meiner Oma Susanne bedanken, für die tolle Großfamilie die wir sind. Mit so einer Familie ist vieles leichter.

Last but not least wil ik mijn lieve vrouw Marasha bedanken. Marasha, jij was tijdens de gehele reis die naar dit proefschrift heeft geleid aanwezig, eerst als een goede vriendin, later als geliefde en uiteindelijk als mijn vrouw. Ik ben erg blij dat jij er altijd was en dat wij de bijzondere tijd in Boston samen hebben beleefd. Bedankt voor al je hulp en liefde die reikte van lekker eten maken tot het nakijken van stukken. Je bent de beste en ik hou van je. René, je bent een geweldige schoonvader en opa. Bedankt voor de prachtige illustratie van de boekomslag. Meine lieben Söhne Max und Lex, ihr habt mir sehr bei der Doktorarbeit geholfen, da ich mein Bestes gegeben habe sie vor Eurer Geburt fertig zu bekommen. Papa ist super stolz auf Euch und hat Euch lieb. 


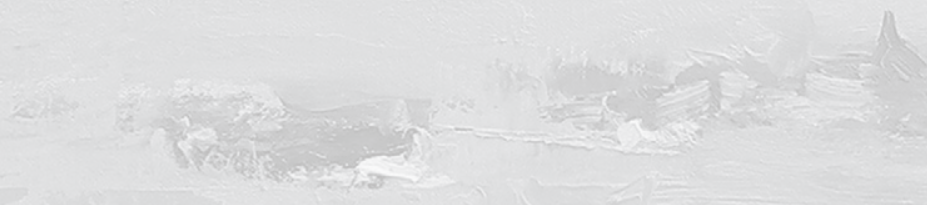


Curriculum VitaE 

Tim Gard was born in Hamburg, Germany on July 24 $4^{\text {th }} 1978$. At the age of 11 he moved to Capelle aan den IJssel, the Netherlands, where he graduated from secondary school at Comenius College in 1997. Tim obtained his MSc. in cognitive psychology at the Faculty of Psychology, Maastricht University, the Netherlands, in 2006. For his Masters research project he spent 10 months at the Homi Bhabha Centre for Science Education, Tata Institute of Fundamental Research, Mumbai, India, where he investigated the effects of yoga on emotion- and cognition regulation in high-school students under the supervision of Prof. dr. Jayashree Ramadas and Prof. dr. Els Boshuizen. After graduation, Tim followed his interest and investigated the neural mechanisms of pain modulation through mindfulness meditation under the supervision of Dr. Ulrich Ott and Prof. dr. Dieter Vaitl at the Bender Institute of Neuroimaging at Justus-Liebig-Universität Giessen, Germany for one year. Subsequently, he spent one and a half years at Maastricht University, where he set up a study to investigate the effects of exposure therapy for patients with complex regional pain syndrome, under the supervision of Prof. dr. Johan Vlaeyen. From 2009-2013, Tim expanded his horizon further and worked at the Lazar-Lab at Massachusetts General Hospital, Harvard Medical School, Boston, MA, USA. During this time, he investigated the neural mechanisms of yoga and mindfulness meditation in a number of contexts including aging, depression, and chronic pain under the supervision of Dr. Sara Lazar and in collaboration with Dr. Britta Hölzel. Furthermore, he was trained in Mindfulness Based Stress Reduction and Mindfulness Based Cognitive Therapy at the Center for Mindfulness at the University of Massachusetts Medical School, Worcester, MA, USA. After his return to the Netherlands in 2013, Tim joined the Vision, Awareness \& Cognition lab of Prof. dr. Alexander Sack where he completed his dissertation under the supervision of Prof. dr. Alexander Sack, Prof. dr. Rainer Göbel, and Dr. Britta Hölzel. Since August 2014 he continues his work at the Vision, Awareness \& Cognition lab as a postdoctoral fellow. Tim is married to his wife Marasha and he is the proud father of two sons, $\operatorname{Max}^{\dagger}$ and Lex. 



\section{Publications}

\section{RefereEd ARTICLES}

Gard, T., Hölzel, B. K., \& Lazar, S. W. (2014). The potential effects of meditation on age-related cognitive decline: a systematic review. Annals of the New York Academy of Sciences, 1307(1), 89-103. doi: 10.1111/nyas.12348

Gard, T., Taquet, M., Dixit, R., Hoelzel, B. K., de Montjoye, Y.-A., Brach, N., Salat, D., Dickerson, B. C., Gray, J. R., \& Lazar, S. (2014). Fluid intelligence and brain functional organization in aging yoga and meditation practitioners. Frontiers in Aging Neuroscience, 6, 76. doi: 10.3389/fnagi.2014.00076

Gard, T. (2014). Different neural correlates of facing pain with mindfulness: Contributions of strategy and skill: Comment on "Facing the experience of pain: A neuropsychological perspective" by Fabbro and Crescentini. Physics of life reviews, 11(3), 564-566. doi: 10.1016/j.plrev.2014.07.003

Gard, T. ${ }^{\star}$, Noggle, J.* Park, C.*, Vago, D. R.* \& Wilson, A.* (2014). Potential selfregulatory mechanisms of yoga for psychological health. Frontiers in Human Neuroscience, 8, 770. doi: 10.3389/fnhum.2014.00770

Desbordes, G.*, Gard, T.*, Hoge, E. A.*, Hölzel, B. K. ${ }^{\star}$, Kerr, C. ${ }^{\star}$, Lazar, S. W., Olendzki, A.* ${ }^{\star}$ \& Vago, D. R. ${ }^{\star}(2014)$. Moving Beyond Mindfulness: Defining Equanimity as an Outcome Measure in Meditation and Contemplative Research. Mindfulness. [Epub ahead of print] doi: 10.1007/s12671-013-0269-8

Hölzel, B. K., Hoge, E. A., Greve, D. N., Gard, T., Creswell, J. D., Brown, K. W., Barrett, L. F., Schwartz, C., Vaitl, D., \& Lazar, S. W. (2013). Neural mechanisms of symptom improvements in generalized anxiety disorder following mindfulness training. NeuroImage: Clinical, 2(0), 448-458. doi: 10.1016/j.nicl.2013.03.011

Gard, T., Hölzel, B. K., Sack, A. T., Hempel, H., Lazar, S. W., Vaitl, D., \& Ott, U. (2012). Pain Attenuation through Mindfulness is Associated with Decreased Cognitive Control and Increased Sensory Processing in the Brain. Cerebral Cortex, 22(11), 2692-2702. doi: 10.1093/cercor/bhr352

Gard, T., Brach, N., Hölzel, B. K., Noggle, J. J., Conboy, L. A., \& Lazar, S. W. (2012). Effects of a yoga-based intervention for young adults on quality of life and perceived stress: The potential mediating roles of mindfulness and self-compassion. The Journal of Positive Psychology, 7(3), 165-175. doi: 10.1080/17439760.2012.667144

Hölzel, B., K. , Carmody, J., Vangel, M., Congleton, Christina, Yerramsetti, S., M. , Gard, T., \& Lazar, S., W. . (2011). Mindfulness practice leads to increases in regional brain gray matter density. Psychiatry Research: Neuroimaging, 191(1), 36-43. doi: 10.1016/j.pscychresns.2010.08.006 
Hölzel, B. K., Lazar, S. W., Gard, T., Schuman-Olivier, Z., Vago, D. R., \& Ott, U. (2011). How Does Mindfulness Meditation Work? Proposing Mechanisms of Action From a Conceptual and Neural Perspective. Perspectives on Psychological Science, 6(6), 537-559. doi: 10.1177/1745691611419671

Hölzel, B. K., Ott, U., Gard, T., Hempel, H., Weygandt, M., Morgen, K., \& Vaitl, D. (2008). Investigation of mindfulness meditation practitioners with voxel-based morphometry. Social Cognitive and Affective Neuroscience, 3(1), 55-61.

\section{BOOK CHAPTERS}

Gard, T., \& Hölzel, B. (2015). Achtsamer Umgang mit Schmerz. In B. Hölzel \& C. Brähler (Eds.), Achtsamkeit mitten im Leben. München, Germany: O.W. Barth.

Hölzel, B. K., Gard, T., \& Ott, U. (2013). Mechanismen der Achtsamkeit: eine Betrachtung aus konzeptueller und neuronaler Perspektive. In A. Knuf \& M. Hammer (Eds.), Achtsamkeit in der Arbeit mit psychisch kranken Menschen. Köln, Germany: Psychiatrie Verlag.

\section{OTHER PUBLICATIONS}

Wiedemann, J., Gard, T., Hölzel, B. K., Sack, A. T., Hempel, H., Lazar, S. W., Vaitl, D., \& Ott, U. (2012). Pain Attenuation through Mindfulness is Associated with Decreased Cognitive Control and Increased Sensory Processing in the Brain. Deutsche Zeitschrift für Akupunktur, 55(2), 25-26. doi: 10.1016/j. dza.2012.06.007

Gard, T. (2002). Theories on the relation between affect and mathematical problem solving. In R. Banerjee, S. Mehrotra \& R. Khunyakari (Eds.), Report on a course in science writing (Vol. VI (01-02), pp. 45-53). Mumbai, India: Homi Bhabha Centre for Science Education, Tata Institute of Fundamental Research.

Note: ${ }^{*}=$ equal authorship

\section{REFEREED PRESENTATIONS}

Gard, T., De Jong, M., Mischoulon, D., Mehling, W., \& Lazar, S. W. (2015, March). Effects of mindfulness-based cognitive therapy on body awareness in patients with chronic pain and comorbid depression. Paper presented at the International Convention of Psychological Science, Amsterdam, Netherlands.

Daubenmier, J. J., Farb, N. A. S., Gard, T., Kerr, C. E., Klein, A. C., Mehling, W., Paulus, M. P., \& Price, C. J. (2014, November). Being in the Body: Contemplative Practice, Interoceptive Awareness, and Health. Paper presented at the Mind \& Life International Symposium for Contemplative Studies, Boston, MA. 
Desbordes, G., Olendzki, A., Vago, D. R., Hoge, E. A., Gard, T., Lazar, S. W., Kerr, C. E., \& Dorjee, D. (2014, October). Can We Measure Mental Balance? Scientific and Contemplative Perspectives on Equanimity. Paper presented at the Mind \& Life International Symposium for Contemplative Studies, Boston, MA.

Wilson, A., Gard, T., Noggle-Taylor, J., Park, C., \& Vago, D. (2014, October). Yoga's Self-Regulatory Functions in Promoting Psychological Health: A Proposed Model. Paper presented at the Mind \& Life International Symposium for Contemplative Studies, Boston, MA.

Gard, T. (2014, September). Neuronale Mechanismen von Achtsamkeit. Paper presented at the Jahrestagung der Gesellschaft für Neuropsychologie, Oldenburg, Germany.

Gard, T. (2014, January). The neural correlates of pain modulation through mindfulness. Paper presented at the Invitational Symposium on Mindfulness Research, Radbout University, Nijmegen, Netherlands.

Gard, T. (2013, October). Neuronale Korrelate von Achtsamkeit im Kontext von Schmerzen. Paper presented at the Deutscher Schmerzkongress, Hamburg, Germany.

Gard, T. (2013, January). Intelligence and Brain Connectivity in Aging Yogis and Meditators. Paper presented at the Advances in Meditation Research: Neuroscience and Clinical Applications, New York Academy of Sciences, New York, NY.

Gard, T., \& Healey, T. (2012, November). Mindfulness: Science, Practice and Implications for the Workplace. Paper presented at the Northeast Human Resources Association's Fall 2012 Conference; Wellness: A Multidimensial Look at Employee Wellbeing, Worcester, MA.

Gard, T. (2012, June). Neural correlates of mindfulness. Paper presented at the 23rd Annual International Trauma Conference, Boston, MA.

Gard, T. (2012, April). Neural mechanisms of pain modulation through the state of mindfulness. Paper presented at the International Symposia for Contemplative Studies, Denver, CO.

de Jong, M., Inamori, A., Dipierro, M., Brill, C., Rhoades, L., Nyer, M., Kueppenbender, K., Kulich, R., Gilligan, C., Brach, N., Gard, T., Lazar, S., Fava, M., Mischoulon, D., Hoge, E., Peeters, F., van Os, J., Britton, W., \& Ashih, H. (2012, April). Mindfulness Based Cognitive Therapy for Chronic Pain and Depression: Background and Design of a Randomized Controlled Trial Poster session presented at the International Symposia for Contemplative Studies, Denver, CO.

Lazar, S. W., \& Gard, T. (2012, March). Altered resting state functional connectivity and fluid intelligence in long-term mindfulness and yoga practitioners. Paper presented at the Investigating and Integrating Mindfulness in Medicine, Health Care, and Society, 10th Annual International Scientific Conference, Center for Mindfulness, University of Massachusetts Medical School, Norwood, MA. 
Brach, N., Gard, T., Hölzel, B. K., Noggle, J. J., Conboy, L. A., \& Lazar, S. W. (2011, November). Effects of a yoga-based intervention for young adults on quality of life and perceived stress: The potential mediating roles of mindfulness and selfcompassion. Poster session presented at the Society for Neuroscience, Washington, DC.

Brach, N., Gard, T., Hölzel, B. K., Noggle, J. J., Conboy, L. A., \& Lazar, S. W. (2011, September). Effects of a yoga-based intervention for young adults on quality of life and perceived stress: The potential mediating roles of mindfulness and selfcompassion. Poster session presented at the IAYT Symposium on Yoga Research, Kripalu Center for Yoga \& Health, Stockbridge, MA.

Gard, T., Hölzel, B. K., Van den Bosch, J. J. F., Sack, A. T., Hempel, H., Lazar, S. W., Vaitl, D., \& Ott, U. (2010, August). Changed effective connectivity in the brain during mindful pain mitigation and anticipation. Poster session presented at the 13th World Congress on Pain, Montreal, Canada.

Gard, T., Ramadas, J., Nandakumar, V., Hölzel, B. K., \& Boshuizen, H. P. A. (2010, June). Regulation of Emotion and Cognition during Mathematical Problem Solving: The Effects of Yoga in an Indian Sample. Poster session presented at the Mind and Life Summer Research Institute, Garrison, NY.

Hölzel, B. K., Gard, T., Ott, U., \& Lazar, S. (2010, June). Can mindfulness training influence the neural processing of aversive stimuli? Paper presented at the World Congress of Behavioral and Cognitive Therapies, Boston, MA.

Gard, T. (2010, April). Altered pain processing during mindfulness. Paper presented at the 8th Annual International Scientific Conference for Clinicians, Researchers and Educators Center for Mindfulness, University of Massachusetts Medical School, Worcester, MA.

Gard, T., Hölzel, B. K., Ott, U., Hempel, H., Sack, A. T., \& Vaitl, D. (2010, March). Pain modulation through mindfulness: an fMRI study. Poster session presented at the Harvard Medical School Psychiatry Research Day, Boston, MA.

Gard, T., Ott, U., Hölzel, B. K., Hempel, H., Sack, A. T., \& Vaitl, D. (2009, June). Mindfulness in the Context of Pain: an fMRI study. Poster session presented at the Mind and Life Summer Research Institute, Garrision, NY.

Gard, T., Ott, U., Hölzel, B. K., Hempel, H., Sack, A. T., \& Vaitl, D. (2008, August). Altered pain processing due to mindfulness: an fMRI study. Poster session presented at the 12th World Congress on Pain, Glasgow, UK.

Hölzel, B., Hempel, H., Gard, T., \& Ott, U. (2007, June). Mindfulness meditation: Brain activation and structure compared between meditators and non-meditators. Poster session presented at the Mind and Life Summer Research Institute, Garrison, NY. 


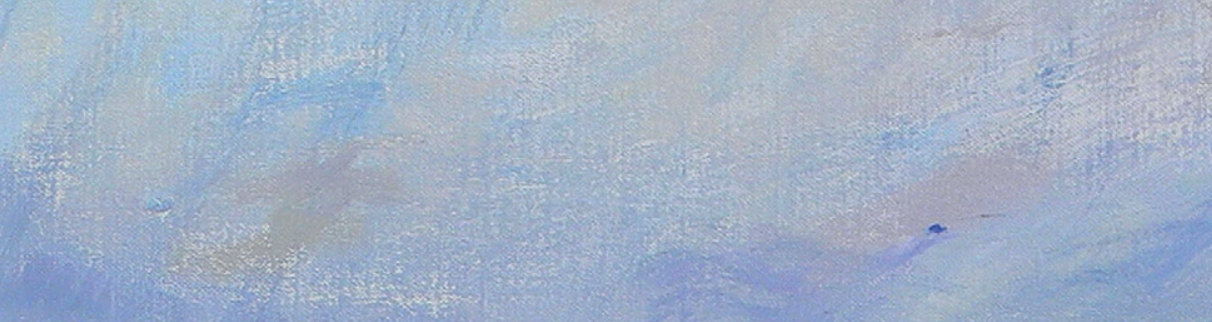

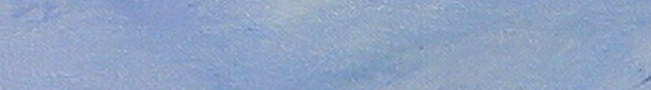
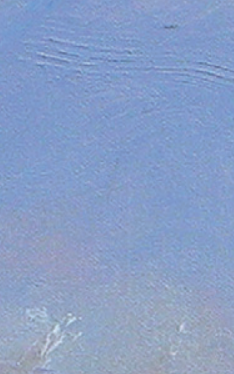

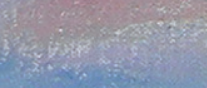

$\left(x+2 x^{2}\right.$

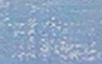

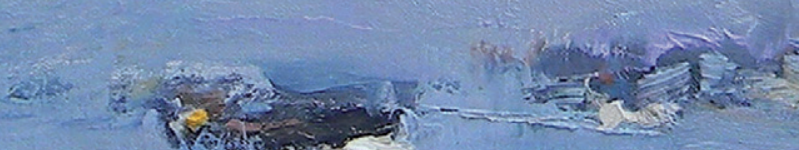
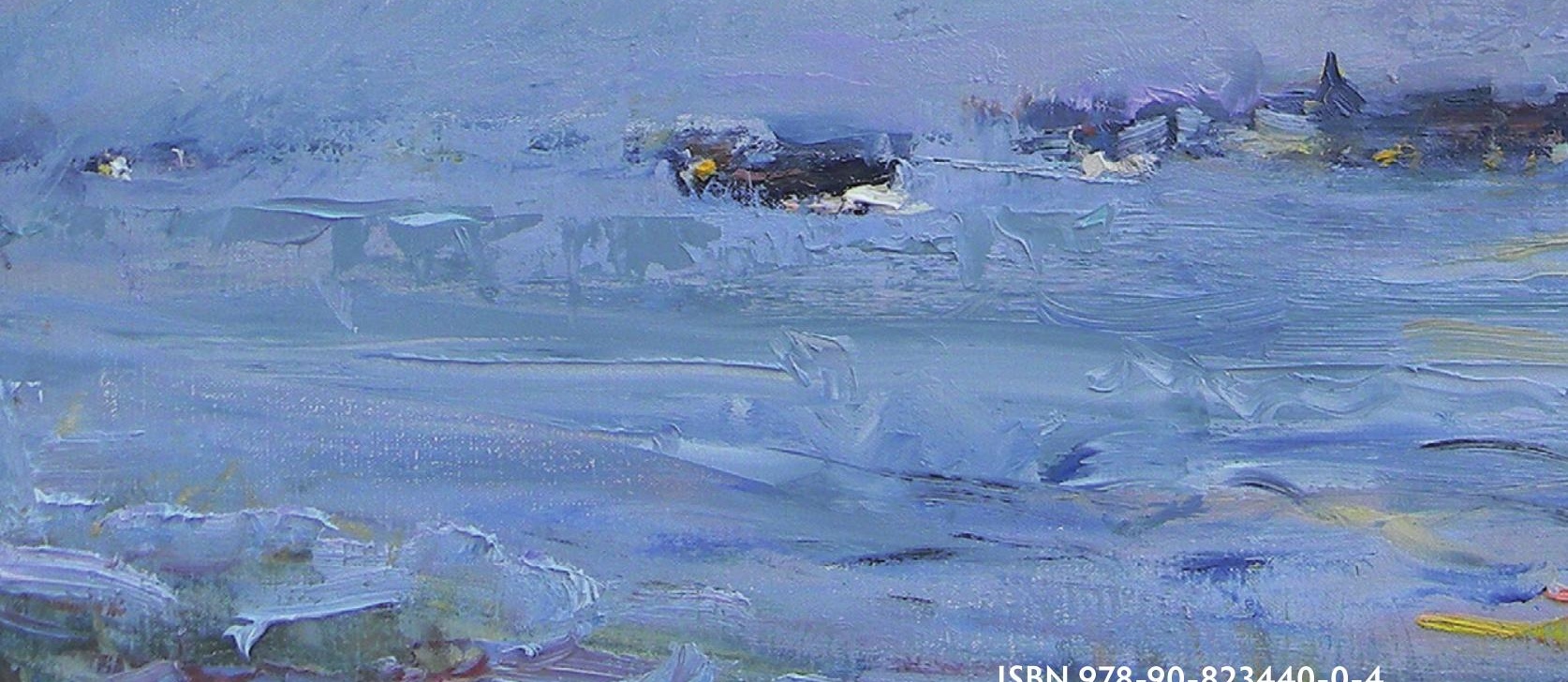

15

ara

ISBN $978-90-823440-0-4$

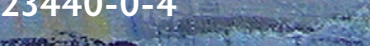

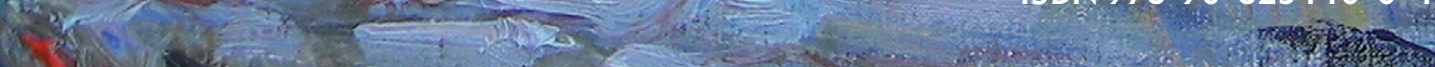

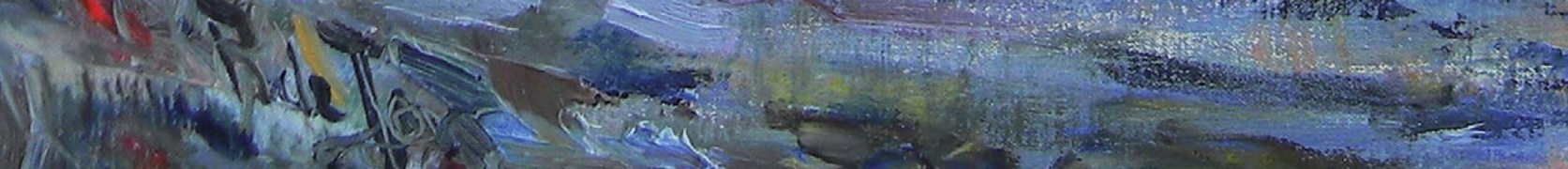

